
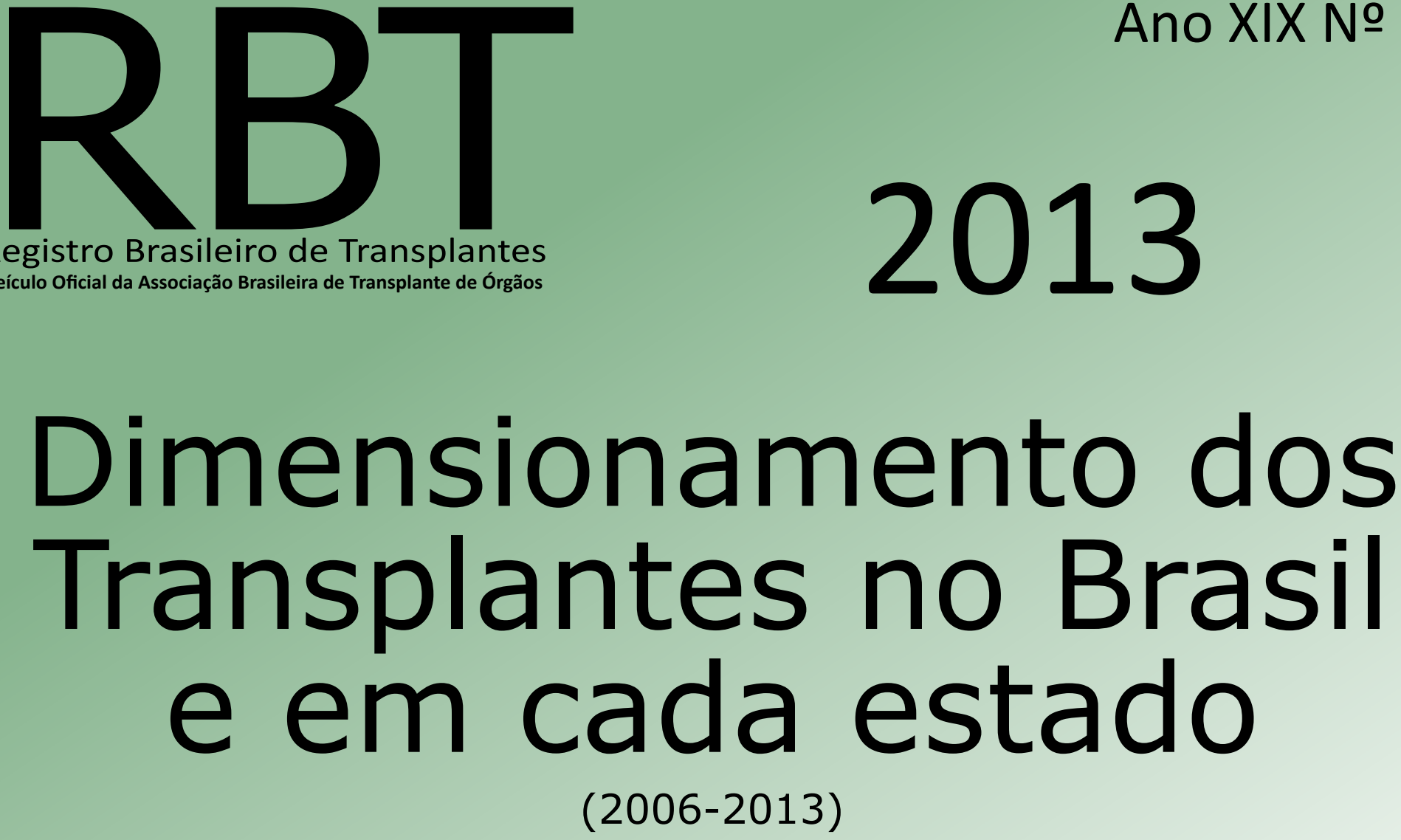

A doação e alocação de órgãos é um processo trabalhoso e delicado que depende do crédito da população no sistema e do comprometimento dos profissionais de saúde no diagnóstico de morte encefálica.O Brasil é o segundo país do mundo em número de transplantes e, para consolidar essa conquista, é crucial a atuação do Ministério da Saúde, dos governos estaduais e das entidades médicas em todo o processo de doação e transplantes

Necessidade Estimada e número de transplantes realizados no Brasil em 2013

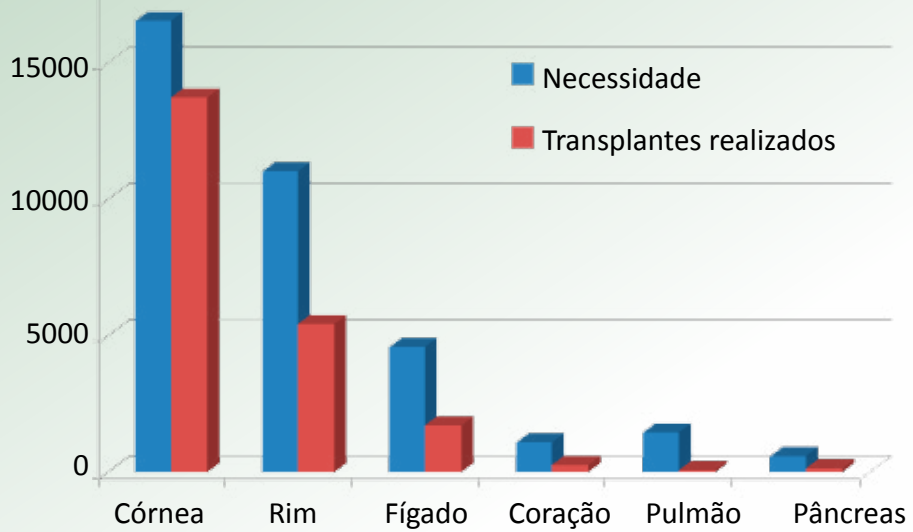

Evolução anual dos doadores efetivos no Brasil - pmp (por milhão de população)

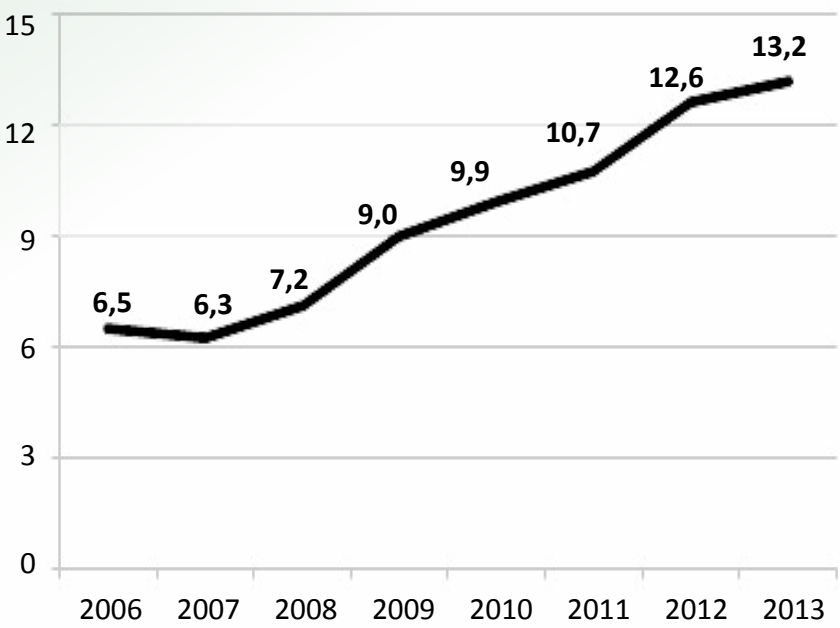

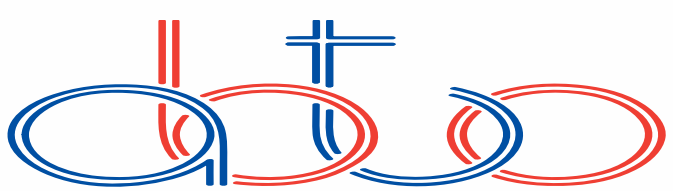



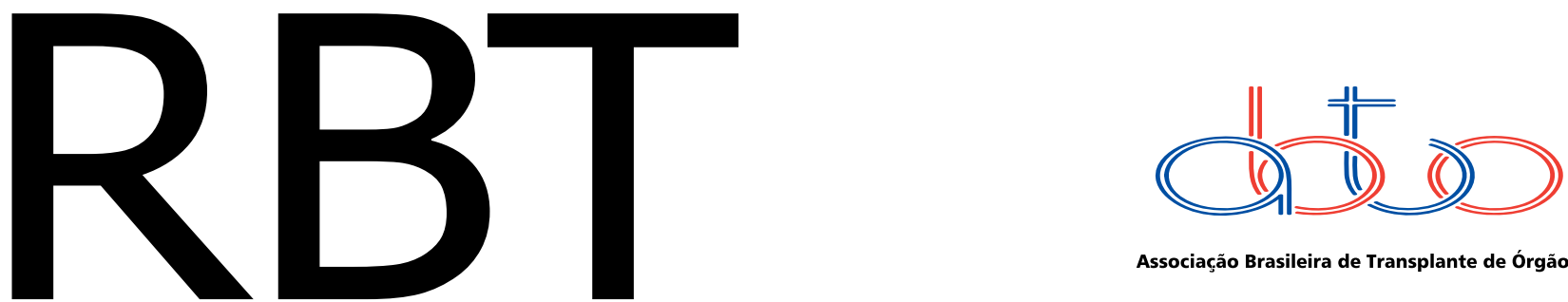

Associação Brasileira de Transplante de Órgãos

Registro Brasileiro de Transplantes

Veículo Oficial da Associação Brasileira de Transplante de Órgãos

Apoio

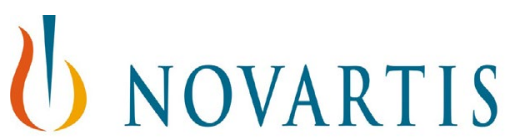

cuidar e curar

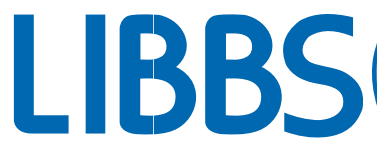

TRANSPLANTES

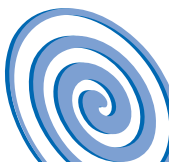

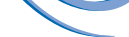

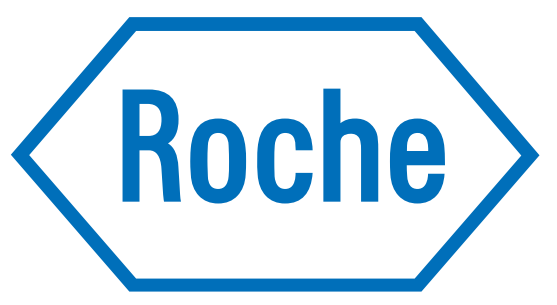

Diretoria: (Biênio 2012-2013)

Presidente: José O. Medina Pestana

Vice-Presidente: Lucio Pacheco

Secretário: Marilda Mazzali

$2^{\circ}$ Secretário: Eliana Régia B. de Almeida

Tesoureiro: Alfredo Inácio Fiorelli

$2^{\circ}$ Tesoureiro: Roberto C. Manfro

\section{Conselho Consultivo:}

Presidente : Valter Duro Garcia

Secretário: Ben-Hur Ferraz Neto

Maria Cristina Ribeiro de Castro

Elias David-Neto

Henry de Holanda Campos

Jorge Neumann

\section{Coordenadores dos Departamentos}

Anestesiologia-Terapia Intensiva: Alexandre Teruya Coordenação de Transplantes: Joel de Andrade Enfermagem em Transplante: Malvina Duarte Ética em Transplantes: Mário Abbud Filho Imunobiologia: Niels Câmara

Transplante de Coração: Noedir Stolf

Transplante de Fígado: Paulo Massarollo Transplante de Pâncreas: Santo Pascual Vitola

Transplante de Pulmão: Spencer Camargo

Transplante de Tecidos: Márcia Regina I S Libanio

Transplante Pediátrico: Clotilde D Garcia

Transplante Renal: Álvaro Pacheco

Expediente:

Editor: Valter Duro Garcia

Coeditor: Lucio Pacheco

Thiago Quintas Camara (thiago@abto.org.br)

Gestão de Dados / Criação e Produção

ABTO - Associação Brasileira de Transplante de Órgãos Av. Paulista, 2001 - $17^{\circ}$ andar - cj 1704 / 1707

São Paulo - SP

CEP 01311-300

Fones: 5511 3283-1753 / 3262-3353

e-mail: abto@abto.org.br

www.abto.org.br 


\section{Crescimento menor que o previsto}

O crescimento previsto em julho de 2007 na taxa de doadores efetivos (que era de 5,4 pmp), de 10 a $15 \%$ ao ano (aumento de 1 a 1,5 doador pmp) foi obtido até 2012 (12,6 pmp). Entretanto, em 2013 o crescimento de $5 \%$ na taxa de doadores efetivos $(13,2 \mathrm{pmp})$ foi menor que o previsto e pela primeira vez não atingimos a meta proposta $(13,5 \mathrm{pmp})$. Essa situação exigirá esforço de todos os segmentos envolvidos para se obter os 15 doadores pmp previstos para 2014. Veja gráfico ao lado.

O dado positivo é o contínuo crescimento na taxa de detecção de potenciais doadores, de $10,5 \%$ em 2013 , tendo passado de 42,1 pmp para 46,5 pmp, contrabalançado pela queda na taxa de efetivação da doação, de $30 \%$ para $28,5 \%$, principalmente devido ao aumento de $15 \%$ na taxa nacional de negativa familiar, que passou de $41 \%$ para $47 \%$.

Onze estados e o Distrito Federal obtiveram taxa de notificação superior a $50 \mathrm{pmp}$, entretanto, em apenas cinco estados a taxa de efetivação foi superior a $35 \%$ e em oito ela foi inferior a $15 \%$. Na taxa de doadores efetivos, destacaram-se, além do Distrito Federal (33,1 pmp), com suas particularidades, Santa Catarina (27,2 pmp) e Ceará (22,2 pmp).

Observa-se que os sete estados com taxa de doadores efetivos superior a $14 \mathrm{pmp}$ apresentaram crescimento e nos oito com taxa inferior a 5 pmp houve diminuição ou estagnação. Essa constatação dá-nos convicção de que são para esses estados e os três que ainda não obtiveram doadores que devem ser dirigidos os esforços para a melhoria das atividades.

O transplante renal cresceu apenas $0,4 \%$ (5.433), não atingindo a meta de 5.700 , tendo havido um aumento de $3,8 \%$ no número de transplantes com doador falecido e uma queda de $8,4 \%$ no transplante com doador vivo. A taxa de 7,2 transplantes renais com doador vivo pmp é a mais baixa dos últimos 15 anos, e distancia-nos muito da meta prevista para 2017, de 15 transplantes com doador vivo pmp. Realizaram mais do que 45 transplantes pmp, o RS $(50,9)$, o DF $(49,8)$ e SP $(46,4)$. Apenas PR $(16,6)$ e SP $(12,6)$ realizaram mais do que dez transplantes renais pmp com doador vivo. Os resultados dos transplantes renais podem ser considerados como bons, com sobrevida em quatro anos do paciente ( $95 \%$ e $88 \%$ ) e do enxerto ( $90 \%$ e $78 \%$ ), respectivamente para doador vivo e falecido. Entretanto, de $22 \%$ dos transplantes, ainda não foram enviados os dados evolutivos.

O transplante hepático cresceu 7,8\% (1.723), próximo dos 1.750 previstos, com aumento tanto no transplante com doador vivo (16,2\%) quanto com doador falecido (7,1\%). Apenas CE (23,0 pmp) e DF (20,6 pmp) ultrapassaram a barreira dos 20 transplantes pmp. Em $67 \%$ dos transplantes, a sobrevida em quatro anos do paciente e do enxerto foi de $70 \%$ e de $68 \%$, respectivamente. A estratificação pelo tipo de doador e pelo MELD pode enriquecer esses dados.

O transplante cardíaco novamente aumentou (19\%) e atingiu o recorde (271). Entretanto, essa taxa (1,4 pmp) é muito baixa e há margem para maior crescimento, pois são utilizados os corações de apenas $11 \%$ dos doadores de órgãos. Apenas o DF (11,3 $\mathrm{pmp}$ ) apresentou taxa superior a cinco transplantes pmp. A sobrevida do paciente em quatro anos foi de $68 \%$, havendo informação de $90 \%$ dos transplantes realizados.

O transplante pulmonar também apresentou aumento em dois anos consecutivos, sendo de $16 \%$ em 2013 . Em apenas 3,2\% dos doadores, os pulmões são utilizados. Pela primeira vez, o transplante foi realizado em cinco estados e, apenas no RS (2,9 pmp), a taxa de transplantes foi superior a $1 \mathrm{pmp}$. A sobrevida do paciente em quatro anos foi de $57 \%$, com quase todos os transplantes analisados (97\%).

Foram realizados em apenas sete estados, 142 transplantes de pâncreas (0,7 pmp), configurando uma queda de $6 \%$ no ano. Apenas PR (2,2 pmp) realizou mais do que dois transplantes pmp.

O transplante de medula óssea, com os dados obtidos pelo RBT, continua com lento e constante crescimento (4\% em 2013), tendo atingido 1.813 transplantes $(9,5 \mathrm{pmp})$ sendo $37 \%$ alogênico. O TMO foi realizado em 13 estados, tendo SP (48,1 pmp) e PE $(39,3 \mathrm{pmp})$ ultrapassado 30 transplantes pmp.

O transplante de córneas, que havia crescido continuamente até 2012, quando atingiu 15.281 (80,1 pmp), diminuiu 10\% em 2013 (72,1 pmp). Essa queda deve ser melhor avaliada, pois pode não se dever apenas a que alguns estados tenham obtido a "lista zero", pois a necessidade estimada é em torno de 90 a 100 transplantes pmp. Realizaram mais do que 100 transplantes pmp, SP (112,6 pmp), DF (119,6 pmp) e GO (116,3 pmp).

Então, embora tenha ocorrido um crescimento no número de transplantes, ele ainda não atende o crescimento previsto para que possa melhor atender a necessidade da população brasileira. 


\section{Sumário}

INSERÇÃO DO BRASIL NO MUNDO

DADOS BRASILEIROS

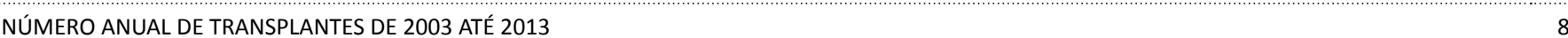

RIM

FÍGADO

CORAÇÃO

PÂNCREAS

PULMÃO

MEDULA ÓSSEA; TECIDOS e CÉLULAS

CÓRNEA

OSSOS

TRANSPLANTES PEDIÁTRICOS

DADOS POR REGIÃO BRASILEIRA

DADOS GERAIS

DOAÇÃO DE ÓRGÃOS

TRANSPLANTES DE TECIDOS

TRANSPLANTES DE ÓRGÃOS

Pacientes Ativos em Lista de Espera (dezembro 2013)

Doação de órgãos durante o ano de 2013

Número de notificações de potenciais doadores, doadores efetivos de órgãos sólidos e doadores cujos órgãos foram transplantados por estado, durante o ano de 2013

Causas de não concretização da doação de órgãos de potenciais doadores notificados nos estados brasileiros, durante o ano de 2013

Perfil etário, gênero, causa óbito e grupo sanguíneo dos doadores de órgãos nos estados brasileiros

Acre

Alagoas

Amapá

Amazonas

Bahia

Ceará

Distrito Federal

Espirito Santo

Goiás

Maranhão

Mato Grosso

Mato Grosso do Sul

Minas Gerais

Pará

Paraíba

Paraná

Pernambuco

Piaui

Rio de Janeiro

Rio Grande do Norte

Rio Grande do Sul

Rondônia

Roraima

Santa Catarina

São Paulo

Sergipe

Tocantins

DADOS POR CENTROS TRANSPLANTADORES

CORAÇÃO

FÍGADO

PÂNCREAS

RIM

PULMÃO

CÓRNEA

MEDULA ÓSSEA

PELE

OSSOS 


\section{INSERÇÃO DO BRASIL NO MUNDO}

Fonte: IRODAT 2012 (último dado disponível)

Brasil é o segundo em número absoluto de transplantes renais (entre 30 países) - ano 2012

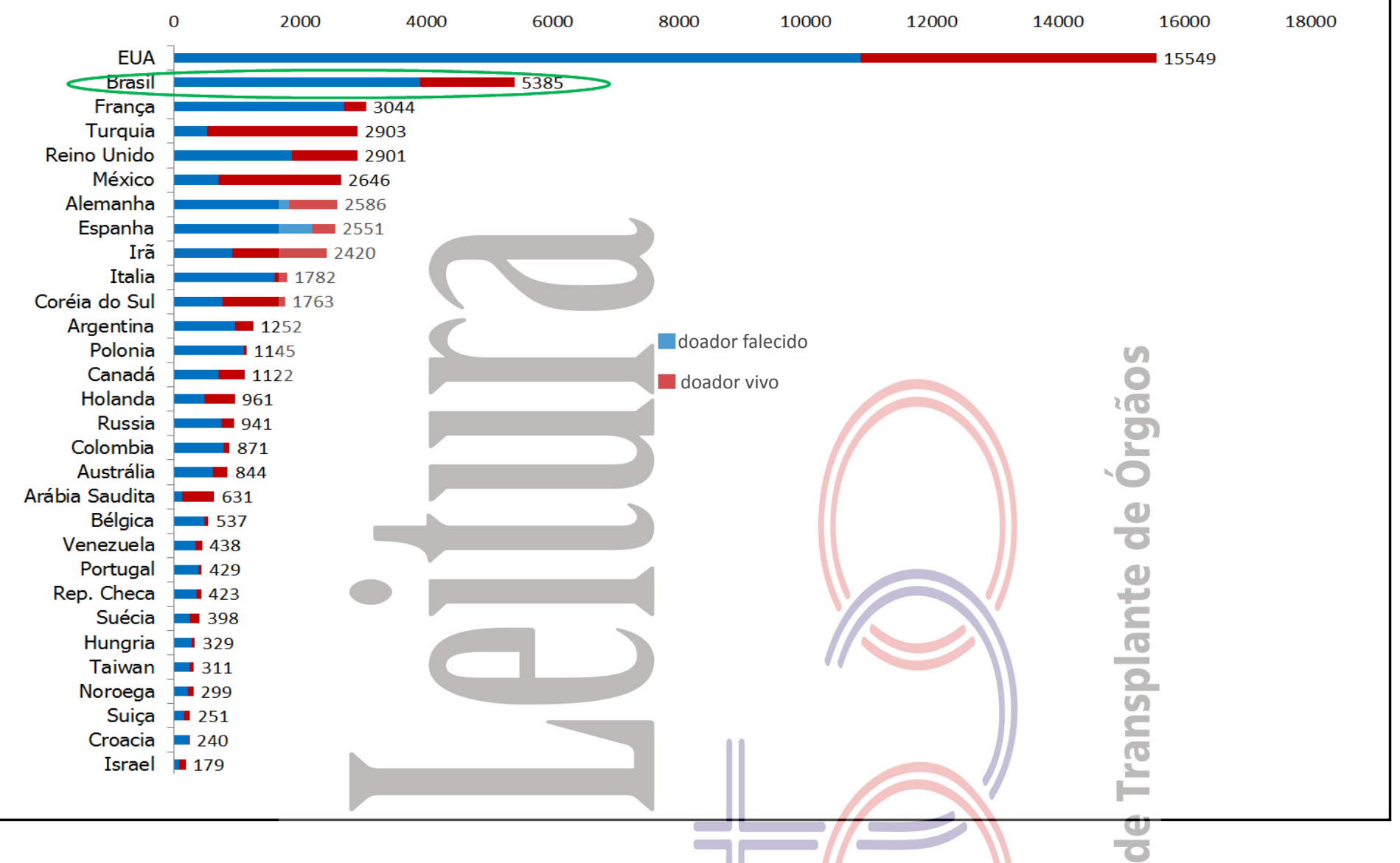

-Brasil é o segundo em número absoluto de transplantes hepáticos (entre 30 países)- ano 2012

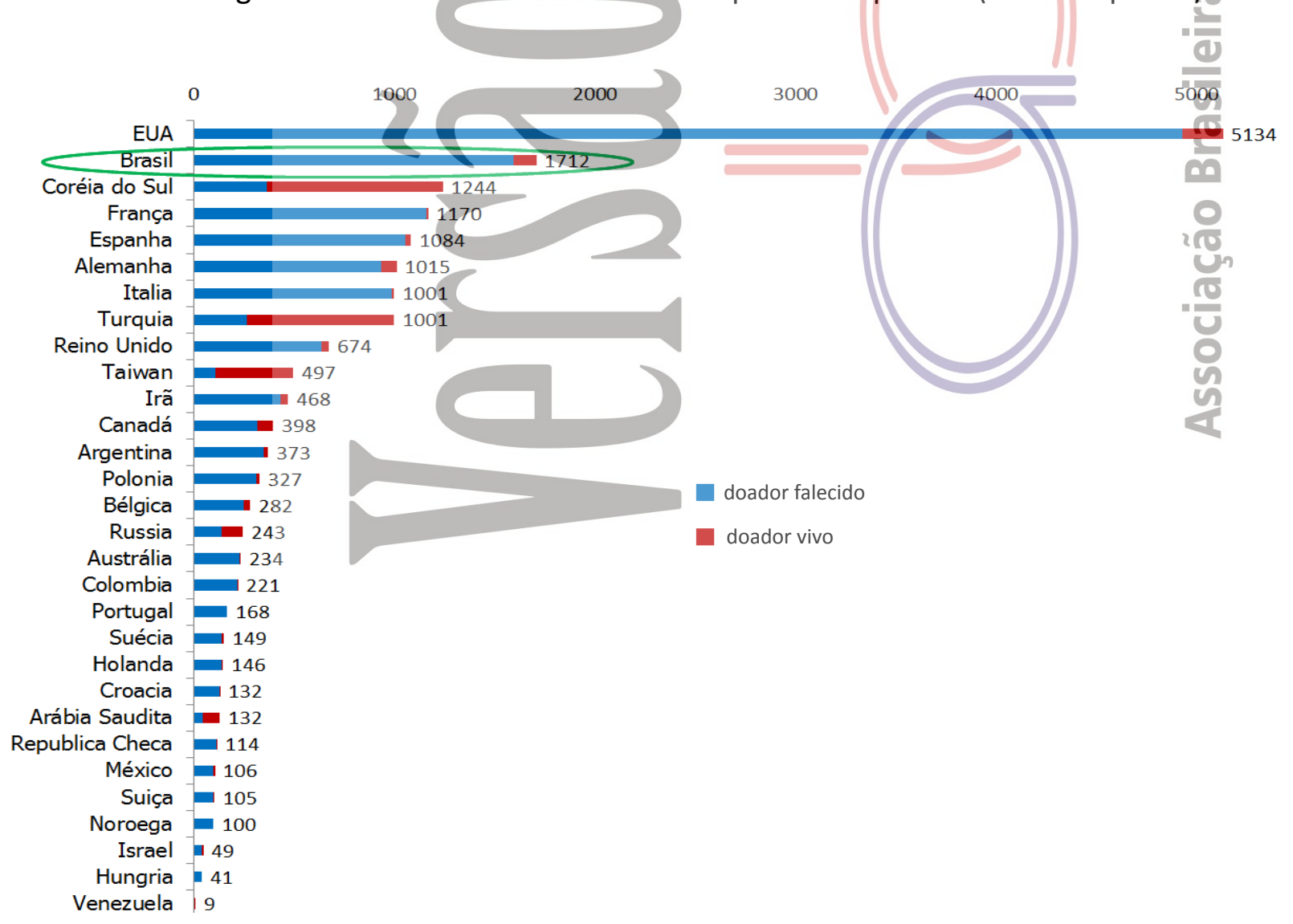




\section{INSERÇÃO DO BRASIL NO MUNDO}

Fonte: IRODAT 2012 (último dado disponível)

Transplantes renais (número pmp), por tipo de doador, durante o ano de 2012. (55 países)

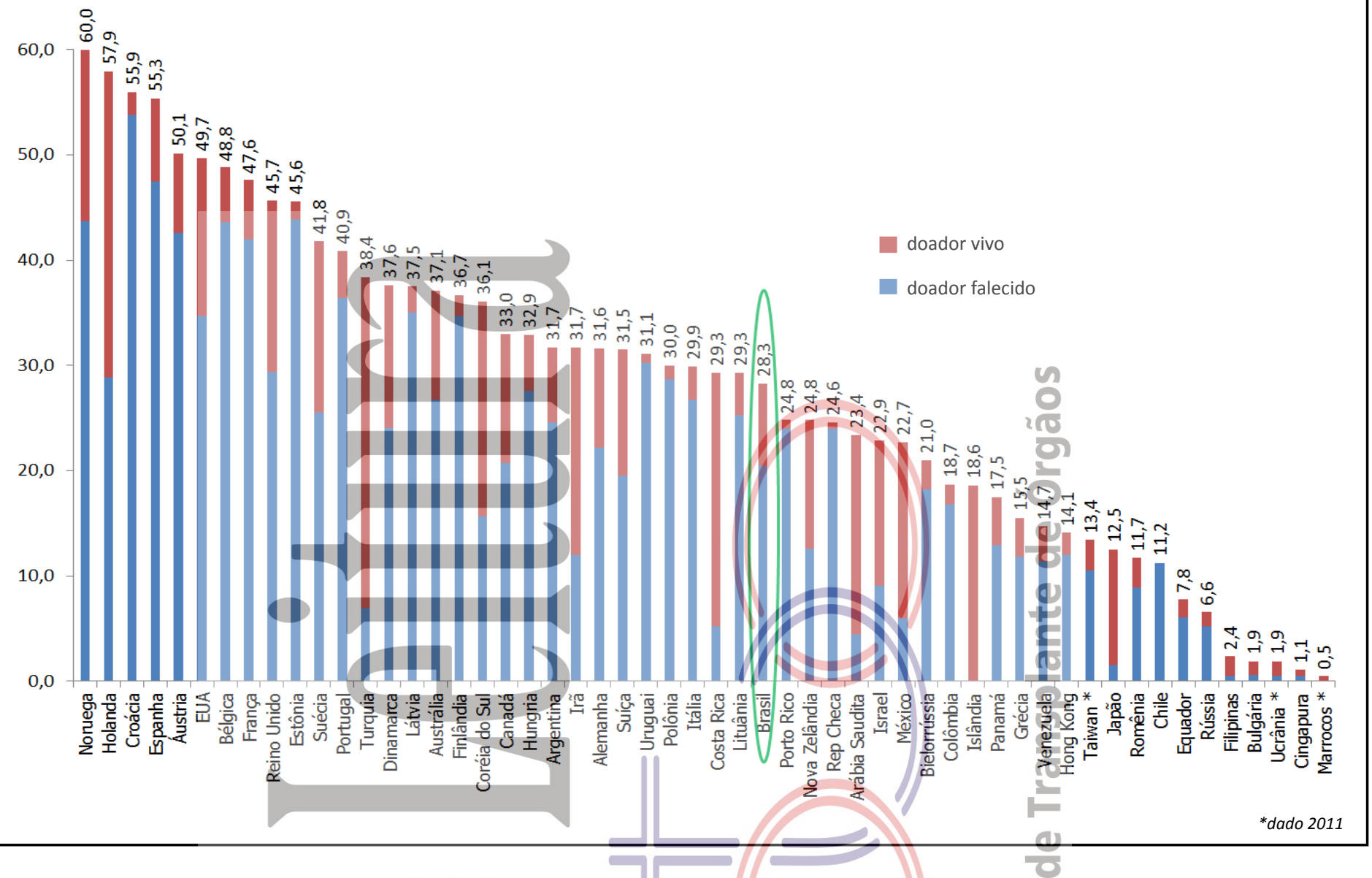

-Transplantes hepáticos (número pmp), por tipo de doador, durante o ano de_2012. (49 países)

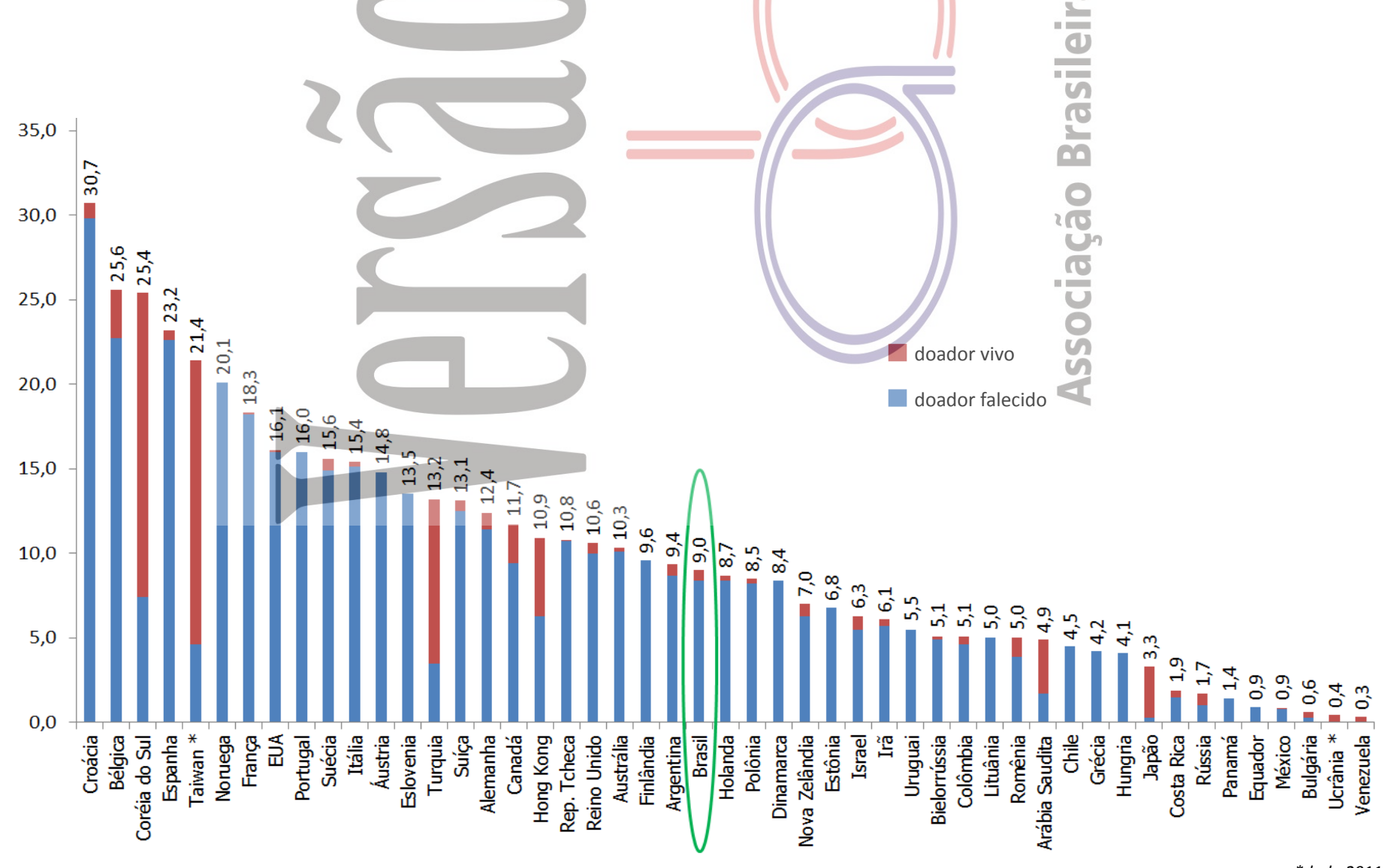




\section{INSERÇÃO DO BRASIL NO MUNDO}
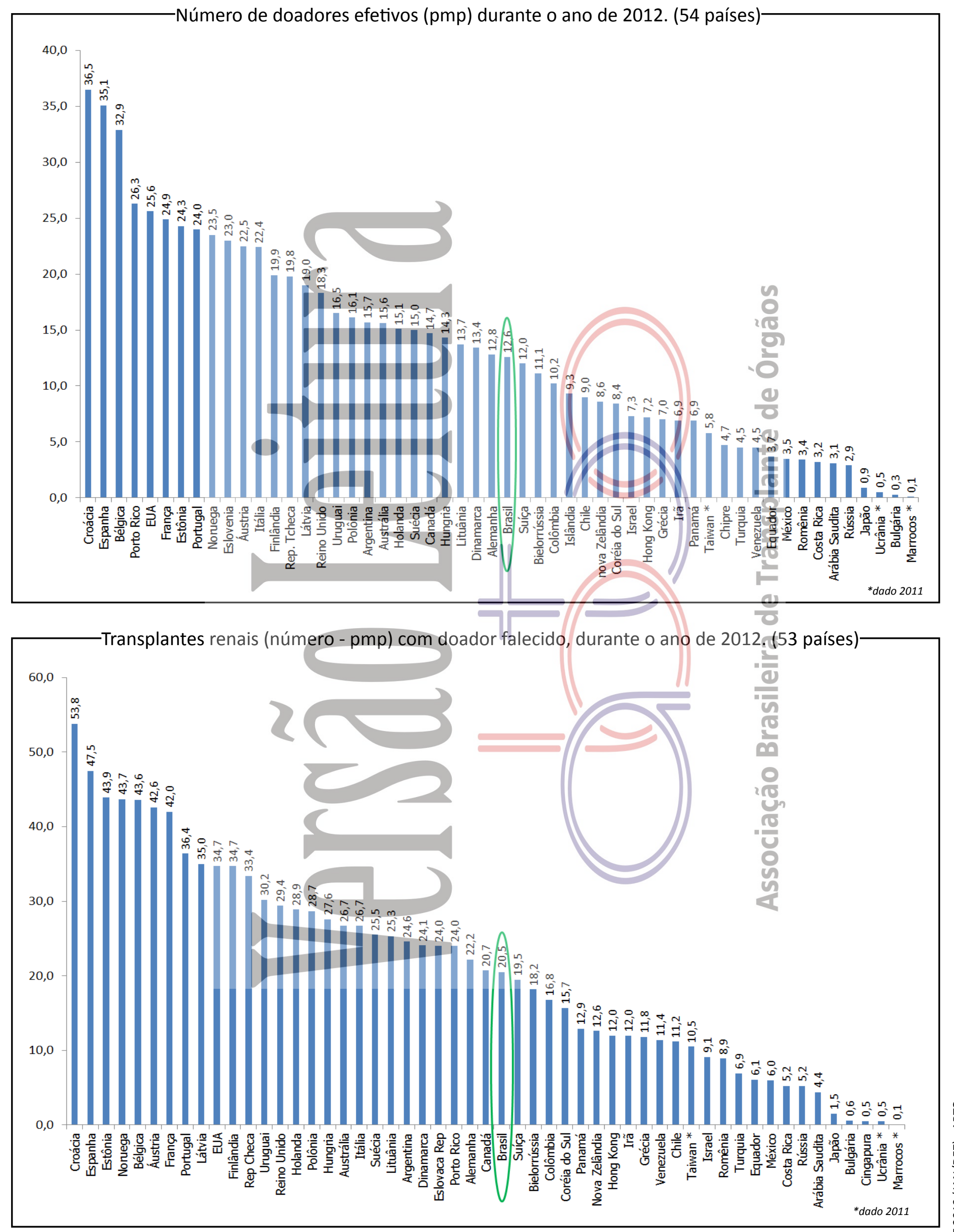


\section{DADOS BRASILEIROS}

População atual

190.755.799

Extensão territorial $\left(\mathrm{Km}^{2}\right)$

$8.514 .876,60$
Necessidade anual estimada e no de transplantes

\section{Necessidade estimada}

Transplantes realizados
Córnea

Rim Fígado Coração

$\begin{array}{rrrr}17.168 & 11.445 & 4.769 & 1.145 \\ 13.744 & 5.433 & 1.723 & 271\end{array}$

\begin{tabular}{lrrrrrrrr}
\hline Número de Óbitos por ano & 2006 & 2007 & 2008 & 2009 & 2010 & 2011 & 2012 & 2013 \\
\hline Todas as causas & 1.031 .691 & 1.047 .824 & 1.077 .007 & 1.103 .088 & 1.136 .947 & 1.170 .498 & Indisponível & Indisponível \\
Causas Externas & 128.388 & 131.032 & 135.936 & 138.697 & 143.256 & 145.842 & Indisponível & Indisponível \\
Causas Neurológicas & 19.166 & 20.413 & 21.609 & 23.018 & 25.303 & 26.948 & Indisponível & Indisponível
\end{tabular}

População (censo IBGE) Fonte: http://cnes.datasus.gov.br 17/12/2013

\section{HOSPITAIS}

№ Total

Capitais dos estados Interior

№ de leitos

№ de leitos UTI

Hospitais com mais de 80 leitos $\quad 1.818$

Hospital de ensino

Escolas médicas

№ serviços de neurocirurgia

Número de CIHDOTTS

Número de OPOs
O Brasil tem um programa de transplantes bem consolidado, mas que deve ser zelado para que $6.295 \quad$ o crescimento dos últimos anos seja sustentado. A regulamentação do programa é justa, mas 1.393 depende da atuação de vários profissionais em sequência, desde a identificação dos potenciais 4.902 doadores até a efetivação dos transplantes e seu acompanhamento ambulatorial. Com mais 475.755 de 190 milhões de habitantes, estamos praticamente zerando a fila para transplantes de : córneas, e atendendo cerca de $40 \%$ da necessidade anual para transplantes renais e $30 \%$ dos 37.815 transplantes hepáticos. O Brasil tem quase 500 mil leitos hospitalares distribuídos em mais de seis mil hospitais, dos quais 1818 apresentam mais de 80 leitos. As comissões intra-hospitalares de transplante, são fundamentais na identificação do potencial doador e sua pronta notificação 136 às centrais estaduais. O número de transplantes com doador vivo vem decrescendo quase que 188 em todos os estados brasileiros, compensado pelo crescimento do transplante com doador 188 falecido. Muitos profissionais de saúde merecem o reconhecimento pelo sucesso desse 411 programa: desde o profissional que faz a notificação do potencial doador, até os profissionais 628 que fazem o acompanhamento ambulatorial após o transplante. Nesse meio, os maiores heróis são os doadores, que propiciam a melhora da vida de muitas outras pessoas.

\section{DOAÇÃO DE ÓRGÃOS}
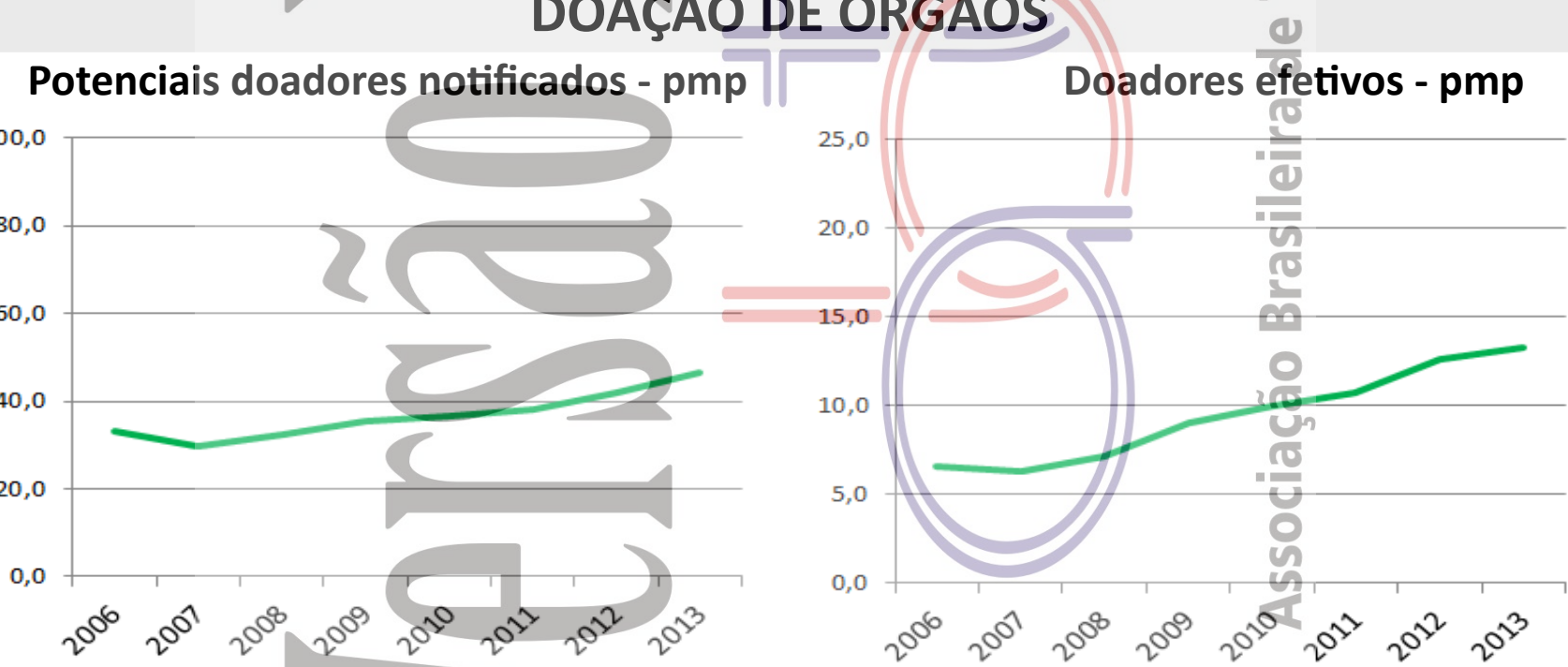

\begin{tabular}{|lrrrrrrrr}
\hline & 2006 & 2007 & 2008 & 2009 & 2010 & 2011 & 2012 & 2013 \\
\hline Número de doadores efetivos & 1.109 & 1.150 & 1.317 & 1.658 & 1.898 & 2.048 & 2.406 & 2.526 \\
\hline Número de doadores efetivos (pmp) & 6,5 & 6,3 & 7,2 & 9,0 & 9,9 & 10,7 & 12,6 & 13,2 \\
$\begin{array}{l}\text { Número de notificações } \\
\text { (potenciais doadores) }\end{array}$ & 5.627 & 5.494 & 5.992 & 6.490 & 6.979 & 7.238 & 8.025 & 8.871 \\
\hline Número de notificações (pmp) & 33,1 & 29,9 & 32,6 & 35,3 & 36,6 & 37,9 & 42,1 & 46,5 \\
\hline Recusa familiar & 1539 & 1507 & 1329 & 1390 & 1800 & 1937 & 2315 & 2.622 \\
\hline Percentual de recusa das entrevistas & Indisponível & Indisponível & Indisponível & Indisponível & Indisponível & Indisponível & $41 \%$ & $47 \%$ \\
Parada Cardíaca & Indisponível & Indisponível & 1428 & 1350 & 1279 & 1205 & 1188 & 1.292 \\
\hline Contraindicação médica & 2173 & 1832 & 839 & 1101 & 991 & 832 & 836 & 1.150 \\
Outros & 806 & 1005 & 1079 & 991 & 1011 & 1216 & 1280 & 1.281
\end{tabular}




\section{DADOS BRASILEIROS}

\section{TRANSPLANTE DE ÓRGÃOS}

\section{RIM com doador falecido - pmp}

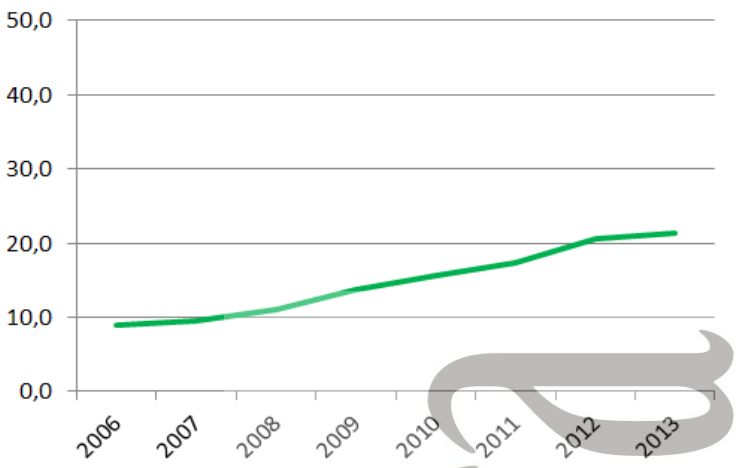

FÍGADO - pmp

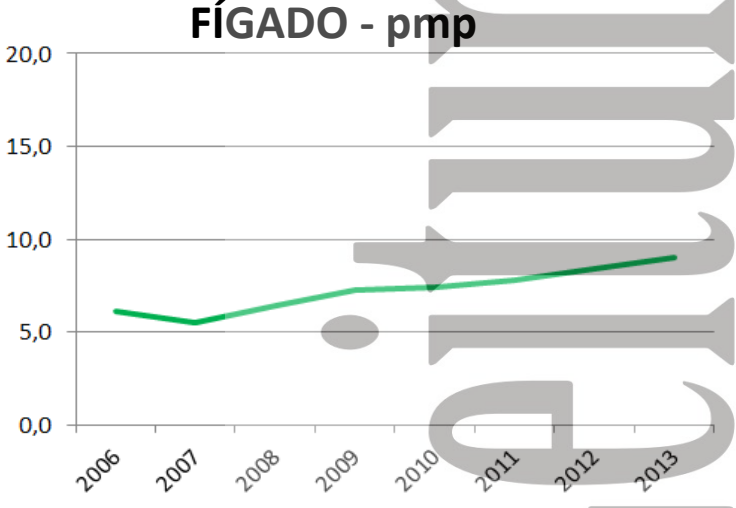

\section{RIM com doador vivo - pmp}

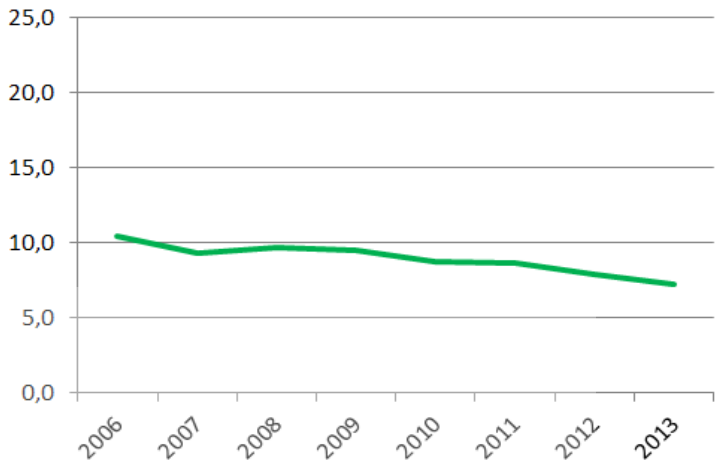

CÓRNEA- pmp

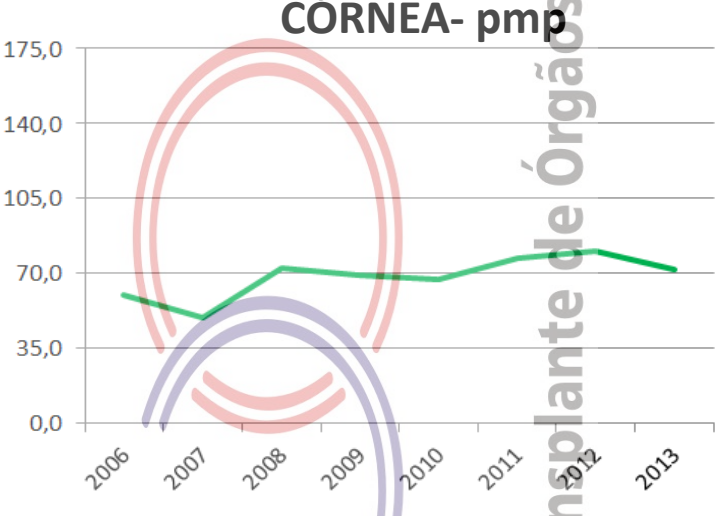

\begin{tabular}{|c|c|c|c|c|c|c|c|c|}
\hline \multicolumn{6}{|c|}{ 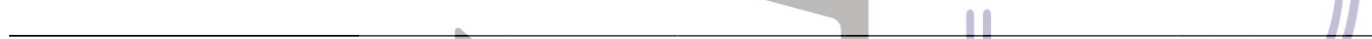 } & \multicolumn{3}{|l|}{ cos } \\
\hline $\begin{array}{l}\text { Número de equipes que realizaram } \\
\text { transplantes durante o ano }\end{array}$ & 2006 & 2007 & 2008 & 2009 & 2010 & 2011 & 2012 & 2013 \\
\hline CÓRNEA & Indisponível & Indisponível & Indisponível & idisponível & ndisponível & Indisponível Ind & disponível & Indisponível \\
\hline RIM & 144 & 140 & 142 & 140 & 140 & 126 & 124 & 129 \\
\hline FÍGADO & 50 & 49 & 48 & 51 & 55 & 57 & 59 & 60 \\
\hline PÂNCREAS & 31 & 29 & 26 & 21 & 21 & 26 & 19 & 21 \\
\hline CORAÇÃO & 29 & 33 & 30 & & & 27 & 27 & 33 \\
\hline PULMÃO & 7 & 4 & 4 & 5 & 4 & 6 & 6 & 7 \\
\hline Número absoluto de transplantes & 2006 & 2007 & 2008 & 2009 & 2010 & 20110 & 2012 & 2013 \\
\hline CÓRNEA & 10.124 & 9.040 & 13.341 & 12.723 & 12.778 & 14.696 ro & 15.281 & 13.744 \\
\hline RIM & 3.285 & 3.463 & 3.815 & 4.285 & 4.656 & $4.975 \cup$ & 5.410 & 5.433 \\
\hline doador vivo & 1.760 & 1.714 & 1.780 & 1.742 & 1.655 & 1.650 & 1.499 & 1.373 \\
\hline doador falecido & 1.525 & 1.749 & 2.035 & 2.543 & 3.001 & 3.325 & 3.911 & 4.060 \\
\hline FÍGADO & 1.037 & 1.008 & 1.177 & 1.334 & 1.413 & 1.494 & 1.599 & 1.723 \\
\hline PÂNCREAS & 191 & 163 & 174 & 160 & 133 & 181 & 151 & 142 \\
\hline CORAÇÃO & 149 & 161 & 201 & 201 & 166 & 160 & 227 & 271 \\
\hline PULMÃO & 49 & 46 & 53 & 59 & 61 & 49 & 69 & 80 \\
\hline Número de transplantes pmp & 2006 & 2007 & 2008 & 2009 & 2010 & 2011 & 2012 & 2013 \\
\hline CÓRNEA & 59,6 & 49,1 & 72,5 & 69,2 & 67,0 & 77,0 & 80,1 & 72,1 \\
\hline RIM & 19,3 & 18,8 & 20,7 & 23,3 & 24,4 & 26,1 & 28,4 & 28,5 \\
\hline doador vivo & 10,4 & 9,3 & 9,7 & 9,5 & 8,7 & 8,6 & 7,9 & 7,2 \\
\hline doador falecido & 9,0 & 9,5 & 11,1 & 13,8 & 15,7 & 17,4 & 20,5 & 21,3 \\
\hline FÍGADO & 6,1 & 5,5 & 6,4 & 7,3 & 7,4 & 7,8 & 8,4 & 9,0 \\
\hline PÂNCREAS & 1,1 & 0,9 & 0,9 & 0,9 & 0,7 & 0,9 & 0,8 & 0,7 \\
\hline CORAÇÃO & 0,9 & 0,9 & 1,1 & 1,1 & 0,9 & 0,8 & 1,2 & 1,4 \\
\hline PULMÃO & 0,3 & 0,3 & 0,3 & 0,3 & 0,3 & 0,3 & 0,4 & 0,4 \\
\hline
\end{tabular}




\section{NÚMERO ANUAL DE TRANSPLANTES DE 2003 ATÉ 2013}

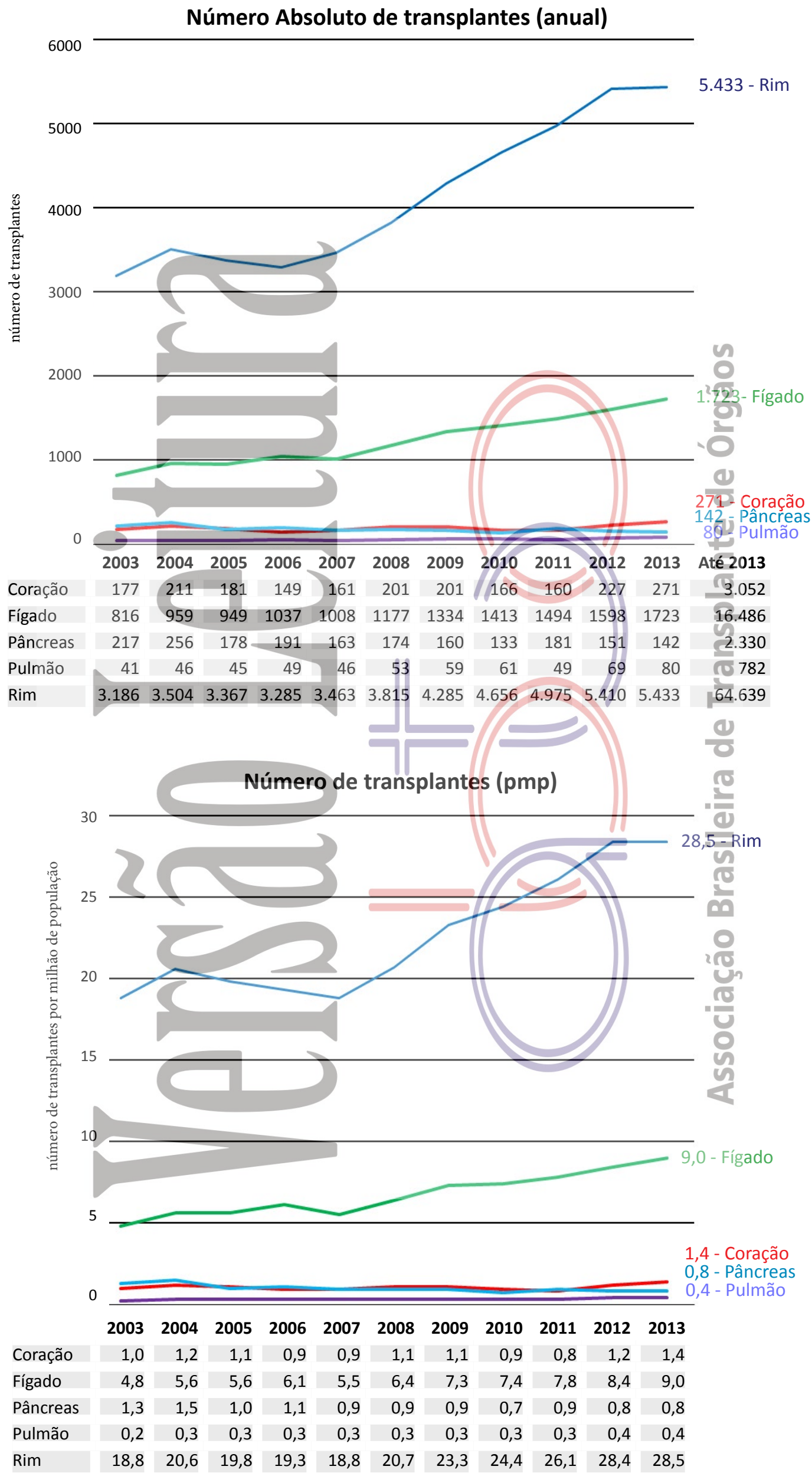




\section{NÚMERO ANUAL DE TRANSPLANTES DE 2003 ATÉ 2013}

RIM (em 21 estados, com 129 centros atuantes)

\section{Número anual conforme tipo de doador}

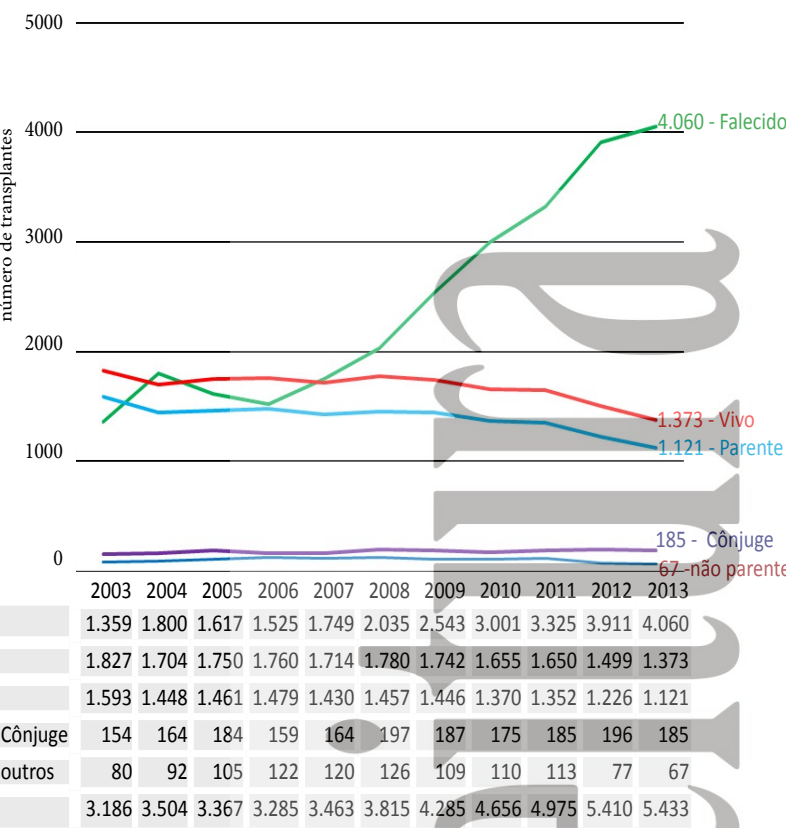

Número anual por estado, durante o ano de 2013

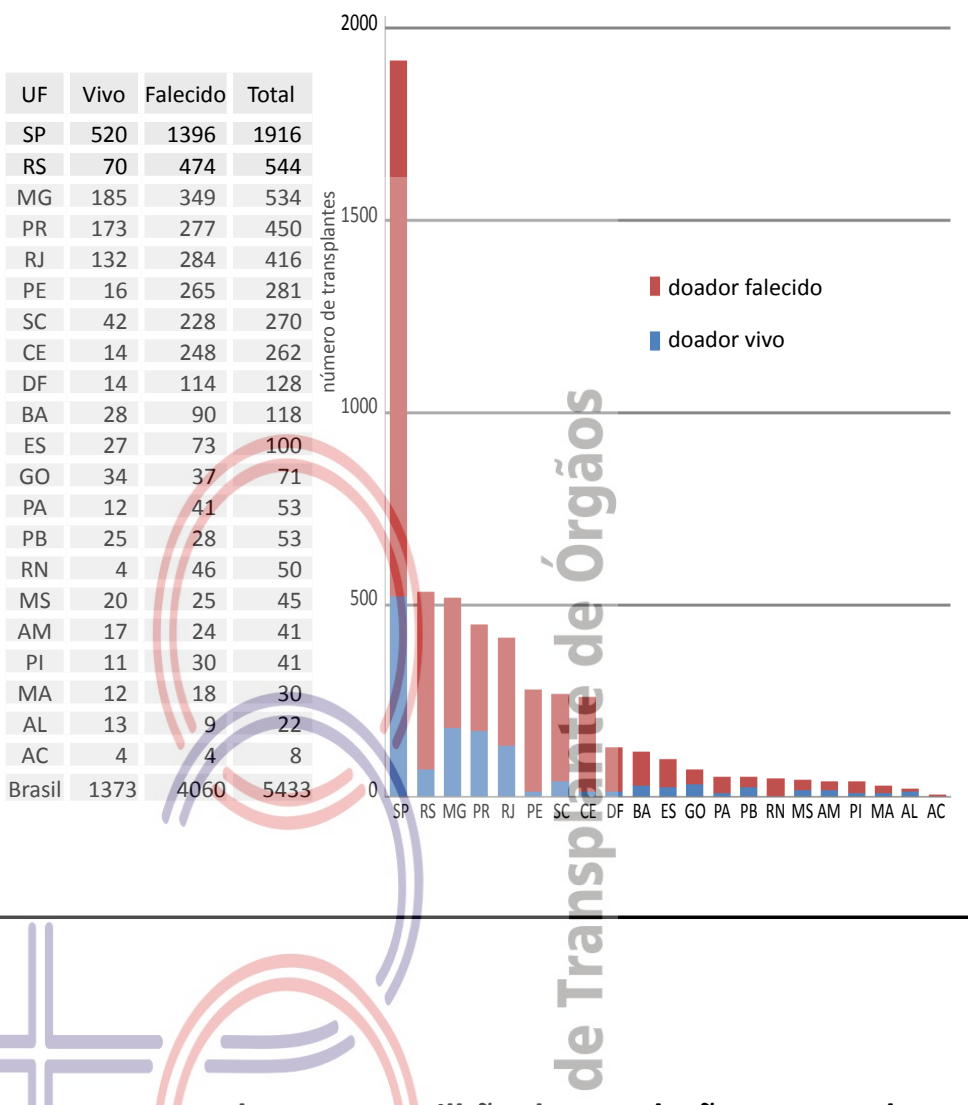

Transplantes por milhão de população por estado, durante o ano de 2013

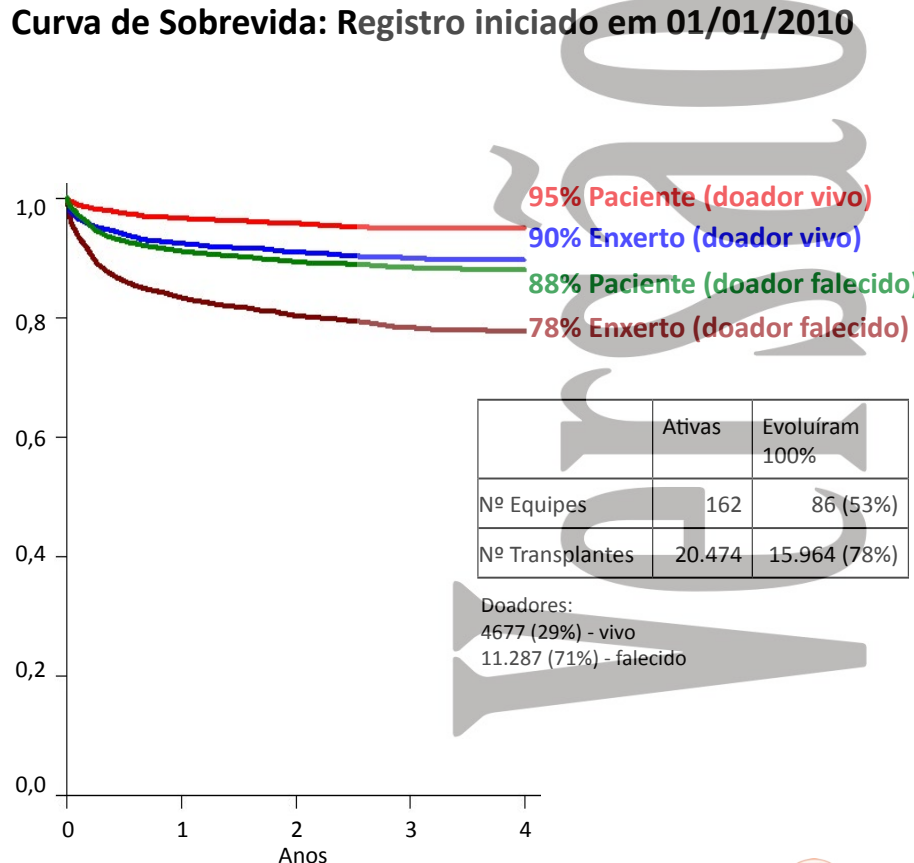

As curvas de sobrevida contemplam apenas as equipes que informaram $100 \%$ dos seus resultados

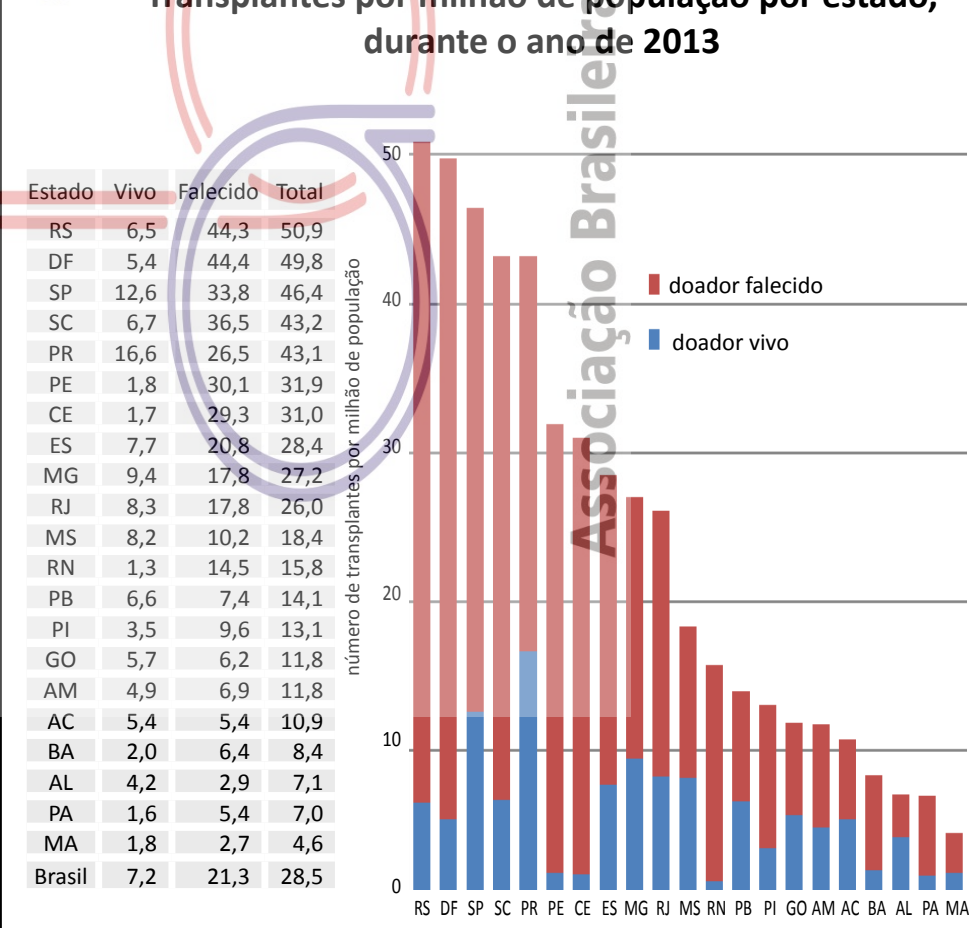




\section{NÚMERO ANUAL DE TRANSPLANTES DE 2003 ATÉ 2013}

\section{FÍGADO - (em 13 estados, com 60 equipes atuantes)}

Número anual conforme tipo de doador

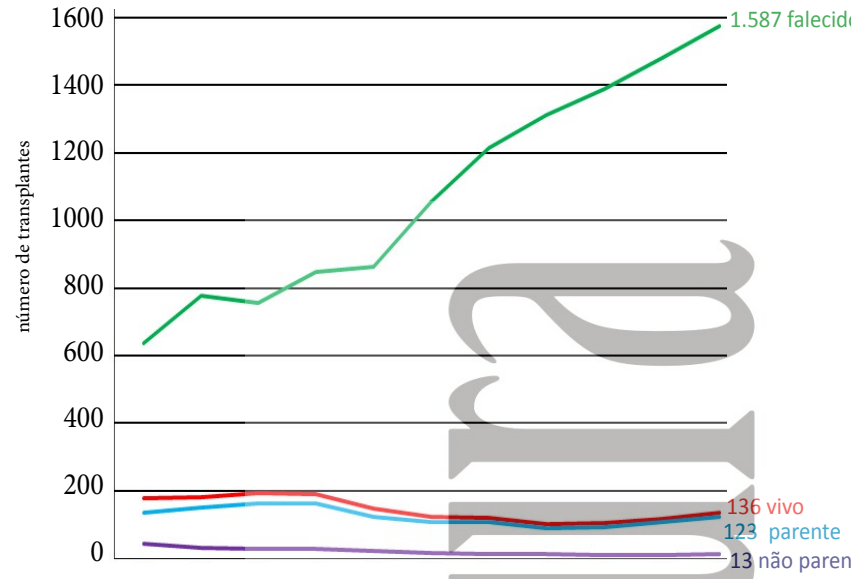

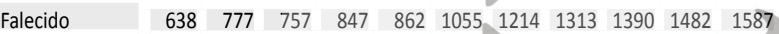
\begin{tabular}{|l|l|l|l|l|l|l|l|l|l|l|l|} 
Parente & 134 & 151 & 164 & 163 & 123 & 107 & 108 & 88 & 93 & 106 & 123 \\
\hline
\end{tabular}

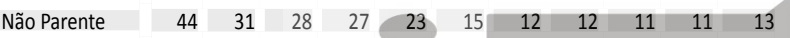
Total $\quad \begin{array}{llllllllllll}816 & 959 & 949 & 1037 & 1008 & 1177 & 1334 & 1413 & 1494 & 1599 & 1723\end{array}$

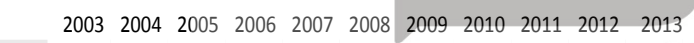

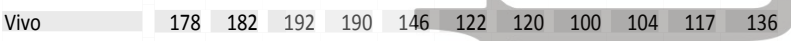

Número anual por estado, durante o ano de 2013

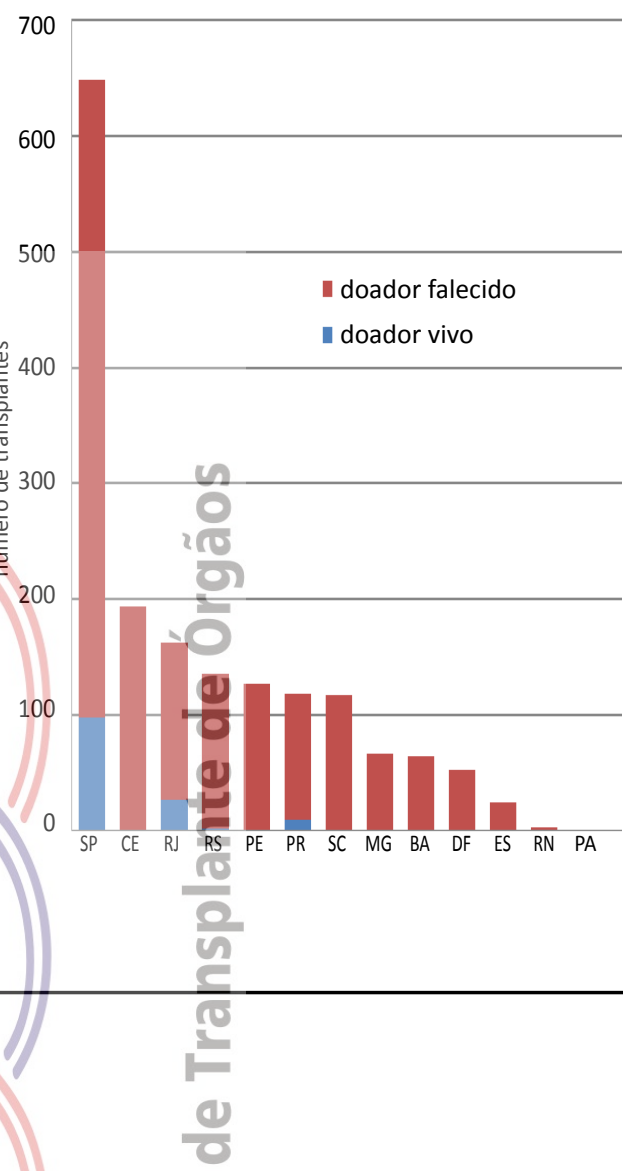

Transplantes por milhão de população por estado, durante o ano de 2013

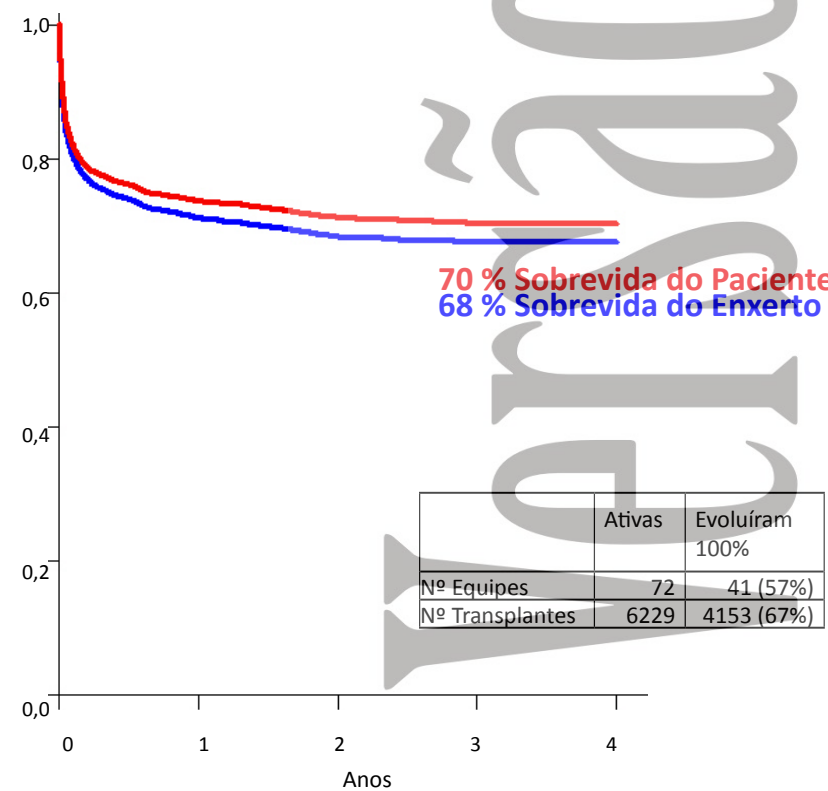

As curvas de sobrevida contemplam apenas as equipes que informaram $100 \%$ dos seus resultados

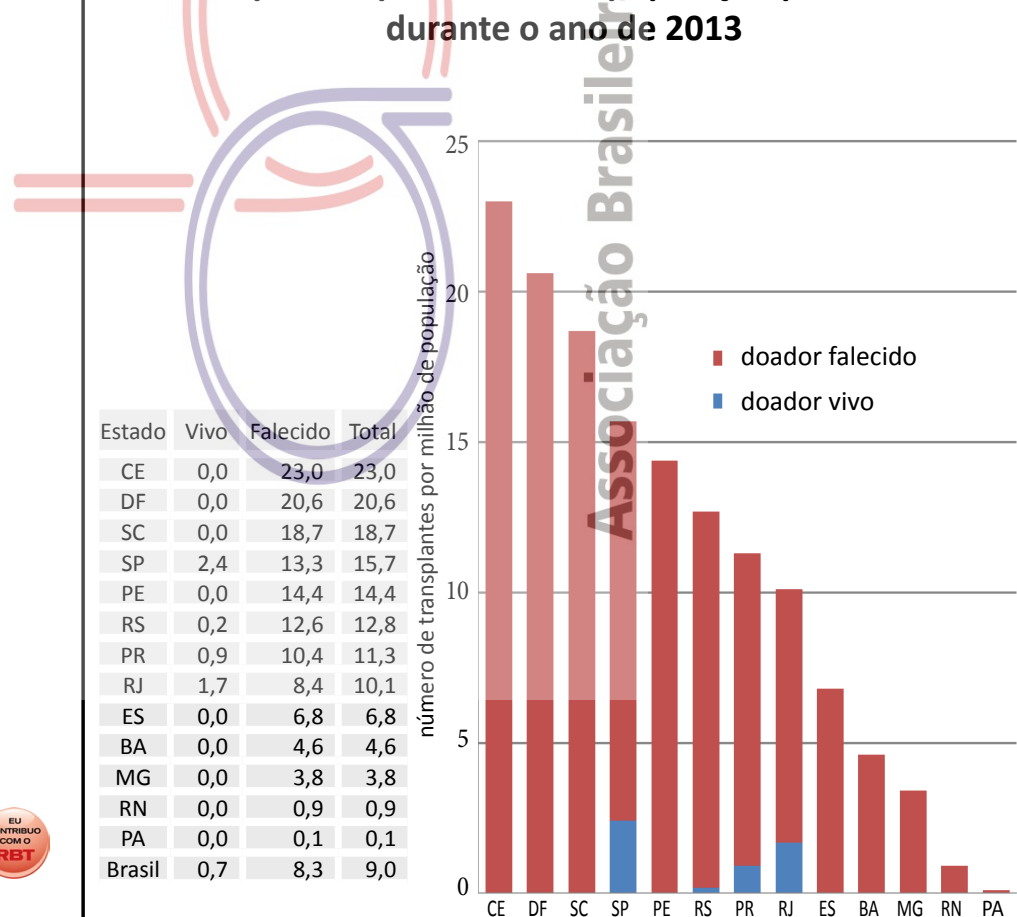




\section{NÚMERO ANUAL DE TRANSPLANTES DE 2003 ATÉ 2013}

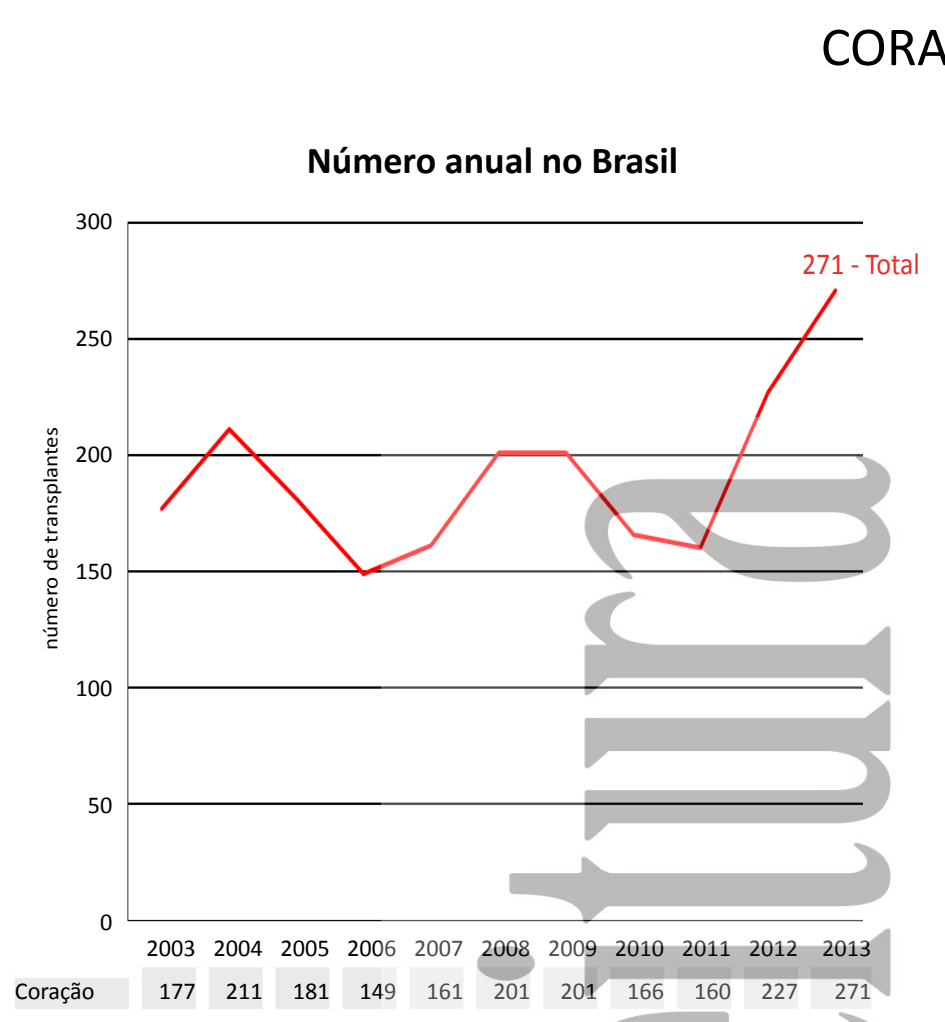

Número anual de transplantes por estado, durante o
ano de 2013
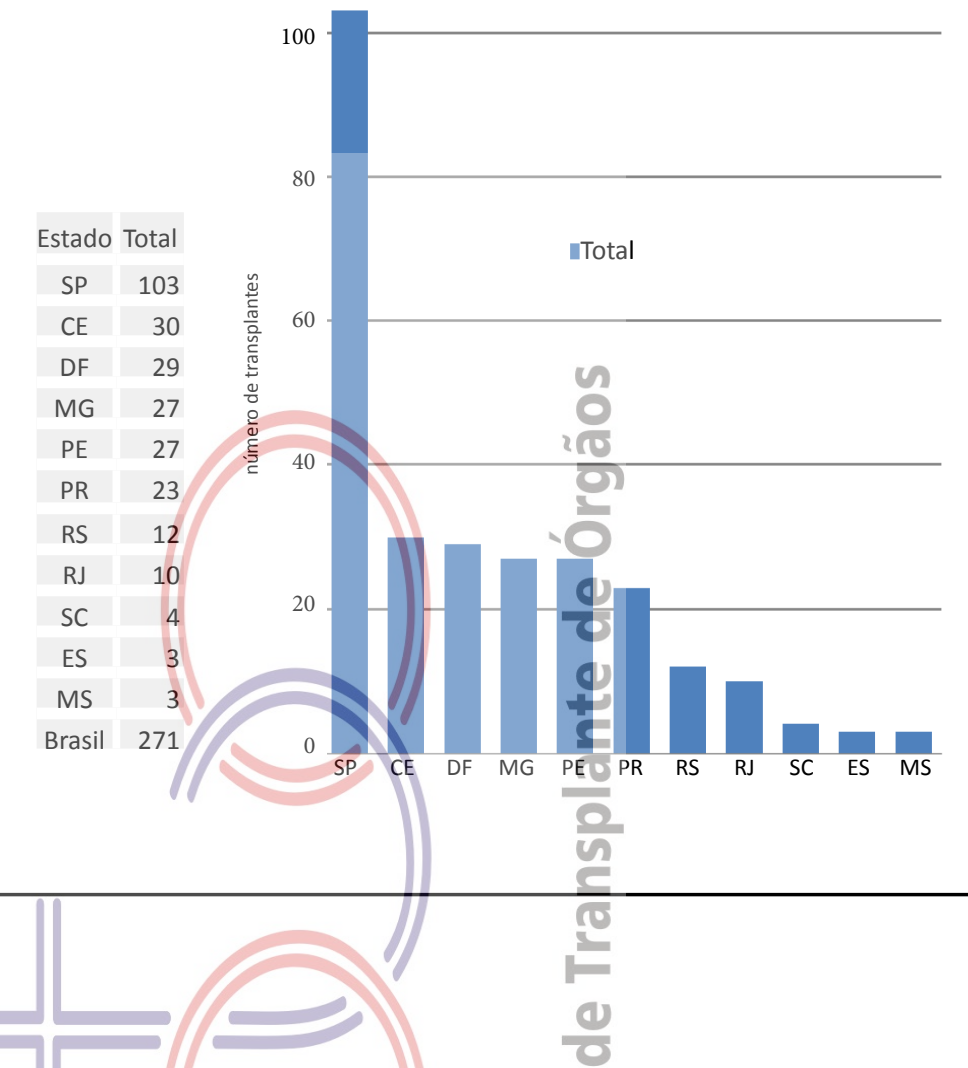

Curva de Sobrevida: Registro iniciado em 01/01/2010

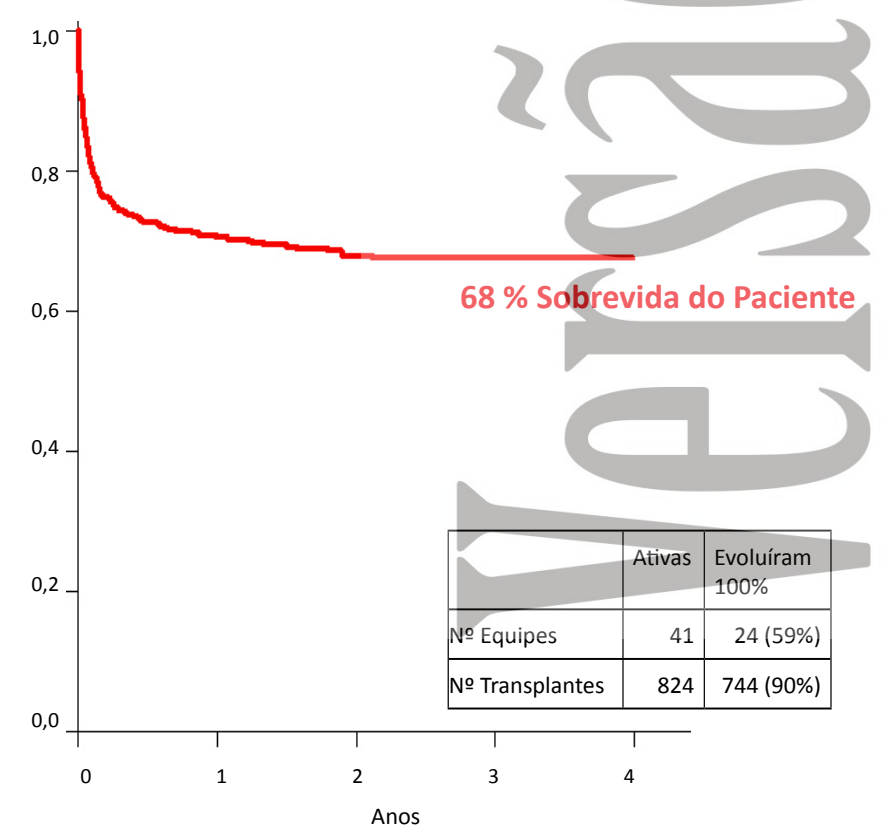

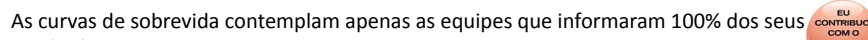
resultados

Transplantes por milhão de população por estado, durante $o$ ano de 2013

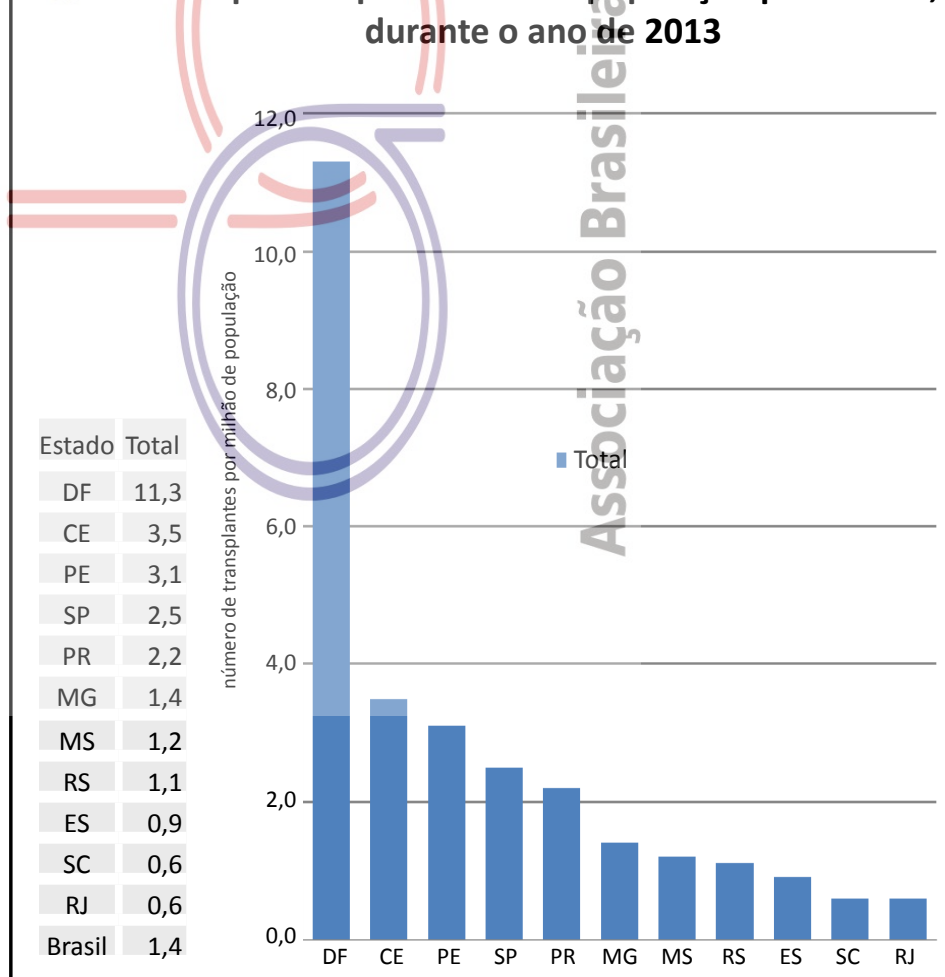




\section{NÚMERO ANUAL DE TRANSPLANTES DE 2003 ATÉ 2013}

\section{PÂNCREAS - (em 7 estados, com 21 centros atuantes)}

Número anual no Brasil

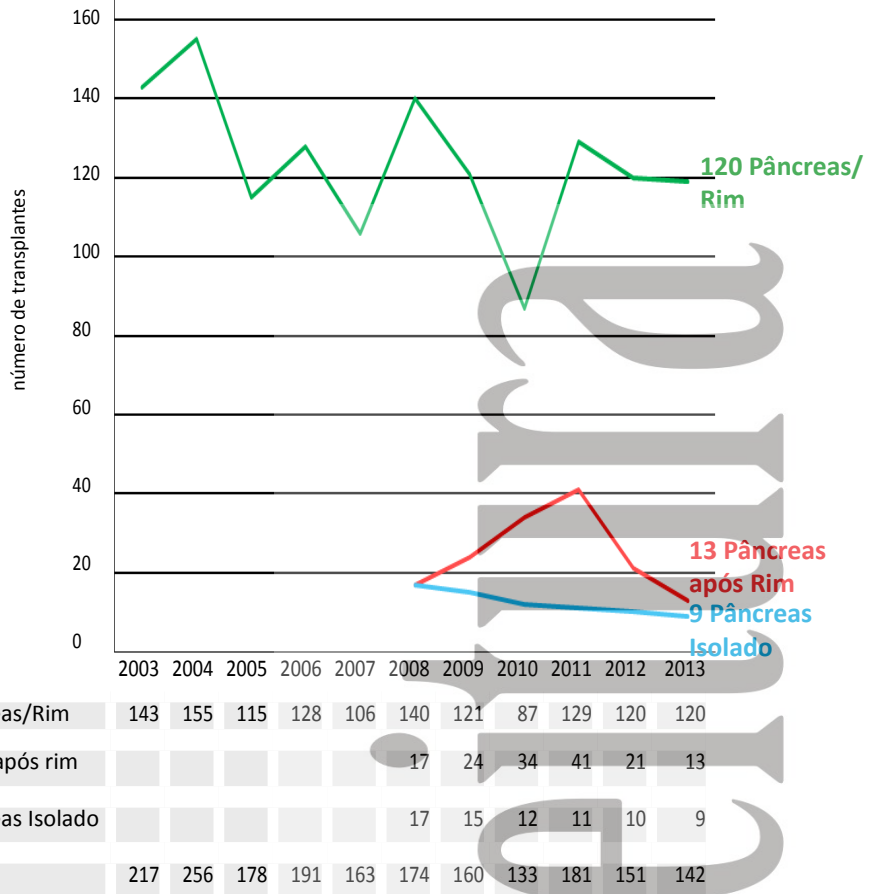

Número anual por estado, durante o ano de 2013

Transplantes por milhão de população por estado, durante o ano de 2013

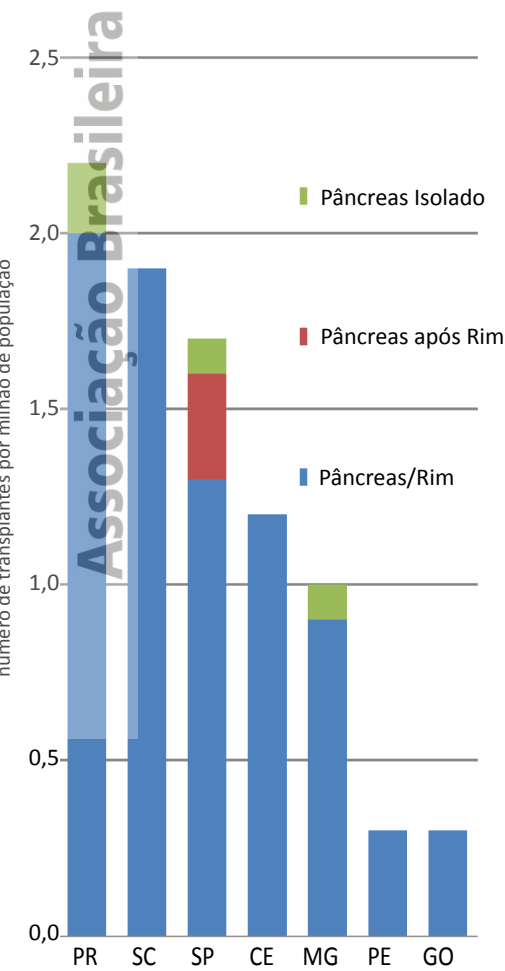

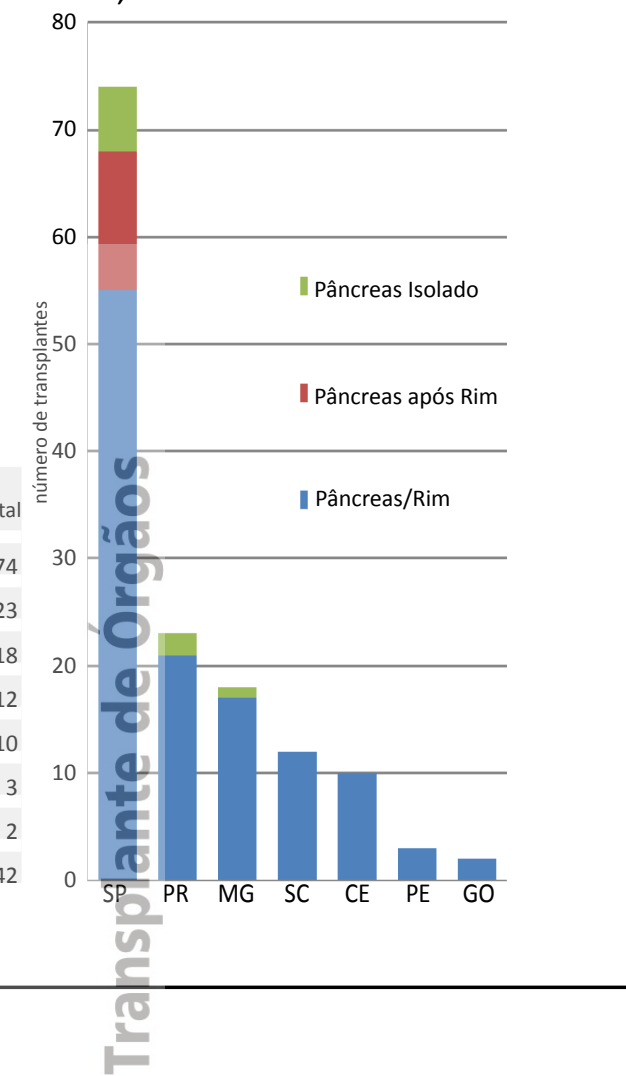

As curvas de sobrevida contemplam apenas as equipes que informaram $100 \%$ dos seus resultados

(Pâncreas/Rim)

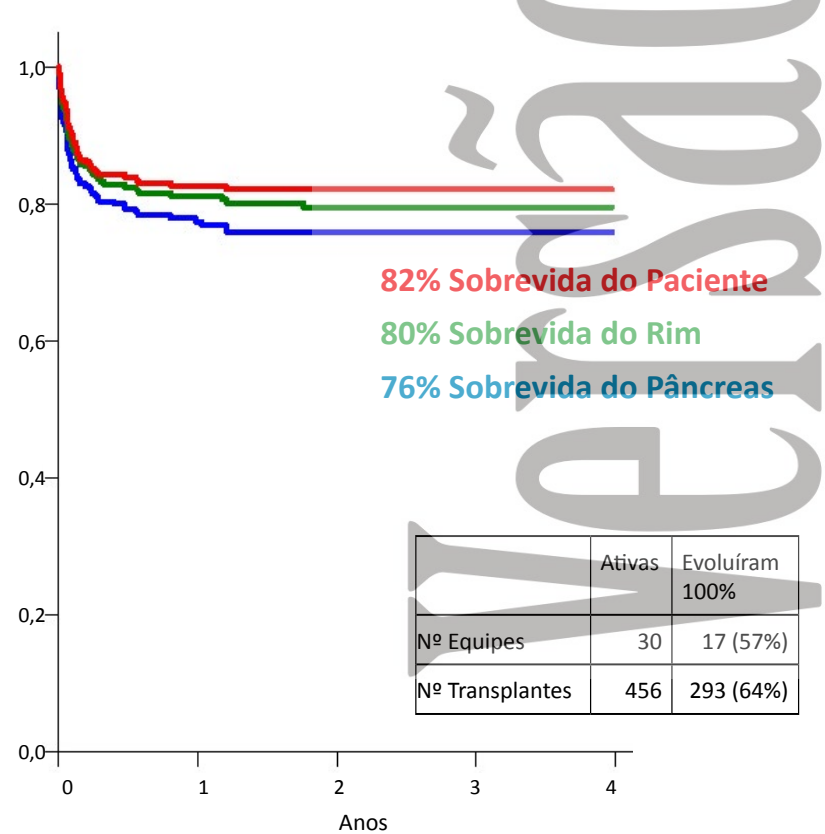

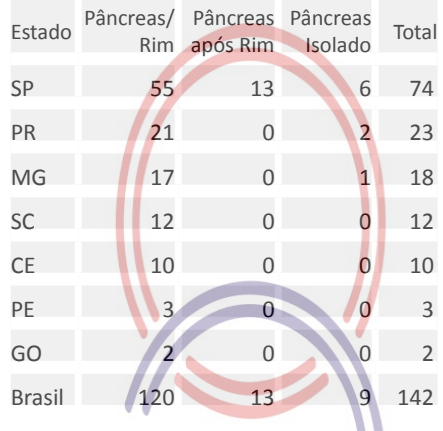

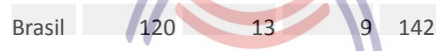

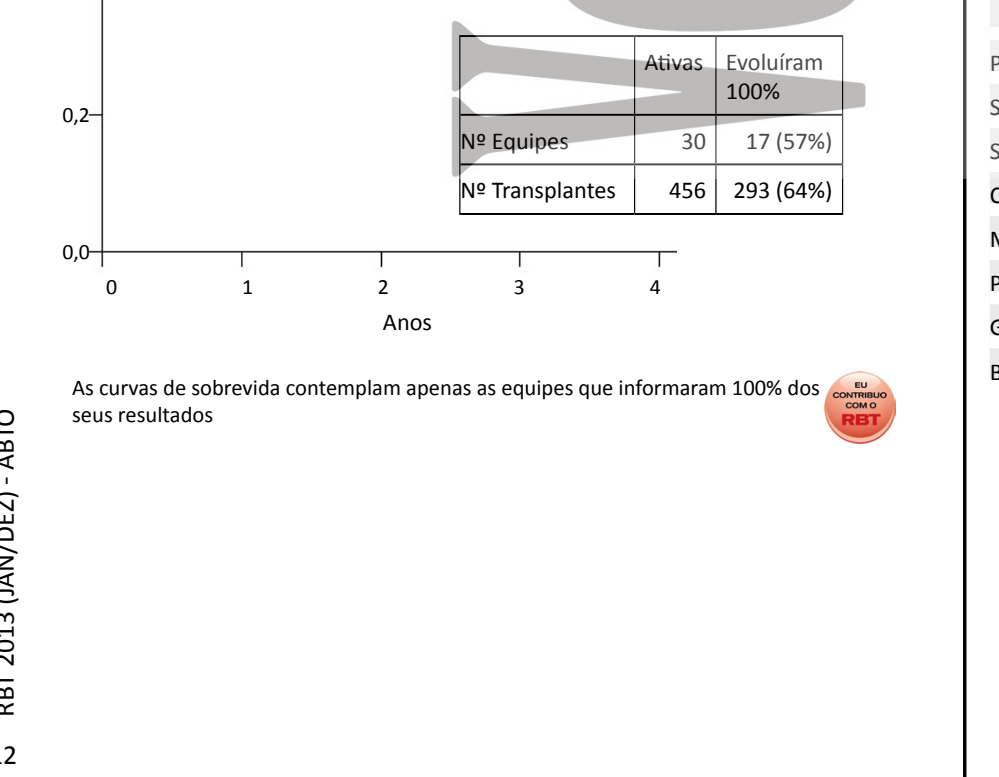




\section{NÚMERO ANUAL DE TRANSPLANTES DE 2003 ATÉ 2013}

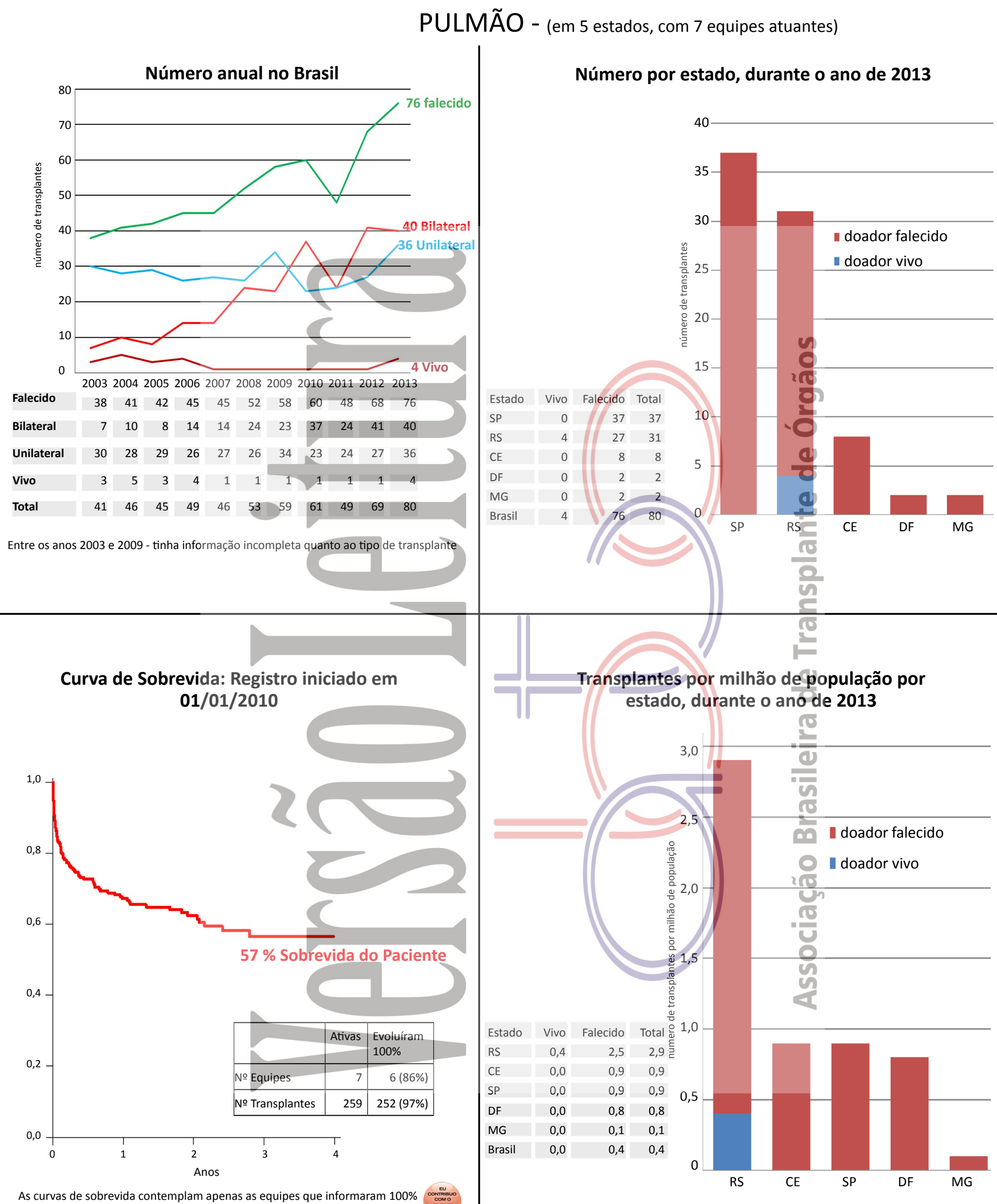

dos seus resultados 


\section{NÚMERO ANUAL DE TRANSPLANTES DE 2003 ATÉ 2013}

\section{MEDULA ÓSSEA - (em 13 estados, com 49 equipes atuantes)}

Número de Transplantes de MEDULA ÓSSEA por estado, durante $O$ ano de 2013

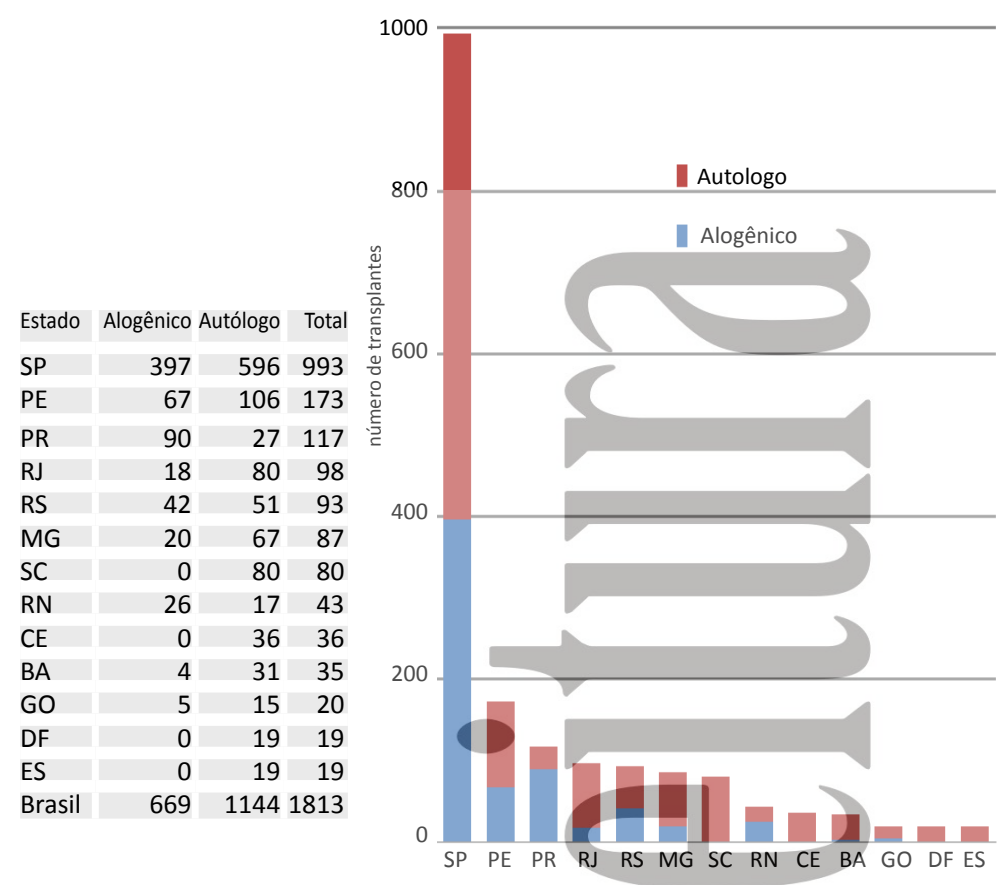

Número por milhão de população de transplantes de MEDULA ÓSSEA por estado, durante o ano 2013

Estado Alogênico Autólogo Tota \begin{tabular}{l|l|l|l|} 
SP & 19,2 & 28,9 & 48,1
\end{tabular} \begin{tabular}{lll|l} 
PE & 15,2 & 24,1 & 39,3
\end{tabular} \begin{tabular}{l|l|l|l|l} 
RN & 16,4 & 10,7 & 27,1 \\
\hline
\end{tabular} SC $\quad 0,0 \quad 25,6 \quad 25,6$ \begin{tabular}{l|l|l|l} 
PR & 17,2 & 5,2 & 22,4
\end{tabular} RS $\quad 7,9 \quad 9,5 \quad 17,4$ \begin{tabular}{l|l|l|l|} 
DF & 0,0 & 14,8 & 14,8
\end{tabular} RJ $\quad 2,3 \quad 10,0 \quad 12,3$ $\begin{array}{llll}\text { ES } & 0,0 & 10,8 & 10,8\end{array}$ MG $\quad 2,0 \quad 6,8 \quad 8,9$ \begin{tabular}{llll|l} 
CE & 0,0 & 8,5 & 8,5
\end{tabular} \begin{tabular}{l|l|l|l|} 
GO & 1,7 & 5,0 & 6,7
\end{tabular} \begin{tabular}{llll|l} 
BA & 0,6 & 4,4 & 5,0
\end{tabular} Brasil $\quad 3,5 \quad 6,0 \quad 9,5$

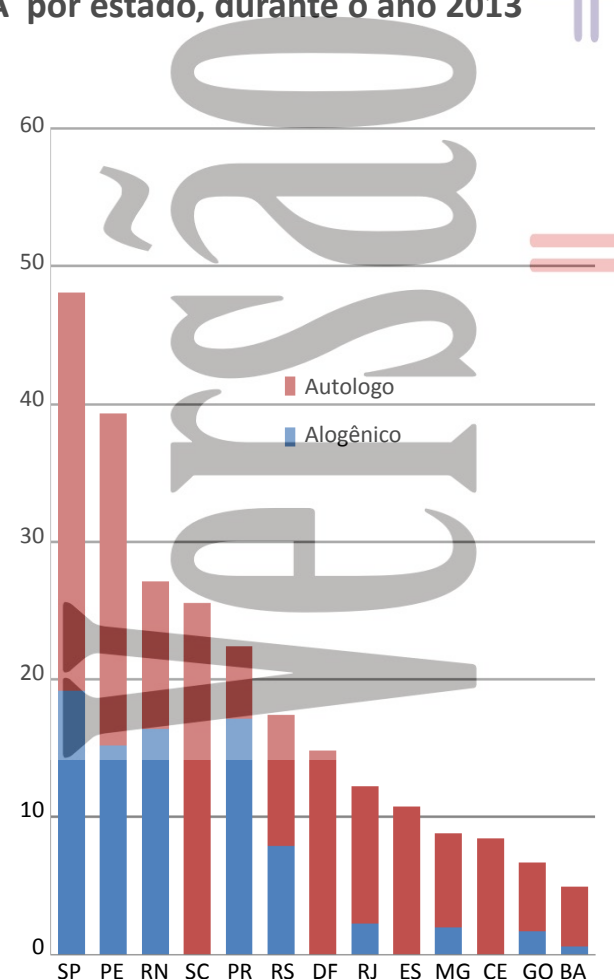

Número total anual de transplantes de TECIDOS e CÉLULAS no Brasil

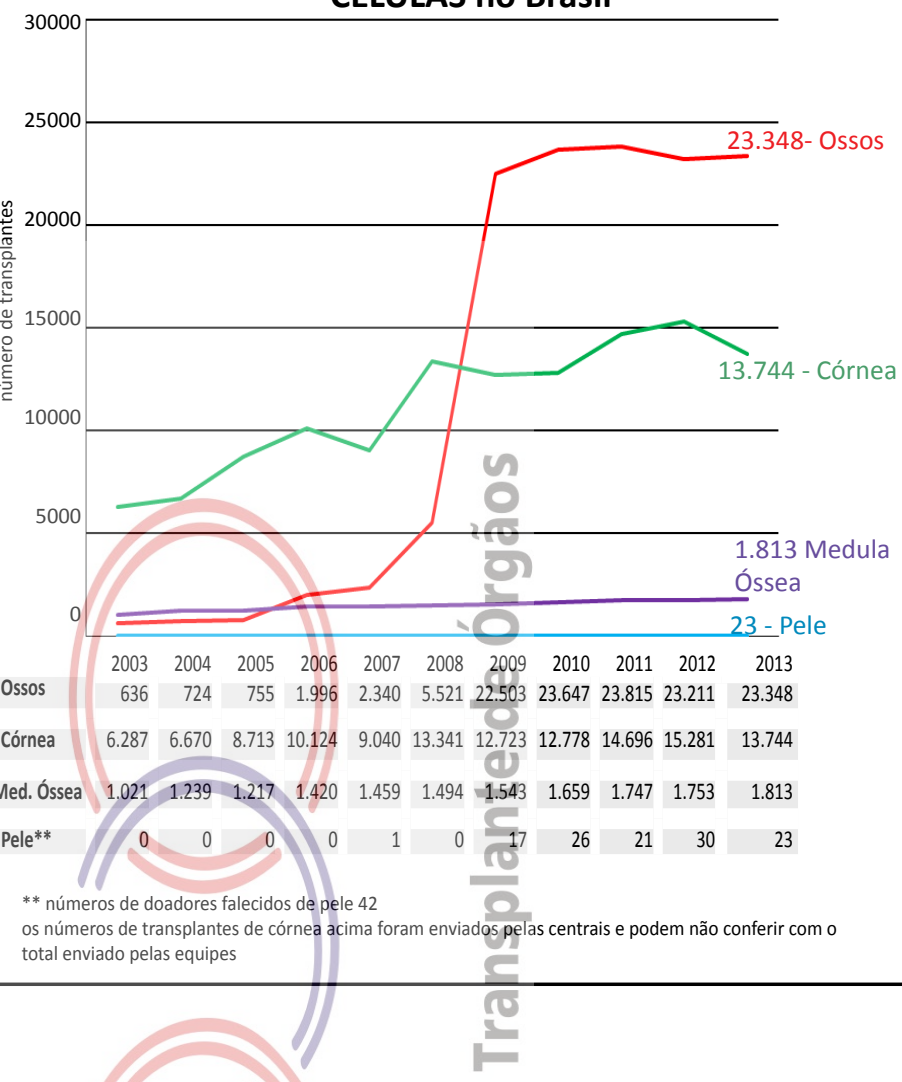

Transplantes por milhão de população anual de TECIDOS e CÉLULAS no Brasil

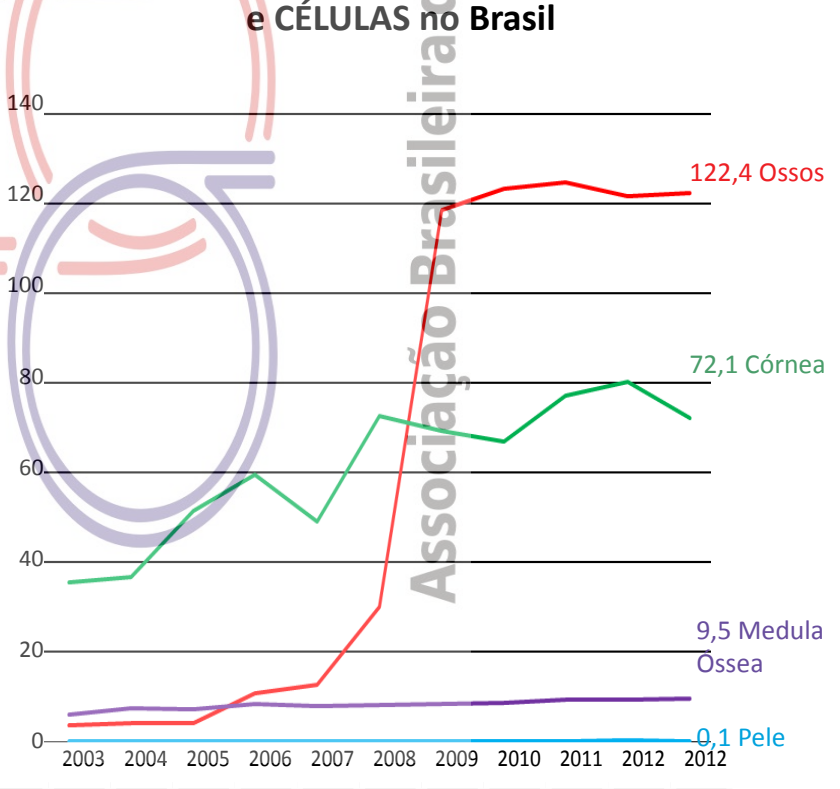

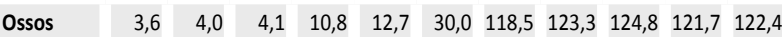

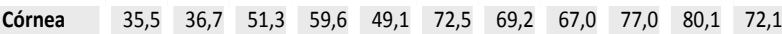

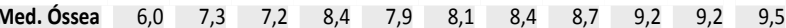

\begin{tabular}{l|l|l|l|l|l|l|l|l|l|l|l|} 
Pele & 0,0 & 0,0 & 0,0 & 0,0 & 0,0 & 0,0 & 0,1 & 0,1 & 0,1 & 0,2 & 0,1
\end{tabular} 


\section{NÚMERO ANUAL DE TRANSPLANTES DE 2003 ATÉ 2013}

CÓRNEA - (em 23 estados)

Número de transplantes de CóRNEA por estado, durante $o$ ano de 2013

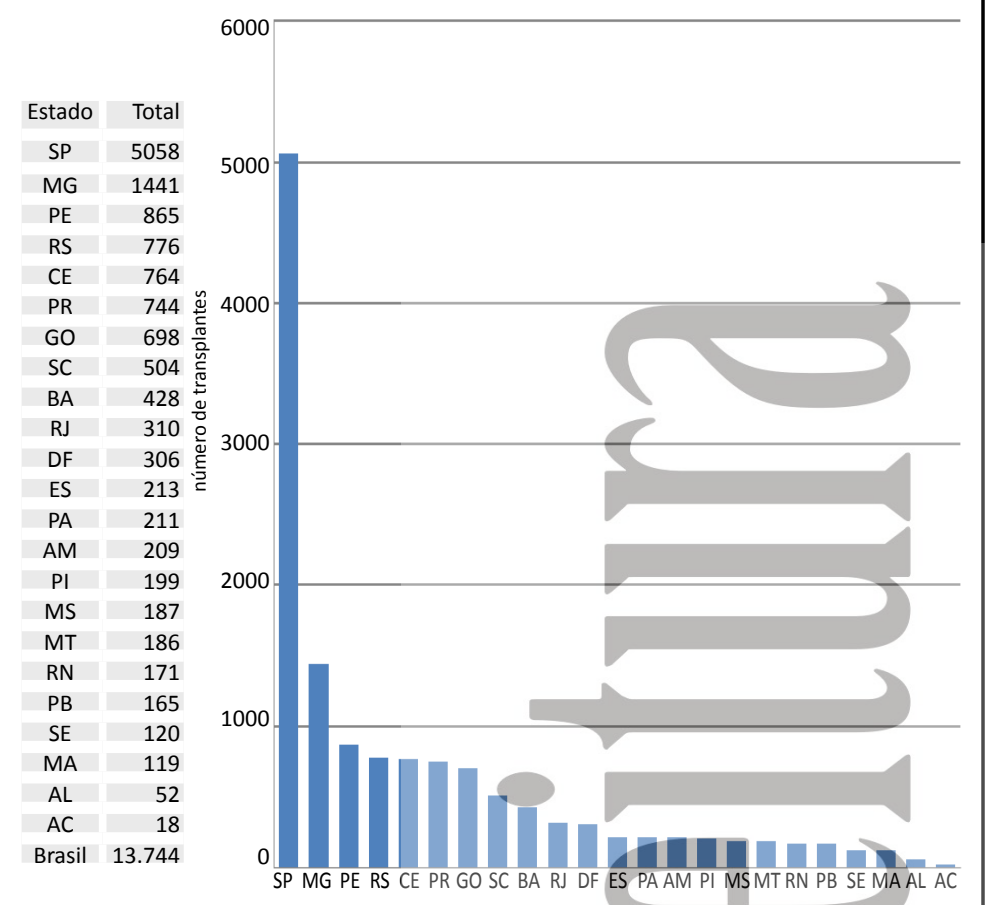

OSSOS- (em 4 estados)

Número de transplantes de OSSOS disponibilizado pelos 6 Bancos de Tecidos (PE,PR,RJ,SP(3)), durante $O$ ano de 2013

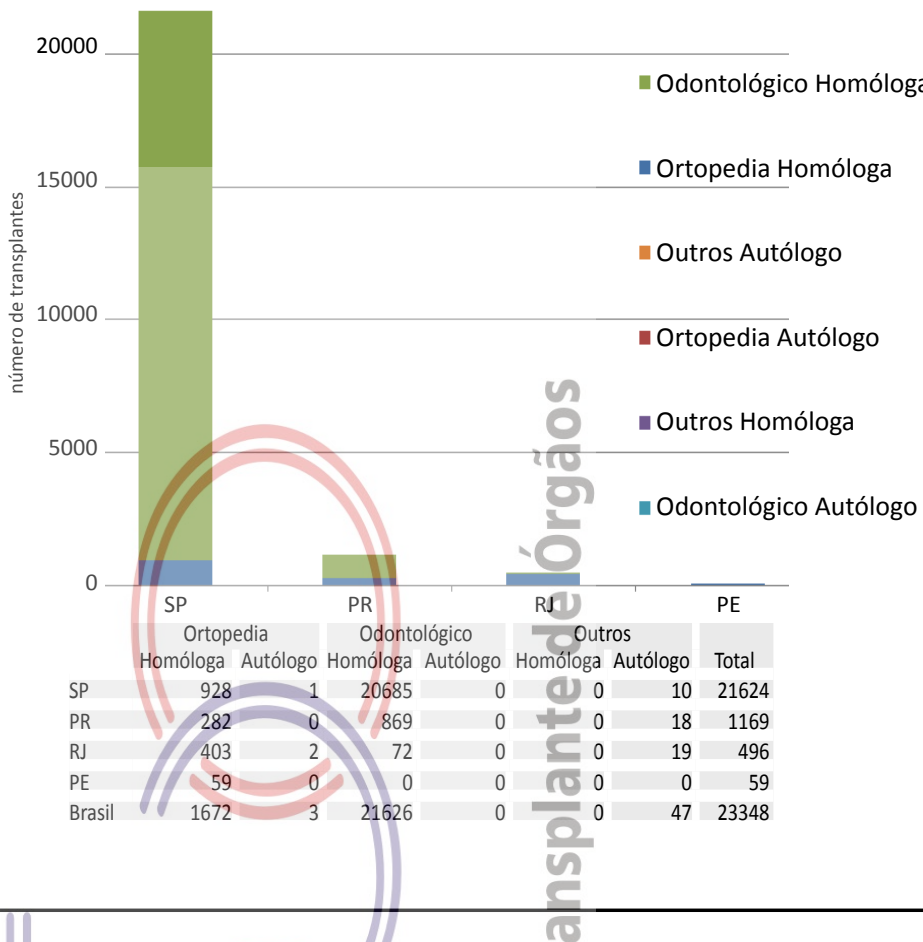

Transplantes de OSSOS por milhão de população, disponibilizados pelos 6 Bancos de Tecidos estado, durante o ano de 2013

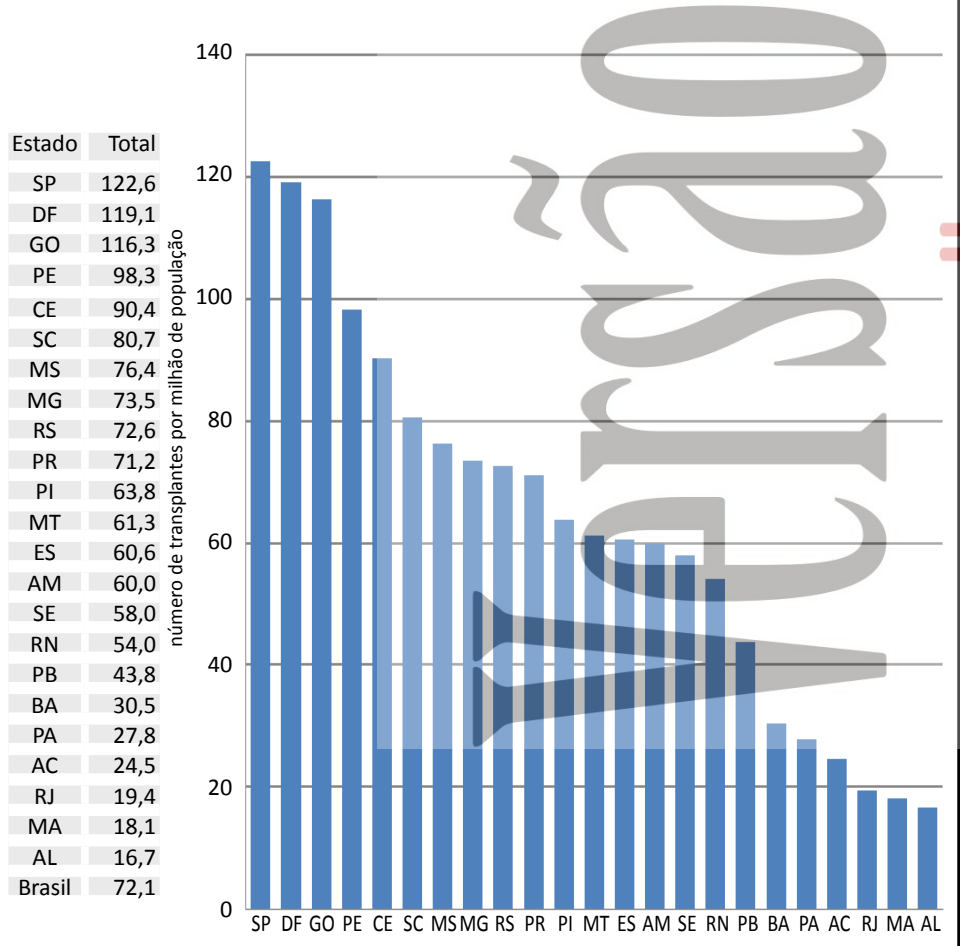

(PE,PR,RJ,SP(3)), durante o ano de 2013

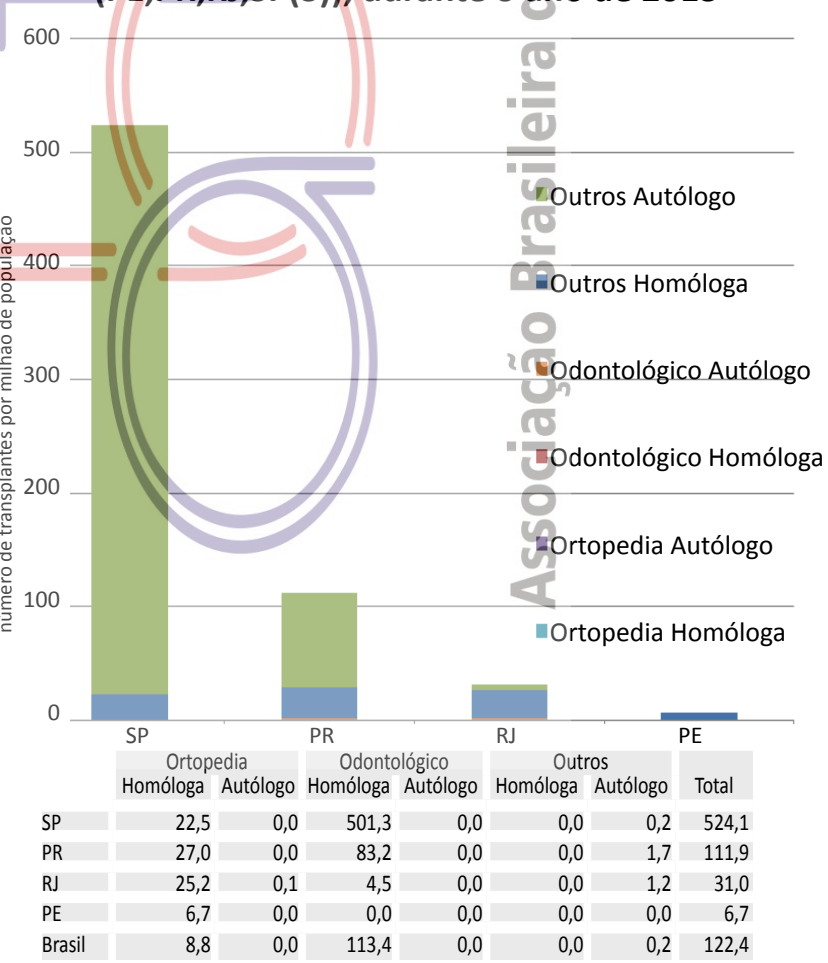


EDITORIAL

\section{O Transplante Pediátrico no ano de 2013}

No ano de 2013, 554 crianças foram transplantadas no Brasil, número inferior a 2012 (600).

O número de transplantes de rim não manteve o aumento que foi conseguido em 2012. No ano de 2013, foram realizados 308 transplantes renais, sendo $252 \mathrm{com}$ doador falecido, $23 \%$ a menos que em 2012. A maioria (79\%) dos transplantes renais pediátricos foram realizados no sul e sudeste. Em 2013, tivemos 233 doadores pediátricos (466 rins): foram utilizados $76 \%$ deles em crianças. Chama atenção o pequeno número de transplantes com doador vivo nos últimos anos. No Brasil, a população pediátrica é de cerca de 63 milhões. A Sociedade Brasileira de Nefrologia estima que atualmente existem 95000 pacientes em diálise. Segundo esse censo, 4,5\% tem idade até 18 anos, sendo que 0,3\% seriam menores de 12 anos.

Porque o transplante renal pediátrico não cresce? Esse assunto tem sido discutido entre os transplantadores pediátricos dos principais centros de transplante do Brasil e a impressão é de dificuldade de acesso aos centros transplantadores.

Outras razões para que o número de transplantes pediátricos não tenha aumentado no último ano podem ser a preferência dos serviços por aguardar doador falecido e com isso realizar poucos transplantes com doador vivo e a demora no encaminhamento das crianças para os serviços de transplante. É importante lembrar que devem ser encaminhadas antes mesmo de iniciar a diálise.

Em 2013, 204 transplantes hepáticos foram realizados, um discreto aumento em relação a 2012. O número de transplantes com doador vivo aumentou e manteve-se o mesmo número de transplantes com doador falecido. Assim como no transplante renal, as criancas portadoras de doencas hepáticas que necessitam de transplante, muitas vezes nao conseguem ter acesso aos centros especializados.

Os transplantes cardíacos e pulmonares em crianças continuam em número muito reduzido no Brasil.

Sempre com otimismo, esperamos um 2014 melhor, e que possamos entender e solucionar os problemas que dificultam os transplantes pediátricos no Brasil.
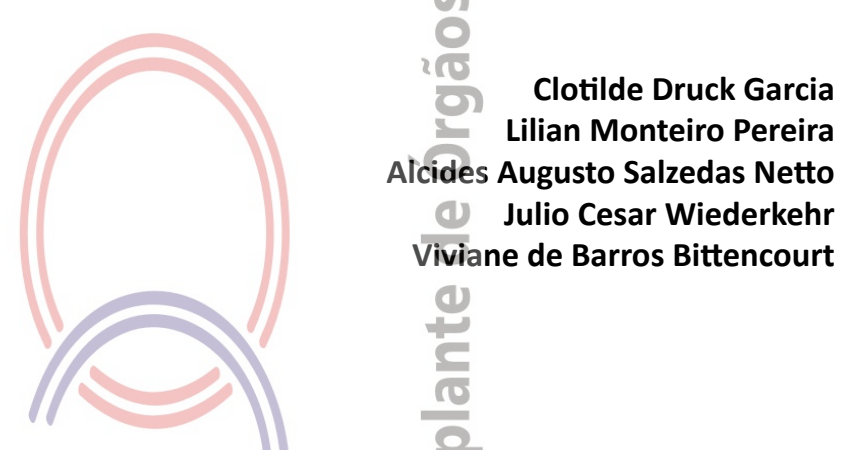

Número de Transplantes Pediátricos de Órgãos Sólidos,

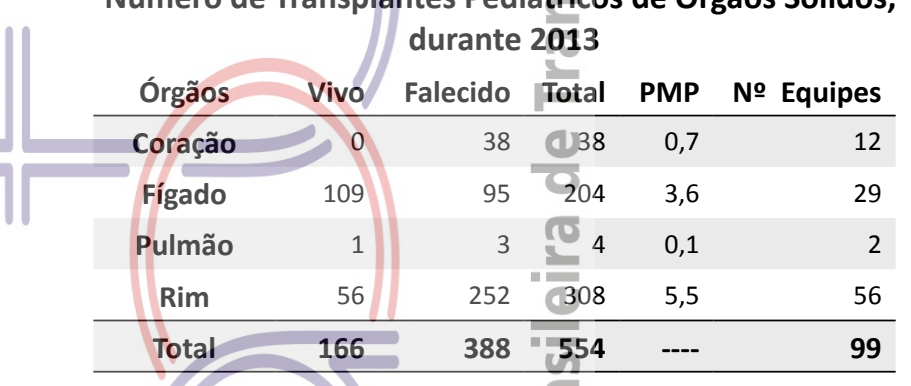
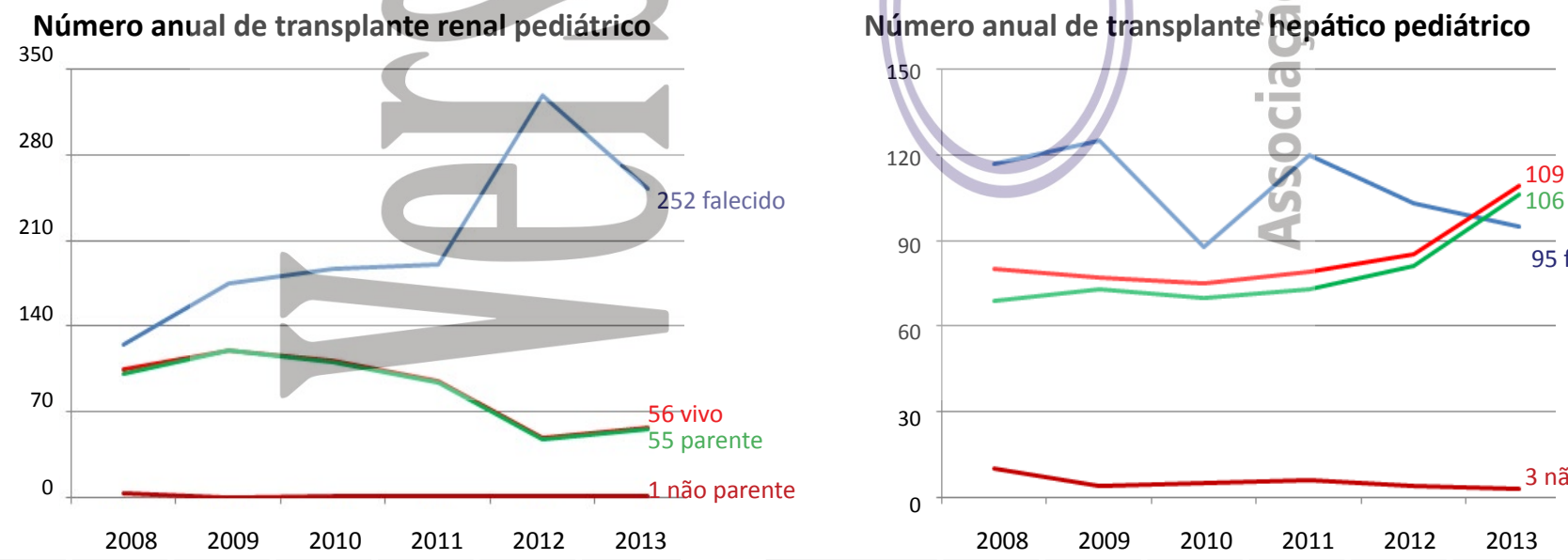

90

60

30

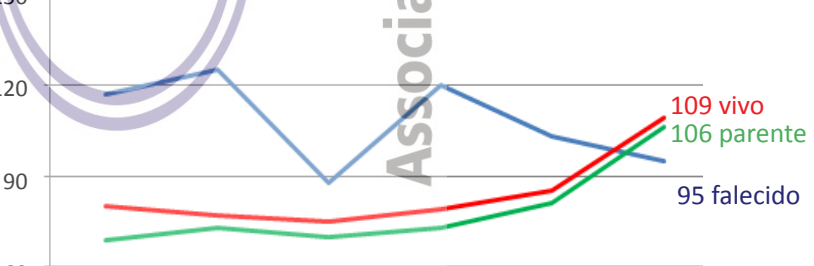

\begin{tabular}{|l|r|r|r|r|r|r|}
\hline & 2008 & 2009 & 2010 & 2011 & 2012 & 2013 \\
\hline Falecido & 117 & 125 & 88 & 120 & 103 & 95 \\
\hline Vivo & 80 & 77 & 75 & 79 & 85 & 109 \\
\hline Parente & 69 & 73 & 70 & 73 & 81 & 106 \\
\hline Não Parente & 10 & 4 & 5 & 6 & 4 & 3 \\
\hline Total & 197 & 202 & 163 & 199 & 188 & 204 \\
\hline
\end{tabular}




\section{TRANSPLANTES PEDIÁTRICOS}

\section{RIM}

Número de transplantes por estado, durante o

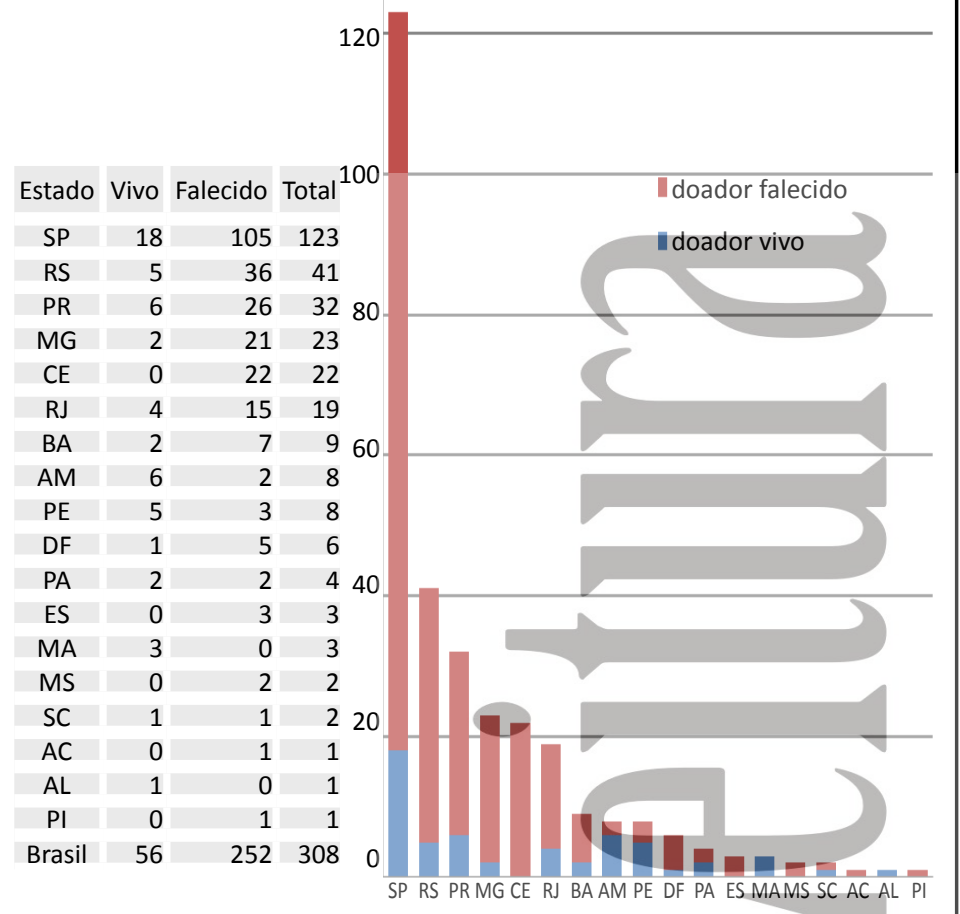
ano de 2013

FÍGADO

\section{Número anual de transplantes por estado durante 0 ano de 2013}

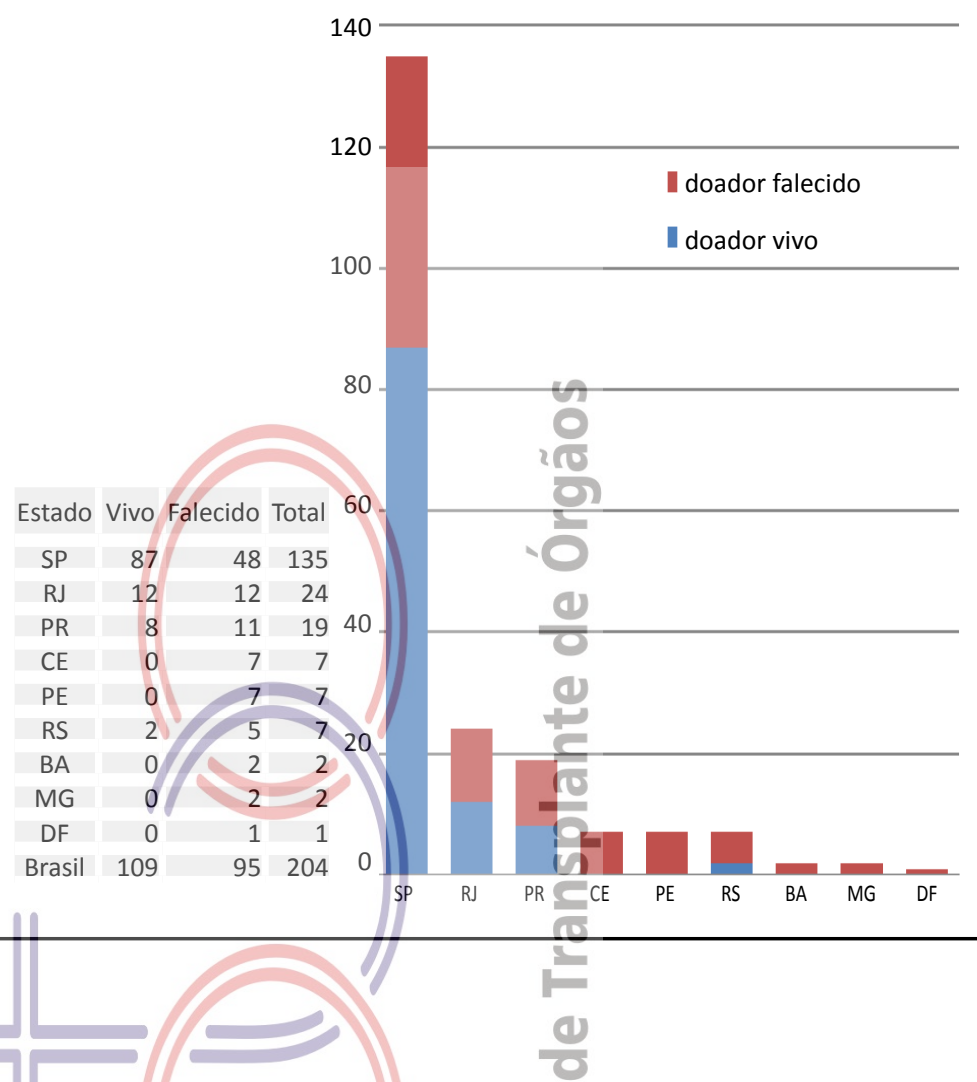

Transplantes por milhão de população por estado, durante 0 ano de 2013 Transplantes por milhão de população por estado
durante o ano de 2013

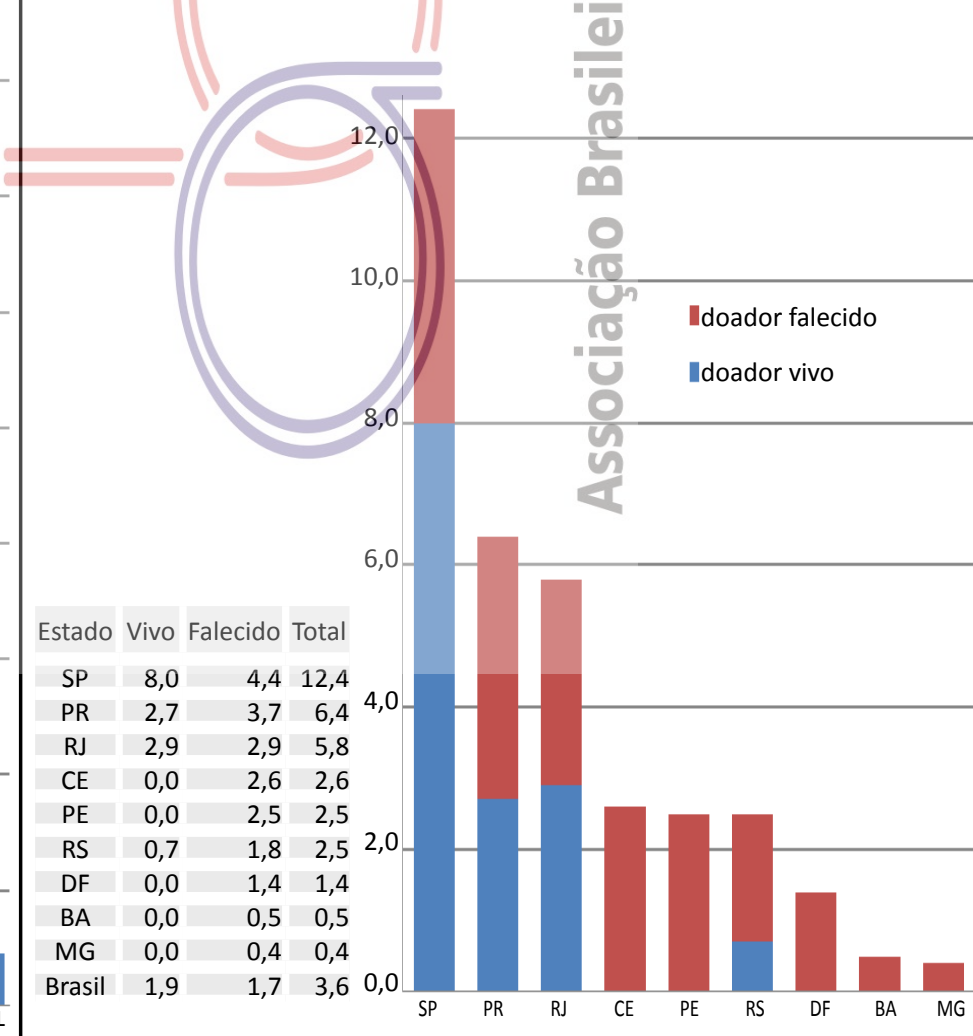

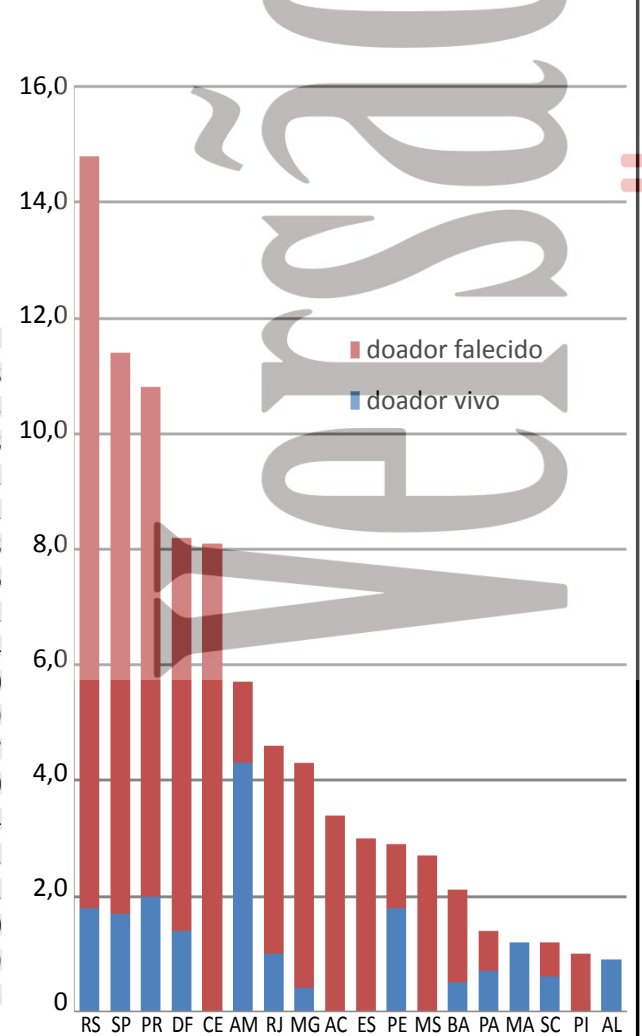

Estado Vivo Falecido Total \begin{tabular}{l|l|l|l} 
RS & 1,8 & 13,0 & 14,8
\end{tabular} \begin{tabular}{l|llll}
$\mathrm{SP}$ & 1,7 & 9,7 & 11,3
\end{tabular} \begin{tabular}{l|lll} 
PR & 2,0 & 8,8 & 10,8
\end{tabular} $\begin{array}{llll}\text { DF } & 1,4 & 6,8 & 8,1\end{array}$ \begin{tabular}{l|ll|l|} 
CE & 0,0 & 8,1 & 8,1
\end{tabular} $\begin{array}{lllll}\text { AM } & 4,3 & 1,4 & 5,8\end{array}$ \begin{tabular}{l|l|l|l} 
RJ & 1,0 & 3,6 & 4,6
\end{tabular} \begin{tabular}{l|lll} 
MG & 0,4 & 3,9 & 4,2
\end{tabular} \begin{tabular}{l|lll} 
AC & 0,0 & 3,4 & 3,4
\end{tabular} ES $\quad 0,0 \quad 3,0 \quad 3,0$ \begin{tabular}{l|l|l|l|} 
PE & 1,8 & 1,1 & 2,9
\end{tabular} \begin{tabular}{l|lll} 
MS & 0,0 & 2,7 & 2,7
\end{tabular} \begin{tabular}{l|l|l|l|} 
BA & 0,5 & 1,6 & 2,0
\end{tabular} $\begin{array}{lllll}\text { PA } & 0,7 & 0,7 & 1,4\end{array}$ \begin{tabular}{l|l|l|l} 
MA & 1,2 & 0,0 & 1,2
\end{tabular} $\begin{array}{llll}\mathrm{SC} & 0,6 & 0,6 & 1,2\end{array}$ \begin{tabular}{l|ll|l}
$\mathrm{PI}$ & 0,0 & 1,0 & 1,0
\end{tabular} \begin{tabular}{l|lll|l}
$\mathrm{AL}$ & 0,9 & 0,0 & 0,9
\end{tabular} Brasil $\quad 1,0 \quad 4,5 \quad 5,5$ 


\section{DADOS POR REGIÃO BRASILEIRA}

DADOS GERAIS

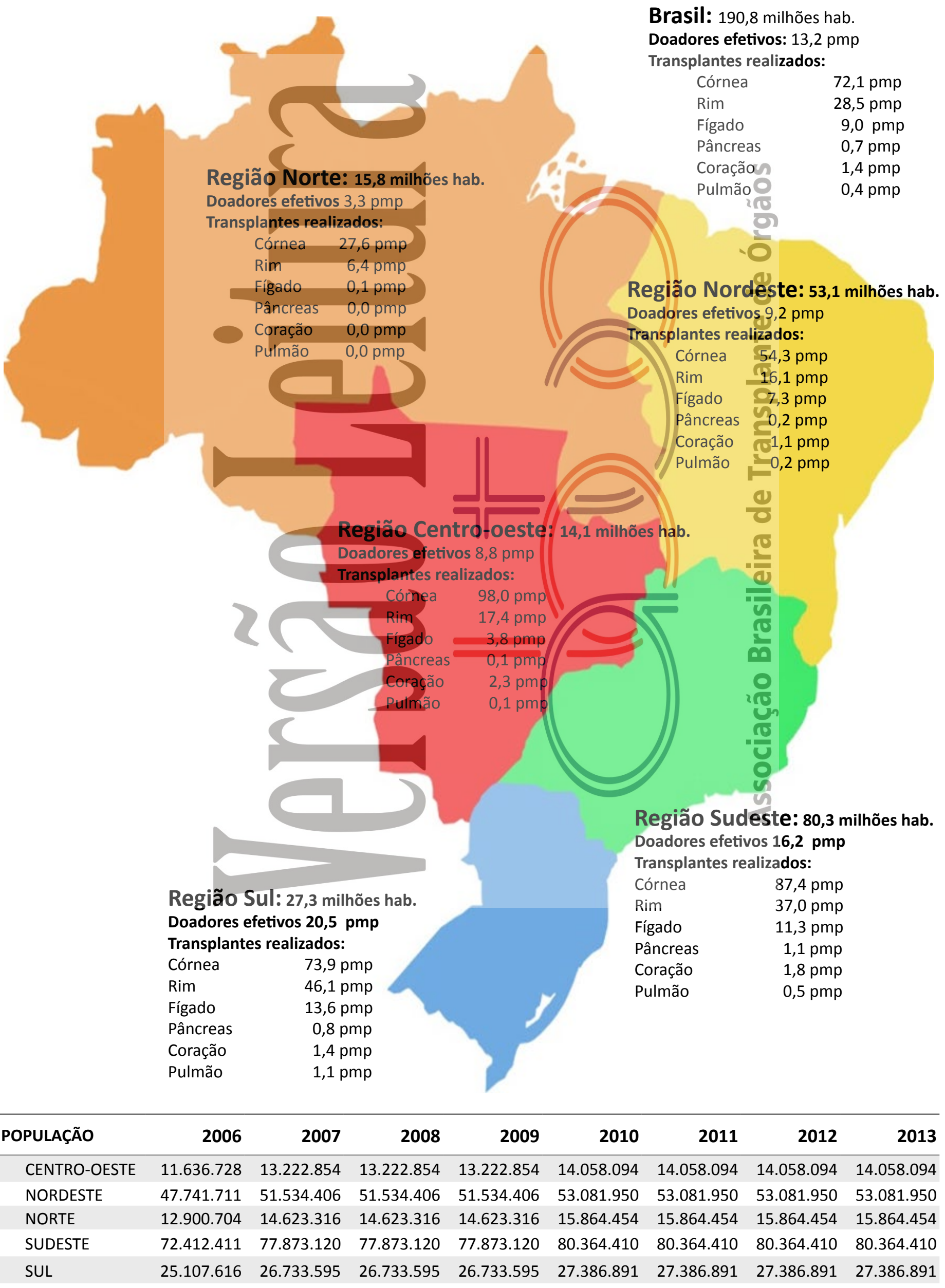




\section{DADOS POR REGIÃO BRASILEIRA}

\section{DOAÇÃO DE ÓRGÃOS}

\section{Potenciais doadores notificados - pmp}

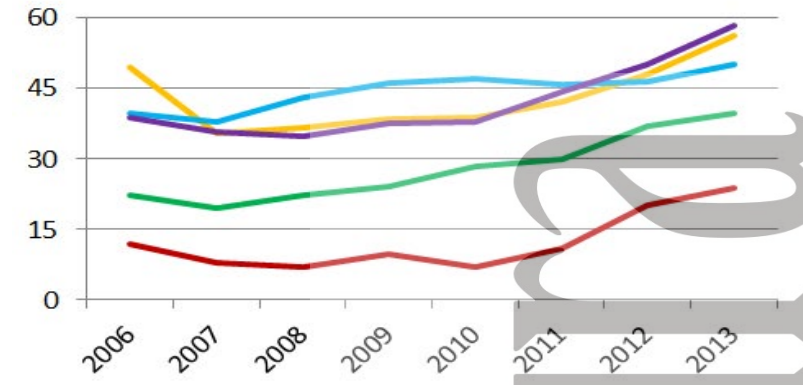

\section{Doadores efetivos - pmp}

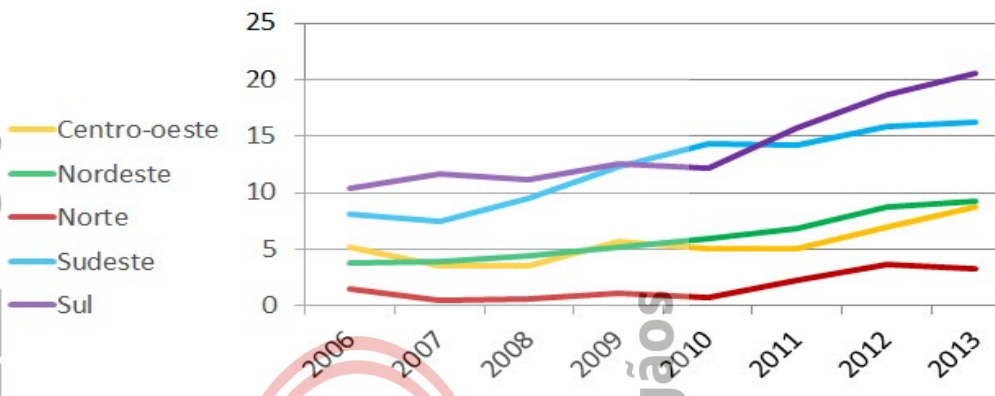

Número de notificações de potenciais doadores por ano

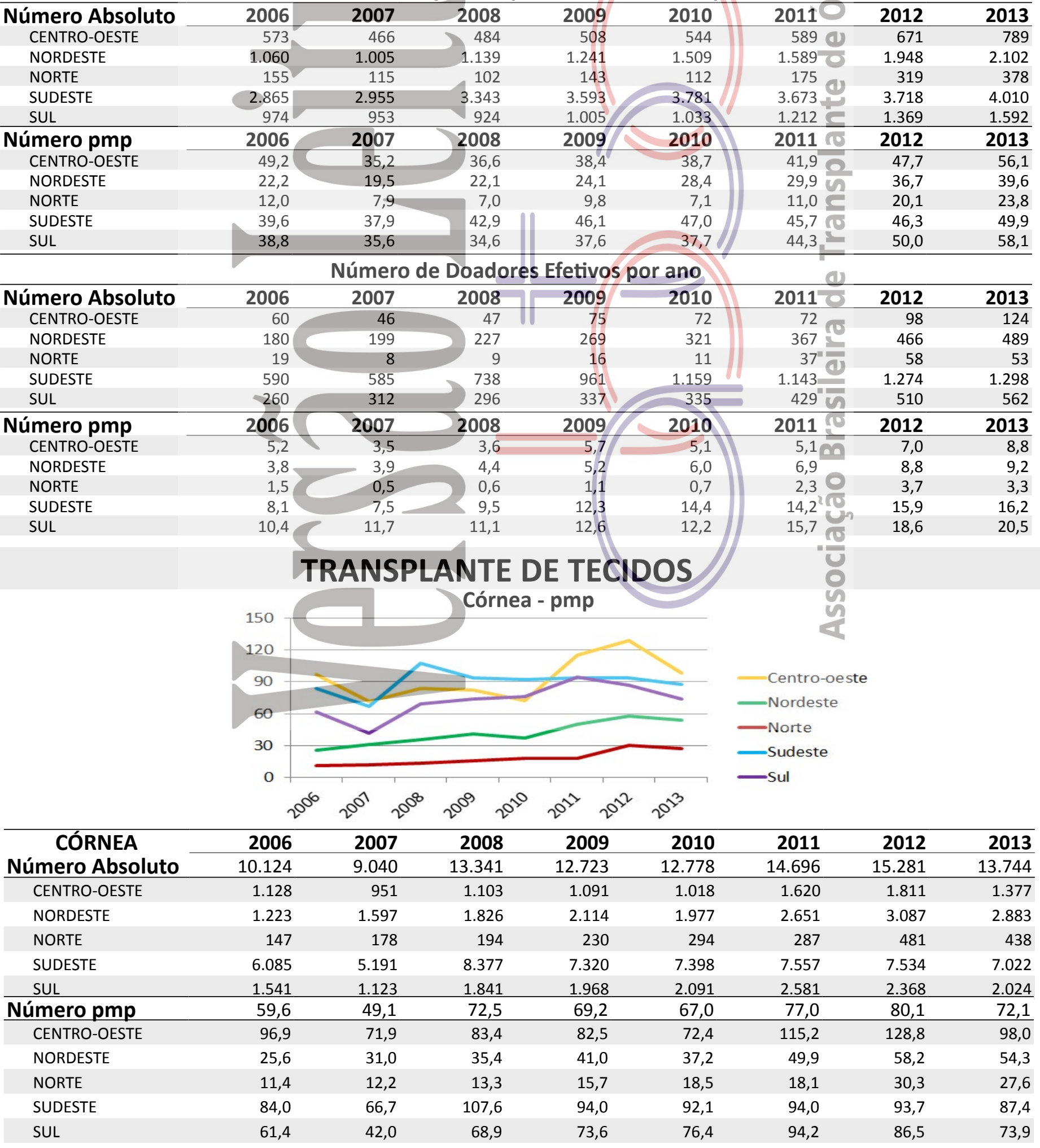




\section{DADOS POR REGIÃO BRASILEIRA}

\section{TRANSPLANTE DE ÓRGÃOS}

\section{Rim com doador falecido - pmp}

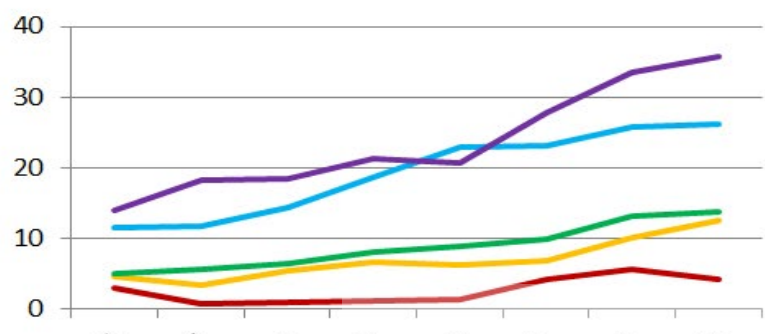

$\nu^{0^{6}} \nu^{0^{1}} \nu^{0^{8}} \nu^{0^{9}} \nu^{\nu^{0}} \nu^{2 x} \nu^{\nu^{2}} \nu^{\nu^{3}}$
Rim com doador vivo - pmp
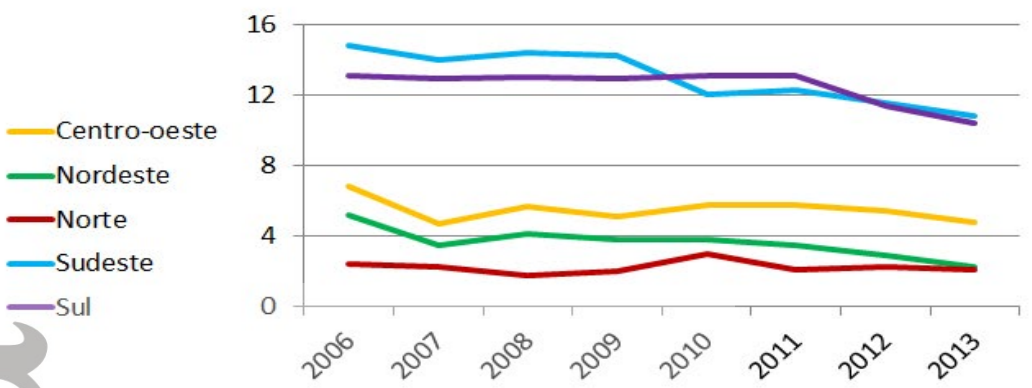

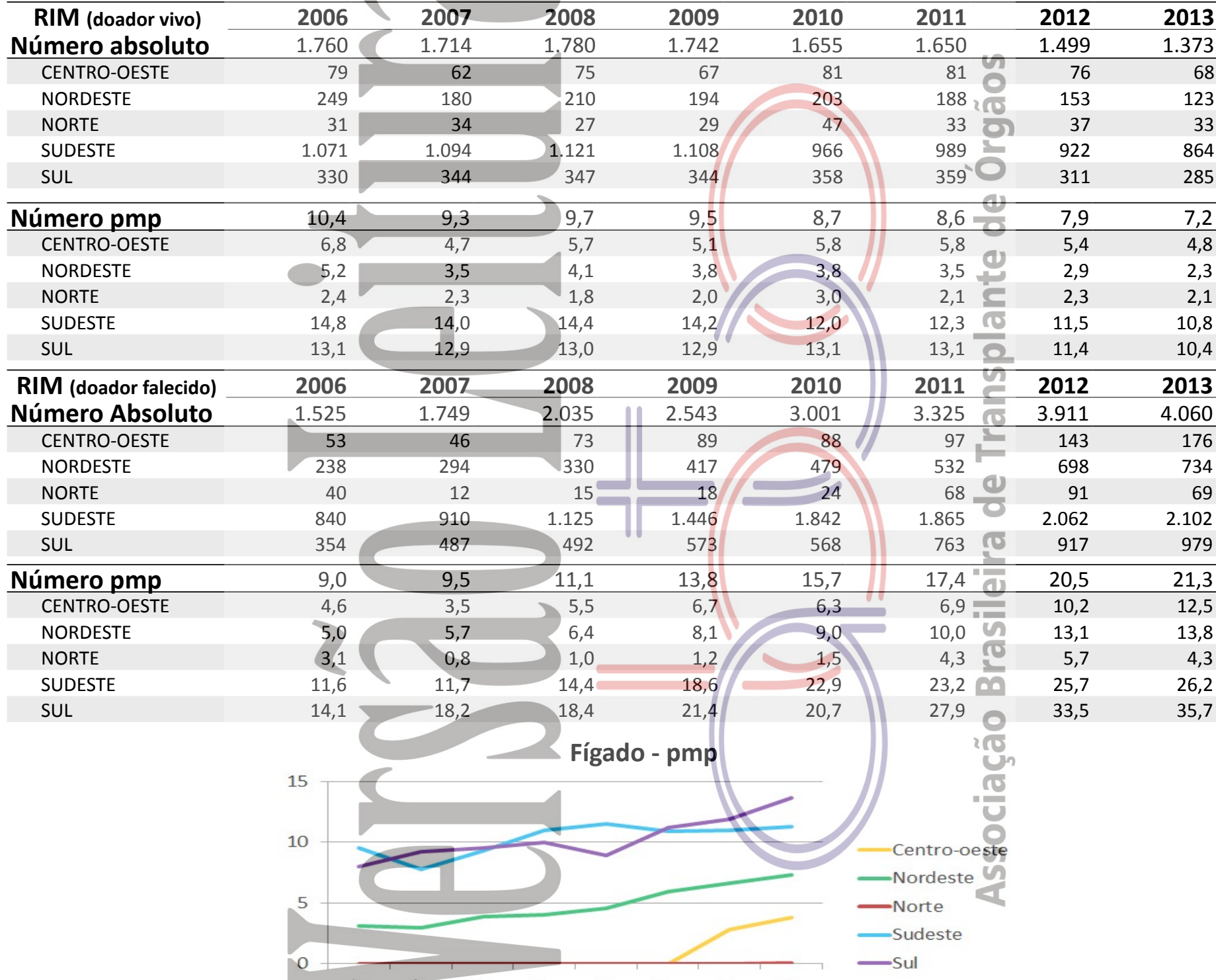

\begin{tabular}{|c|c|c|c|c|c|c|c|c|c|}
\hline \multirow{2}{*}{\multicolumn{2}{|c|}{$\begin{array}{c}\text { FíGADO } \\
\text { Número absoluto }\end{array}$}} & 2006 & 2007 & 2008 & 2009 & 2010 & 2011 & 2012 & 2013 \\
\hline & & 1.037 & 1.008 & 1.177 & 1.334 & 1.413 & 1.494 & 1.599 & 1.723 \\
\hline \multirow{5}{*}{ 号 } & CENTRO-OESTE & 0 & 0 & 0 & 0 & 0 & 0 & 39 & 53 \\
\hline & NORDESTE & 149 & 156 & 201 & 208 & 244 & 314 & 352 & 388 \\
\hline & NORTE & 0 & 0 & 0 & 0 & 0 & 0 & 0 & 1 \\
\hline & SUDESTE & 686 & 605 & 721 & 859 & 926 & 872 & 882 & 909 \\
\hline & SUL & 202 & 247 & 255 & 267 & 243 & 308 & 326 & 372 \\
\hline \multirow{6}{*}{ 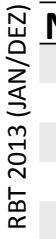 } & Número pmp & 6,1 & 5,5 & 6,4 & 7,3 & 7,4 & 7,8 & 8,4 & 9,0 \\
\hline & CENTRO-OESTE & 0,0 & 0,0 & 0,0 & 0,0 & 0,0 & 0,0 & 2,8 & 3,8 \\
\hline & NORDESTE & 3,1 & 3,0 & 3,9 & 4,0 & 4,6 & 5,9 & 6,6 & 7,3 \\
\hline & NORTE & 0,0 & 0,0 & 0,0 & 0,0 & 0,0 & 0,0 & 0,0 & 0,1 \\
\hline & SUDESTE & 9,5 & 7,8 & 9,3 & 11,0 & 11,5 & 10,9 & 11,0 & 11,3 \\
\hline & SUL & 8,0 & 9,2 & 9,5 & 10,0 & 8,9 & 11,2 & 11,9 & 13,6 \\
\hline
\end{tabular}




\section{DADOS POR REGIÃO BRASILEIRA}

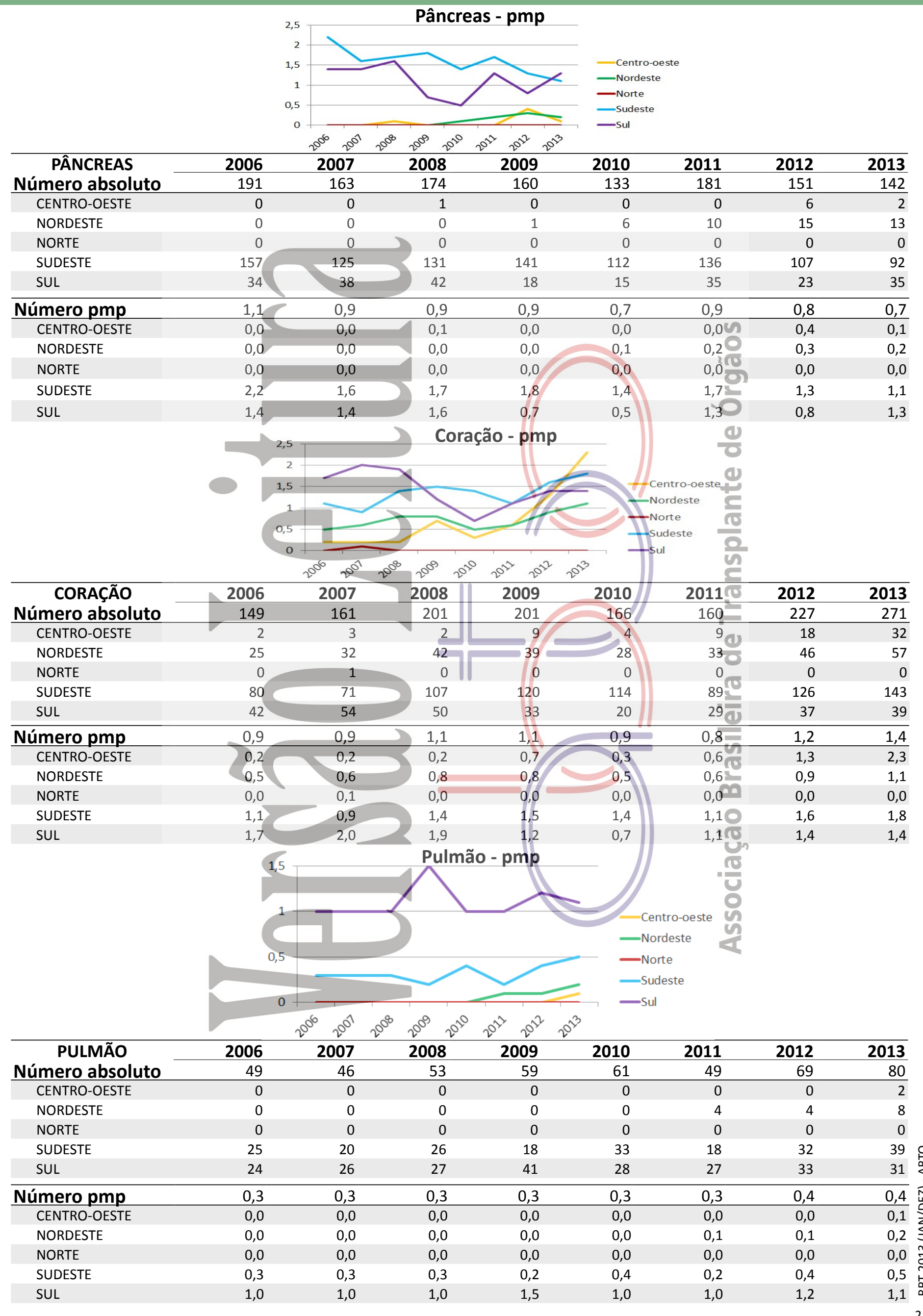




\section{DADOS POR ESTADO}

\section{Pacientes ativos em Lista de Espera - (dezembro 2013)}

\begin{tabular}{|c|c|c|c|c|c|c|c|}
\hline Estado & RIM & FÍGADO & CORAÇÃO & PULMÃO & PÂNCREAS & PÂNC/RIM & CÓRNEA \\
\hline Total - Brasil & 16.302 & 1.357 & 253 & 187 & 25 & 416 & 5.379 \\
\hline Acre & 2 & $\mathrm{NI}$ & $\mathrm{NI}$ & $\mathrm{NI}$ & $\mathrm{NI}$ & $\mathrm{NI}$ & 8 \\
\hline Alagoas & $\mathrm{NI}$ & $\mathrm{NI}$ & 2 & $\mathrm{NI}$ & $\mathrm{NI}$ & $\mathrm{NI}$ & 94 \\
\hline Amazonas & 77 & $\mathrm{NI}$ & $\mathrm{NI}$ & $\mathrm{NI}$ & $\mathrm{NI}$ & $\mathrm{NI}$ & 349 \\
\hline Bahia & 440 & 29 & $\mathrm{NI}$ & $\mathrm{NI}$ & $\mathrm{NI}$ & $\mathrm{NI}$ & 800 \\
\hline Ceará & 329 & 122 & 9 & 5 & 1 & $\mathrm{NI}$ & 246 \\
\hline Distrito Federal & 110 & 30 & 6 & 3 & 0 & 0 & 102 \\
\hline Espírito Santo & 644 & 25 & 5 & 0 & 0 & 0 & 139 \\
\hline Goiás & 165 & $\mathrm{Ni}$ & 1 & $\mathrm{NI}$ & $\mathrm{NI}$ & 6 & $\mathrm{NI}$ \\
\hline Maranhão & $\mathrm{NI}$ & NI & $\mathrm{NI}$ & $\mathrm{NI}$ & $\mathrm{NI}$ & $\mathrm{NI}$ & 604 \\
\hline Mato Grosso & 3 & $\mathrm{NI}$ & $\mathrm{NI}$ & $\mathrm{NI}$ & $\mathrm{NI}$ & $\mathrm{NI}$ & 56 \\
\hline Mato Grosso do Sul & 296 & $\mathrm{NI}$ & 16 & $\mathrm{NI}$ & $\mathrm{NI}$ & $\mathrm{NI}$ & 10 \\
\hline Minas Gerais & 1.997 & 27 & 35 & 9 & 1 & 16 & 55 \\
\hline Pará & 149 & $\mathrm{NI}$ & $\mathrm{NI}$ & $\mathrm{NI}$ & $\mathrm{NI}$ & 20 & 604 \\
\hline Paraíba & 24 & 3 & 0 & 0 & 0 & 는 & 148 \\
\hline Paraná & 915 & 55 & 42 & 0 & 4 & 0 & 8 \\
\hline Pernambuco & 330 & 64 & 6 & 0 & 0 & (d) & 1 \\
\hline Piauí & 180 & NI & $\mathrm{NI}$ & $\mathrm{NI}$ & $\mathrm{NI}$ & 0 & 389 \\
\hline Rio de Janeiro & 766 & 131 & 6 & 0 & 0 & (a) & 931 \\
\hline Rio Grande do Norte & 30 & 5 & 0 & & 0 & \pm & 70 \\
\hline Rio Grande do Sul & 980 & 132 & 16 & 61 & 2 & 19 & 10 \\
\hline Rondonia & 0 & 0 & 0 & 0 & 0 & ro & 0 \\
\hline Santa Catarina & 256 & 33 & 1 & $\mathrm{NI}$ & 2 & 으 & 447 \\
\hline São Paulo & 8.609 & 701 & 108 & 109 & 15 & 353 & 260 \\
\hline Sergipe & $\mathrm{NI}$ & $\mathrm{NI}$ & $\mathrm{NI}$ & $\mathrm{NI}$ & $\mathrm{NI}$ & $\mathrm{NI}$ & 48 \\
\hline
\end{tabular}

\section{Doação de órgãos durante o ano de 2013}

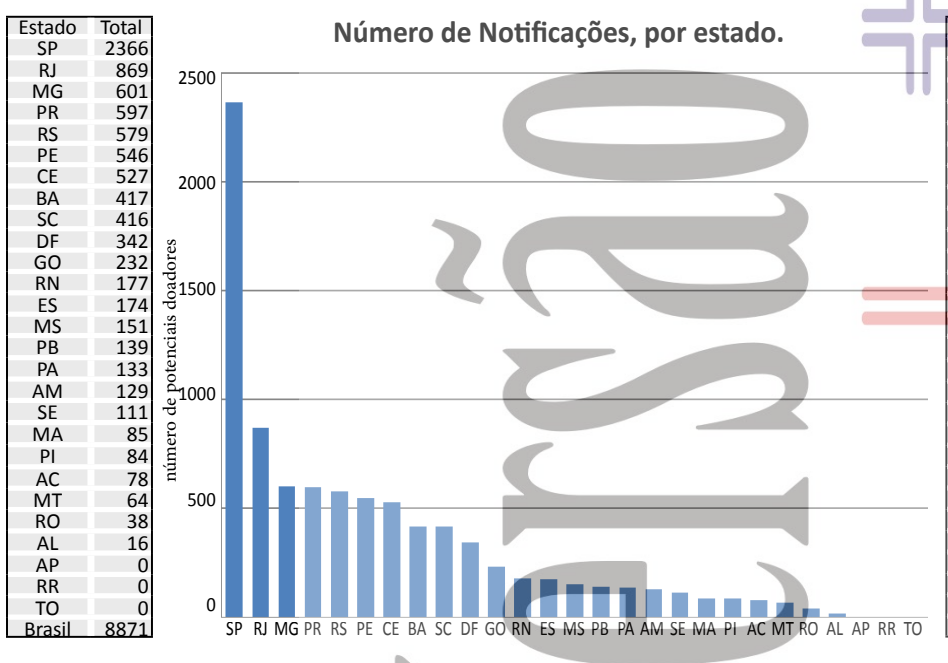

Número de notificações por milhão de população

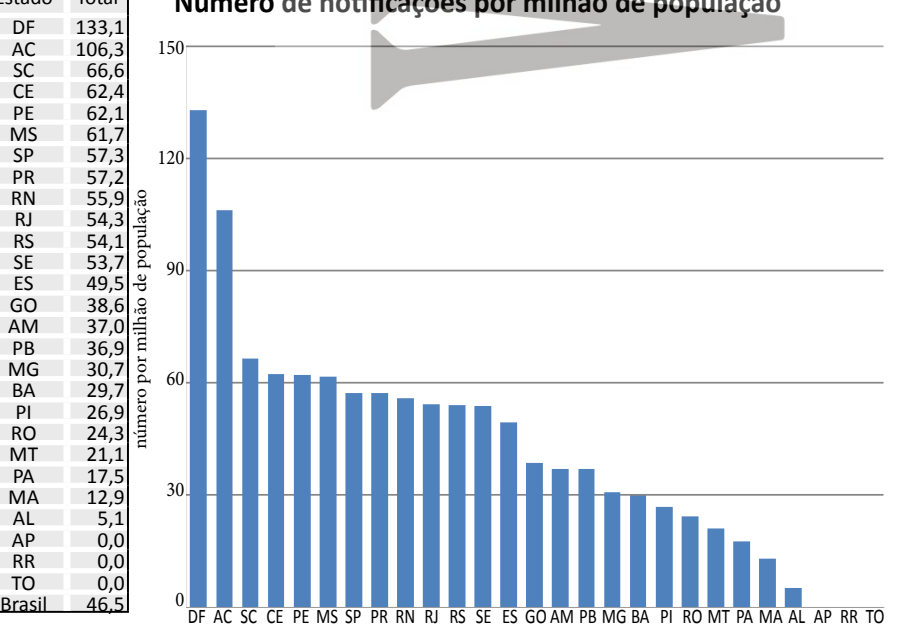

Número absoluto de doadores efetivos, por estado.
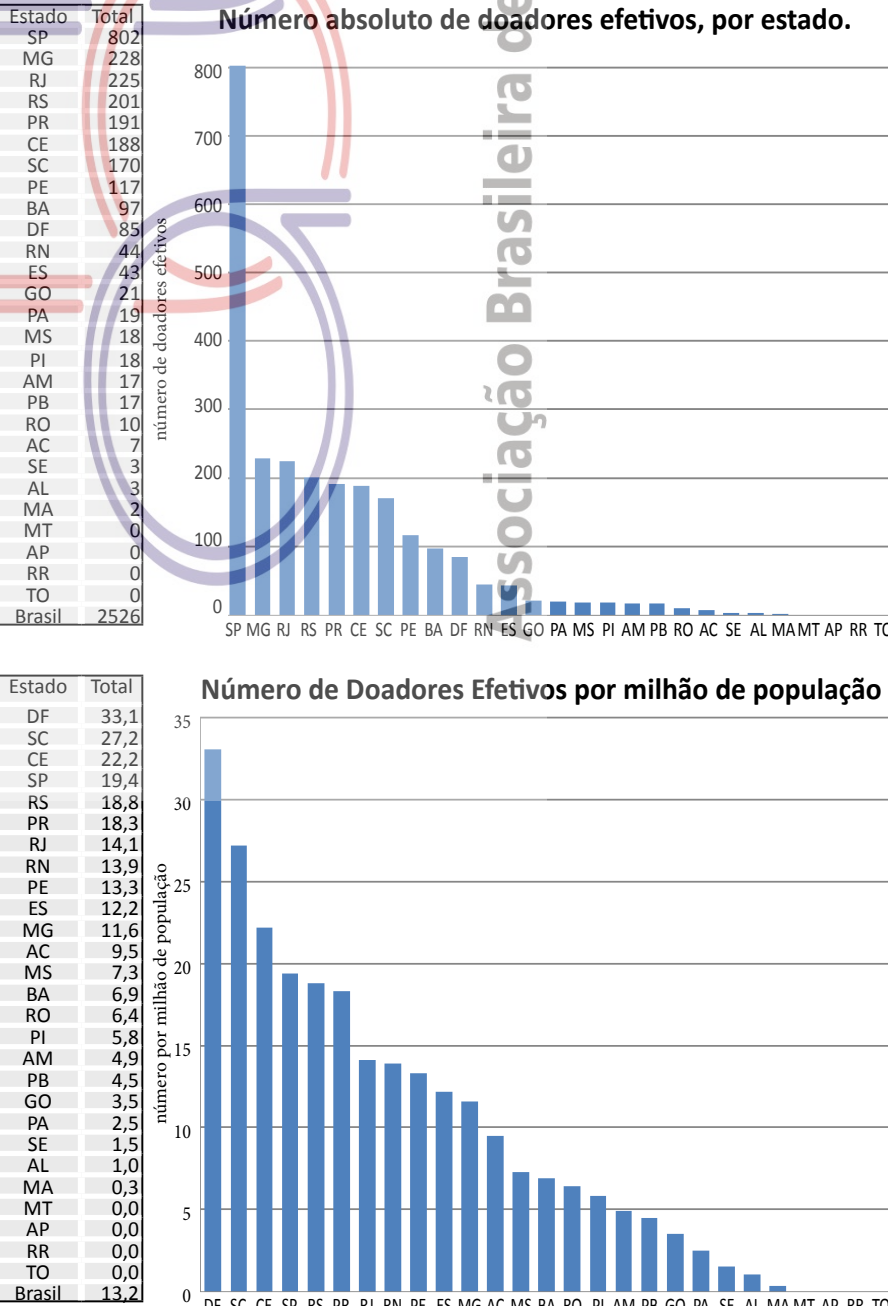

Número de Doadores Efetivos por milhão de população 


\section{DADOS POR ESTADO}

\section{Número de notificações de potenciais doadores, doadores efetivos e doadores}

cujos órgãos foram transplantados por estado, durante o ano de 2013.

\begin{tabular}{|c|c|c|c|c|c|c|c|c|c|}
\hline \multirow{2}{*}{ Estado } & \multirow{2}{*}{\multicolumn{2}{|c|}{$\begin{array}{l}\text { Notificações } \\
\text { (potenciais } \\
\text { doadores) } \\
\text { № pmp/ }\end{array}$}} & \multirow[t]{2}{*}{ Não Doadores } & \multicolumn{2}{|c|}{$\begin{array}{l}\text { Doadores } \\
\text { Efetivos }\end{array}$} & \multicolumn{2}{|c|}{$\begin{array}{l}\text { Doadores cujos } \\
\text { órgãos foram } \\
\text { transplantados }\end{array}$} & \multicolumn{2}{|c|}{$\begin{array}{l}\text { Doadores de } \\
\text { Múltiplos Órgãos }\end{array}$} \\
\hline & & & & № & mp/ & № & $\begin{array}{r}\mathrm{pmp} / \\
\text { ano }\end{array}$ & № & $\%$ \\
\hline Total - Brasil & 8.871 & 46,5 & $6345(72 \%)$ & 2.526 & 13,2 & 2.390 & 12,5 & 1.620 & $(68 \%)$ \\
\hline Acre & 78 & 106,3 & 71 (91\%) & 7 & 9,5 & 6 & 8,2 & 3 & (50\%) \\
\hline Alagoas & 16 & 5,1 & $13 \quad(81 \%)$ & 3 & 1,0 & 3 & 1,0 & 0 & $(0 \%)$ \\
\hline Amapá & 0 & 0,0 & $\begin{array}{ll}0 & (0 \%)\end{array}$ & 0 & 0,0 & 0 & 0,0 & 0 & (0\%) \\
\hline Amazonas & 129 & 37,0 & $112 \quad(87 \%)$ & 17 & 4,9 & 17 & 4,9 & 1 & (6\%) \\
\hline Bahia & 417 & 29,7 & $320 \quad(77 \%)$ & 97 & 6,9 & 96 & 6,8 & 89 & (93\%) \\
\hline Ceará & 527 & 62,4 & $339 \quad(64 \%)$ & 188 & 22,2 & 179 & 21,2 & 157 & (88\%) \\
\hline Distrito Federal & 342 & 133,1 & $257 \quad(75 \%)$ & 85 & 33,1 & 79 & 30,7 & 52 & (66\%) \\
\hline Espírito Santo & 174 & 49,5 & $131 \quad(75 \%)$ & 43 & 12,2 & 35 & 10,0 & 23 & (66\%) \\
\hline Goiás & 232 & 38,6 & 211 (91\%) & 21 & 3,5 & 14 & 2,3 & 8 & (57\%) \\
\hline Maranhão & 85 & 12,9 & $83 \quad(98 \%)$ & 2 & 0,3 & 2 & 0,3 & 0 & $(0 \%)$ \\
\hline Mato Grosso & 64 & 21,1 & 64 (100\%) & 0 & 0,0 & 0 & 0,0 & 0 & $(0 \%)$ \\
\hline Mato Grosso do Sul & 151 & 61,7 & $133 \quad(88 \%)$ & 18 & 7,3 & 18 & 7,3 & 13 & $(72 \%)$ \\
\hline Minas Gerais & 601 & 30,7 & $373 \quad(62 \%)$ & 228 & 11,6 & 202 & 10,3 & 135 & (67\%) \\
\hline Pará & 133 & 17,5 & $114 \quad(86 \%)$ & 19 & 2,5 & 19 & 2,5 & 13 & (68\%) \\
\hline Paraíba & 139 & 36,9 & $122 \quad(88 \%)$ & 17 & 4,5 & 17 & 4,0 & 17 & $(0 \%)$ \\
\hline Paraná & 597 & 57,2 & $406 \quad(68 \%)$ & 191 & 18,3 & 191 & 18,3 & 121 & (63\%) \\
\hline Pernambuco & 546 & 62,1 & $429 \quad(79 \%)$ & 117 & 13,3 & 114 & 13,0 & 88 & $(77 \%)$ \\
\hline Piauí & 84 & 26,9 & $66 \quad(79 \%)$ & 18 & 5,8 & 18 & 5,8 & 11 & (61\%) \\
\hline Rio de Janeiro & 869 & 54,3 & $644 \quad(74 \%)$ & 225 & 14,1 & 185 & 11,6 & 115 & $(62 \%)$ \\
\hline Rio G.do Norte & 177 & 55,9 & $133 \quad(75 \%)$ & 44 & 13,9 & 43 & 13,6 & 36 & (84\%) \\
\hline Rio G.do Sul & 579 & 54,1 & $378 \quad(65 \%)$ & 201 & 18,8 & 181 & 16,9 & 127 & (70\%) \\
\hline Rondonia & 38 & 24,3 & $28 \quad(74 \%)$ & 10 & 6,4 & 10 & 6,4 & 1 & $(10 \%)$ \\
\hline Roraima & 0 & 0,0 & $\begin{array}{ll}0 & (0 \%)\end{array}$ & 0 & 0,0 & 0 & 0,0 & 0 & $(0 \%)$ \\
\hline Santa Catarina & 416 & 66,6 & $246 \quad(59 \%)$ & 170 & 27,2 & 163 & 26,1 & 136 & (83\%) \\
\hline São Paulo & 2366 & 57,3 & $1564 \quad(66 \%)$ & 802 & 19,4 & 795 & $19,3^{2}$ & 471 & (59\%) \\
\hline Sergipe & 111 & 53,7 & $108 \quad(97 \%)$ & 3 & 1,5 & 3 & 1,5 & 3 & $(0 \%)$ \\
\hline Tocantins & 0 & 0,0 & $0 \quad(0 \%)$ & 0 & 0,0 & 0 & 0,0 & 0 & $(0 \%)$ \\
\hline
\end{tabular}

Percentual de efetivação de doadores em relação ao número de notificações

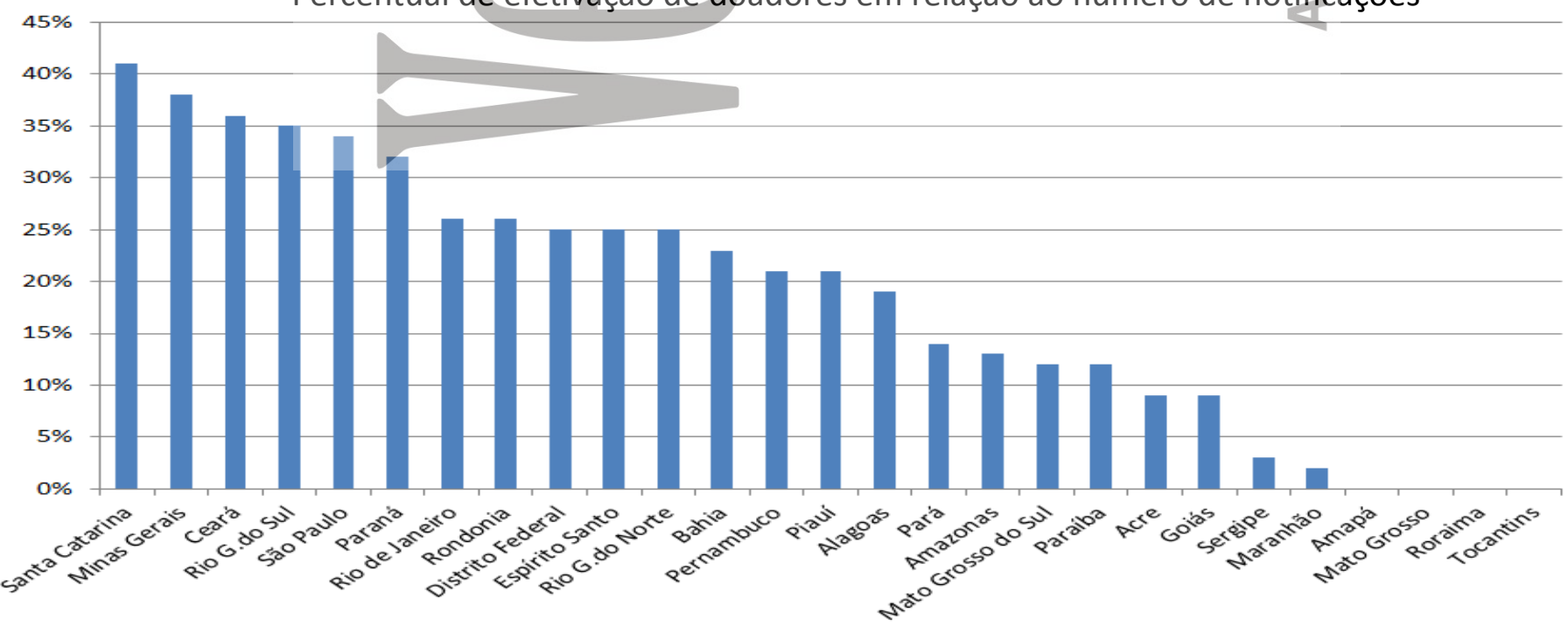




\section{Causas da não concretização da doação de órgãos de potenciais doadores notificados nos estados brasileiros, durante o ano de 2013.}

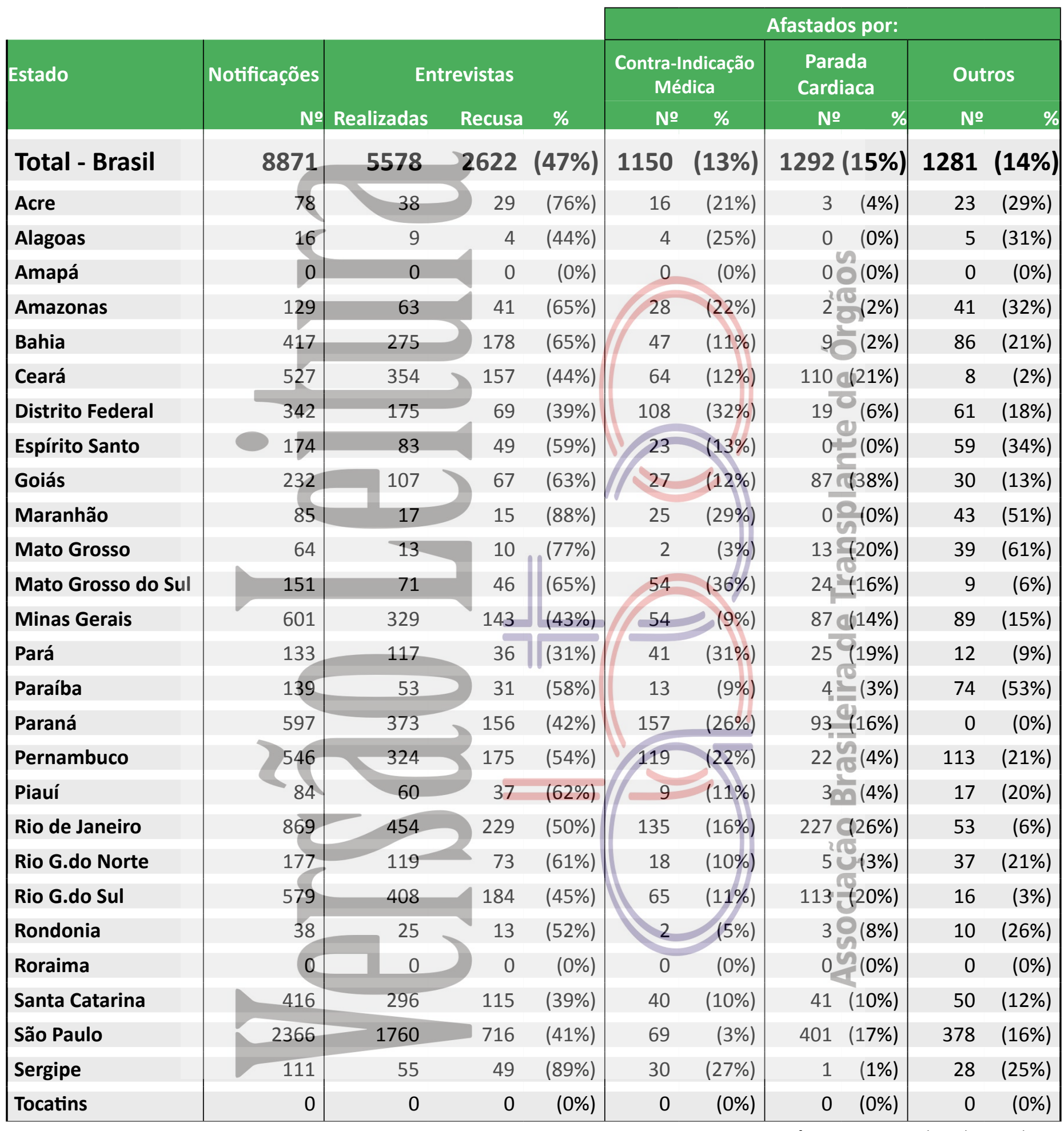




\section{DADOS POR ESTADO}

\section{Perfil etário, gênero, causa do óbito e grupo șanguíneo dos doadores de órgãos nos estados brasileiros}

\begin{tabular}{|c|c|c|c|c|c|c|c|c|c|c|c|c|c|c|c|}
\hline \multirow[t]{2}{*}{ Estado } & \multicolumn{2}{|c|}{ Gênero } & \multicolumn{3}{|c|}{ Causa da óbito } & \multicolumn{6}{|c|}{ Faixa Etária } & \multicolumn{4}{|c|}{ Grupo Sanguíneo } \\
\hline & Masc & Fem & TCE & AVC & Outros & $\leq 5$ & 6-10|: & $11-17$ & $|18-34|$ & $|35-49|$ & $|50-64|$ & A & $A B$ & B & 0 \\
\hline TOTAL - Brasil & 1528 & 998 & 964 & 1227 & 335 & 39 & 45 & 149 & 671 & 689 & 750 & 939 & 147 & 249 & 1191 \\
\hline Percentual & $60 \%$ & $40 \%$ & $38 \%$ & $49 \%$ & $13 \%$ & $2 \%$ & $2 \%$ & $6 \%$ & $27 \%$ & $27 \%$ & $30 \%$ & $37 \%$ & $6 \%$ & $10 \%$ & $647 \%$ \\
\hline Acre & 4 & & 2 & 4 & & 0 & 0 & 0 & 3 & 2 & 2 & 2 & 2 & 0 & 3 \\
\hline Alagoas & 3 & & 1 & 2 & 0 & 0 & 0 & 0 & 1 & 1 & 0 & 2 & 0 & 0 & 1 \\
\hline Amapa & 0 & & 0 & 0 & 0 & 0 & 0 & 0 & 0 & 0 & $0 \backsim 0$ & 0 & 0 & 0 & 0 \\
\hline Amazonas & 10 & & 7 & 10 & & 0 & 0 & & & 5 & 50 & 6 & 1 & 1 & 9 \\
\hline Bahia & 58 & 39 & 50 & 38 & 9 & 2 & 2 & o & 31 & 31 & 23 ? 2 & 24 & 4 & 11 & 58 \\
\hline Ceará & 126 & 62 & 106 & 65 & 17 & 4 & 5 & 15 & 67 & 44 & $41 \bigcirc 12$ & 77 & 5 & 15 & 91 \\
\hline Distrito Federal * & 57 & 28 & 42 & 38 & & 3 & 2 & 7 & 25 & 28 & $17 \div 3$ & 33 & 5 & 13 & 34 \\
\hline Espírito Santo & 29 & 14 & 13 & 26 & 4 & 0 & 0 & & & 13 & 14 (d) 1 & 15 & 0 & 6 & 22 \\
\hline Goiás & 15 & & 16 & 3 & 2 & 0 & 0 & & & 10 & $5=0$ & 6 & 1 & 4 & 10 \\
\hline Maranhão & 0 & & 0 & 2 & 0 & 0 & 0 & 0 & 1 & 0 & $1=0$ & 1 & 0 & 1 & 0 \\
\hline Mato Grosso & 0 & & 0 & 0 & 0 & 0 & 0 & 0 & 0 & 0 & $0 \stackrel{n}{\varepsilon} 0$ & 0 & 0 & 0 & 0 \\
\hline Mato Grosso do Sul & 11 & 7 & 5 & 3 & 10 & 0 & 0 & 3 & & 6 & 60 & 9 & 0 & 2 & 7 \\
\hline Minas Gerais & & 129 & 82 & 112 & 34 & 5 & 1 & 13 & & 69 & $63-12$ & 74 & 9 & 22 & 2123 \\
\hline Pará & 16 & & 16 & 2 & & 0 & 0 & & 10 & 8 & $0=0$ & 5 & 0 & 2 & 12 \\
\hline Paraíba & 11 & & 11 & 3 & 3 & 0 & 1 & 1 & 10 & 4 & 100 & 5 & 2 & 1 & 9 \\
\hline Paraná & 129 & 62 & 81 & 62 & 48 & 2 & 3 & 13 & 52 & 52 & 50 (d) 19 & 73 & 8 & 21 & 89 \\
\hline Pernambuco & 71 & 46 & 42 & 65 & 10 & 0 & 1 & & & & $45 \backsim 7$ & 51 & 5 & 11 & 50 \\
\hline Piauí & 13 & & & 10 & & 0 & 0 & & & 3 & 5 & 7 & 0 & 0 & 11 \\
\hline Rio de Janeiro & 125 & 100 & 66 & 113 & 46 & 4 & 8 & 16 & 69 & 52 & $54 \quad 22$ & 83 & 16 & 46 & 80 \\
\hline Rio Grande do Norte & 28 & 16 & & & 10 & 1 & 0 & 5 & 13 & 12 & $13 \stackrel{20}{0} 0$ & 18 & 3 & 2 & 21 \\
\hline Rio Grande do Sul & 120 & 81 & 47 & 128 & 26 & 3 & 4 & 9 & 38 & 54 & $69=24$ & 71 & 6 & 22 & 2102 \\
\hline Rondonia & 6 & & 4 & 4 & 2 & 0 & 1 & & & 2 & $1 \% 0$ & 3 & 0 & 3 & 4 \\
\hline Roraima & 0 & & 0 & 0 & 0 & 0 & 0 & 0 & 0 & 0 & $0 \leqslant 0$ & 0 & 0 & 0 & 0 \\
\hline Santa Catarina & 107 & 63 & 63 & 88 & 19 & 2 & 1 & 6 & 44 & 40 & 19 & 75 & 4 & 15 & 76 \\
\hline São Paulo & 488 & 314 & 283 & 431 & & 13 & 16 & 37 & 182 & 218 & 276 & 298 & 76 & 50 & 378 \\
\hline Sergipe & 2 & 1 & 2 & 1 & 0 & 0 & 0 & 0 & 2 & 1 & 0 & 1 & 0 & 1 & 1 \\
\hline Tocantins & 0 & 0 & 0 & 0 & 0 & 0 & 0 & $\underline{0}$ & 0 & 0 & 0 & 0 & 0 & 0 & 0 \\
\hline
\end{tabular}




\title{
ACRE
}

$\begin{array}{lr}\text { População atual } & 733.559(0,4 \%) \\ \text { Rio Branco } & 336.038 \\ \text { Extensão territorial }\left(\mathrm{Km}^{2}\right) & 152.581,39\end{array}$

\begin{tabular}{lccccc}
\hline $\begin{array}{l}\text { Necessidade anual estimada } \\
\text { e no de transplantes }\end{array}$ & Córnea & Rim & Fígado & Coração \\
\hline Necessidade estimada & 66 & 44 & 18 & 4 \\
Transplantes realizados & 18 & 8 & 0 & 0
\end{tabular}

\begin{tabular}{lrrrrrrrr}
\hline Número de Óbitos por ano & 2006 & 2007 & 2008 & 2009 & 2010 & 2011 & 2012 & 2013 \\
\hline Todas as causas & 2.759 & 2.799 & 2.858 & 2.892 & 3.009 & 3.157 & Indisponível & Indisponível \\
Causas Externas & 375 & 357 & 355 & 387 & 439 & 488 & Indisponível & Indisponível \\
Causas Neurológicas & 38 & 35 & 48 & 58 & 50 & 43 & Indisponível & Indisponível \\
População (censo IBGE) & 557.526 & 655.385 & 655.385 & 655.385 & 733.559 & 733.559 & 733.559 & 733.559
\end{tabular}

\section{HOSPITAIS}

№ Total

Capital do estado Interior

№ de leitos

№ de leitos UTI

$\%$ Brasil $\quad$ CNCDO. Regiane Clélia Ferrari

Fonte: http://cnes.datasus.gov.br 17/12/2013

Hospitais com mais de 80 leitos

Hospital de ensino

Escolas médicas

№ serviços de neurocirurgia

Número de CIHDOTTS

Número de OPOs

\author{
$22(0,3) \quad \vdots$ Fone: (68) 3227-6399 / (68) 9985-2061

$\begin{array}{c:c}22(0,3) & \text { E-Mail: cncdoacre@gmail.com } \\ 9 & \vdots\end{array}$

$1.368(0,3)$

$73(0,2)$

Conta com apoio do governo local para o desenvolvimento do programa e enfrenta as

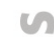

O

5 dificuldades de programas iniciantes, como baixa notificação, dificuldade em fechar 0 o protocolo de morte encefálica e elevada recusa familiar. Recentemente obteve o $\begin{array}{lll}1(0,5) & \text { credenciamento do transplante de fígado junto ao Sistema Nacional de Transplantes }\end{array}$

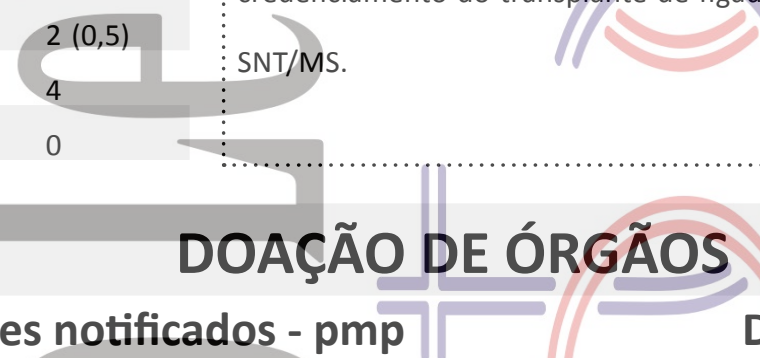

Potenciais doadores notificados - pmp
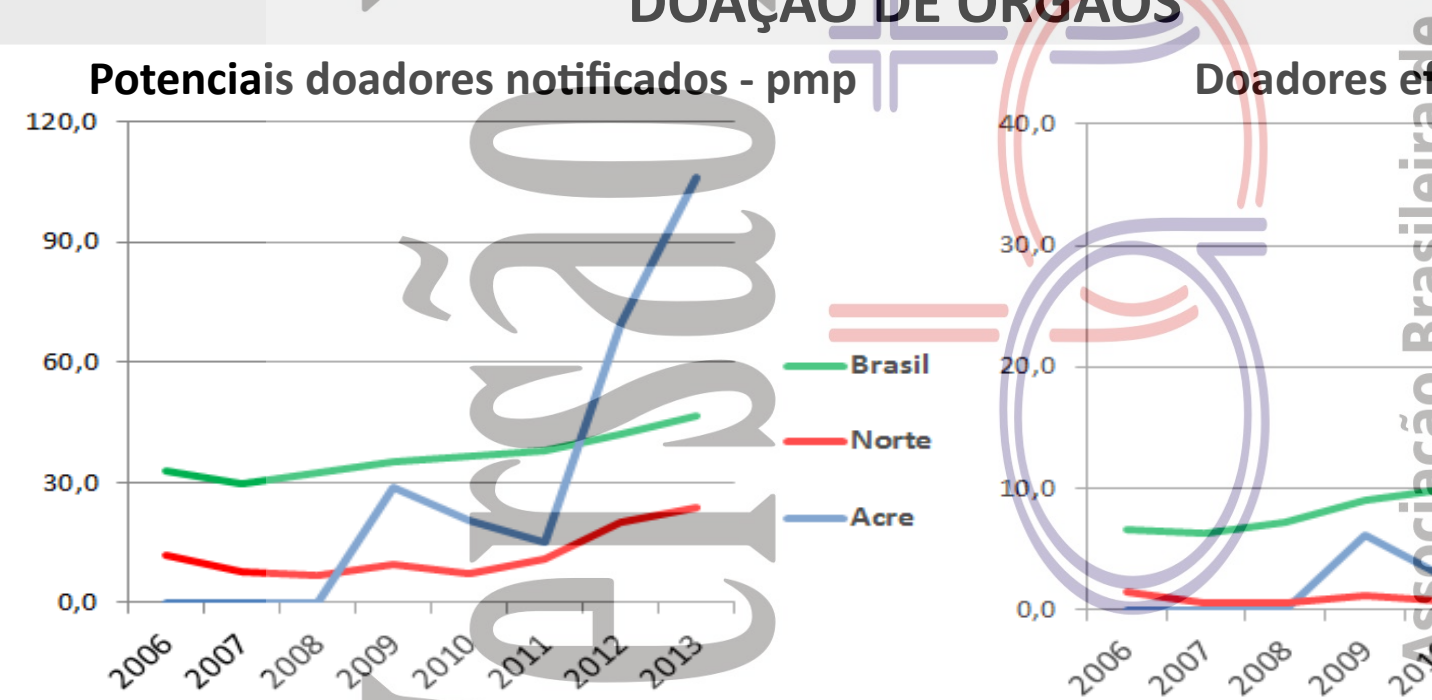

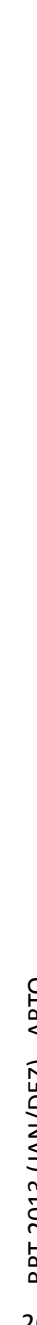

\begin{tabular}{|c|c|c|c|c|c|c|c|c|}
\hline & 2006 & 2007 & 2008 & 2009 & 2010 & 2011 & 2012 & 2013 \\
\hline Número de doadores efetivos & 0 & 0 & 0 & 4 & 2 & 4 & 4 & 7 \\
\hline Número de doadores efetivos (pmp) & 0,0 & 0,0 & 0,0 & 6,1 & 2,7 & 5,5 & 5,5 & 9,5 \\
\hline $\begin{array}{l}\text { Número de notificações } \\
\text { (potenciais doadores) }\end{array}$ & 0 & 0 & 0 & 19 & 15 & 11 & 51 & 78 \\
\hline Número de notificações (pmp) & 0,0 & 0,0 & 0,0 & 29,0 & 20,4 & 15,0 & 69,5 & 106,3 \\
\hline Recusa familiar & 0 & 0 & 0 & 6 & 4 & 3 & 21 & 29 \\
\hline Percentual de recusa das entrevistas & Indisponível & Indisponível & Indisponível & Indisponível & Indisponível & Indisponível & 78 & 76 \\
\hline Parada Cardíaca & Indisponível & Indisponível & & 2 & 2 & 0 & 0 & 3 \\
\hline Contraindicação médica & 0 & 0 & 0 & 6 & 5 & 1 & 5 & 16 \\
\hline Outros & 0 & 0 & 0 & 1 & 2 & 3 & 21 & 23 \\
\hline
\end{tabular}




\section{ACRE}

\section{TRANSPLANTE DE ÓRGÃOS}

\section{RIM com doador falecido - pmp}

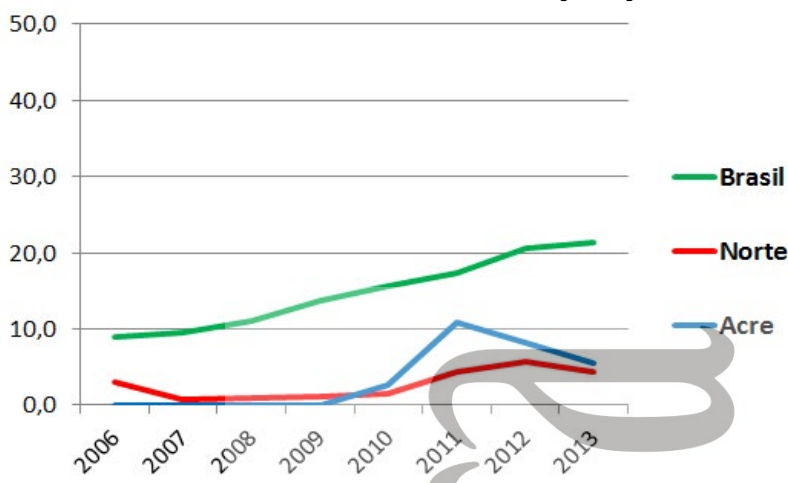

FíGADO - pmp (não realiza)

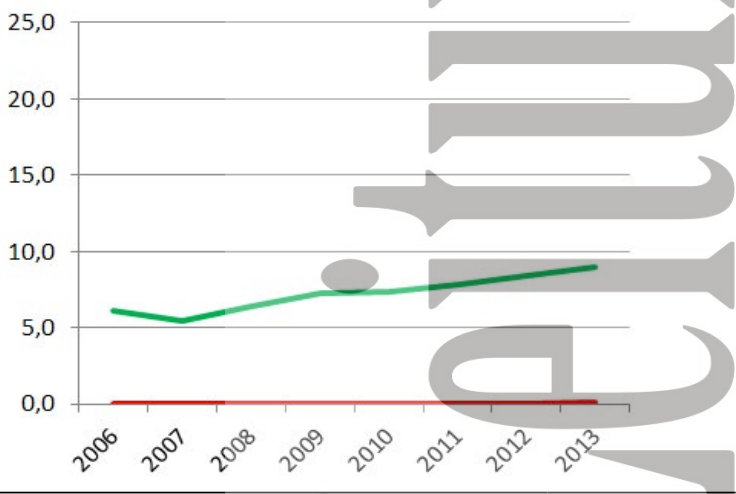

RIM com doador vivo - pmp

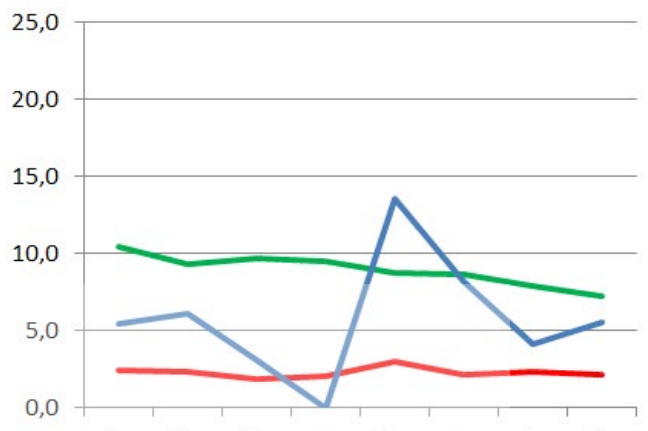

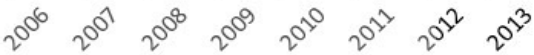
CÓRNEA- pmp

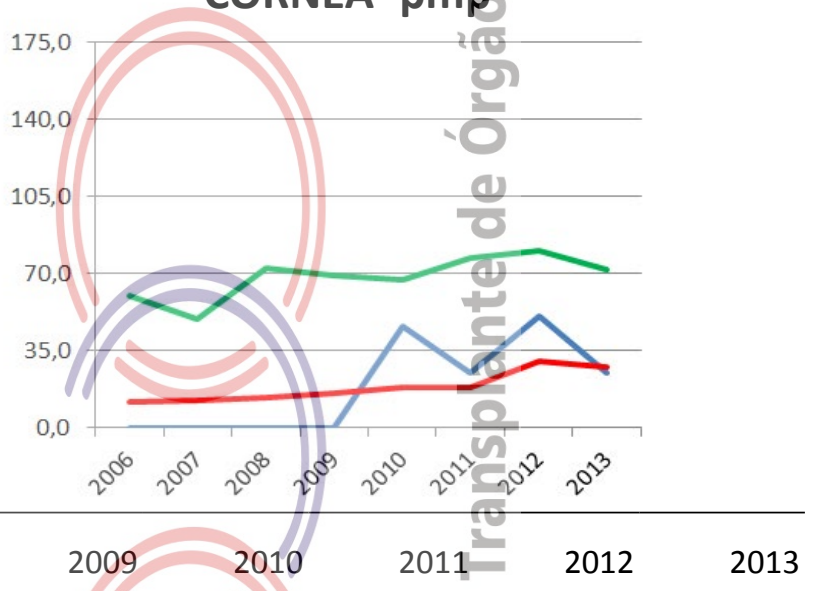

Número de equipes que realizaram $2006 \quad 2007$
transplantes durante o ano CÓRNEA

RIM

FÍGADO (não realiza)

PÂNCREAS (não realiza)

CORAÇÃO (não realiza)

PULMÃO (não realiza)

Número absoluto de transplantes

Indisponível Indisponível Indisponível Indisponível Indisponível Indisponível Indisponível Indisponível

\begin{tabular}{|c|c|c|c|c|c|c|c|c|}
\hline & & & & & & 2. $(10)$ & & \\
\hline CÓRNEA & $>0$ & 0 & 0 & 0 & 34 & 18 ? & 37 & 18 \\
\hline RIM & 3 & 4 & 2 & 10 & 12 & & 9 & 8 \\
\hline doador vivo & 3 & 4 & 2 & 0 & 10 & 0 & 3 & 4 \\
\hline doador falecido & 0 & 0 & 0 & 0 & 2 & $8 \omega$ & 6 & 4 \\
\hline FÍGADO (não realiza) & & & & & & $<$ & & \\
\hline PÂNCREAS (não realiza) & 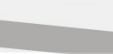 & & & & & & & \\
\hline CORAÇÃO (não realiza) & & & & & & & & \\
\hline PULMÃO (não realiza) & & & & & & & & \\
\hline Número de transplantes pmp & 2006 & 2007 & 2008 & 2009 & 2010 & 2011 & 2012 & 2013 \\
\hline CÓRNEA & 0,0 & 0,0 & 0,0 & 0,0 & 46,3 & 24,5 & 50,4 & 24,5 \\
\hline RIM & 5,4 & 6,1 & 3,1 & 0,0 & 16,4 & 19,1 & 12,3 & 10,9 \\
\hline doador vivo & 5,4 & 6,1 & 3,1 & 0,0 & 13,6 & 8,2 & 4,1 & 5,4 \\
\hline doador falecido & 0,0 & 0,0 & 0,0 & 0,0 & 2,7 & 10,9 & 8,2 & 5,4 \\
\hline
\end{tabular}

FÍGADO (não realiza)

PÂNCREAS (não realiza)

CORAÇÃO (não realiza)

PULMÃO (não realiza)
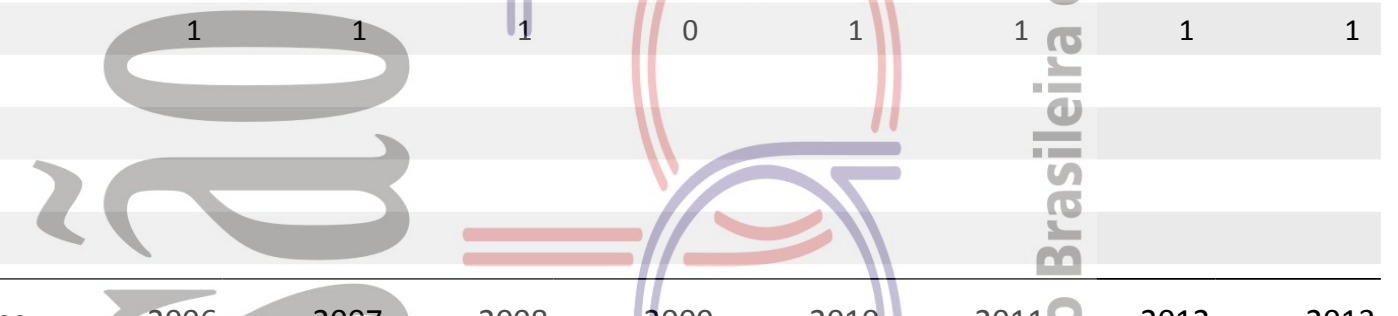


\section{ALAGOAS}

População atual

$3.120 .494(1,6 \%)$

Maceió

932.748

Extensão territorial $\left(\mathrm{Km}^{2}\right)$

$27.767,66$

\begin{tabular}{|c|c|c|c|c|c|c|}
\hline \multicolumn{3}{|c|}{$\begin{array}{l}\text { Necessidade anual estimada } \\
\text { e no de transplantes }\end{array}$} & Córnea & Rim & Fígado & Coração \\
\hline Necessidade & stimada & & 281 & 187 & 78 & 19 \\
\hline Transplantes & ealizados & & 52 & 22 & 0 & 0 \\
\hline 2008 & 2009 & & 2010 & 2011 & 2012 & 2013 \\
\hline 16.403 & 17.056 & & 17.737 & 18.645 & Indisponível & Indisponível \\
\hline 2.956 & 3.060 & & 3.403 & 3.572 & Indisponível & Indisponível \\
\hline 190 & 194 & & 169 & 197 & Indisponível & Indisponível \\
\hline 3.037 .103 & 3.037 .103 & 3.12 & 20.494 & $\begin{array}{l}3.120 .494 \\
\text { Fonte: http: }\end{array}$ & $\begin{array}{l}3.120 .494 \\
\text { //cnes.datasus.g }\end{array}$ & $\begin{array}{r}3.120 .494 \\
\text { v.br } 17 / 12 / 2013\end{array}$ \\
\hline
\end{tabular}

\section{HOSPITAIS}

№ Total

Capital do estado Interior

№ de leitos

№ de leitos UTI

$\begin{array}{rr}2006 & 2007 \\ 15.422 & 16.594 \\ 2.691 & 2.984 \\ 161 & 182 \\ 822.621 & 3.037 .103\end{array}$

$\begin{array}{cl}\% \text { Brasil } & \text { CNCDO: Kelly Karina de Araújo Brandão } \\ 72(1,1) & \text { Fone/Fax: (82) 3376-8186 / (82) 3315-7440 }\end{array}$

$42 \quad \vdots$ E-Mail: doevida@saude.al.gov.br

(

$30 \quad$ Estado com declínio acentuado no programa de transplantes em todas suas etapas. $5.640(1,2) \quad \vdots$ Enfrenta dificuldades na formação de equipe técnica para implantação da OPO - etapa $354(0,9) \quad \vdots$ II, baixa notificação e elevada taxa de recusa familiar $(77,7 \%)$. Não realiza doação de Hospitais com mais de 80 leitos $24 \quad$ órgãos e, por consequência, transplantes. Está em descompasso com o crescimento dos Hospital de ensino Escolas médicas № serviços de neurocirurgia Número de CIHDOTTS

Número de OPOs

0 $2(1,1)$ $5(1,2)$ 2 0 programas de transplantes dos estados da região nordeste, como Ceará e Pernambuco. Nem mesmo o transplante de córneas atende à necessidade estimada. Necessita apoio para priorizar a reativação dos programas de doação de órgãos e de transplante de rim e córneas e, como ação subsequente, criação de um programa de transplantes de fígado.

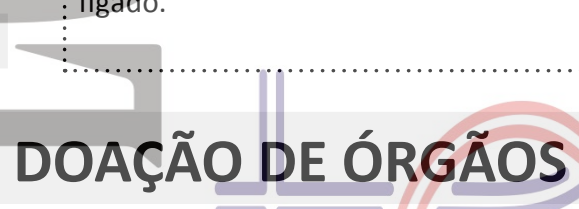

\section{Potenciais doadores notificados - pmp}

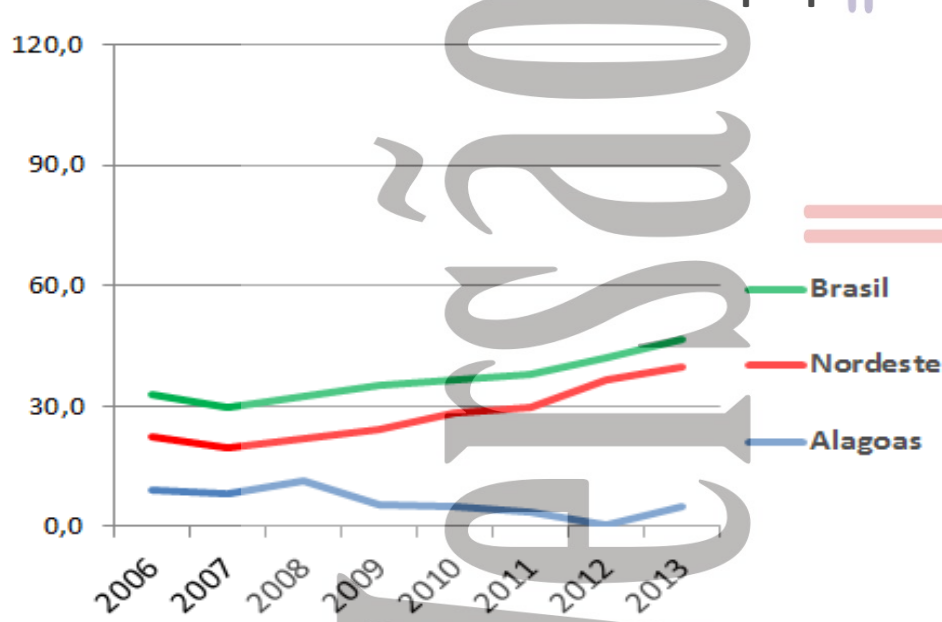

Doadores efetivos - pmp

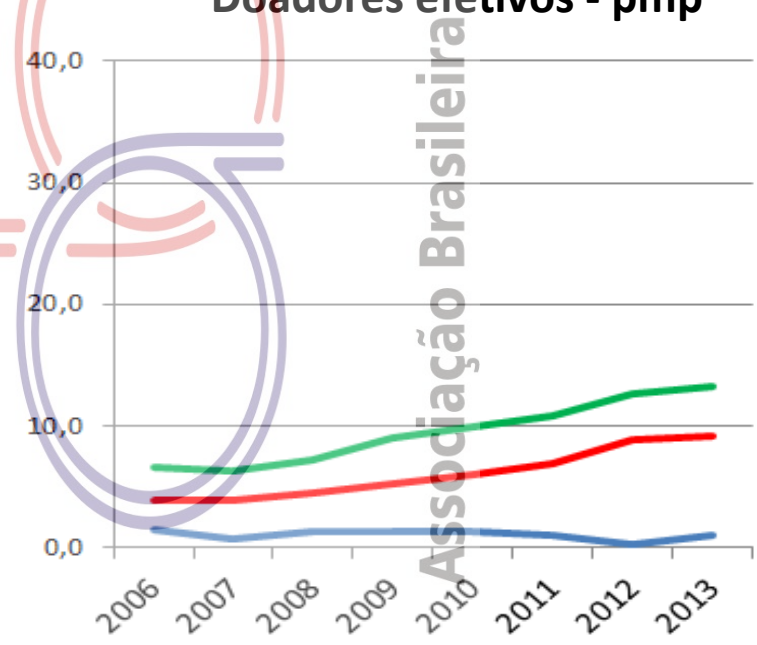

\begin{tabular}{|c|c|c|c|c|c|c|c|c|}
\hline & 2006 & 2007 & 2008 & 2009 & 2010 & 2011 & 2012 & 2013 \\
\hline Número de doadores efetivos & 4 & 2 & 4 & 4 & 4 & 3 & 1 & 3 \\
\hline Número de doadores efetivos (pmp) & 1,4 & 0,7 & 1,3 & 1,3 & 1,3 & 1,0 & 0,3 & 1,0 \\
\hline $\begin{array}{l}\text { Número de notificações } \\
\text { (potenciais doadores) }\end{array}$ & 26 & 25 & 35 & 16 & 15 & 12 & 2 & 16 \\
\hline Número de notificações (pmp) & 9,2 & 8,2 & 11,5 & 5,3 & 4,8 & 3,8 & 0,6 & 5,1 \\
\hline Recusa familiar & 9 & 7 & 15 & 5 & 4 & 0 & 0 & 4 \\
\hline Percentual de recusa das entrevistas & Indisponível & Indisponível & Indisponível & Indisponível & Indisponível & Indisponível & 0 & 44 \\
\hline Parada Cardíaca & Indisponível & Indisponível & 2 & 1 & 0 & 0 & 0 & 0 \\
\hline Contraindicação médica & 6 & 8 & 8 & 1 & 3 & 1 & 0 & 4 \\
\hline Outros & 7 & 8 & 6 & 5 & 4 & 8 & 1 & 5 \\
\hline
\end{tabular}




\section{ALAGOAS}

\section{TRANSPLANTE DE ÓRGÃOS}

\section{RIM com doador falecido - pmp}

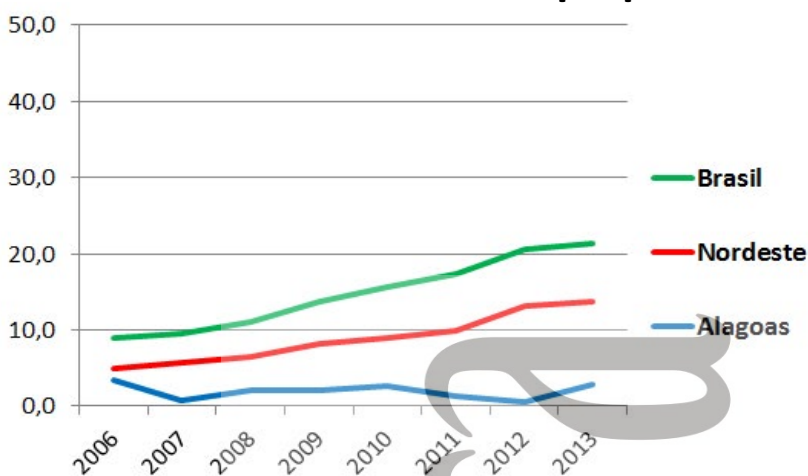

FÍGADO - pmp (não realiza)

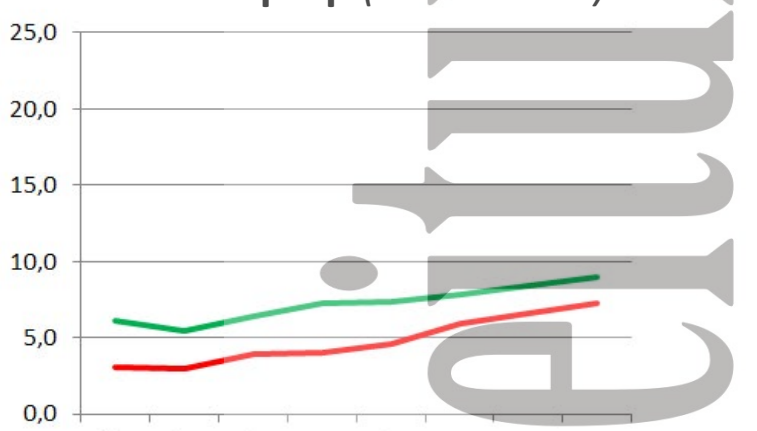

RIM com doador vivo - pmp

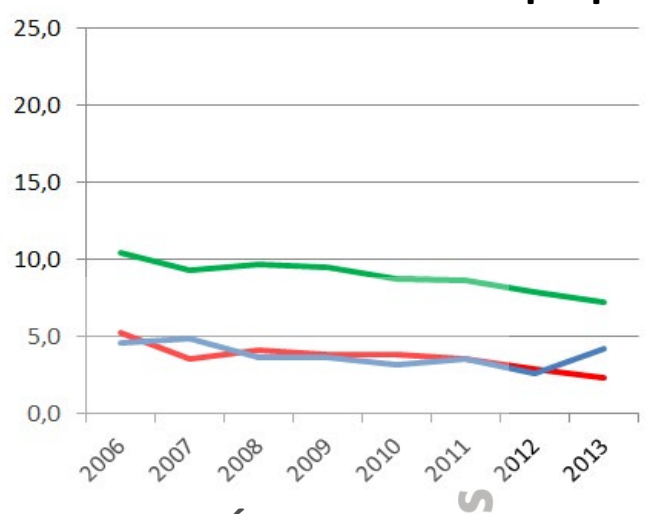

CÓRNEA- pmp

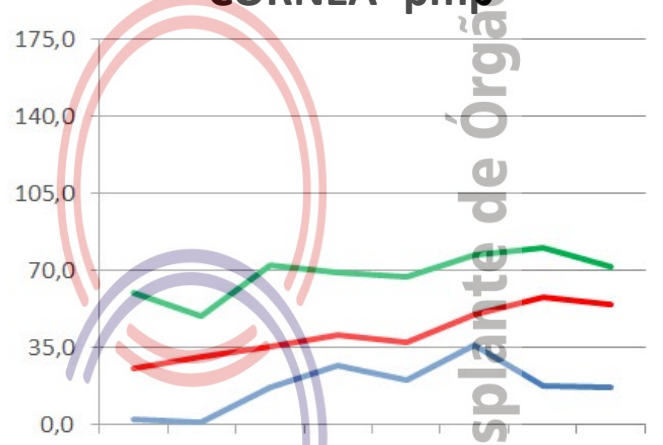

Número de equipes que realizaram $2006 \quad 2007$ transplantes durante o ano

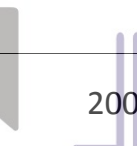

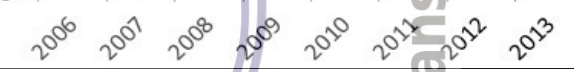

\begin{tabular}{|c|c|c|c|c|c|c|c|c|}
\hline \multirow{2}{*}{$\begin{array}{l}\text { CÓRNEA } \\
\text { RIM }\end{array}$} & \multirow{2}{*}{$\begin{array}{r}\text { Indisponível } \\
3 \\
3\end{array}$} & \multirow{2}{*}{$\begin{array}{r}\text { Indisponível } \\
3\end{array}$} & \multicolumn{3}{|c|}{ Indisponível Indisponível Indisponível } & \multicolumn{2}{|c|}{ Indisponível Indisponível } & \multirow{2}{*}{$\begin{array}{r}\text { Indisponível } \\
3\end{array}$} \\
\hline & & & 3 & 3 & 3 & 2 & 2 & \\
\hline FÍGADO (não realiza) & & & & & & -름 & & \\
\hline PÂNCREAS (não realiza) & & & & & & 믄 & & \\
\hline CORAÇÃO & & & 1 & & & $0 \stackrel{0}{r}$ & 0 & 0 \\
\hline PULMÃO (não realiza) & & & 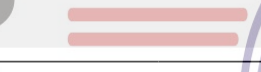 & & & 을 & & \\
\hline Júmero absoluto de transplantes & 2006 & 2007 & 2008 & 2009 & 2010 & $2011 \frac{0}{2(0)}$ & 2012 & 2013 \\
\hline CÓRNEA & 7 & 2 & 51 & 82 & 64 & 113 (0) & 54 & 52 \\
\hline RIM - total & 23 & 17 & 17 & 17 & 18 & $15^{-U}$ & 10 & 22 \\
\hline doador vivo & 13 & 15 & 11 & & 10 & 110 & 8 & 13 \\
\hline doador falecido & 10 & 2 & 6 & 6 & 8 & 4 น & 2 & 9 \\
\hline FÍGADO (não realiza) & & & & & & $<$ & & \\
\hline \multicolumn{9}{|l|}{ PÂNCREAS (não realiza) } \\
\hline CORAÇÃO & 0 & 0 & 2 & 1 & 2 & 0 & 0 & 0 \\
\hline \multicolumn{9}{|l|}{ PULMÃO (não realiza) } \\
\hline Júmero de transplantes pmp & 2006 & 2007 & 2008 & 2009 & 2010 & 2011 & 2012 & 2013 \\
\hline CÓRNEA & 2,5 & 0,7 & 16,8 & 27,0 & 20,5 & 36,2 & 17,3 & 16,7 \\
\hline RIM - total & 8,1 & 5,6 & 5,6 & 5,6 & 5,8 & 4,8 & 3,2 & 7,1 \\
\hline doador vivo & 4,6 & 4,9 & 3,6 & 3,6 & 3,2 & 3,5 & 2,6 & 4,2 \\
\hline doador falecido & 3,5 & 0,7 & 2,0 & 2,0 & 2,6 & 1,3 & 0,6 & 2,9 \\
\hline \multicolumn{9}{|l|}{ FÍGADO (não realiza) } \\
\hline \multicolumn{9}{|l|}{ PÂNCREAS (não realiza) } \\
\hline CORAÇÃO & 0,0 & 0,0 & 0,7 & 0,3 & 0,6 & 0,0 & 0,0 & 0,0 \\
\hline
\end{tabular}




\section{AMAPÁ}

$\begin{array}{ll}\text { População atual } & 669.526(0,4 \%) \\ \text { Macapá } & 398.204\end{array}$

Extensão territorial $\left(\mathrm{Km}^{2}\right) \quad 142.814,59$

\begin{tabular}{|c|c|c|c|c|c|}
\hline \multicolumn{2}{|c|}{$\begin{array}{l}\text { Necessidade anual estimada } \\
\text { e no de transplantes }\end{array}$} & Córnea & Rim & Fígado & Coração \\
\hline \multicolumn{2}{|c|}{ Necessidade estimada } & 60 & 40 & 17 & 4 \\
\hline \multicolumn{2}{|c|}{ Transplantes realizados } & 0 & 0 & 0 & 0 \\
\hline 2008 & 2009 & 2010 & 2011 & 2012 & 2013 \\
\hline 2.113 & 2.140 & 2.172 & 2.495 & Indisponível & Indisponível \\
\hline 429 & 421 & 503 & 488 & Indisponível & Indisponível \\
\hline 17 & 27 & 29 & 35 & Indisponível & Indisponível \\
\hline 587.311 & 587.311 & 669.526 & $\begin{array}{l}669.526 \\
\text { Fonte: http:/ }\end{array}$ & $\begin{array}{r}669.526 \\
\text { //cnes.datasus.g }\end{array}$ & $\begin{array}{r}669.526 \\
\operatorname{br} 17 / 12 / 2013\end{array}$ \\
\hline
\end{tabular}

\section{HOSPITAIS}

№ Total

Capital do estado Interior

№ de leitos

№ de leitos UTI

Hospitais com mais de 80 leitos Hospital de ensino Escolas médicas № serviços de neurocirurgia Número de CIHDOTTS Número de OPOs

$\begin{array}{rr}2006 & 2007 \\ 1.803 & 1.886 \\ 439 & 406 \\ 11 & 7\end{array}$

\section{$\%$ Brasil $\quad$ CNCDO: Eduardo Monteiro Cardoso}

$12(0,2) \quad$ Fone: (96) 3212-6281

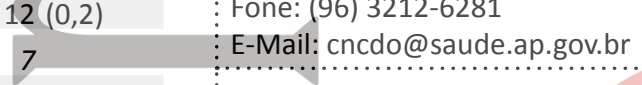

() $5 \quad \vdots \begin{aligned} & 5 \\ & \vdots\end{aligned}$ $967(0,2) \quad \vdots$ autorização, do estabelecimento de saúde (Hospital Escola São Camilo e São Luís $46(0,1) \quad \vdots$ HESCSL) para a implantação do serviço de transplante de rim, no entanto, estamos viabilizando a continuação da capacitação da equipe médica para concluir os processos

$\begin{array}{lll}0 & \text { de autorização. } \\ 1(0,5) & \vdots\end{array}$ $1(0,5) \quad$ Assim, ainda não realizou captação e nem transplante dérgãos e tecidos no Estado.

$\begin{array}{lll}1(0,2) & \vdots \\ 0 & \vdots\end{array}$

0

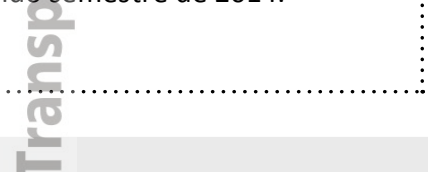

\section{DOAÇÃO DE ÓRGÃOS}

\section{Potenciais doadores notificados - pmp (não realiza)}
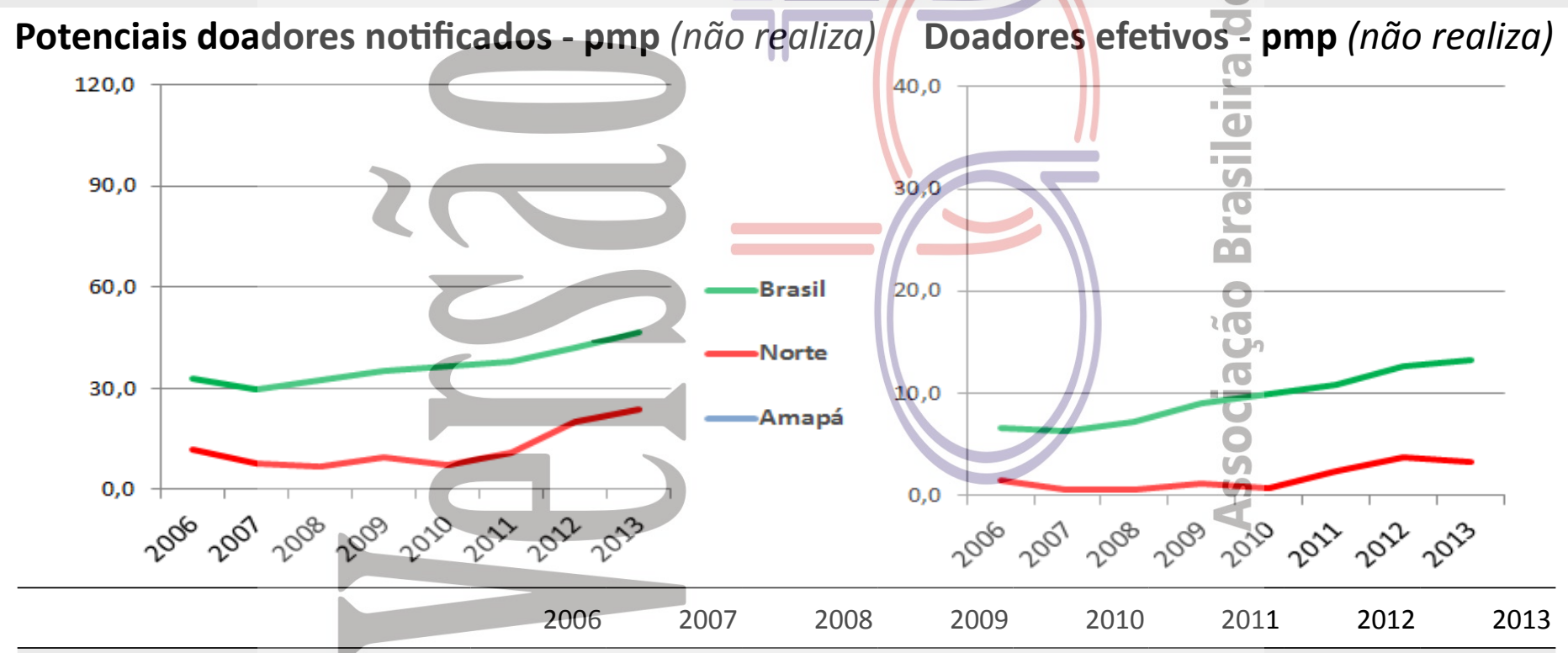

pmp (não realiza)

Número de doadores efetivos

Número de doadores efetivos (pmp)

Número de notificações

(potenciais doadores)

Número de notificações (pmp)

Recusa familiar

Percentual de recusa das entrevistas

Parada Cardíaca

Indisponível Indisponível Indisponível Indisponível Indisponível Indisponível

Contraindicação médica

Outros 


\section{AMAPÁ}

\section{TRANSPLANTE DE ÓRGÃOS}

RIM com doador falecido - pmp (não realiza)

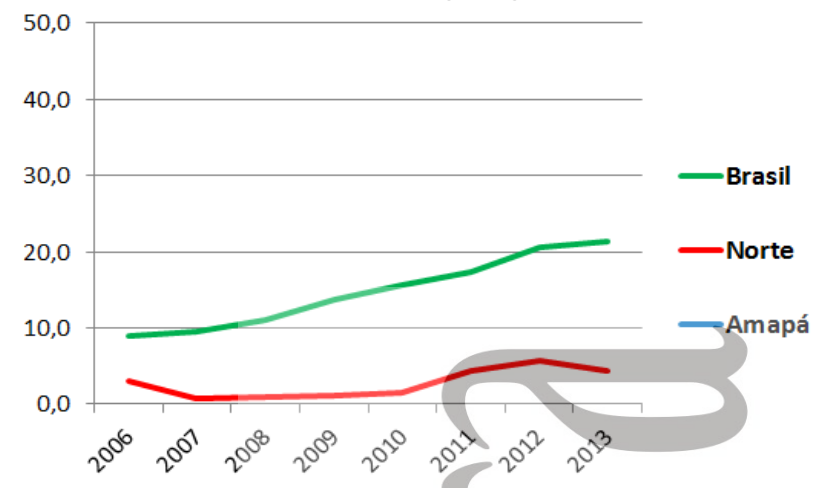

FÍGADO - pmp (não realiza)

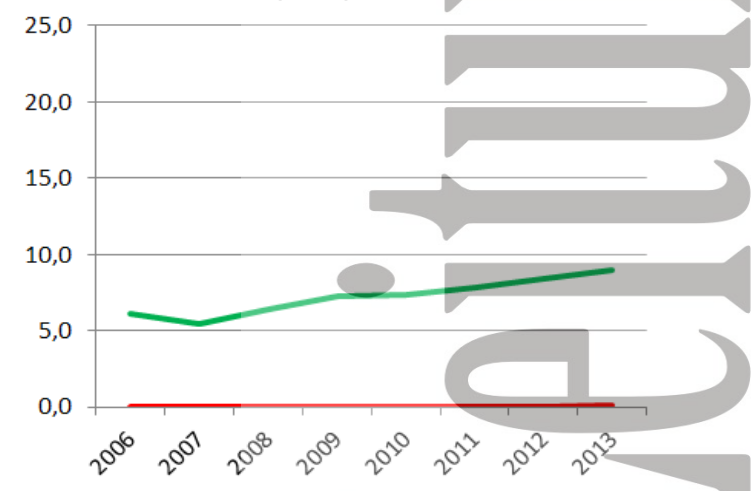

RIM com doador vivo - pmp (não realiza)
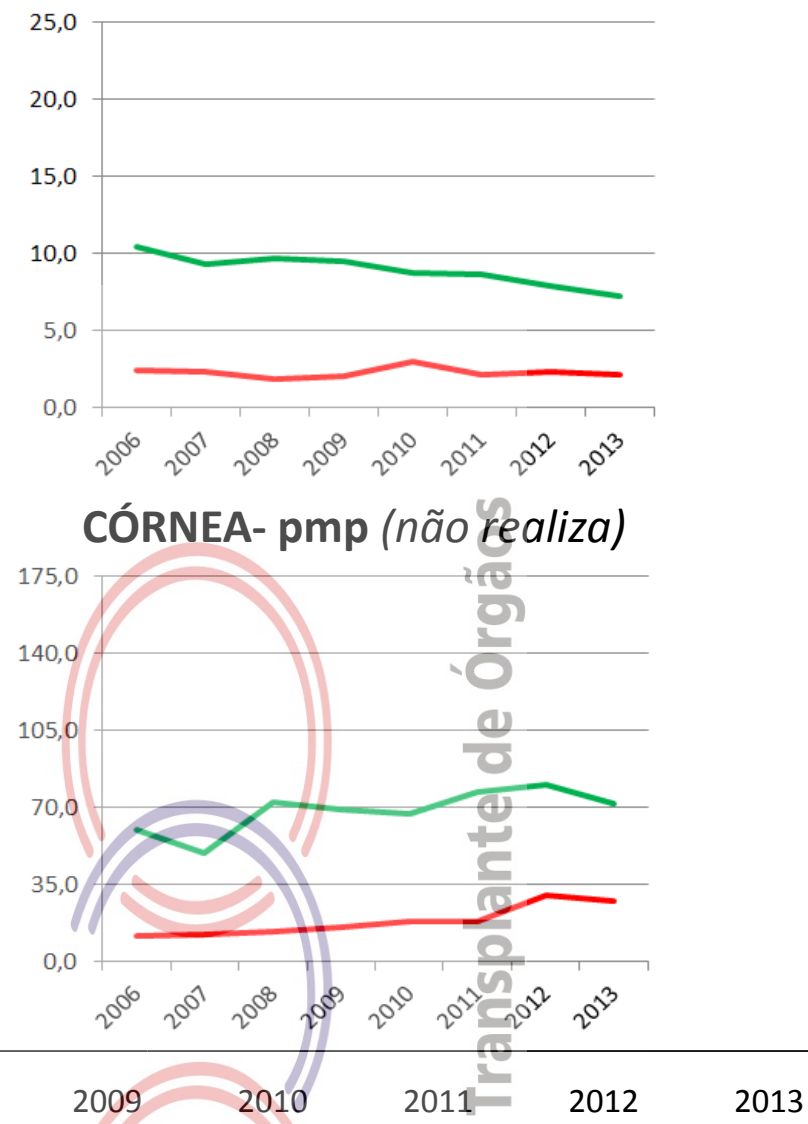

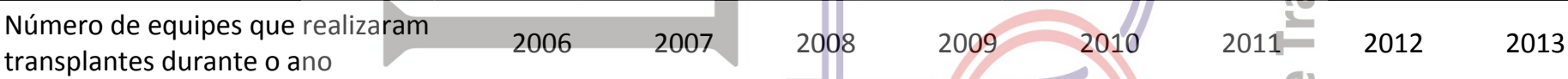

transplantes durante o ano

RIM (não realiza)

FÍGADO (não realiza)

PÂNCREAS (não realiza)

CORAÇÃO (não realiza)

PULMÃO (não realiza)

\begin{tabular}{c}
\hline Número absoluto de trans \\
\hline CÓRNEA (não realiza) \\
RIM - total (não realiza) \\
doador vivo \\
doador falecido \\
FÍGADO (não realiza) \\
PÂNCREAS (não realiza) \\
CORAÇÃO (não realiza) \\
PULMÃO (não realiza)
\end{tabular}

Número de transplantes pmp

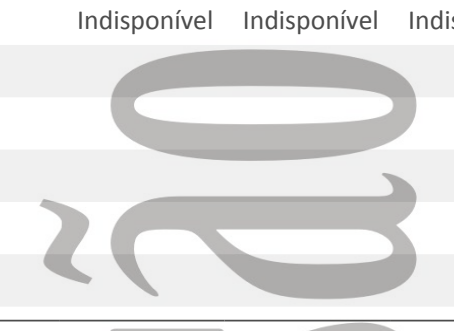

20062007
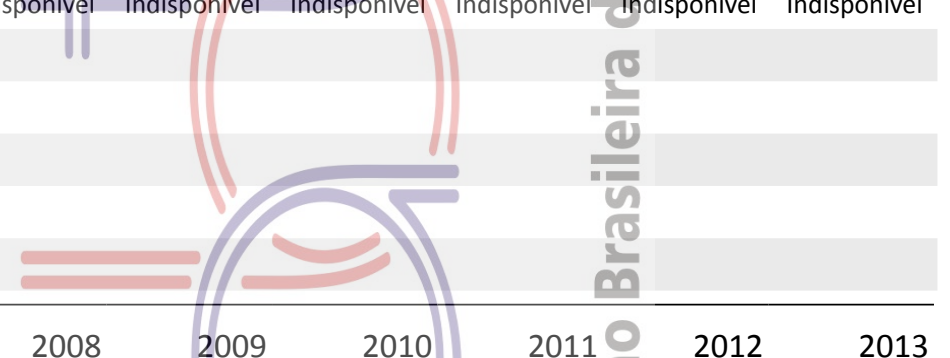

2008

$2009 \quad 2010 \quad 2011$

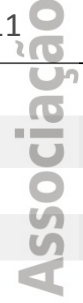

2012

\footnotetext{
CÓRNEA (não realiza)

RIM - total (não realiza)

doador vivo

doador falecido

FÍGADO (não realiza)

PÂNCREAS (não realiza)

CORAÇÃO (não realiza)

PULMÃO (não realiza)
} 


\section{AMAZONAS}

População atual

$3.483 .985(1,8 \%)$

Manaus

1.802 .014

Extensão territorial $\left(\mathrm{Km}^{2}\right)$ 1.570.745,68

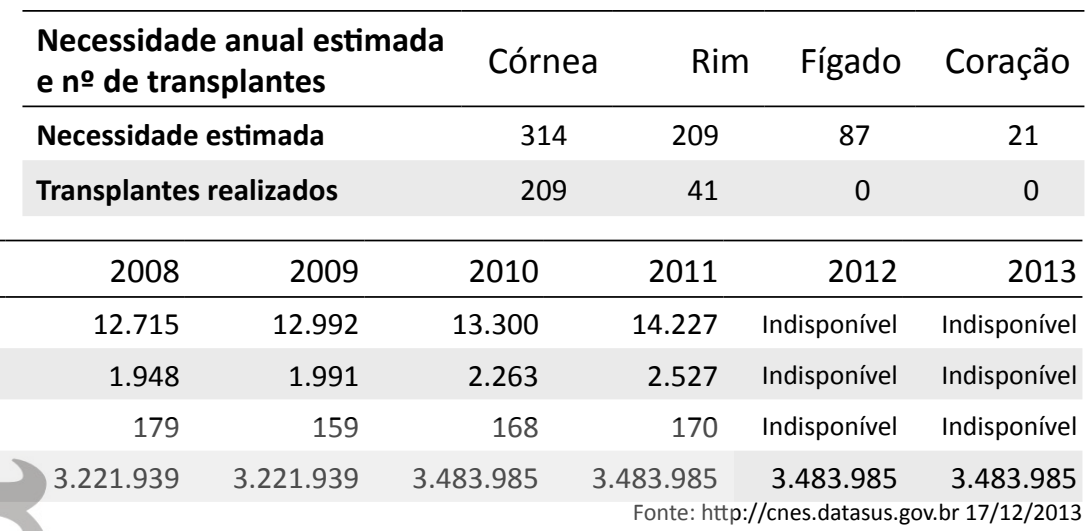

\section{HOSPITAIS}

№ Total

Capital do estado Interior

№ de leitos

№ de leitos UTI

Hospitais com mais de 80 leitos Hospital de ensino

Escolas médicas

№ serviços de neurocirurgia

Número de CIHDOTTS

Número de OPOs

$\begin{array}{rr}2006 & 2007 \\ 11.594 & 11.757 \\ 1.671 & 1.681 \\ 140 & 120 \\ 12.557 & 3.221 .939\end{array}$

$\%$ Brasil

$$
98(1,6)
$$$$
\begin{aligned}
& 41 \\
& 57
\end{aligned}
$$
$288(0,8)$
CNCDO: Dra. Leny Nascimento da Motta Passos Fone/ Fax: (92) 3664-2616 / (92) 8802-6801 E-Mail: cncdo.am@saude.gov.br Em 2013, tive algumas dificuldades, tais como, redução de pessoal técnico especializado, manutenção adequada dos equipamentos de doppler transcraniano e de EEG que refletiram no número das doações. No entanto, o trabalho educacional realizado pela Central de Transplante passou a contar com o apoio das Secretarias $3(1,6) \quad$ sobre Captação e Doação de Órgão, junto ao Ministério da Saúde. Espera, também, $4(1,0)$
4

0

\section{DOAÇÃO DE ÓRGÃOS}
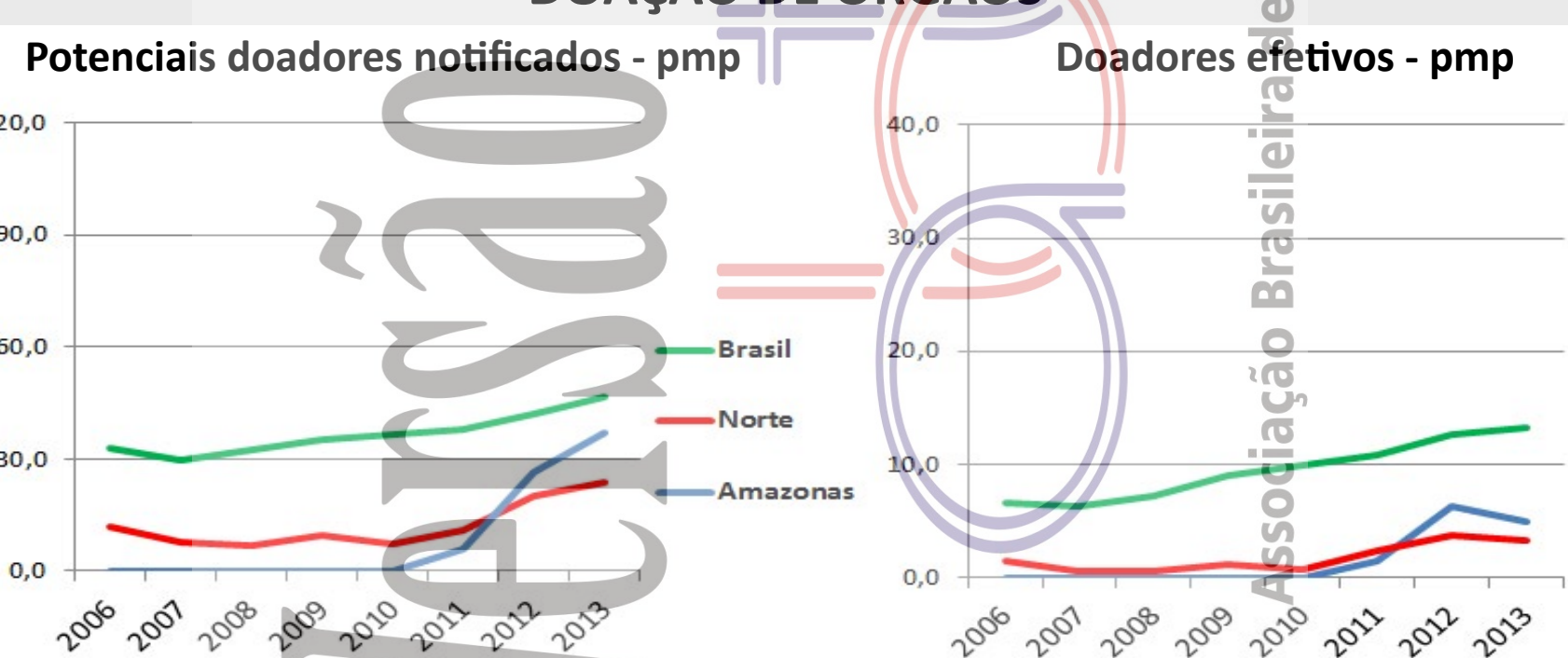

\begin{tabular}{|c|c|c|c|c|c|c|c|c|}
\hline & 2006 & 2007 & 2008 & 2009 & 2010 & 2011 & 2012 & 2013 \\
\hline Número de doadores efetivos & 0 & 0 & 0 & 0 & 0 & 5 & 22 & 17 \\
\hline Número de doadores efetivos (pmp) & 0,0 & 0,0 & 0,0 & 0,0 & 0,0 & 1,4 & 6,3 & 4,9 \\
\hline $\begin{array}{l}\text { Número de notificações } \\
\text { (potenciais doadores) }\end{array}$ & 0 & 0 & 0 & 0 & 0 & 21 & 92 & 129 \\
\hline Número de notificações (pmp) & 0,0 & 0,0 & 0,0 & 0,0 & 0,0 & 6,0 & 26,4 & 37,0 \\
\hline Recusa familiar & 0 & 0 & 0 & 0 & 0 & 9 & 30 & 41 \\
\hline Percentual de recusa das entrevistas & Indisponível & Indisponível & Indisponível & Indisponível & Indisponível & Indisponível & 57 & 65 \\
\hline Parada Cardíaca & Indisponível & Indisponível & 0 & 0 & 0 & 2 & 1 & 2 \\
\hline Contraindicação médica & 0 & 0 & 0 & 0 & 0 & 2 & 18 & 28 \\
\hline Outros & 0 & 0 & 0 & 0 & 0 & 3 & 21 & 41 \\
\hline
\end{tabular}




\section{AMAZONAS}

\section{TRANSPLANTE DE ÓRGÃOS}

\section{RIM com doador falecido - pmp}

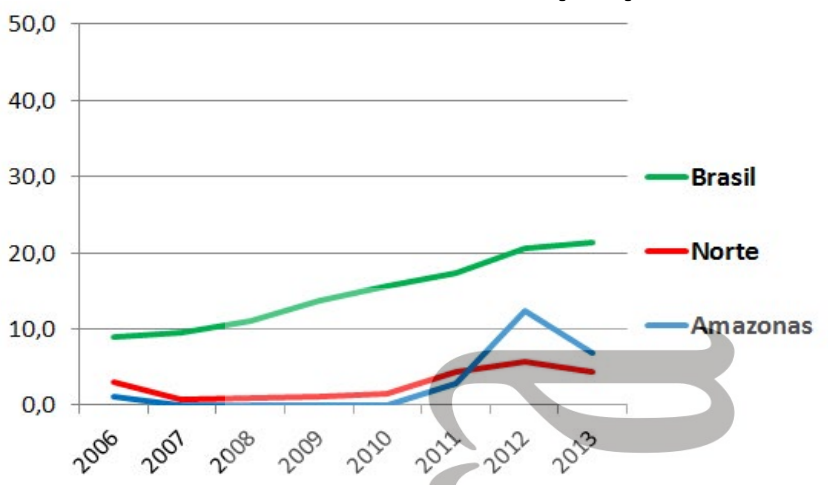

FíGADO - pmp (não realiza)

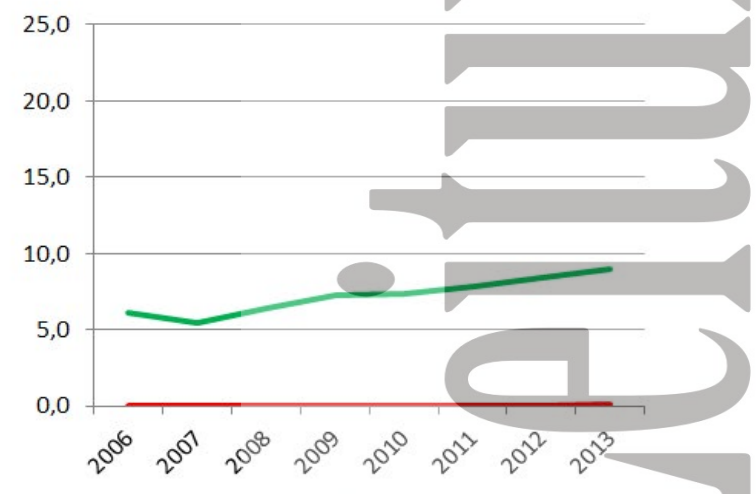

RIM com doador vivo - pmp

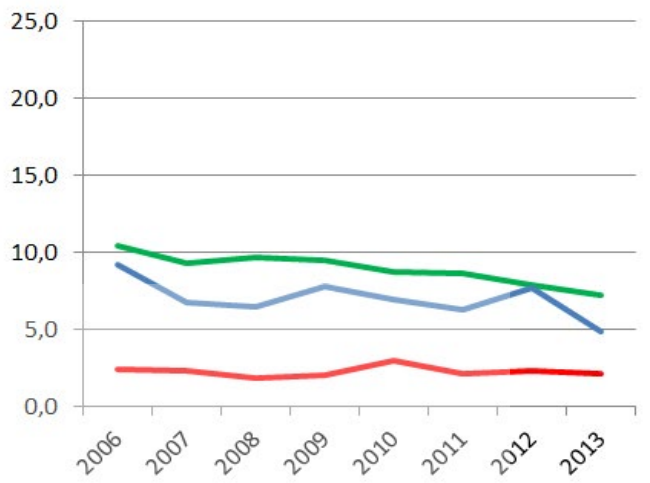

CÓRNEA- pmp

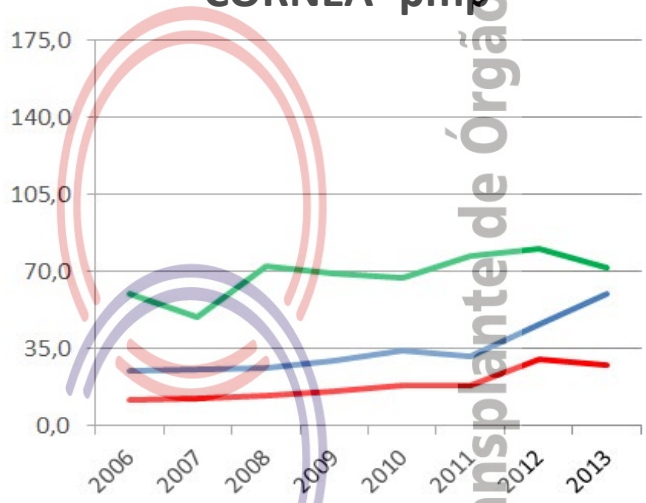

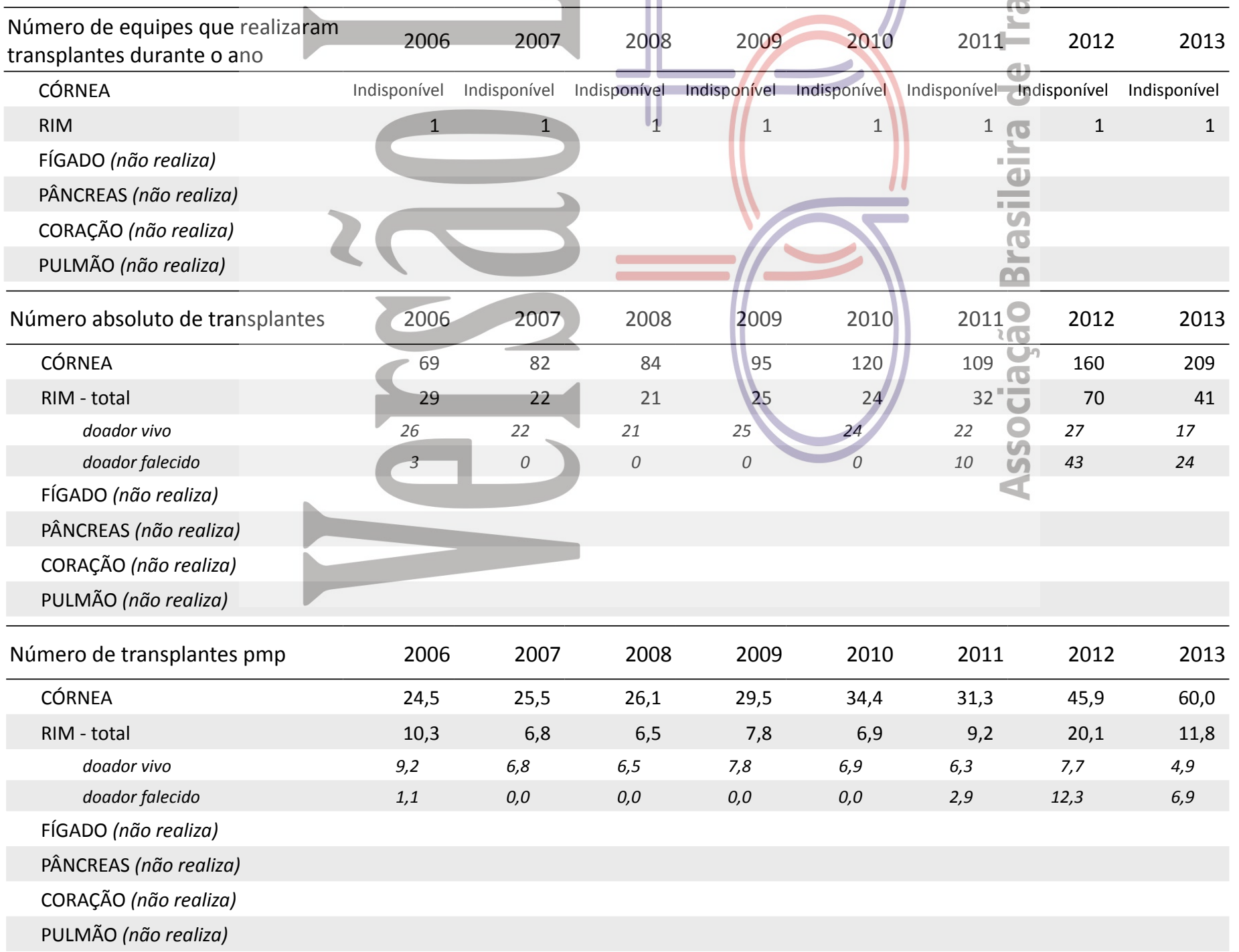


População atual

$14.016 .906(7,3 \%)$

Salvador

2.675 .656

Extensão territorial $\left(\mathrm{Km}^{2}\right)$

$564.692,67$

\begin{tabular}{lrrrrr}
\hline $\begin{array}{l}\text { Necessidade anual estimada } \\
\text { e no de transplantes }\end{array}$ & Córnea & Rim & Fígado & Coração \\
\hline Necessidade estimada & 1.262 & 841 & 350 & 84 \\
Transplantes realizados & 428 & 118 & 64 & 0
\end{tabular}

\begin{tabular}{|c|c|c|c|c|c|c|c|c|}
\hline Número de Óbitos por ano & 2006 & 2007 & 2008 & 2009 & 2010 & 2011 & 2012 & 2013 \\
\hline Todas as causas & 67.533 & 67.588 & 71.013 & 73.492 & 76.337 & 78.046 & Indisponível & Indisponível \\
\hline Causas Externas & 8.435 & 9.440 & 10.653 & 11.493 & 12.168 & 11.968 & Indisponível & Indisponível \\
\hline Causas Neurológicas & 869 & 869 & 919 & 1.010 & 1.032 & 1.132 & Indisponível & Indisponível \\
\hline População (censo IBGE) & 13.070 .250 & .080 .654 & 4.080 .654 & 14.080 .654 & 14.016 .906 & 14.016.906 & 14.016 .906 & 14.016 .906 \\
\hline
\end{tabular}

HOSPITAIS

№ Total

Capital do estado Interior

$\%$ Brasil $\quad$ CNCDO: Eraldo Salustiano de Moura

\begin{tabular}{c|l}
$547(8,7)$ & Fone: (71) 3356-6776 \\
64 & E-Mail: transplantes.ba@gmail.com \\
483 &
\end{tabular}

()

№ de leitos

$31.000(6,5)$

№ de leitos UTI

$1.658(4,4)$

Hospitais com mais de 80 leitos 95

Hospital de ensino

Escolas médicas

№ serviços de neurocirurgia

Número de CIHDOTTS

Número de OPOs

\section{5

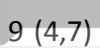 \\ $22(5,4)$
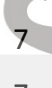 \\ 7 bem como aumentar o número de transplantes. \\ DOAÇÃO DE ÓRGÃOS}

14 milhões de habitantes e vasto território, 417 municípios com número de doação e transplantes crescendo nos últimos anos. Apresenta atividades ligadas a educação e parcerias público privada. Ainda apresenta taxa de notificação baixa, com recusa familiar superior a $60 \%$. Adotou o sistema de OPOs, sendo sete, distribuídas pelo estado, o que tem aumentado a doação de córneas e múltiplos órgãos no interior. Enfrenta dificuldades para organizar equipes de captação e para a realização dos transplantes. Está reestruturando todo o processo para chegar a dez doadores pmp,

Potenciais doadores notificados - pmp

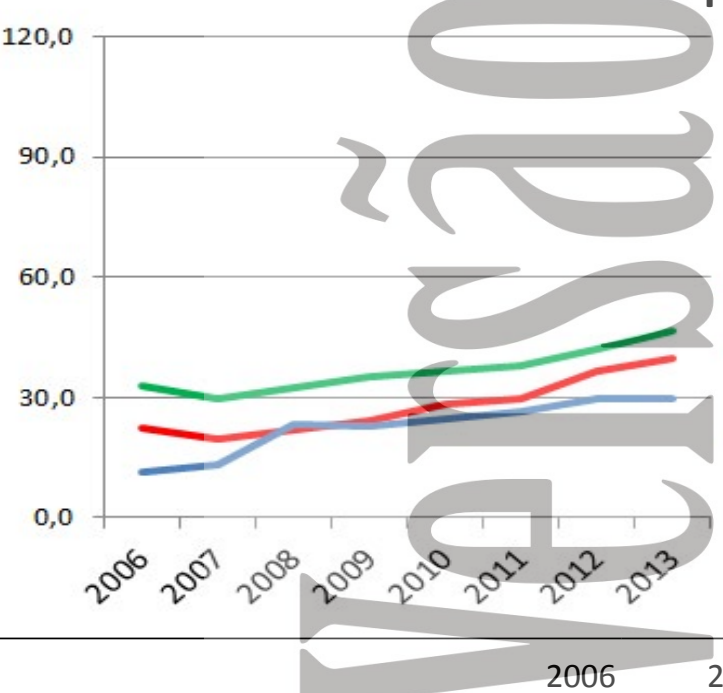

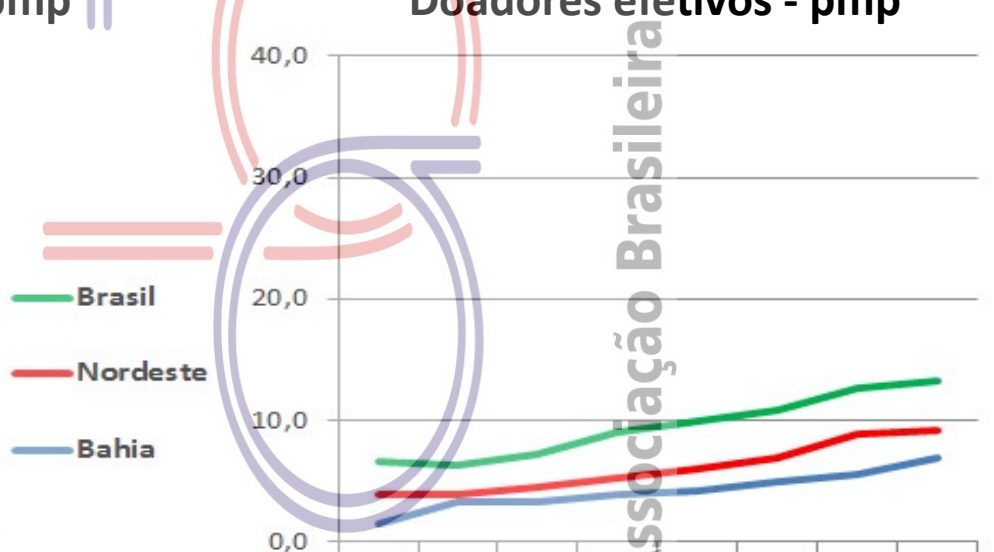

\section{( DC}

Doadores efetivos - pmp

0,0

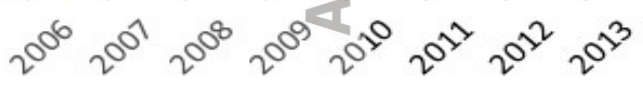

$2007 \quad 2008$

$\begin{array}{rrrrrrrr}18 & 46 & 47 & 53 & 57 & 69 & 77 & 97 \\ 1,4 & 3,3 & 3,3 & 3,8 & 4,1 & 4,9 & 5,5 & 6,9 \\ 149 & 186 & 329 & 320 & 346 & 374 & 414 & 417 \\ 11,4 & 13,2 & 23,4 & 22,7 & 24,7 & 26,7 & 29,5 & 29,7 \\ 49 & 72 & 94 & 70 & 107 & 132 & 174 & 178 \\ \text { onível } & \text { Indisponível } & \text { Indisponível } & \text { Indisponível } & \text { Indisponível } & \text { Indisponível } & 63 & 65 \\ \text { onível } & \text { Indisponível } & 19 & 18 & 12 & 8 & 23 & 9 \\ 51 & 43 & 35 & 17 & 23 & 32 & 35 & 47 \\ 31 & 25 & 134 & 162 & 147 & 133 & 105 & 86\end{array}$




\section{BAHIA}

\section{TRANSPLANTE DE ÓRGÃOS}

\section{RIM com doador falecido - pmp}

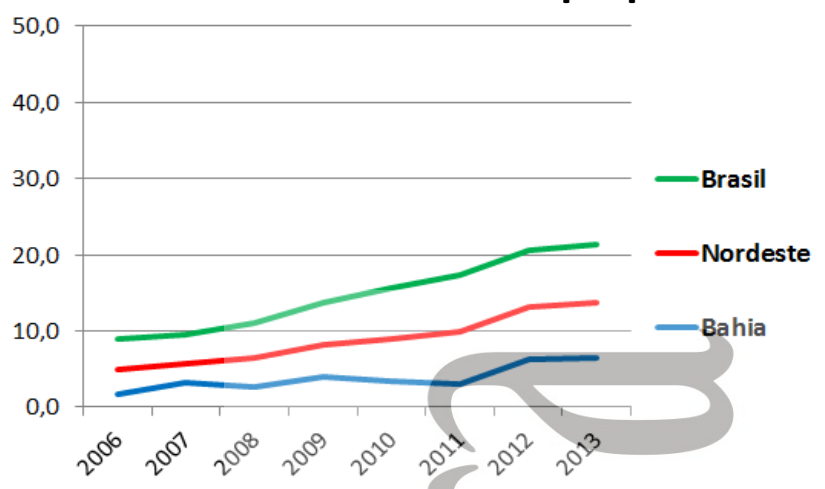

FÍGADO - pmp

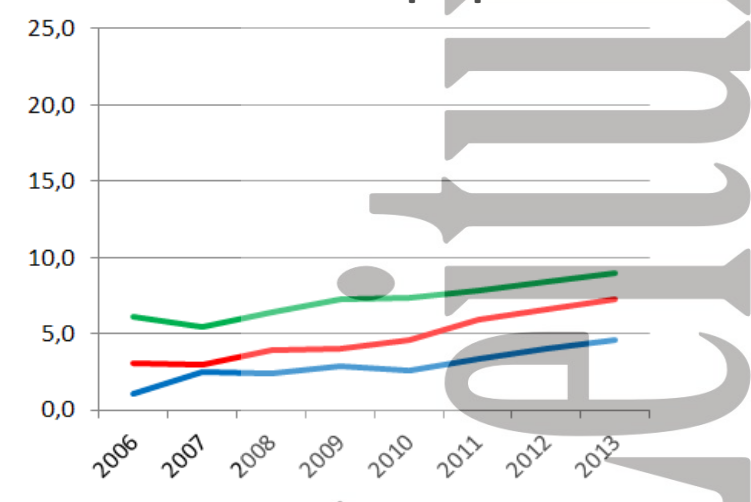

\section{RIM com doador vivo - pmp}

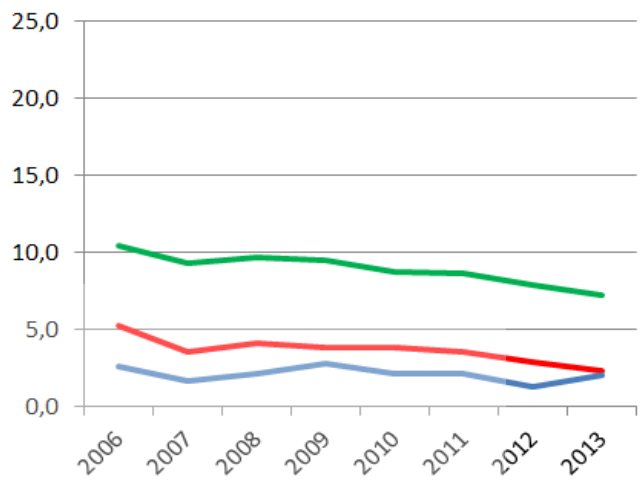

CÓRNEA-pmp

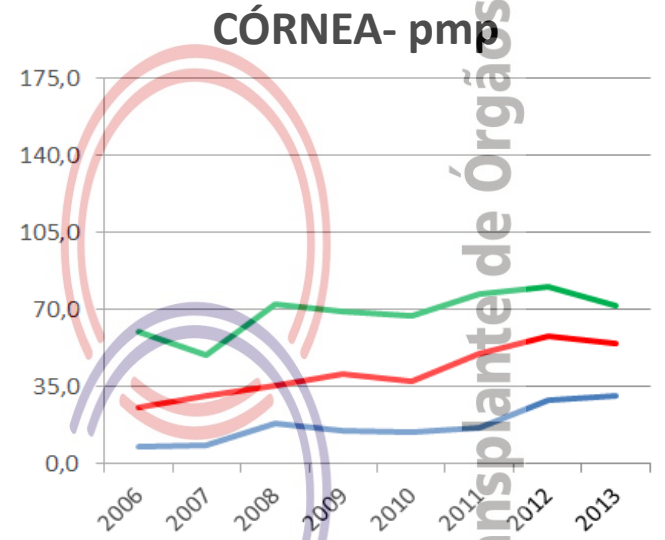

Número de equipes que realizaram 2006 transplantes durante o ano CÓRNEA

RIM

FÍGADO

PÂNCREAS (não realiza)

CORAÇÃO

PULMÃO (não realiza)

\begin{tabular}{l} 
Número absoluto de trans \\
\hline CÓRNEA \\
RIM - total \\
doador vivo \\
doador falecido \\
FÍGADO \\
PÂNCREAS (não realiza) \\
CORAÇÃO \\
PULMÃO (não realiza)
\end{tabular}

Número de transplantes pmp

CÓRNEA

RIM - total

doador vivo

doador falecido

FÍGADO

PÂNCREAS (não realiza)

CORAÇÃO

PULMÃO (não realiza)

Indisponível Indisponível Indisponível Indisponível Indisponível Indisponível Indisponível Indisponível
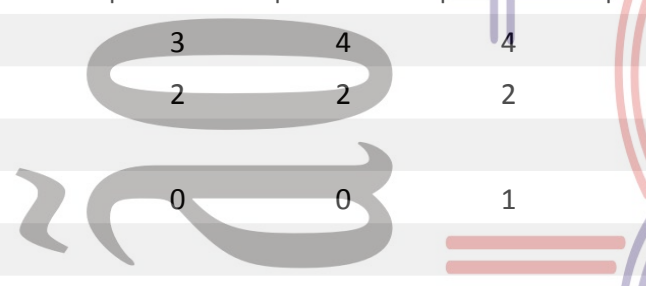

\begin{tabular}{ll}
2006 & 2007 \\
\hline 98 & -119
\end{tabular}

\begin{tabular}{rr}
98 & 119 \\
56 & 70 \\
34 & 24 \\
\hline
\end{tabular}

2008

2009

258

68

30

$\begin{array}{rr}22 & 46 \\ 14 & 35\end{array}$

38

34

2

209
96

40

56

41

\section{0}

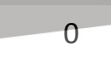

3

0

0

$\begin{array}{ll}40 & 4 \\ 2 & 2\end{array}$

4
2

4

2

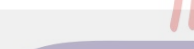

$0 \frac{1}{4} 0$

0

0

$\infty$

\begin{tabular}{cccc}
2011 & 2012 & 2013 \\
\hline 231 & 408 & 428 \\
73 & 105 & 118 \\
29 & 18 & 28 \\
44 & 87 & 90 \\
48 & 56 & 64
\end{tabular}

37

56

64 


\section{CEARÁ}

\section{Potenciais doadores notificados - pmp} 120,0



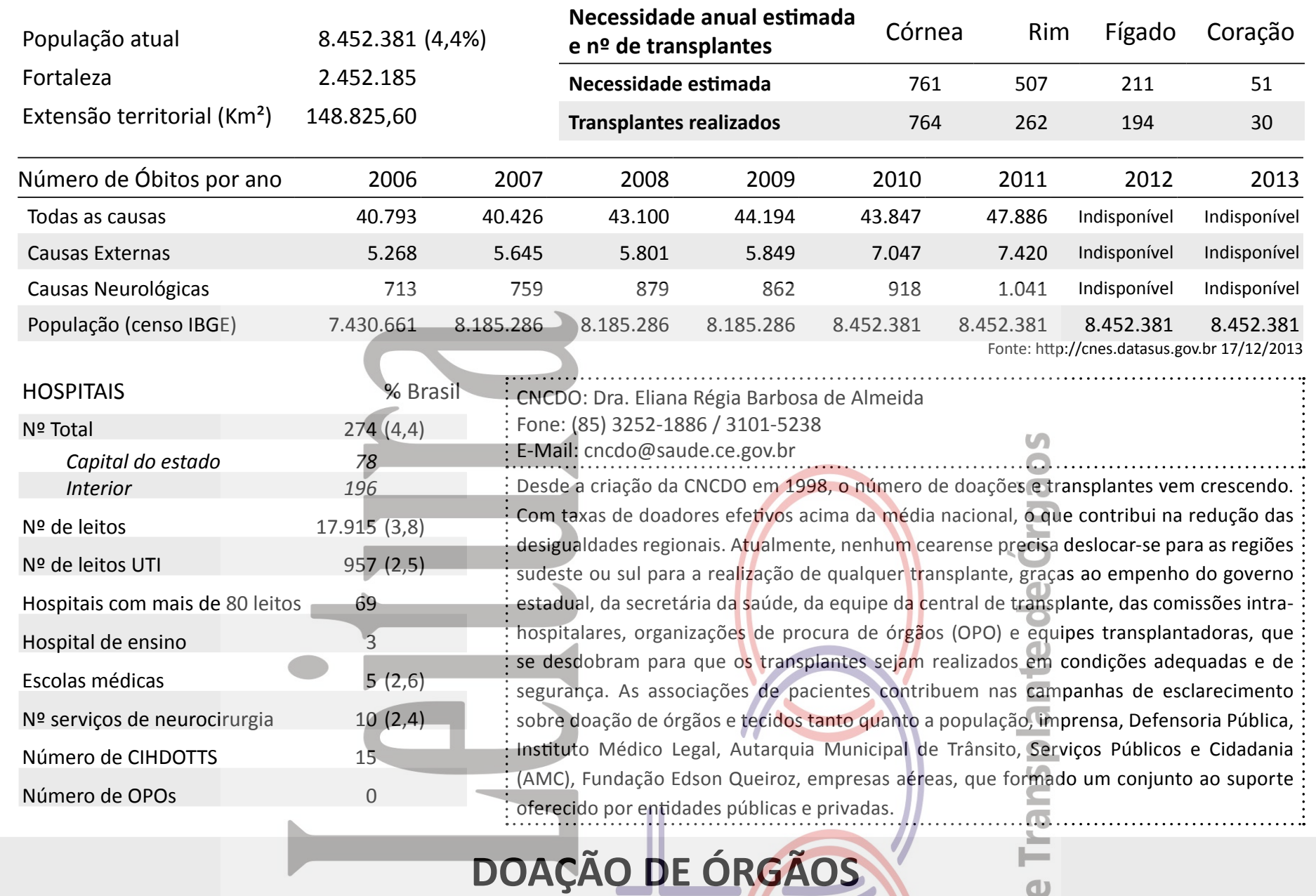




\section{CEARÁ}

\section{TRANSPLANTE DE ÓRGÃOS}

\section{RIM com doador falecido - pmp}
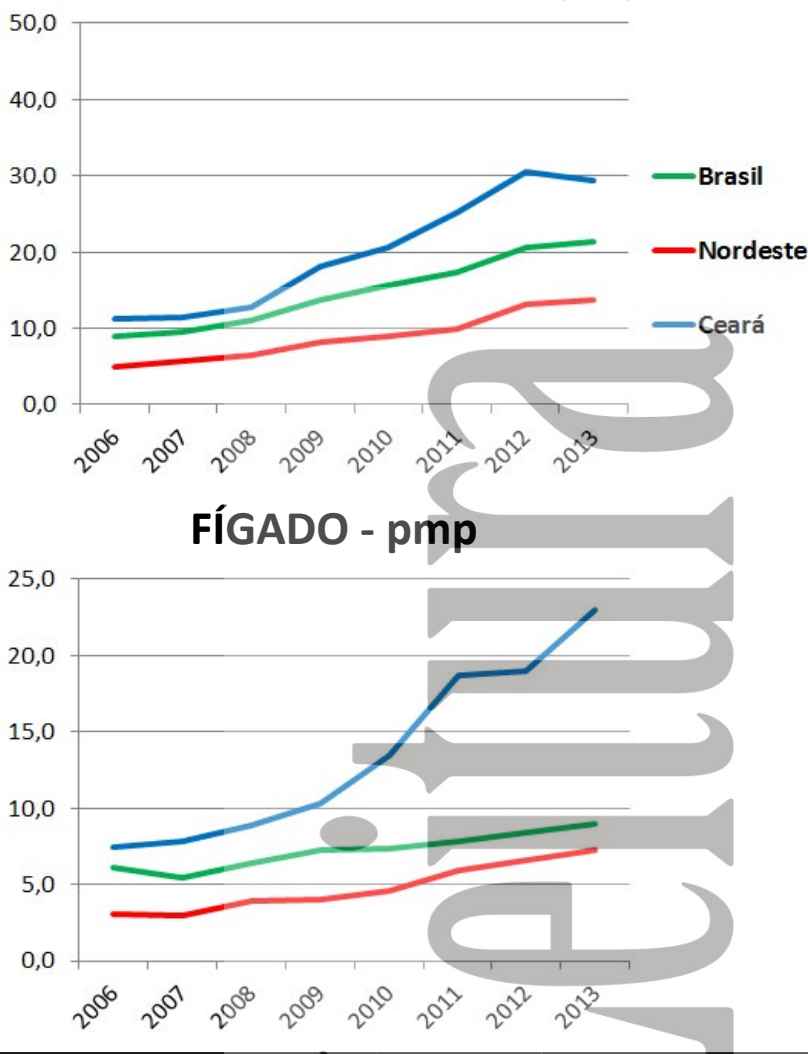

RIM com doador vivo - pmp

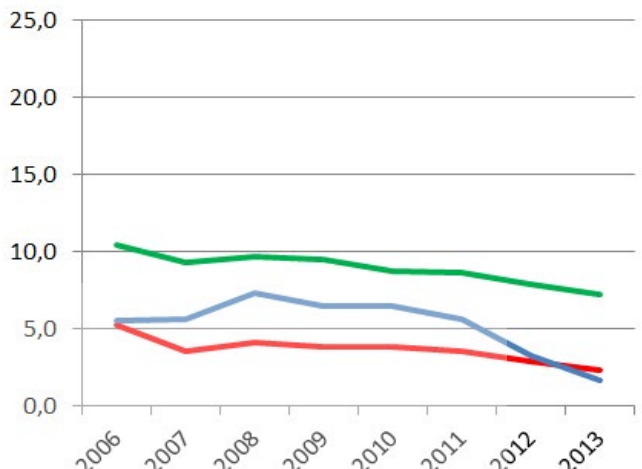

CÓRNEA- pmp

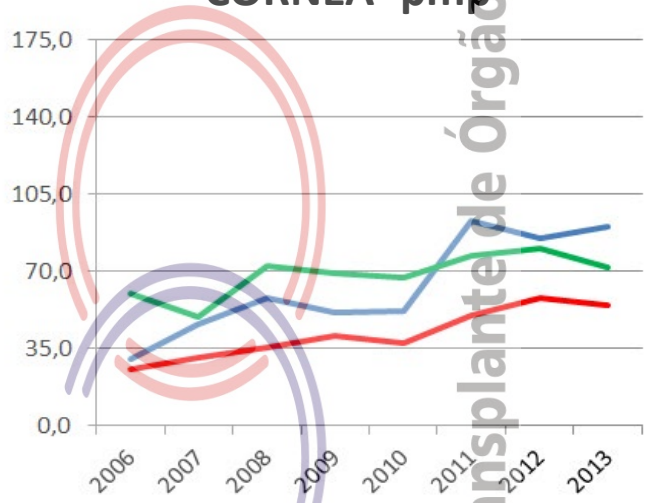

\begin{tabular}{|c|c|c|c|c|c|c|c|c|}
\hline $\begin{array}{l}\text { Número de equipes que realizaram } \\
\text { transplantes durante o ano }\end{array}$ & \multirow[b]{2}{*}{ Indisponível } & \multirow[b]{2}{*}{ Indisponível } & 2008 & 2009 & 2010 & 2011 & 2012 & 2013 \\
\hline CÓRNEA & & & Indisponivel & sponivel & sponível & Indisponível Ind & sponível & Indisponível \\
\hline RIM & 3 & 3 & 4 & 4 & 4 & 30 & 3 & 3 \\
\hline FÍGADO & 1 & 1 & 2 & 3 & 3 & $3=$ & 3 & 3 \\
\hline PÂNCREAS & 0 & 0 & 0 & 1 & 1 & $2=$ & 2 & 2 \\
\hline CORAÇÃO & & & 1 & & & $1 \frac{n}{r}$ & 1 & 1 \\
\hline PULMÃO & 0 & 0 & 0 & 0 & 0 & 1 은 & 1 & 1 \\
\hline Número absoluto de transplantes & 2006 & 2007 & 2008 & 2009 & 2010 & 20119 & 2012 & 2013 \\
\hline CÓRNEA & 224 & 376 & 473 & 420 & 436 & 786 (0) & 718 & 764 \\
\hline RIM - total & 125 & 140 & 164 & 201 & 229 & $260=$ & 285 & 262 \\
\hline doador vivo & 41 & 46 & 60 & 53 & 55 & 47 & 28 & 14 \\
\hline doador falecido & 84 & 94 & 104 & 148 & 174 & 213 ص & 257 & 248 \\
\hline FÍGADO & 56 & 64 & 73 & 84 & 114 & $158<$ & 161 & 194 \\
\hline PÂNCREAS & 0 & 0 & 0 & 1 & 6 & 10 & 12 & 10 \\
\hline CORAÇÃO & 17 & 22 & 31 & 25 & 16 & 25 & 28 & 30 \\
\hline PULMÃO & 0 & 0 & 0 & 0 & 0 & 4 & 4 & 8 \\
\hline Número de transplantes pmp & 2006 & 2007 & 2008 & 2009 & 2010 & 2011 & 2012 & 2013 \\
\hline CÓRNEA & 30,1 & 45,9 & 57,8 & 51,3 & 51,6 & 93,0 & 84,9 & 90,4 \\
\hline RIM - total & 16,8 & 17,1 & 20,0 & 24,6 & 27,1 & 30,8 & 33,7 & 31,0 \\
\hline doador vivo & 5,5 & 5,6 & 7,3 & 6,5 & 6,5 & 5,6 & 3,3 & 1,7 \\
\hline doador falecido & 11,3 & 11,5 & 12,7 & 18,1 & 20,6 & 25,2 & 30,4 & 29,3 \\
\hline FÍGADO & 7,5 & 7,8 & 8,9 & 10,3 & 13,5 & 18,7 & 19,0 & 23,0 \\
\hline PÂNCREAS & 0,0 & 0,0 & 0,0 & 0,1 & 0,7 & 1,2 & 1,4 & 1,2 \\
\hline CORAÇÃO & 2,3 & 2,7 & 3,8 & 3,1 & 1,9 & 3,0 & 3,3 & 3,5 \\
\hline PULMÃO & 0,0 & 0,0 & 0,0 & 0,0 & 0,0 & 0,5 & 0,5 & 0,9 \\
\hline
\end{tabular}




\section{DISTRITO FEDERAL - Brasília}

\begin{tabular}{|c|c|c|c|c|c|c|c|c|c|}
\hline População atual & \multicolumn{2}{|c|}{$2.570 .160(1,3 \%)$} & \multicolumn{3}{|c|}{$\begin{array}{l}\text { Necessidade anual estimada } \\
\text { e no de transplantes }\end{array}$} & Córnea & Rim & Fígado & Coração \\
\hline Brasília & 2.570 .160 & & \multicolumn{3}{|c|}{ Necessidade estimada } & 231 & 154 & 64 & 15 \\
\hline Extensão territorial $\left(\mathrm{Km}^{2}\right)$ & $5.801,94$ & & \multicolumn{3}{|c|}{ Transplantes realizados } & 306 & 128 & 53 & 29 \\
\hline Número de Óbitos por ano & 2006 & 2007 & 2008 & 2009 & & 2010 & 2011 & 2012 & 2013 \\
\hline Todas as causas & 9.513 & 9.866 & 10.284 & 10.459 & & 10.851 & 11.253 & Indisponível & Indisponível \\
\hline Causas Externas & 1.636 & 1.746 & 1.848 & 1.918 & & 1.878 & 1.940 & Indisponível & Indisponível \\
\hline Causas Neurológicas & 239 & 226 & 224 & 253 & & 287 & 310 & Indisponível & Indisponível \\
\hline População (censo IBGE) & $2.051 .146 \quad 2$. & 455.903 & 2.455 .903 & 2.455 .903 & 2.57 & 70.160 & $\begin{array}{l}2.570 .160 \\
\quad \text { Fonte: http }\end{array}$ & $\begin{array}{l}2.570 .160 \\
/ / \text { cnes.datasus.go }\end{array}$ & $\begin{array}{r}2.570 .160 \\
\text { v.br } 17 / 12 / 2013\end{array}$ \\
\hline HOSPITAIS & & CNCD & OO: Dra. Danie & a Ferreira Salo & não & & & & \\
\hline $\begin{array}{l}\text { № Total } \\
\quad \text { Capital do estado }\end{array}$ & $\begin{array}{l}68(1,1) \\
28\end{array}$ & $\begin{array}{l}\text { Fone: } \\
\text { E-Mail }\end{array}$ & $\begin{array}{l}\text { (61) 3315-17 } \\
\text { ail: centraldetr }\end{array}$ & $\begin{array}{l}55 \text { / 3315-167 } \\
\text { nsplantedf@g }\end{array}$ & nail.c & com & ڤ & & \\
\hline Interior & 40 & A cen & ntral está ben & estruturada & do $p$ & onto de & vista de recu & rsos humanos & e estende $\vdots$ \\
\hline № de leitos & $7.907(1,7)$ & sua as & ção na defini & ăo de morte & ncefá & fálica par & a toda a popi & ılação local, c & om ou sem $\vdots$ \\
\hline $\begin{array}{l}\text { № de leitos UTI } \\
\text { Hospitais com mais de } 80 \text { leitos }\end{array}$ & $\begin{array}{l}1.122(3,0) \\
29\end{array}$ & $\begin{array}{l}\text { no nú } \\
\text { doado }\end{array}$ & $\begin{array}{l}\text { úmero de doa } \\
\text { lores notificad }\end{array}$ & lores nos últir & $0 \mathrm{pm}$ & lois anos, & com elevada & $\begin{array}{l}\text { proporção de } \\
\text { lacionado à tra }\end{array}$ & $\begin{array}{l}\text { potenciais } \\
\text { ansferência }\end{array}$ \\
\hline Hospital de ensino & 3 & de pa & acientes dos & ospitais das & idade & es do en & torno. É ouúr & ico estado co & m número \\
\hline Escolas médicas & $5(2,6)$ & cresce & sente de trans & lantes cardía & & & $23 \%$ dos dc & adores efetiv & os também \\
\hline № serviços de neurocirurgia & $5(1,2)$ & $\begin{array}{l}\text { como } \\
\text { estadc }\end{array}$ & $\begin{array}{l}\text { o doadores } \\
\text { dos (apoio FAE }\end{array}$ & $\begin{array}{l}\text { coração, di } \\
\text { o que corres }\end{array}$ & pond & $\begin{array}{l}\text { ibilizando } \\
\text { deu a 31\% }\end{array}$ & $\begin{array}{l}\text { equipes par } \\
\text { dos transpla }\end{array}$ & $\begin{array}{l}\text { a captações } \\
\text { ntes cardíacos }\end{array}$ & $\begin{array}{l}\text { em outros: } \\
\text { s realizados }\end{array}$ \\
\hline Número de CIHDOTTS & & em 20 & 013, a maiori & das vezes no & & & as Geraise 4 & ma vez no est & tado do Rio \\
\hline Numero de OPOs & 0 & Grand & de do Sul & & & & $\ldots$ & & \\
\hline
\end{tabular}

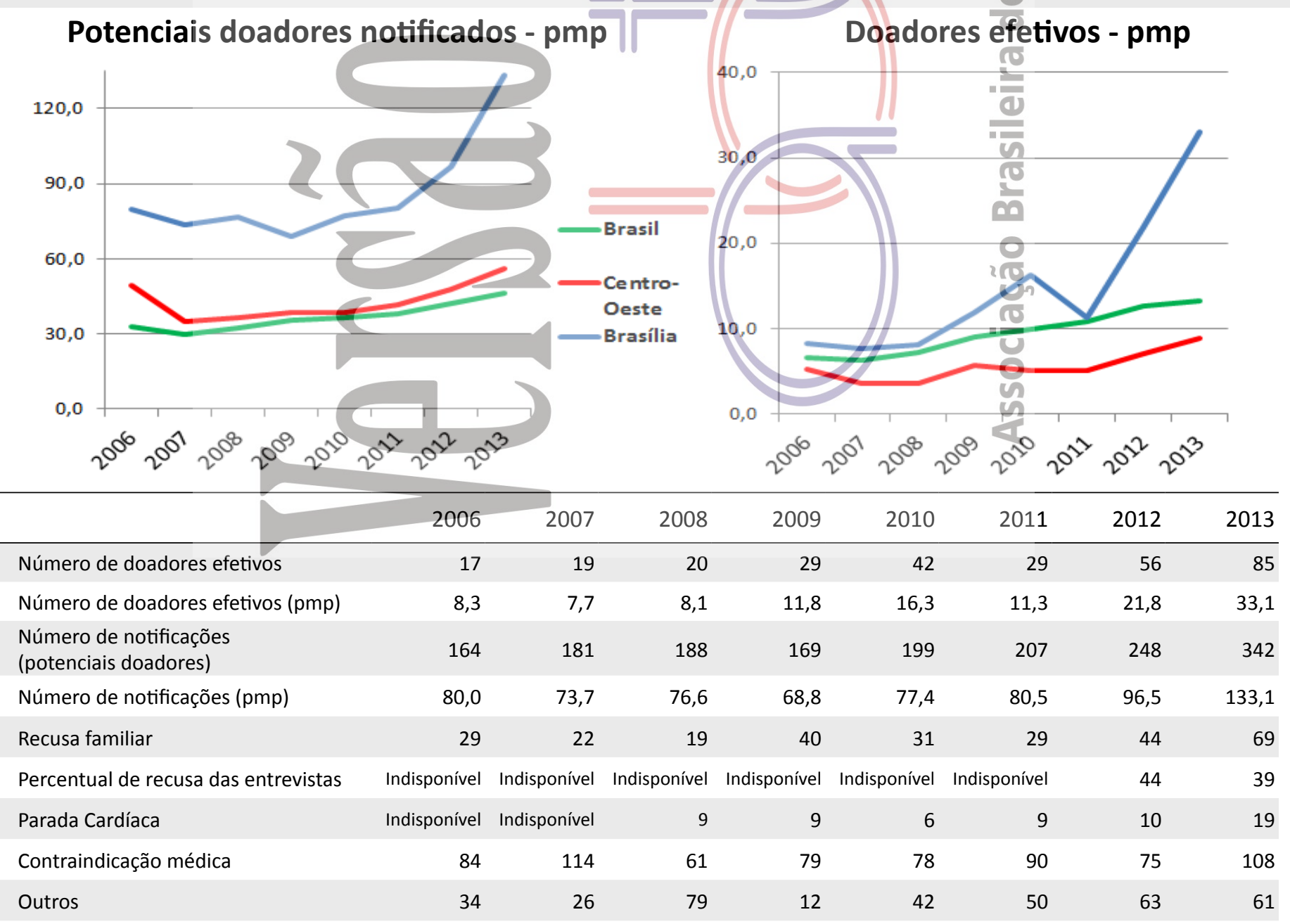




\section{DISTRITO FEDERAL - Brasília}

\section{TRANSPLANTE DE ÓRGÃOS}

\section{RIM com doador falecido - pmp}

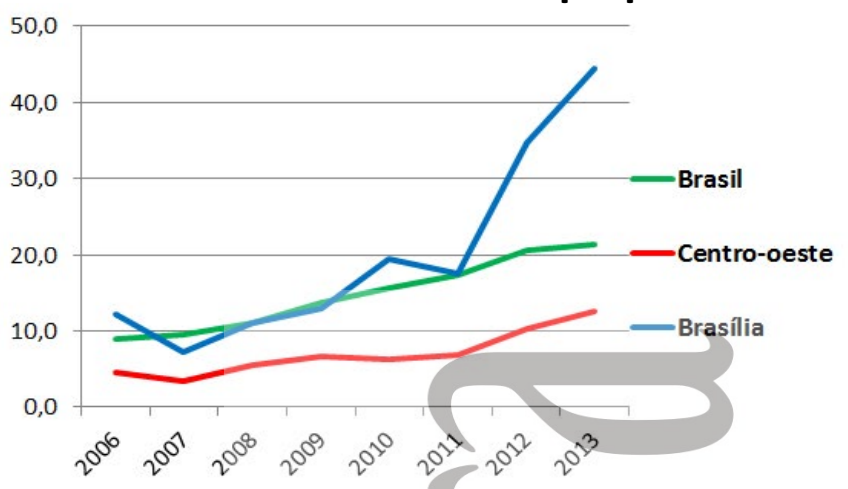

FÍGADO - pmp

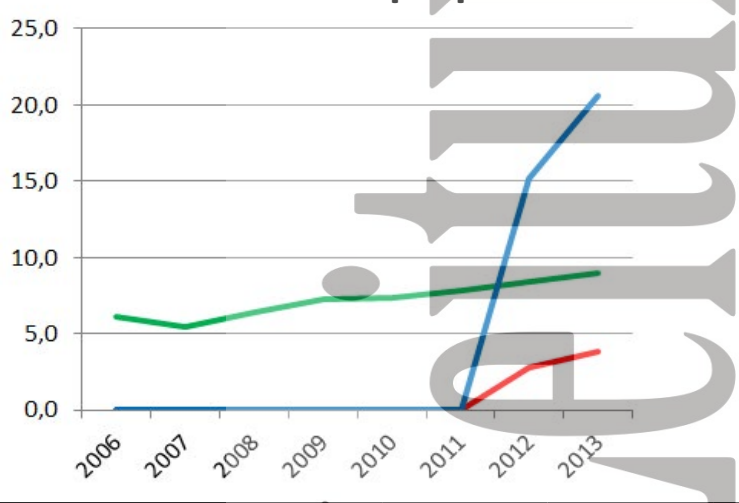

RIM com doador vivo - pmp

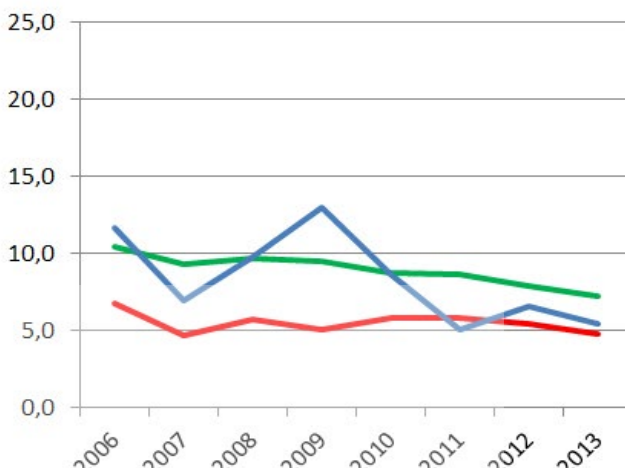
CÓRNEA- pmp

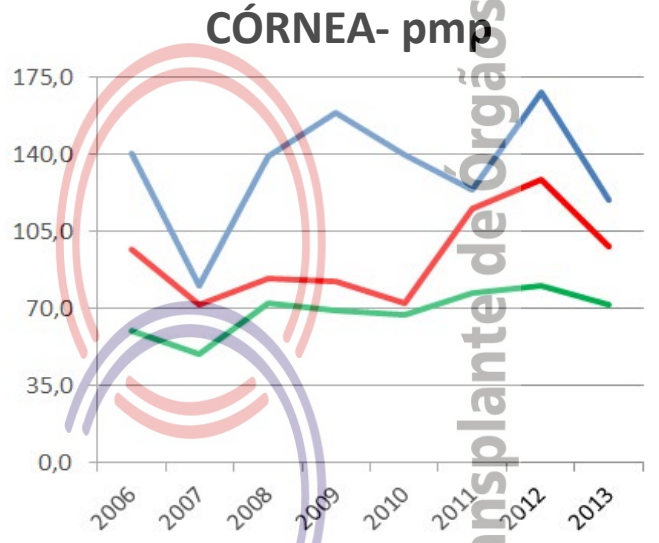

Número de equipes que realizaram $\quad 2006 \quad 2007$ transplantes durante o ano CÓRNEA

RIM FÍGADO

PÂNCREAS (não realiza) CORAÇÃO PULMÃO $\begin{array}{lll}3 & 3 & 3\end{array}$ $2009 \quad 2010$ $2011-2012$

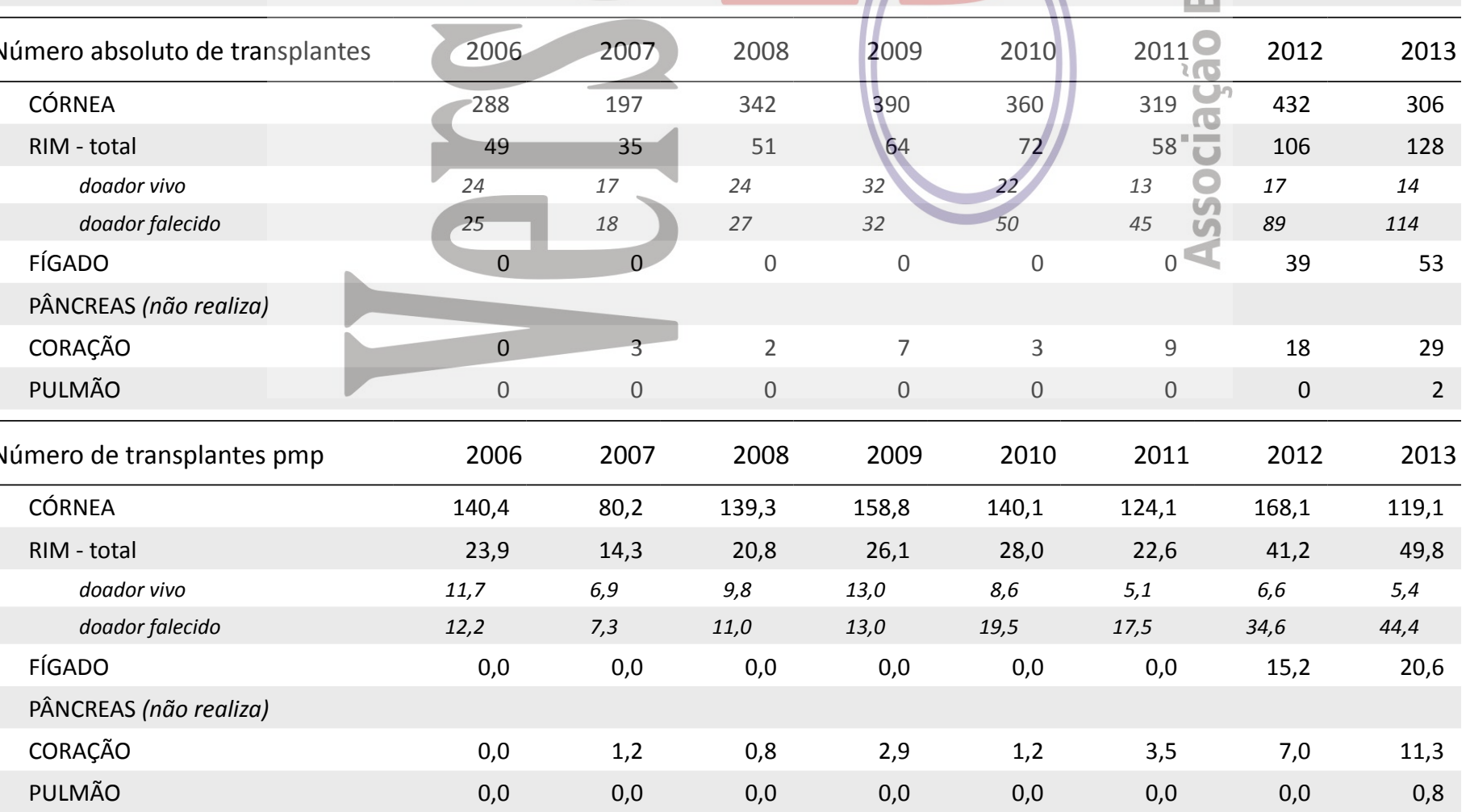




\section{ESPÍRITO SANTO}

$\begin{array}{ll}\text { População atual } & 3.514 .952(1,8 \%) \\ \text { Vitória } & 327.801\end{array}$

Extensão territorial $\left(\mathrm{Km}^{2}\right) \quad 46.077,52$

\begin{tabular}{|c|c|c|c|c|c|c|}
\hline \multirow[b]{2}{*}{$3.514 .952(1,8 \%)$} & \\
\hline & $\begin{array}{l}\text { Necessidad } \\
\text { e no de tran }\end{array}$ & $\begin{array}{l}\text { anual estimada } \\
\text { plantes }\end{array}$ & Córnea & $\operatorname{Rim}$ & Fígado & Coração \\
\hline 327.801 & Necessidade & stimada & 316 & 211 & 88 & 21 \\
\hline $46.077,52$ & Transplantes & ealizados & 213 & 100 & 24 & 3 \\
\hline 2007 & 2008 & 2009 & 2010 & 2011 & 2012 & 2013 \\
\hline 19.665 & 20.447 & 20.396 & 21.205 & 21.403 & Indisponível & Indisponível \\
\hline 3.881 & 3.984 & 3.930 & 3.944 & 3.804 & Indisponível & Indisponível \\
\hline 402 & 503 & 526 & 546 & 647 & Indisponível & Indisponível \\
\hline 3.351 .669 & 3.351 .669 & 3.351 .669 & 14.952 & $\begin{array}{l}3.514 .952 \\
\text { Fonte: http:/ }\end{array}$ & $\begin{array}{c}3.514 .952 \\
\text { //cnes.datasus.g }\end{array}$ & $\begin{array}{r}3.514 .952 \\
\text { br } 17 / 12 / 2013\end{array}$ \\
\hline
\end{tabular}

HOSPITAIS

№ Total

Capital do estado

Interior

№ de leitos

№ de leitos UTI

Hospitais com mais de 80 leitos

Hospital de ensino

Escolas médicas

№ serviços de neurocirurgia

Número de CIHDOTTS

Número de OPOs

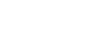

$\begin{array}{cl}\text { \% Brasil } & \ldots \ldots \ldots \ldots \ldots \ldots \ldots \ldots \\ 114(1,8) & \text { CNCDO: Rosemery Gueis Nunes } \\ 21 & \text { Fone: }(27) \text { 3235-1028 } \\ 93 & \text { E-Mail: cncdo@saude.es.gov.br } \\ & \vdots\end{array}$

$8.890(1,9) \quad \vdots$ Tem programa de doação de órgãos e de transplantes já consolidado e com equipes

$813(2,1) \quad \vdots$ alinhadas. Conta com apoio do governo local e tem maior facilidade com a doação no 37 interior, por contar com malha viária adequada e municípios, cuja maior distância da $\begin{array}{ll}0 & \\ 5(2,6) & \text { capital não ultrapassa } 350 \mathrm{~km} \text {. Está em processo para instalação de OPOs regionais e o } \\ 10(2,4) & \text { maior obstáculo está na subnotificação de potenciais doadores de morte encefálica. } \mathrm{O}\end{array}$

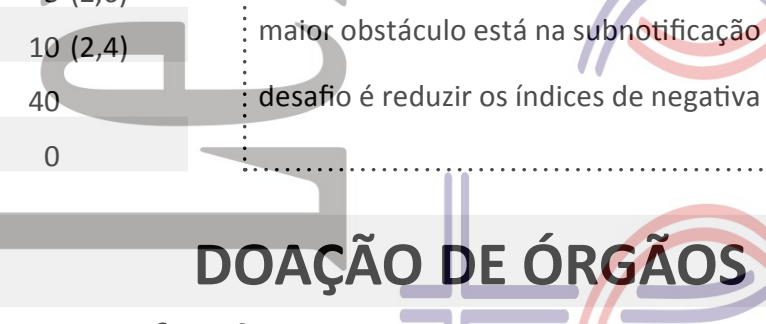

Potenciais doadores notificados - pmp

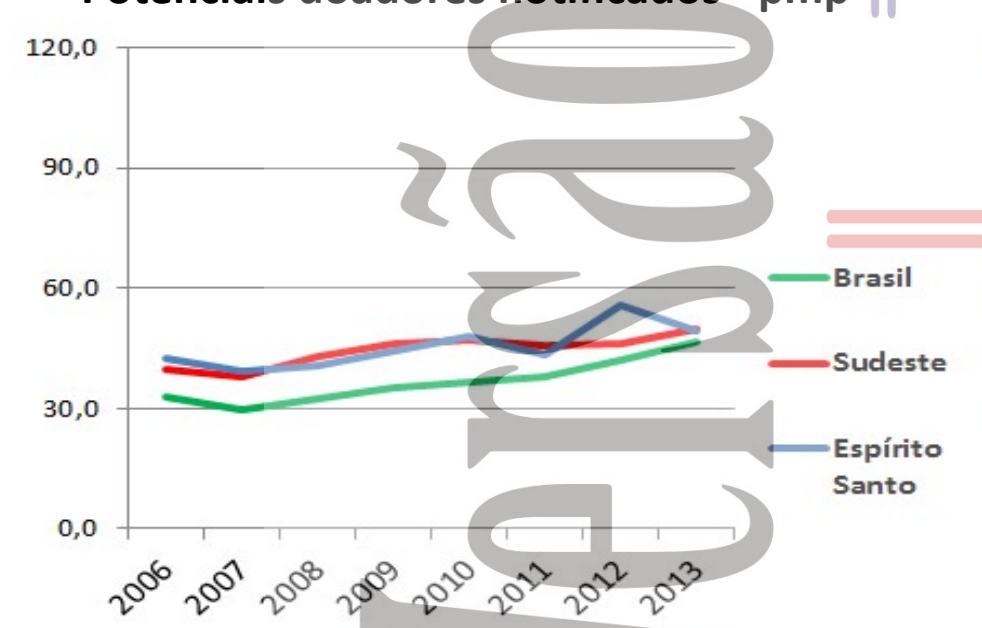

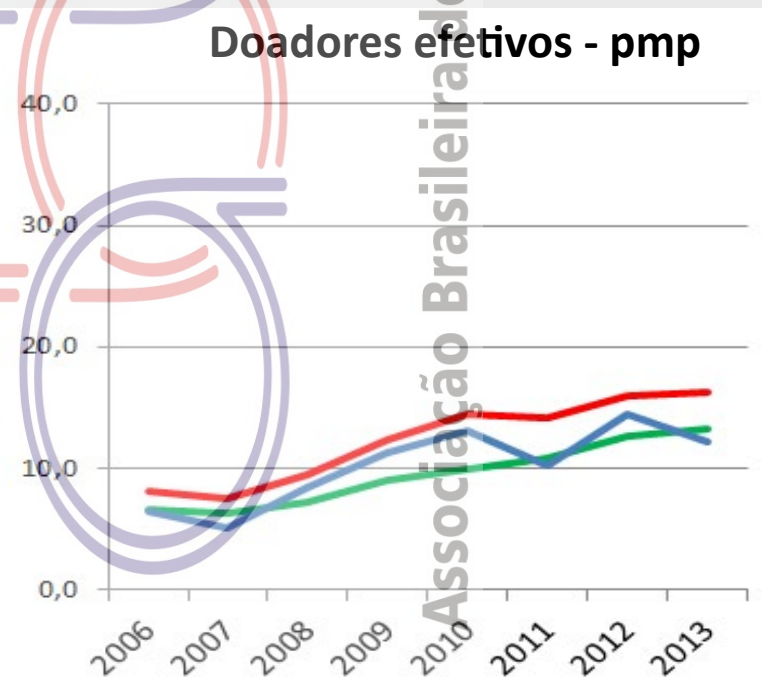

\begin{tabular}{|lrrrrrrrr}
\hline & 2006 & 2007 & 2008 & 2009 & 2010 & 2011 & 2012 & 2013 \\
\hline Número de doadores efetivos & 20 & 17 & 28 & 38 & 46 & 36 & 51 & 43 \\
\hline Número de doadores efetivos (pmp) & 6,5 & 5,1 & 8,4 & 11,3 & 13,1 & 10,2 & 14,5 & 12,2 \\
\hline $\begin{array}{l}\text { Número de notificações } \\
\text { (potenciais doadores) }\end{array}$ & 132 & 132 & 137 & 149 & 169 & 153 & 196 & 174 \\
\hline Número de notificações (pmp) & 42,6 & 39,4 & 40,9 & 44,5 & 48,1 & 43,5 & 55,8 & 49,5 \\
Recusa familiar & 54 & 61 & 41 & 44 & 41 & 47 & 41 & 49 \\
\hline Percentual de recusa das entrevistas & Indisponível & Indisponível & Indisponível & Indisponível Indisponível & Indisponível & 40 & 59 \\
\hline Parada Cardíaca & Indisponível & Indisponível & 1 & 3 & 23 & 14 & 3 & 0 \\
\hline Contraindicação médica & 53 & 46 & 63 & 59 & 41 & 20 & 16 & 23 \\
\hline Outros & 5 & 8 & 4 & 5 & 18 & 36 & 85 & 59
\end{tabular}




\section{ESPÍRITO SANTO}

\section{TRANSPLANTE DE ÓRGÃOS}

\section{RIM com doador falecido - pmp}
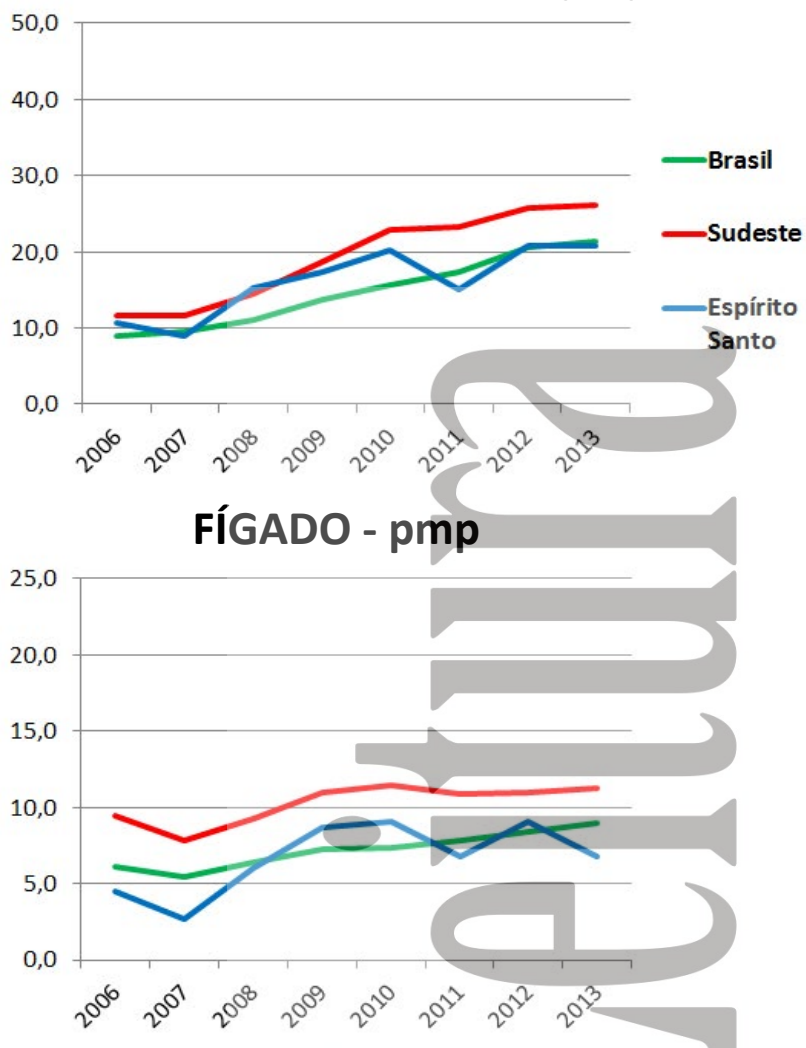

RIM com doador vivo - pmp

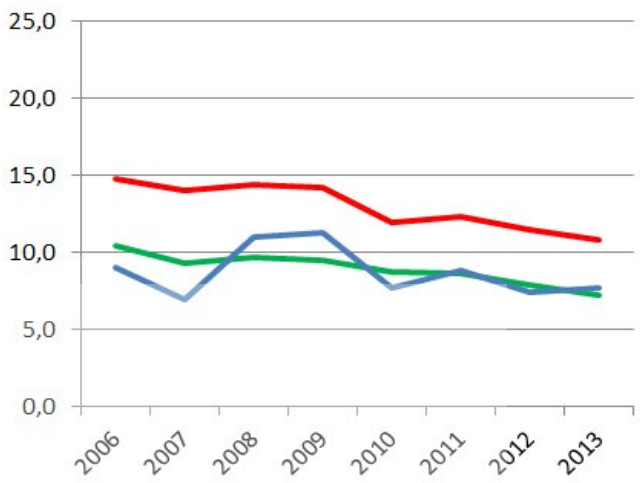

CÓRNEA- pmp

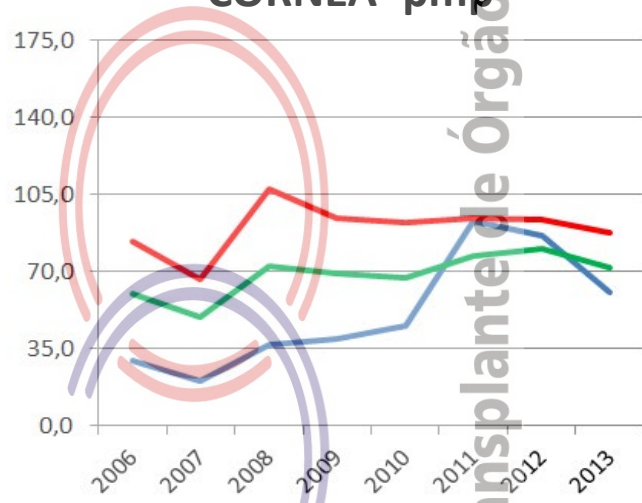

\begin{tabular}{|c|c|c|c|c|c|c|c|c|}
\hline $\begin{array}{l}\text { Número de equipes que realizaram } \\
\text { transplantes durante o ano }\end{array}$ & \multirow[b]{2}{*}{ Indisponível } & \multicolumn{2}{|r|}{2008} & \multicolumn{2}{|c|}{$2009 \quad 2010$} & 2011 & 2012 & 2013 \\
\hline CÓRNEA & & Indisponível & \multicolumn{3}{|c|}{ Indisponível Indisponivel Indisponível } & \multicolumn{2}{|c|}{ Indisponível-Indisponível } & Indisponível \\
\hline RIM & 6 & 4 & 4 & 5 & 5 & 40 & 3 & 3 \\
\hline FÍGADO & 1 & 1 & 1 & 2 & 2 & $2=$ & 1 & 1 \\
\hline PÂNCREAS & 1 & 0 & 0 & 0 & 0 & 0 & 0 & 0 \\
\hline CORAÇÃO & & & 1 & & & $1 \frac{1}{10}$ & 1 & 1 \\
\hline PULMÃO (não realiza) & & & 5 & 1 & & 은 & & \\
\hline Número absoluto de transplantes & 2006 & 2007 & 2008 & 2009 & 2010 & 20119 & 2012 & 2013 \\
\hline CÓRNEA & 91 & 67 & 122 & 131 & 159 & 326 (ด) & 304 & 213 \\
\hline RIM - total & 61 & 53 & 88 & 96 & 98 & $84=$ & 99 & 100 \\
\hline doador vivo & 28 & 23 & 37 & 38 & 27 & 310 & 26 & 27 \\
\hline doador falecido & 33 & 30 & 51 & 58 & 71 & 53 ๘ & 73 & 73 \\
\hline FÍGADO & 14 & 9 & 20 & 29 & 32 & $24<$ & 32 & 24 \\
\hline PÂNCREAS & 4 & 0 & 0 & 0 & 0 & 0 & 0 & 0 \\
\hline CORAÇÃO & 0 & 0 & 4 & 1 & 8 & 3 & 7 & 3 \\
\hline \multicolumn{9}{|l|}{ PULMÃO (não realiza) } \\
\hline Número de transplantes pmp & 2006 & 2007 & 2008 & 2009 & 2010 & 2011 & 2012 & 2013 \\
\hline CÓRNEA & 29,4 & 20,0 & 36,4 & 39,1 & 45,2 & 92,7 & 86,5 & 60,6 \\
\hline RIM - total & 19,7 & 15,8 & 26,3 & 28,6 & 27,9 & 23,9 & 28,2 & 28,4 \\
\hline doador vivo & 9,0 & 6,9 & 11,0 & 11,3 & 7,7 & 8,8 & 7,4 & 7,7 \\
\hline doador falecido & 10,7 & 9,0 & 15,2 & 17,3 & 20,2 & 15,1 & 20,8 & 20,8 \\
\hline FÍGADO & 4,5 & 2,7 & 6,0 & 8,7 & 9,1 & 6,8 & 9,1 & 6,8 \\
\hline PÂNCREAS & 1,3 & 0,0 & 0,0 & 0,0 & 0,0 & 0,0 & 0,0 & 0,0 \\
\hline CORAÇÃO & 0,0 & 0,0 & 1,2 & 0,3 & 2,3 & 0,9 & 2,0 & 0,9 \\
\hline
\end{tabular}

PULMÃO (não realiza) 


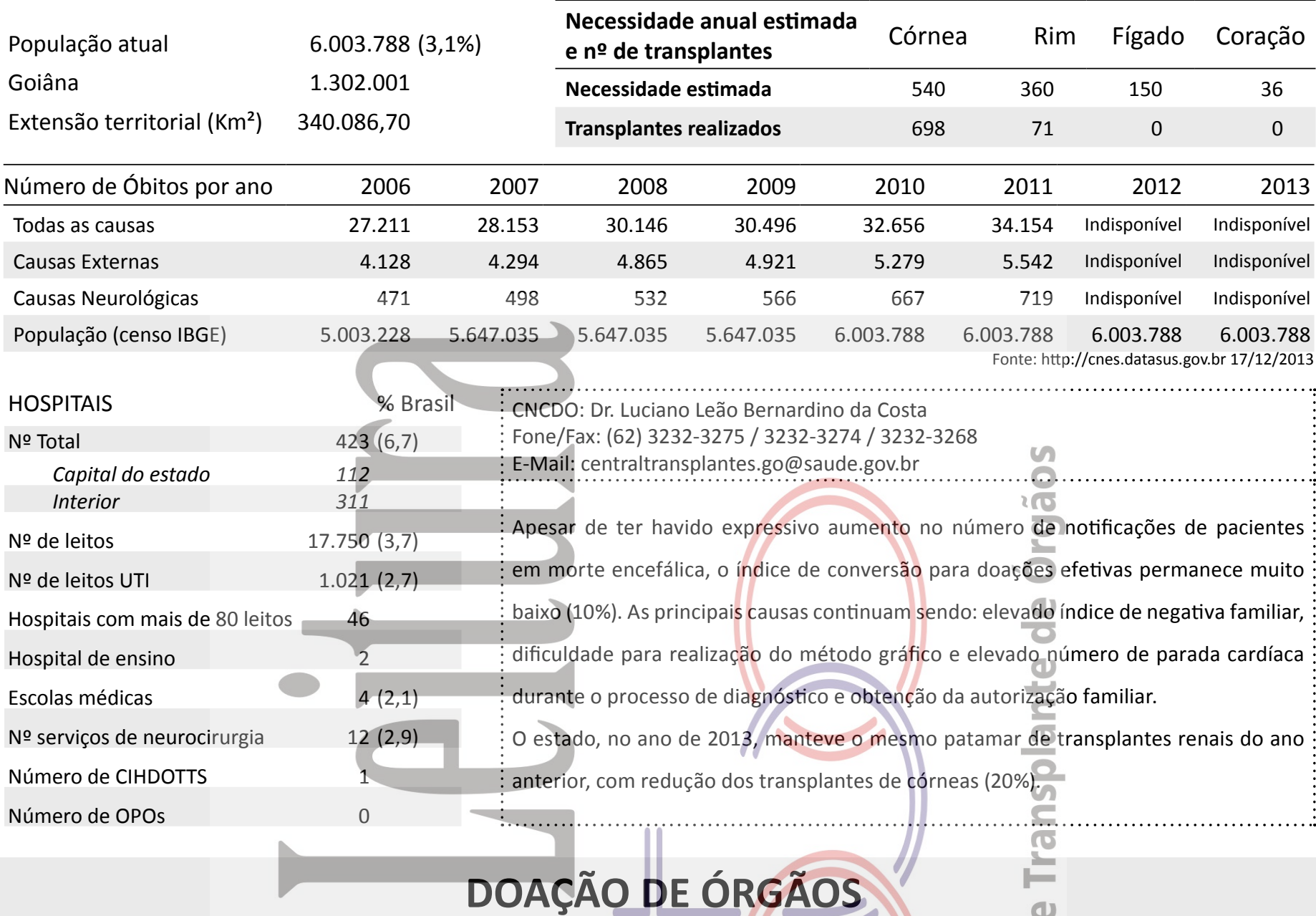
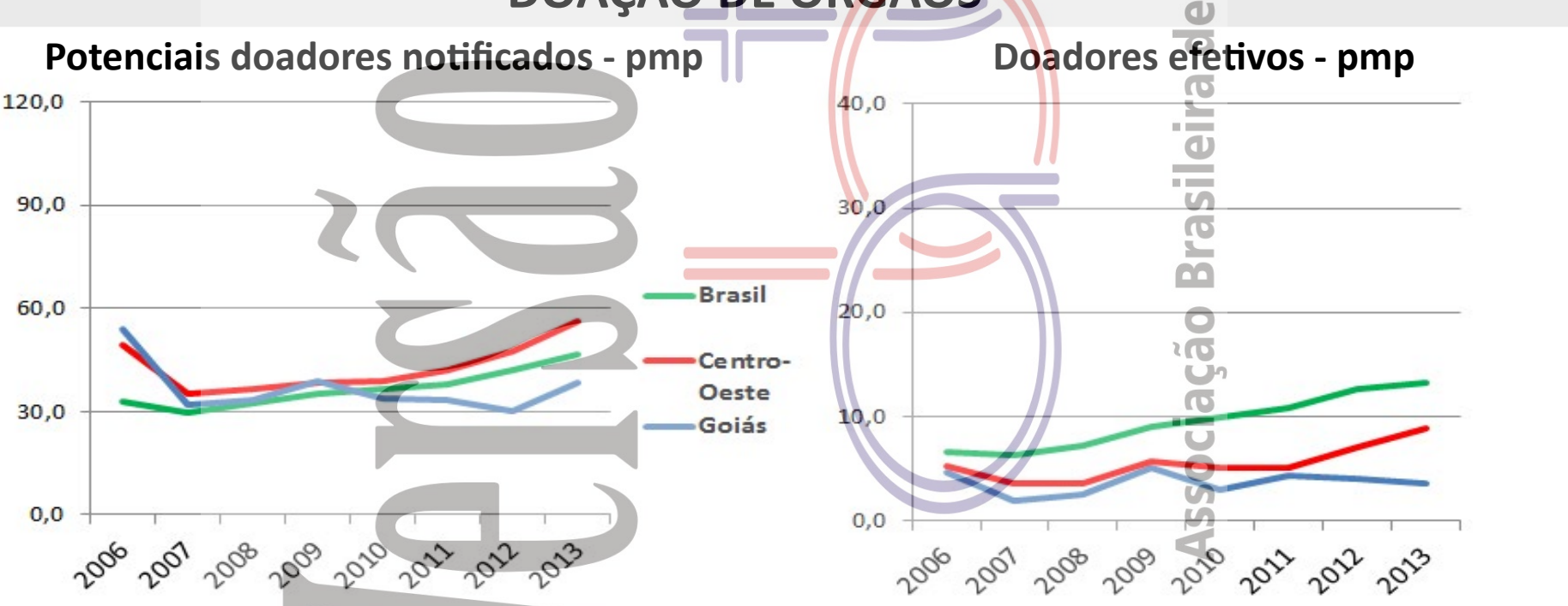

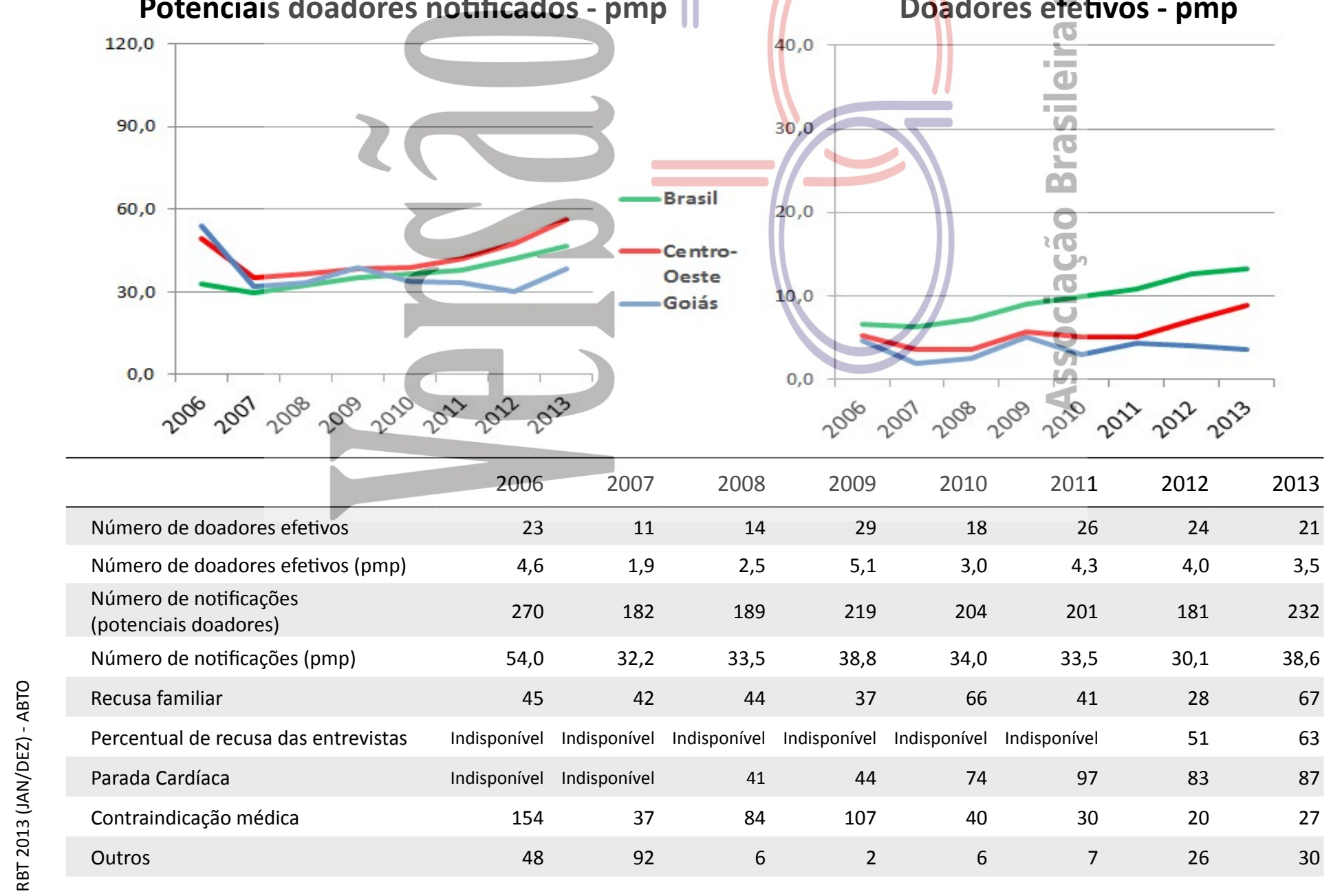




\section{GOIÁS}

\section{TRANSPLANTE DE ÓRGÃOS}

\section{RIM com doador falecido - pmp}

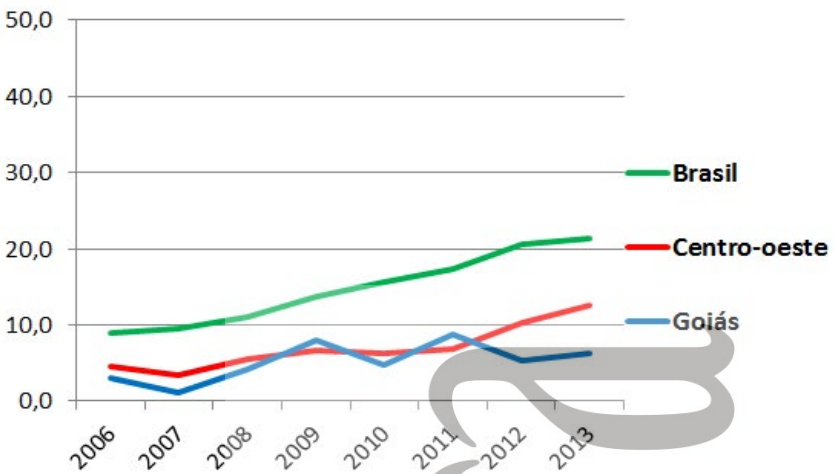

FíGADO - pmp (não realiza)

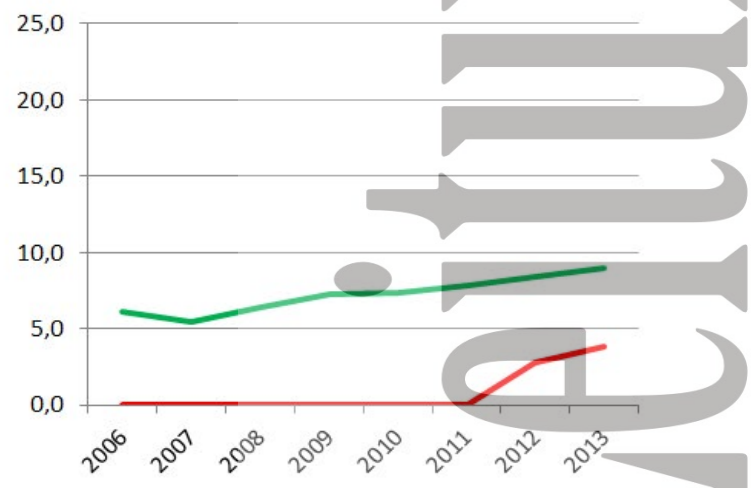

RIM com doador vivo - pmp

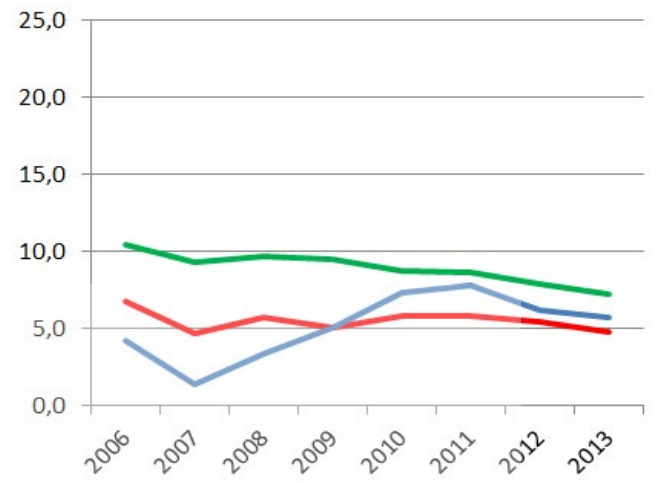

CÓRNEA- pmp

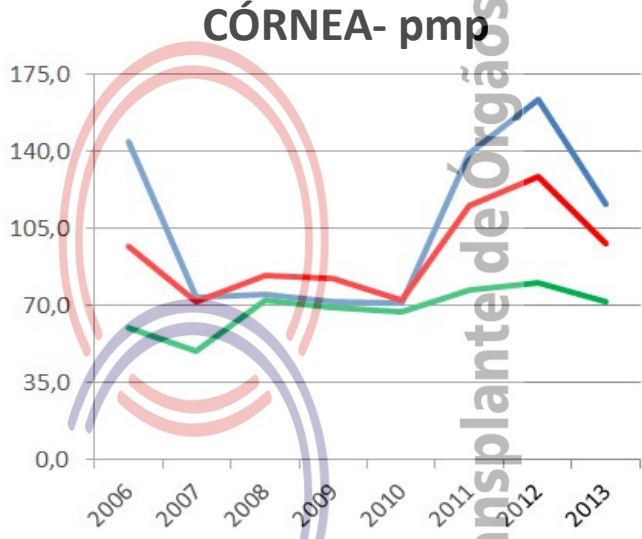

Número de equipes que realizaram $2006 \quad 2007$ transplantes durante o ano $2006 \quad 2007$

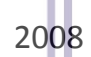
$20092010 \quad 2011-2012$ 2013 CÓRNEA

RIM

FÍGADO (não realiza)

PÂNCREAS

CORAÇÃO

PULMÃO (não realiza)

Número absoluto de transplantes

CÓRNEA

RIM - total

doador vivo

doador falecido

Indisponível Indisponível Indisponível Indisponivel Indisponível Indisponível- Indisponível Indisponível

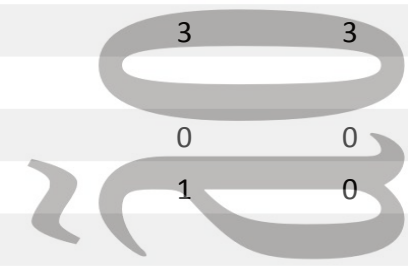

FÍGADO (não realiza)

PÂNCREAS

CORAÇÃO

\begin{tabular}{lll}
$\frac{2006}{723}-\frac{2007}{418}$ & 2008 \\
\hline & 426
\end{tabular}

$36 \quad 15$

$\begin{array}{lll}21 & 8 & 19\end{array}$

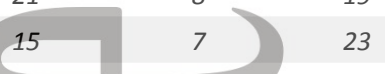

PULMÃO (não realiza)

\begin{tabular}{ccccccccc}
\hline Número de transplantes pmp & 2006 & 2007 & 2008 & 2009 & 2010 & 2011 & 2012 & 2013 \\
\hline CÓRNEA & 144,5 & 74,0 & 75,4 & 71,5 & 71,3 & 139,2 & 163,6 & 116,3 \\
RIM - total & 7,2 & 2,7 & 7,4 & 13,1 & 12,2 & 16,5 & 11,5 & 11,8 \\
\hline doador vivo & 4,2 & 1,4 & 3,4 & 5,1 & 7,3 & 7,8 & 6,2 & 5,7 \\
\hline doador falecido & 3,0 & 1,2 & 4,1 & 8,0 & 4,8 & 8,7 & 5,3 & 6,2
\end{tabular}

FÍGADO (não realiza)

PÂNCREAS

0,0

0,0

0,2

0,0

0,0

0,0

1,0

CORAÇÃO

$0,4 \quad 0,0$

0,0

0,4

0,2

0,0

0,0

0,0

PULMÃo (não realiza) 


\section{MARANHÃO}

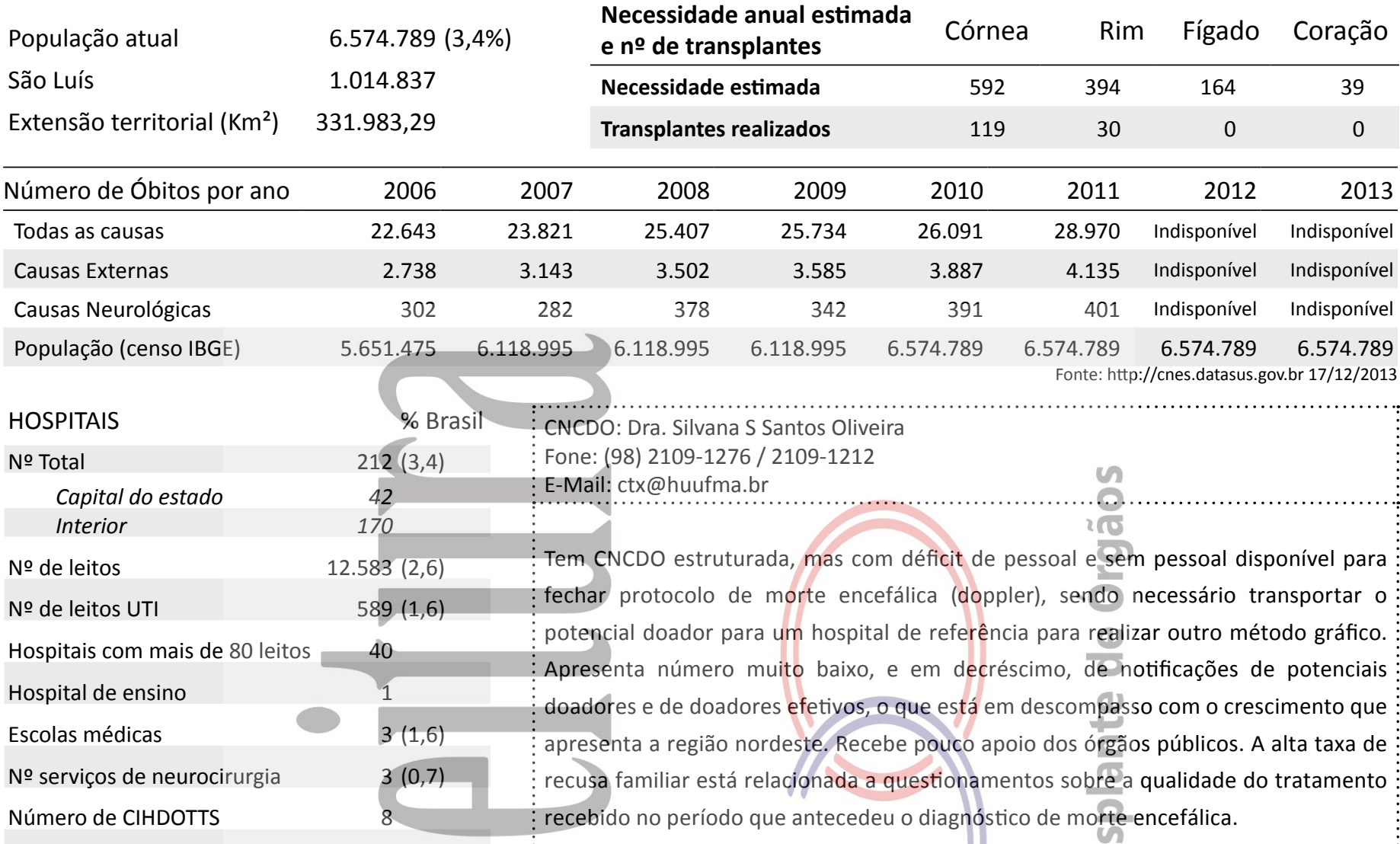

Número de OPOs

\section{DOAÇÃO DE ÓRGÃOS}

\section{Potenciais doadores notificados - pmp}

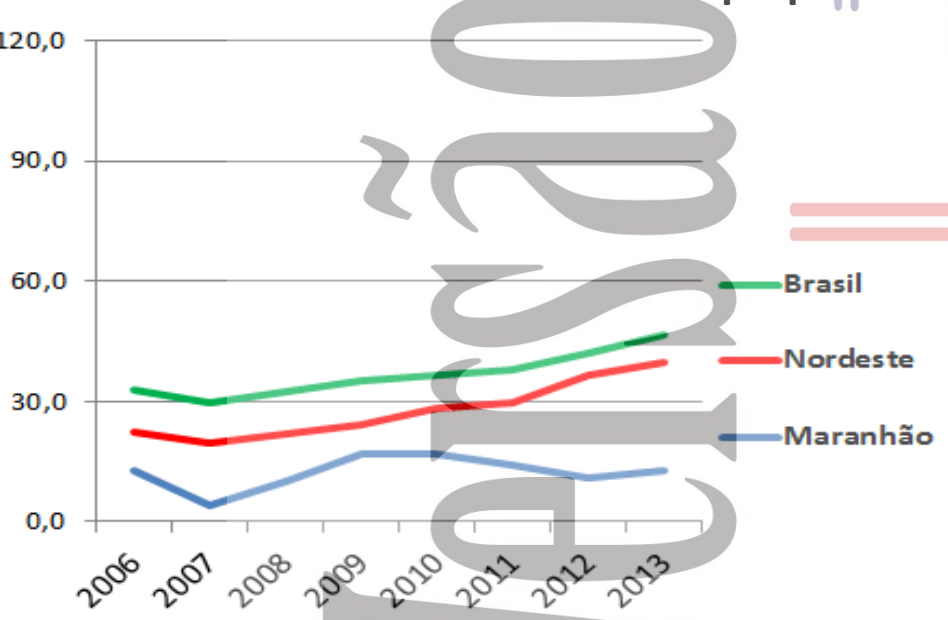

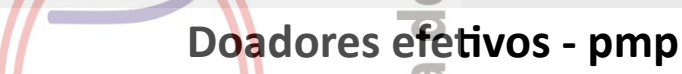

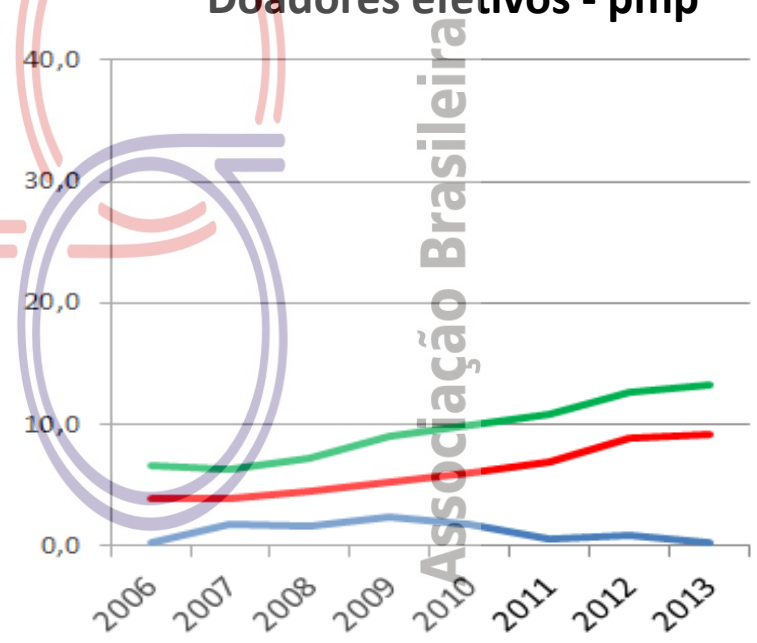

\begin{tabular}{lrrrrrrrr}
\hline & 2006 & 2007 & 2008 & 2009 & 2010 & 2011 & 2012 & 2013 \\
\hline Número de doadores efetivos & 1 & 11 & 10 & 14 & 11 & 4 & 6 & 2 \\
\hline Número de doadores efetivos (pmp) & 0,2 & 1,8 & 1,6 & 2,3 & 1,7 & 0,6 & 0,9 & 0,3 \\
$\begin{array}{l}\text { Número de notificações } \\
\text { (potenciais doadores) }\end{array}$ & 71 & 26 & 62 & 102 & 111 & 92 & 72 & 85 \\
Número de notificações (pmp) & 12,6 & 4,2 & 10,1 & 16,7 & 16,9 & 14,0 & 11,0 & 12,9 \\
Recusa familiar & 30 & 5 & 34 & 33 & 37 & 33 & 25 & 15 \\
Percentual de recusa das entrevistas & Indisponível & Indisponível & Indisponível & Indisponível & Indisponível & Indisponível & 81 & 88 \\
Parada Cardíaca & Indisponível & Indisponível & 9 & 15 & 23 & 2 & 11 & 0 \\
Contraindicação médica & 18 & 5 & 0 & 17 & 9 & 13 & 11 & 25 \\
Outros & 22 & 5 & 9 & 23 & 31 & 40 & 19 & 43
\end{tabular}




\section{MARANHÃO}

\section{TRANSPLANTE DE ÓRGÃOS}

RIM com doador falecido - pmp

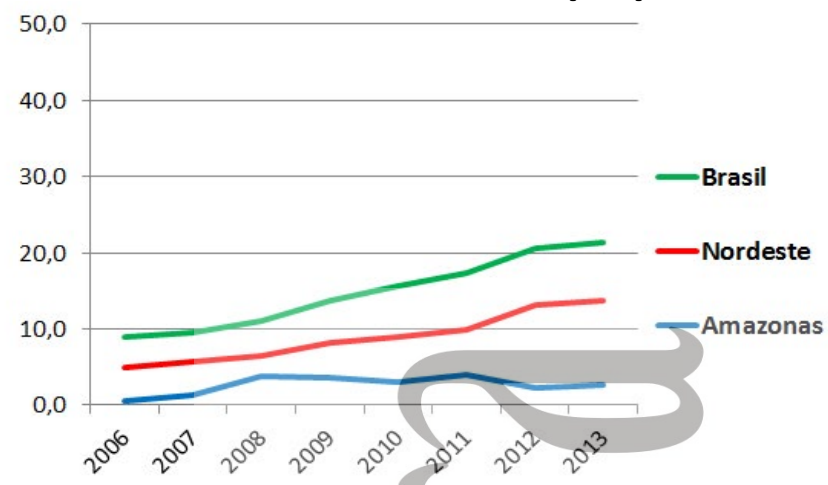

FÍGADO - pmp (não realiza)

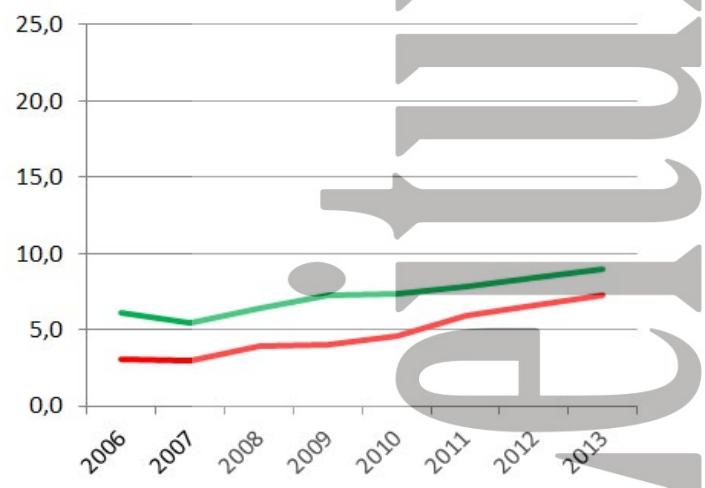

RIM com doador vivo - pmp

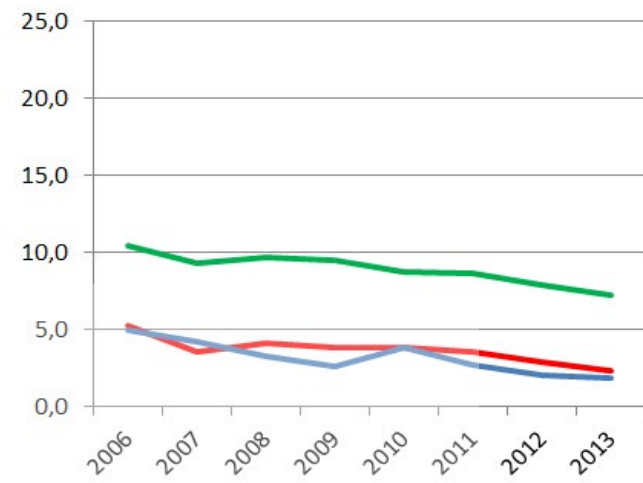

CÓRNEA- pmp

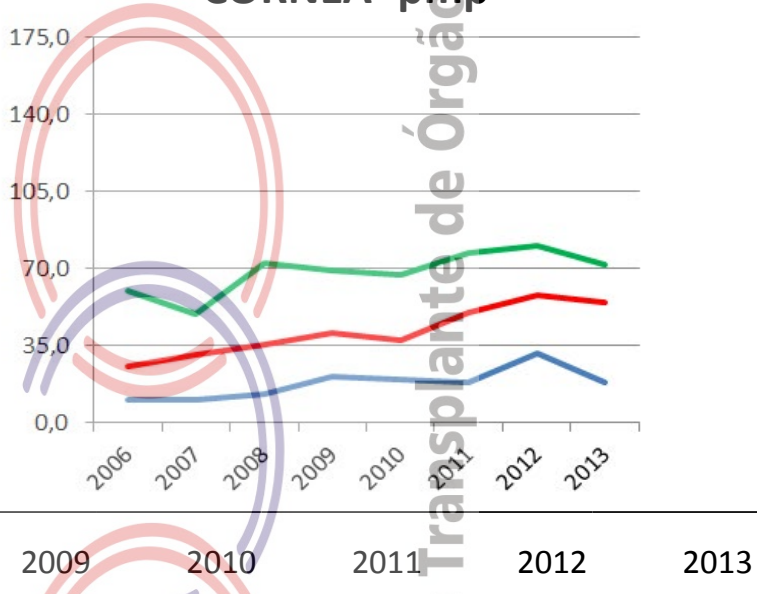

\begin{tabular}{llllllllll}
$\begin{array}{l}\text { Número de equipes que realizaram } \\
\text { transplantes durante o ano }\end{array}$ & 2006 & 2007 & 2008 & 2009 & 2010 & 2011 & 2012 & 2013 \\
\hline
\end{tabular}

\begin{tabular}{|c|c|c|c|c|c|c|c|c|}
\hline \multirow{2}{*}{$\begin{array}{l}\text { CÓRNEA } \\
\text { RIM }\end{array}$} & \multirow{2}{*}{$\begin{array}{r}\text { Indisponível } \\
1\end{array}$} & \multirow{2}{*}{$\begin{array}{r}\text { Indisponível } \\
1\end{array}$} & \multicolumn{3}{|c|}{ Indisponível Indisponivel Indisponivel } & \multicolumn{2}{|c|}{ Indisponível- Indisponível } & \multirow{2}{*}{$\begin{array}{r}\text { Indisponível } \\
1\end{array}$} \\
\hline & & & 1 & 1 & 1 & 10 & 1 & \\
\hline FÍGADO (não realiza) & & & & & & 는 & & \\
\hline PÂNCREAS (não realiza) & & & & & & 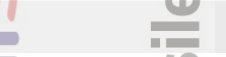 & & \\
\hline CORAÇÃO (não realiza) & & & & & & n & & \\
\hline PULMÃO (não realiza) & & & 2 & & & an & & \\
\hline Número absoluto de transplantes & 2006 & 2007 & 2008 & 2009 & 2010 & 2011 & 2012 & 2013 \\
\hline CÓRNEA & 57 & 61 & 79 & 129 & 128 & 119 एक & 208 & 119 \\
\hline RIM - total & 31 & 34 & 43 & 38 & 45 & $44=$ & 28 & 30 \\
\hline doador vivo & 28 & 26 & 20 & 16 & 25 & 180 & 13 & 12 \\
\hline doador falecido & 3 & 8 & 23 & 22 & 20 & 26 น & 15 & 18 \\
\hline FÍGADO (não realiza) & & & & & & $<$ & & \\
\hline PÂNCREAS (não realiza) & 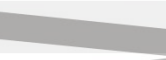 & & & & & & & \\
\hline CORAÇÃO (não realiza) & & & & & & & & \\
\hline PULMÃO (não realiza) & & & & & & & & \\
\hline Número de transplantes $p m p$ & 2006 & 2007 & 2008 & 2009 & 2010 & 2011 & 2012 & 2013 \\
\hline CÓRNEA & 10,1 & 10,0 & 12,9 & 21,1 & 19,5 & 18,1 & 31,6 & 18,1 \\
\hline RIM - total & 5,5 & 5,6 & 7,0 & 6,2 & 6,8 & 6,7 & 4,3 & 4,6 \\
\hline doador vivo & 5,0 & 4,2 & 3,3 & 2,6 & 3,8 & 2,7 & 2,0 & 1,8 \\
\hline doador falecido & 0,5 & 1,3 & 3,8 & 3,6 & 3,0 & 4,0 & 2,3 & 2,7 \\
\hline
\end{tabular}

FÍGADO (não realiza)

PÂNCREAS (não realiza)

CORAÇÃO (não realiza)

PULMÃO (não realiza) 


\section{MATO GROSSO}

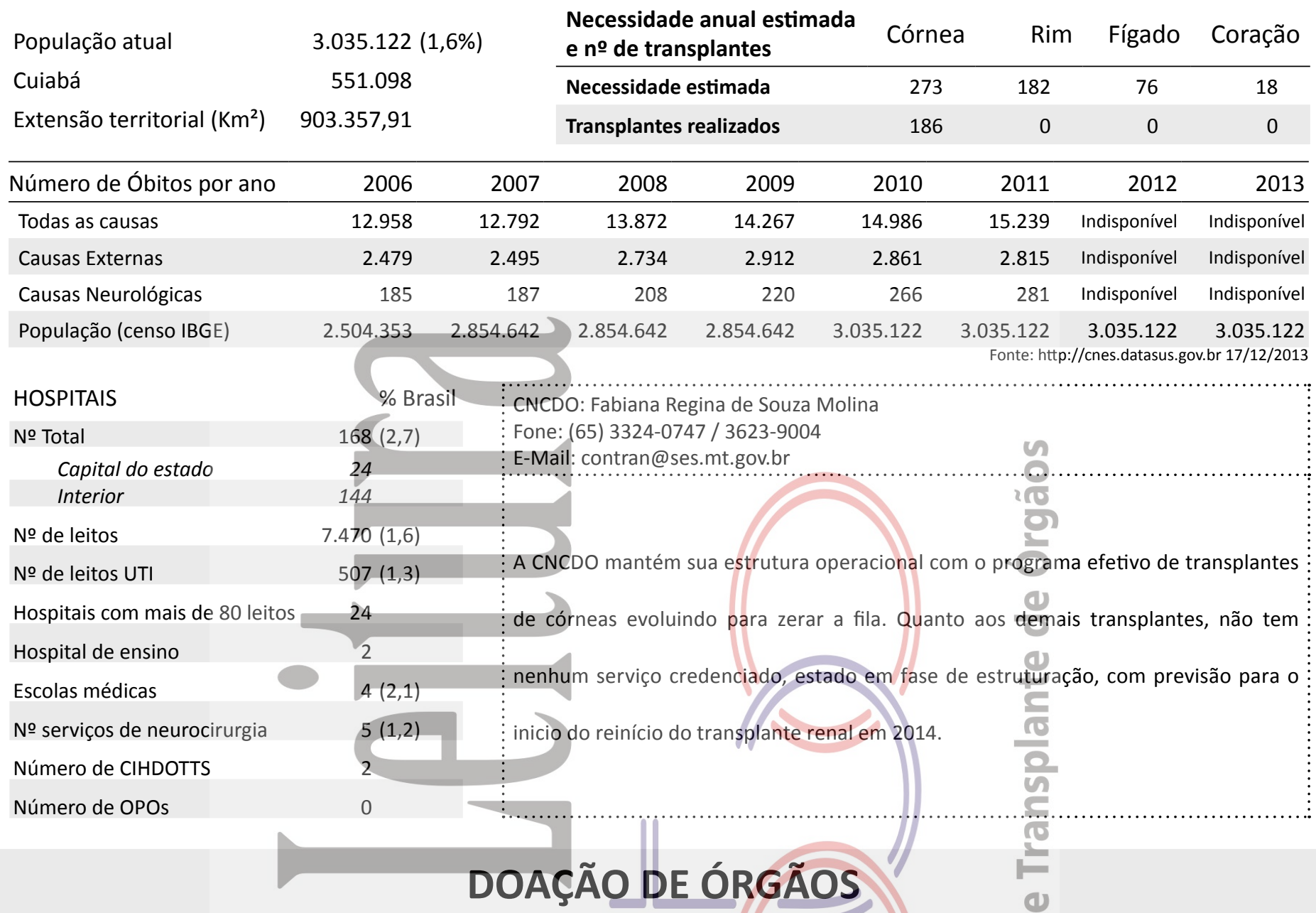

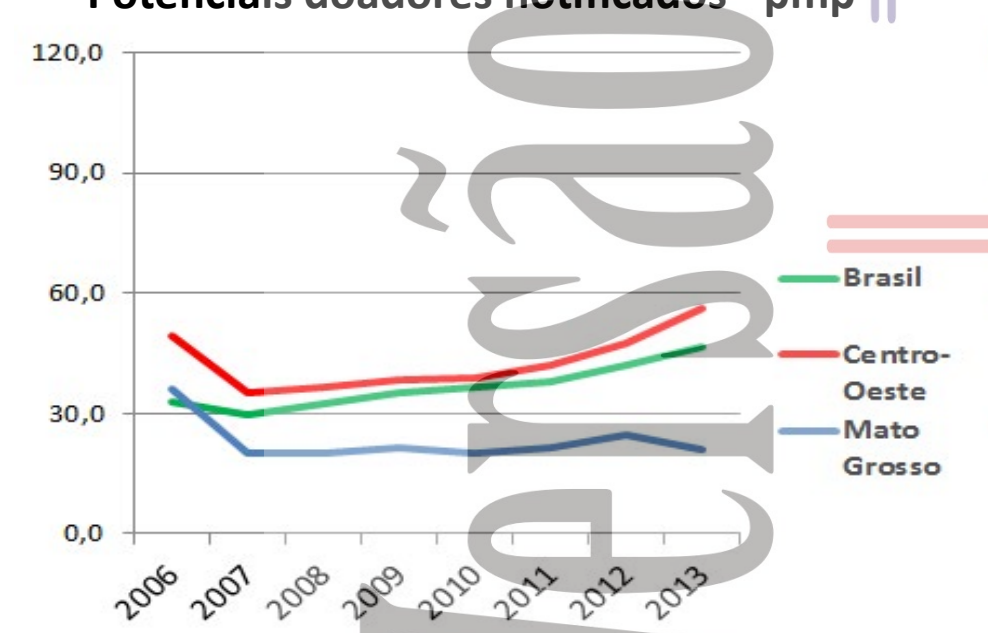

\section{Potenciais doadores notificados - pmp}

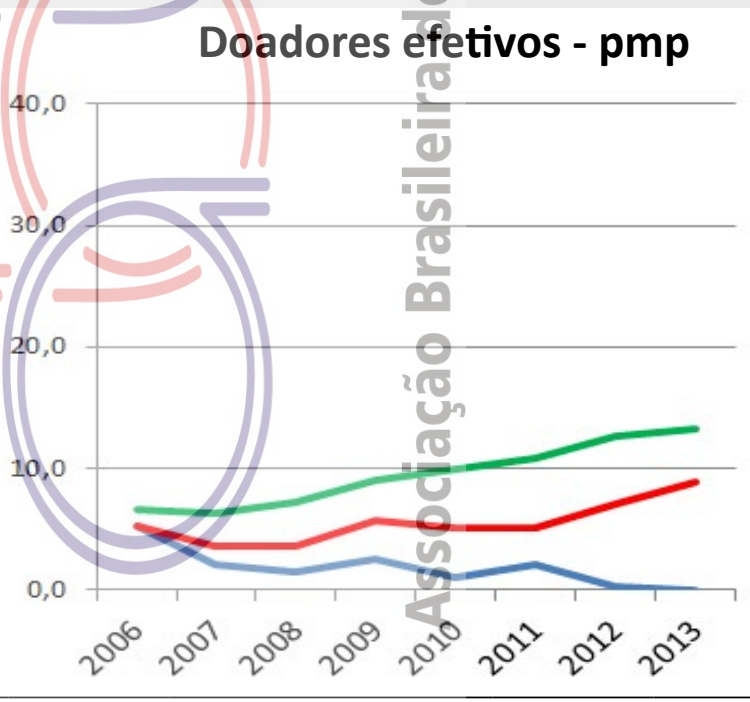

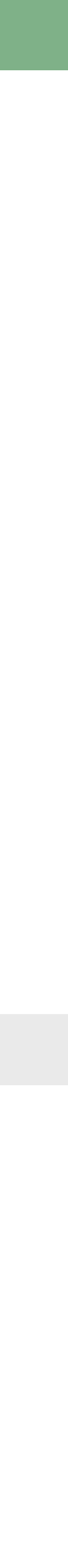

\begin{tabular}{|c|c|c|c|c|c|c|c|c|}
\hline & 2006 & 2007 & 2008 & 2009 & 2010 & 2011 & 2012 & 2013 \\
\hline Número de doadores efetivos & 13 & 6 & 4 & 7 & 3 & 6 & 1 & 0 \\
\hline Número de doadores efetivos (pmp) & 5,2 & 2,1 & 1,4 & 2,5 & 1,0 & 2,0 & 0,3 & 0,0 \\
\hline $\begin{array}{l}\text { Número de notificações } \\
\text { (potenciais doadores) }\end{array}$ & 90 & 57 & 57 & 61 & 61 & 66 & 75 & 64 \\
\hline Número de notificações (pmp) & 35,9 & 20,0 & 20,0 & 21,4 & 20,1 & 21,7 & 24,7 & 21,1 \\
\hline Recusa familiar & 27 & 25 & 15 & 11 & 12 & 11 & 11 & 10 \\
\hline Percentual de recusa das entrevistas & Indisponível & Indisponível & Indisponível & Indisponível & Indisponível & Indisponível & 50 & 77 \\
\hline Parada Cardíaca & Indisponível & Indisponível & 3 & 12 & 23 & 37 & 39 & 13 \\
\hline Contraindicação médica & 43 & 19 & 24 & 21 & 12 & 6 & 12 & 2 \\
\hline Outros & 7 & 7 & 11 & 10 & 11 & 6 & 12 & 39 \\
\hline
\end{tabular}




\section{MATO GROSSO}

\section{TRANSPLANTE DE ÓRGÃOS}

\section{RIM com doador falecido - pmp}

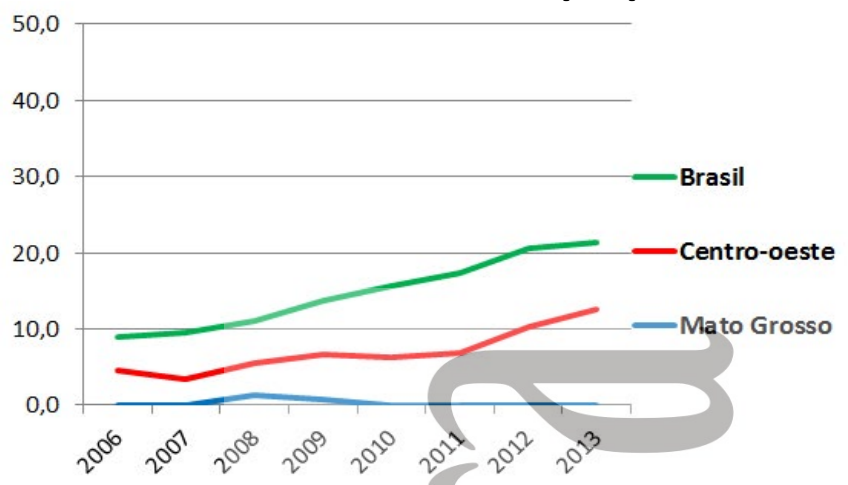

FÍGADO - pmp (não realiza)

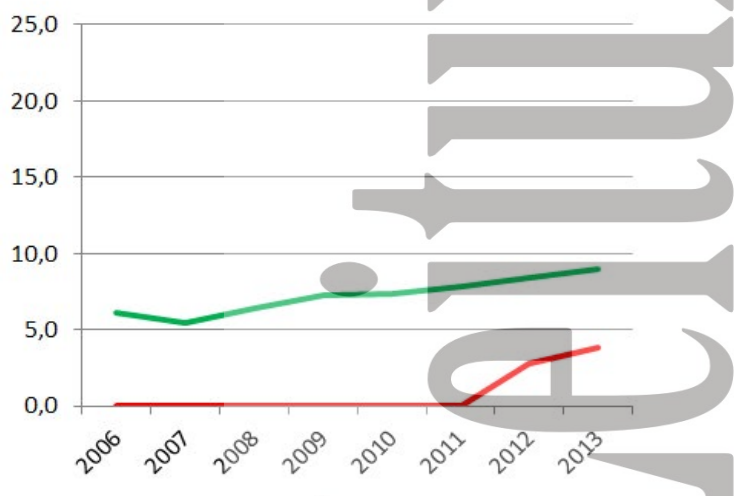

Número de equipes que realizaram $2006 \quad 2007$ transplantes durante o ano CÓRNEA

RIM

FÍGADO (não realiza)

PÂNCREAS (não realiza)

CORAÇÃO (não realiza)

PULMÃo (não realiza)

\begin{tabular}{l} 
Número absoluto de trans \\
\hline CÓRNEA \\
RIM - total \\
doador vivo \\
doador falecido \\
FÍGADO (não realiza) \\
PÂNCREAS (não realiza) \\
CORAÇÃO (não realiza) \\
PULMÃO (não realiza)
\end{tabular}

\begin{tabular}{ccccccccc}
\hline Número de transplantes pmp & 2006 & 2007 & 2008 & 2009 & 2010 & 2011 & 2012 & 2013 \\
\hline CÓRNEA & 10,0 & 54,6 & 56,7 & 41,0 & 17,5 & 93,9 & 65,9 & 61,3 \\
RIM - total & 2,4 & 3,2 & 2,1 & 1,4 & 0,0 & 0,0 & 0,0 & 0,0 \\
$\quad$ doador vivo & 2,4 & 3,2 & 0,7 & 0,7 & 0,0 & 0,0 & 0,0 & 0,0 \\
doador falecido & 0,0 & 0,0 & 1,4 & 0,7 & 0,0 & 0,0 & 0,0 & 0,0
\end{tabular}

FÍGADO (não realiza)

PÂNCREAS (não realiza)

CORAÇÃO (não realiza)

PULMÃo (não realiza)
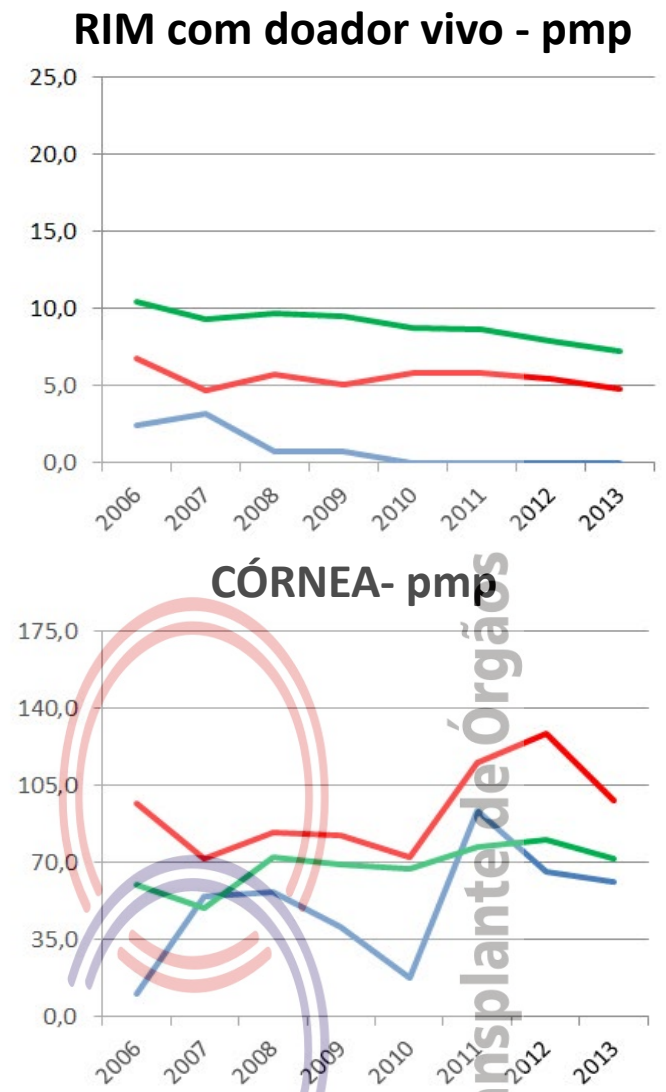


\section{MATO GROSSO DO SUL}

$\begin{array}{lc}\text { População atual } & 2.449 .024(1,3 \%) \\ \text { Campo Grande } & 786.797\end{array}$

Extensão territorial $\left(\mathrm{Km}^{2}\right) \quad 357.124,96$

\begin{tabular}{|rrrrrr}
\hline $\begin{array}{l}\text { Necessidade anual estimada } \\
\text { e no de transplantes }\end{array}$ & Córnea & Rim & Fígado & Coração \\
\hline \multicolumn{2}{l}{$\begin{array}{l}\text { Necessidade estimada } \\
\text { Transplantes realizados }\end{array}$} & 220 & 147 & 61 & 15 \\
\hline 2008 & 2009 & 2010 & 2011 & 2012 & 2013 \\
\hline 13.235 & 13.610 & 14.471 & 14.291 & Indisponível & Indisponível \\
\hline 2.004 & 2.110 & 2.120 & 2.224 & Indisponível & Indisponível \\
307 & 281 & 348 & 359 & Indisponível & Indisponível \\
2.265 .274 & 2.265 .274 & 2.449 .024 & 2.449 .024 & $\begin{array}{l}2.449 .024 \\
2.449 .024\end{array}$ \\
\hline
\end{tabular}

HOSPITAIS

№ Total

Capital do estado

Interior

№ de leitos

№ de leitos UTI

Hospitais com mais de 80 leitos

Hospital de ensino

Escolas médicas

№ serviços de neurocirurgia

Número de CIHDOTTS

Número de OPOs

\begin{tabular}{|c|c|c|c|}
\hline 2006 & 2007 & 2008 & 2009 \\
\hline 12.760 & 13.208 & 13.235 & 13.610 \\
\hline 1.955 & 2.006 & 2.004 & 2.110 \\
\hline 255 & 303 & 307 & 281 \\
\hline 2.078 .001 & 2.265 .274 & 2.265 .274 & 2.265 .274 \\
\hline $114(1,8)$ & \multirow{2}{*}{\multicolumn{3}{|c|}{$\begin{array}{l}\text { CNCDO: Claire Carmem Miozzo } \\
\text { Fone: (67) 3312-1456 } \\
\text { E-Mail: cet@saude.ms.gov.br }\end{array}$}} \\
\hline 24 & & & \\
\hline 90 & & & \\
\hline
\end{tabular}

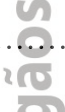

(c)

$\begin{aligned} 6.077(1,3) & \text { Mantém número de doadores efetivos inferior a 10, mas com crescimento sustentado } \\ 362(1,0) & \vdots \text { nos últimos quatro anos. Tem alta taxa de notificação (62 pmp) e alta taxa de recusa }\end{aligned}$ $362(1,0)$ familiar.

2

3ealizou no ano, 45 transplantes renais e três cardíacos, entretanto o credenciamento $3(0,7) \quad$ das equipes não foi sustentado, e para 2014 existe previsão de credenciamento de 5 novas equipes. Os órgãos doados são encaminhados para a Central Nacional.

0
DOAÇ̃̃O DE ÓRGÃOS
Potenciais doadores notificados - pmp

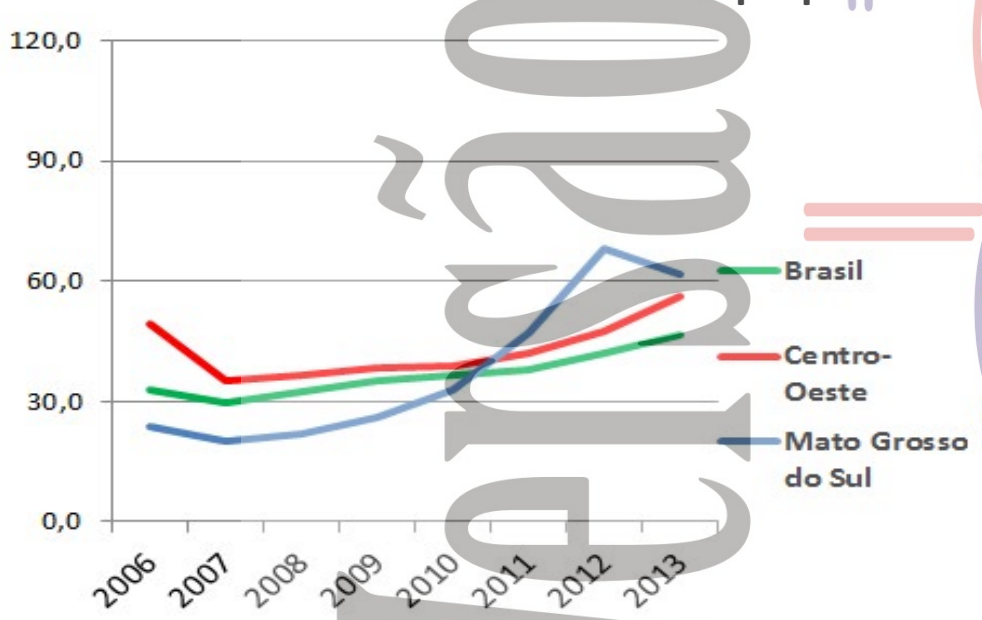

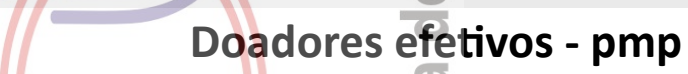

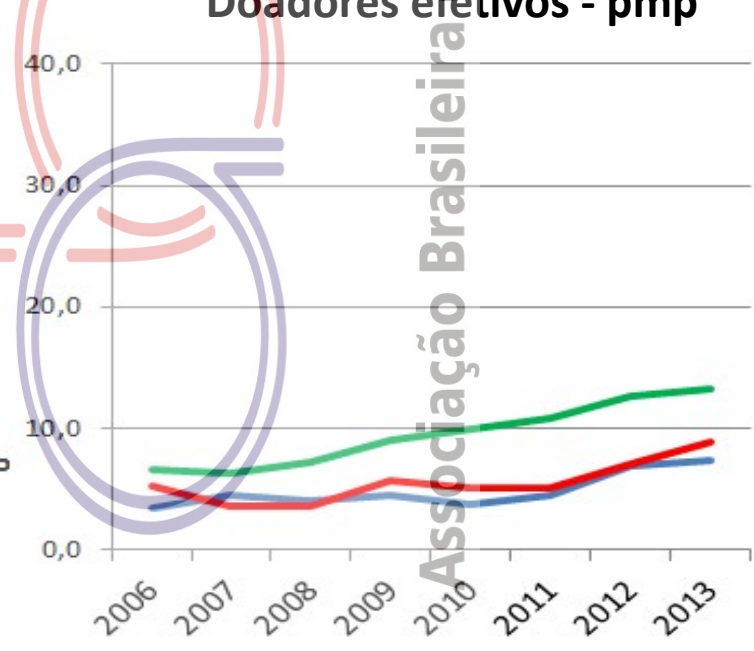

$\begin{array}{lrrrrrrrr}\text { Número de doadores efetivos } & 7 & 10 & 9 & 10 & 9 & 11 & 17 & 18 \\ \text { Número de doadores efetivos (pmp) } & 3,4 & 4,4 & 4,0 & 4,4 & 3,7 & 4,5 & 6,9 & 7,3 \\ \begin{array}{l}\text { Número de notificações } \\ \text { (potenciais doadores) }\end{array} & 49 & 46 & 50 & 59 & 80 & 115 & 167 & 151 \\ \text { Número de notificações (pmp) } & 23,6 & 20,3 & 22,1 & 26,0 & 32,7 & 47,0 & 68,2 & 61,7 \\ \text { Recusa familiar } & 14 & 19 & 13 & 6 & 20 & 19 & 36 & 46 \\ \text { Percentual de recusa das entrevistas } & \text { Indisponível } & \text { Indisponível } & \text { Indisponível } & \text { Indisponível } & \text { Indisponível } & \text { Indisponível } & 63 & 65 \\ \text { Parada Cardíaca } & \text { Indisponível } & \text { Indisponível } & 7 & 11 & 8 & 14 & 16 & 24 \\ \text { Contraindicação médica } & 22 & 13 & 18 & 30 & 41 & 66 & 79 & 54 \\ \text { Outros } & 6 & 4 & 3 & 2 & 2 & 5 & 19 & 9\end{array}$




\section{MATO GROSSO DO SUL}

\section{TRANSPLANTE DE ÓRGÃOS}

\section{RIM com doador falecido - pmp}

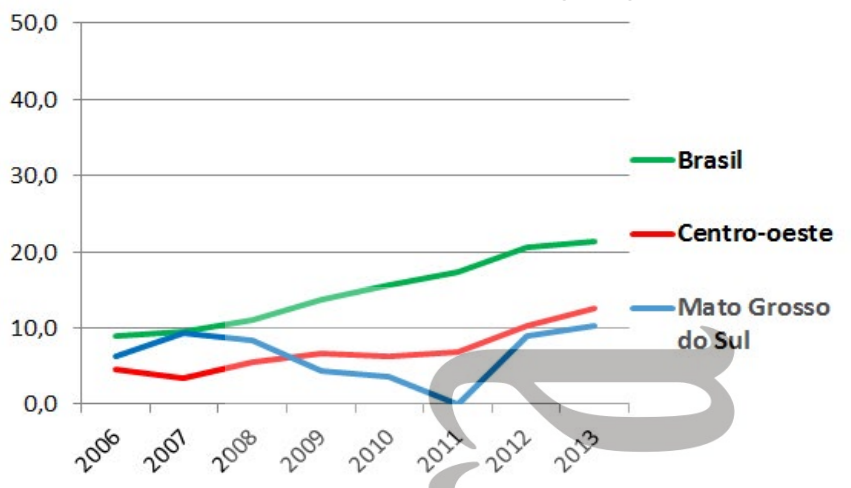

FÍGADO - pmp (não realiza)

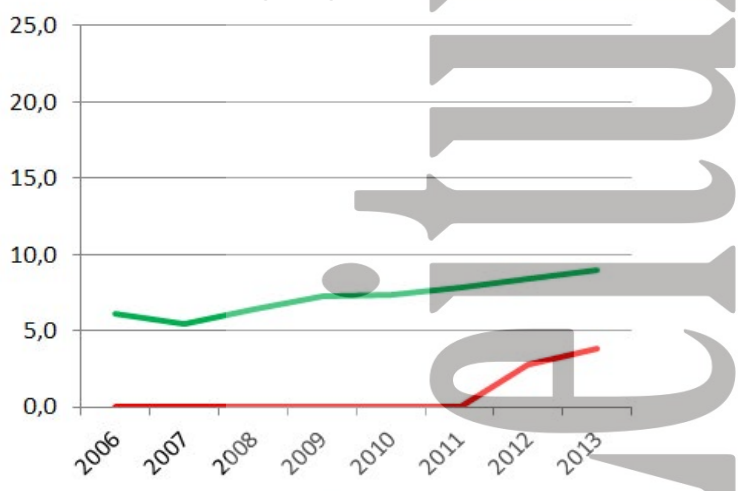

RIM com doador vivo - pmp

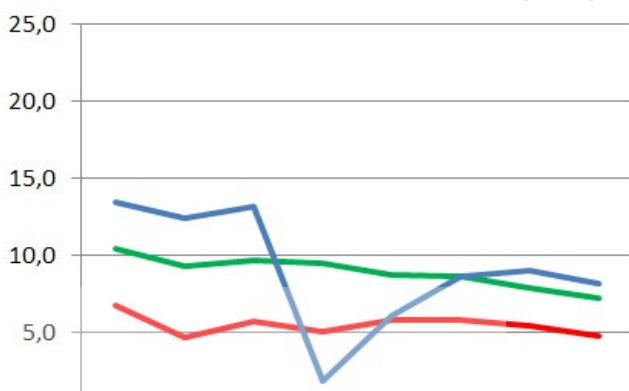

0,0

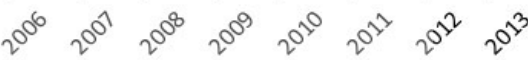
CÓRNEA- pmp

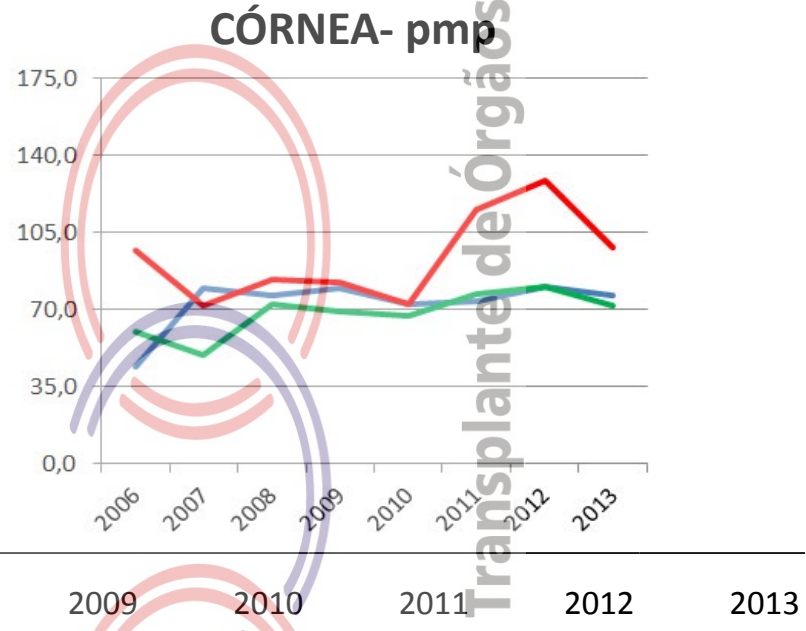

\begin{tabular}{|c|c|c|c|c|c|c|c|c|}
\hline \multirow{2}{*}{$\begin{array}{l}\text { CÓRNEA } \\
\text { RIM }\end{array}$} & \multirow{2}{*}{$\begin{array}{r}\text { Indisponível } \\
2\end{array}$} & \multirow{2}{*}{$\begin{array}{r}\text { Indisponível } \\
2\end{array}$} & \multicolumn{3}{|c|}{ Indisponível Indisponivel Indisponivel } & \multicolumn{2}{|c|}{ Indisponível-Indisponível } & \multirow{2}{*}{$\begin{array}{r}\text { Indisponível } \\
2\end{array}$} \\
\hline & & & 2 & 2 & 2 & 20 & 2 & \\
\hline FÍGADO (não realiza) & & & & & & 늘 & & \\
\hline PÂNCREAS (não realiza) & & & & & & 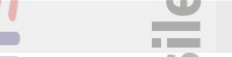 & & \\
\hline CORAÇÃO & & & 0 & & & $0 \frac{1}{0}$ & 0 & 1 \\
\hline PULMÃO (não realiza) & & & 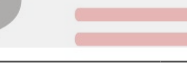 & & & 은 & & \\
\hline Número absoluto de transplantes & 2006 & 2007 & 2008 & 2009 & 2010 & 20119 & 2012 & 2013 \\
\hline CÓRNEA & 92 & 180 & 173 & 180 & 177 & 180 एक & 197 & 187 \\
\hline RIM - total & 41 & 49 & 49 & 14 & 24 & $21=$ & 44 & 45 \\
\hline doador vivo & 28 & 28 & 30 & 4 & 15 & 210 & 22 & 20 \\
\hline doador falecido & 13 & 21 & 19 & 10 & 9 & $0 \backsim$ & 22 & 25 \\
\hline FÍGADO (não realiza) & & & & & & $<$ & & \\
\hline \multicolumn{9}{|l|}{ PÂNCREAS (não realiza) } \\
\hline CORAÇÃO & 0 & 0 & 0 & 0 & 0 & 0 & 0 & 3 \\
\hline \multicolumn{9}{|l|}{ PULMÃO (não realiza) } \\
\hline Número de transplantes pmp & 2006 & 2007 & 2008 & 2009 & 2010 & 2011 & 2012 & 2013 \\
\hline CÓRNEA & 44,3 & 79,5 & 76,4 & 79,5 & 72,3 & 73,5 & 80,4 & 76,4 \\
\hline RIM - total & 19,7 & 21,6 & 21,6 & 6,2 & 9,8 & 8,6 & 18,0 & 18,4 \\
\hline doador vivo & 13,5 & 12,4 & 13,2 & 1,8 & 6,1 & 8,6 & 9,0 & 8,2 \\
\hline doador falecido & 6,3 & 9,3 & 8,4 & 4,4 & 3,7 & 0,0 & 9,0 & 10,2 \\
\hline
\end{tabular}

FÍGADO (não realiza)

PÂNCREAS (não realiza)

CORAÇÃO

0,0

0,0

0,0

0,0

0,0

0,0

0,0

1,2

PULMÃo (não realiza) 


\section{MINAS GERAIS}

População atual

$19.597 .330(10,3 \%)$

Belo Horizonte

2.375 .151

Extensão territorial $\left(\mathrm{Km}^{2}\right)$

\begin{tabular}{lcrrr}
\hline $\begin{array}{l}\text { Necessidade anual estimada } \\
\text { e no de transplantes }\end{array}$ & Córnea & Rim & Fígado & Coração \\
\hline Necessidade estimada & 1.764 & 1.176 & 490 & 118 \\
Transplantes realizados & 1.441 & 534 & 75 & 27 \\
\hline
\end{tabular}

\begin{tabular}{|c|c|c|c|c|c|c|c|c|}
\hline Número de Óbitos por ano & 2006 & 2007 & 2008 & 2009 & 2010 & 2011 & 2012 & 2013 \\
\hline Todas as causas & 111.807 & 111.366 & 112.756 & 114.301 & 120.803 & 122.653 & Indisponível & Indisponível \\
\hline Causas Externas & 12.183 & 12.415 & 12.187 & 12.681 & 12.931 & 14.263 & Indisponível & Indisponível \\
\hline Causas Neurológicas & 2.399 & 2.424 & 2.529 & 2.701 & 3.057 & 3.231 & Indisponível & Indisponível \\
\hline População (censo IBGE) & 17.891 .494 & 19.273.506 & 9.273 .506 & 19.273 .506 & 19.597.330 & 19.597 .330 & 19.597 .330 & 19.597 .330 \\
\hline
\end{tabular}

HOSPITAIS

№ Total

Capital do estado

Interior

№ de leitos

№ de leitos UTI

$\%$ Brasil

$632(10,0) \quad$ Fone: (31) 3219-9200

\begin{tabular}{c|c}
$632(10,0)$ & E-Mail: mgtransplantes@saude.mg.gov.br \\
69 & $\vdots$
\end{tabular}

(

...

$45.759(9,6) \quad$ Apresentou 11,6 pmp no ano, com crescimento no último quadrimestre (taxa de 13,8 $3.607(9,5) \quad \vdots$ pmp). Dez OPO's estão em funcionamento, juntamente com uma Superintendência de Hospitais com mais de 80 leitos 169 Hospital de ensino

Escolas médicas

№ serviços de neurocirurgia

Número de CIHDOTTS

18 18 pmp, contrapondo-se a outras com taxas muito baixas. Mantém alta taxa de efetivação $30(15,8) \quad \vdots$ de doadores, crescente número de CIHDOTT's sendo cadastradas e aumento gradativo $42(10,2) \quad \vdots$ no número de notificações. É pioneiro na oferta de córneas preparadas para transplante 60

Número de OPOs 10 lamelar endotelial e há um Hospital Estadual de Transplantes sendo implantado.

\section{DOAÇÃO DE ÓRGÃOS}

Potenciais doadores notificados - pmp

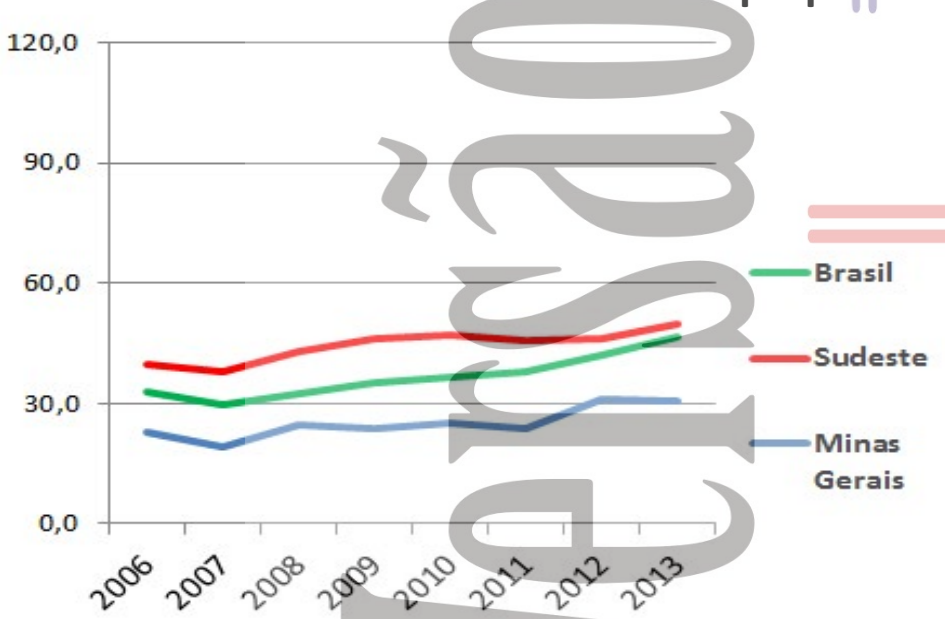

Doadores efetivos - pmp

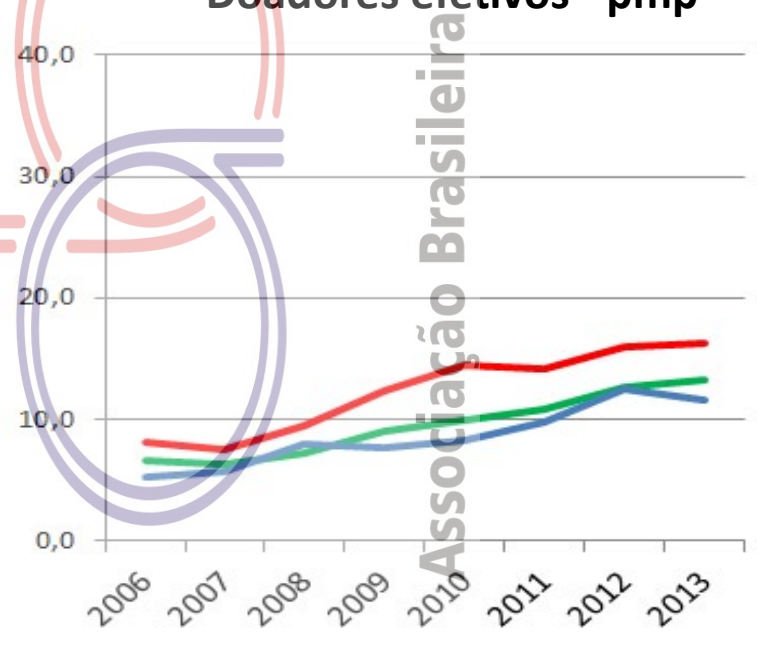

$2007 \quad 2008$

Número de doadores efetivos

$2006 \quad 2007$

2009

Número de doadores efetivos (pmp)

$93 \quad 110 \quad 153$

Número de notificações

(potenciais doadores)

5,2

5,7

7,9

411

370

478

23,0

19,2

24,8

86

90

149
7,7

2010

2011

Recusa familiar

Indisponível Indisponível Indisponíve Indisponível Indisponível

\begin{tabular}{|c|c|c|c|}
\hline Percentual de recusa das entrevistas & Indisponível & Indisponível & Indisponível \\
\hline Parada Cardíaca & Indisponível & Indisponível & 114 \\
\hline Contraindicação médica & 236 & 158 & 93 \\
\hline Outros & 0 & 16 & 28 \\
\hline
\end{tabular}

$\begin{array}{lrrr}\text { Contraindicação médica } & 236 & 158 & 93 \\ \text { Outros } & 0 & 16 & 28\end{array}$

$\begin{array}{rrrrr}112 & 133 & 73 & 42 & 87 \\ 22 & 89 & 75 & 40 & 54 \\ & 23 & 39 & 153 & 89\end{array}$




\section{MINAS GERAIS}

\section{TRANSPLANTE DE ÓRGÃOS}

RIM com doador falecido - pmp
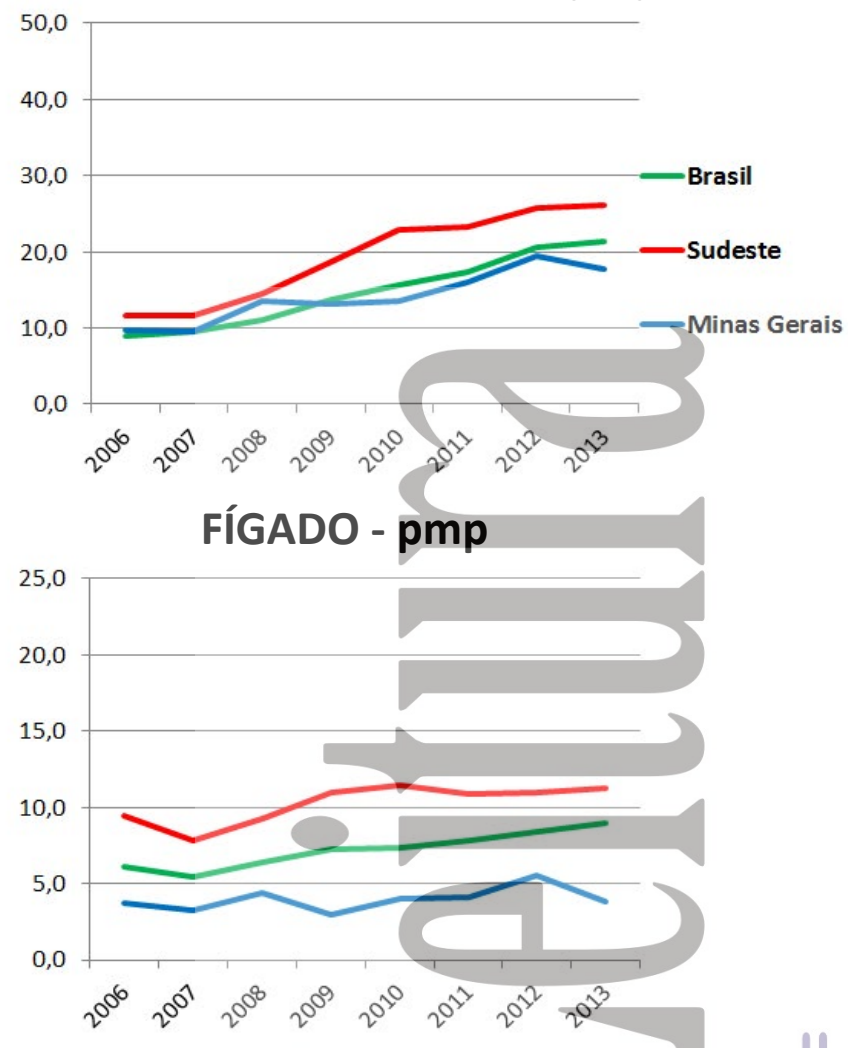

RIM com doador vivo - pmp

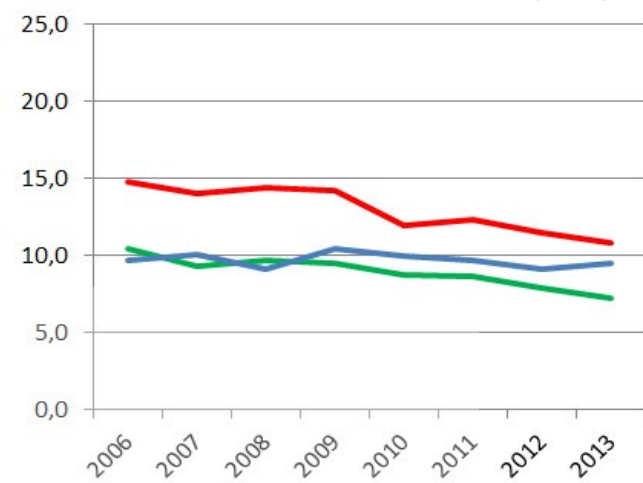

CÓRNEA- pmp

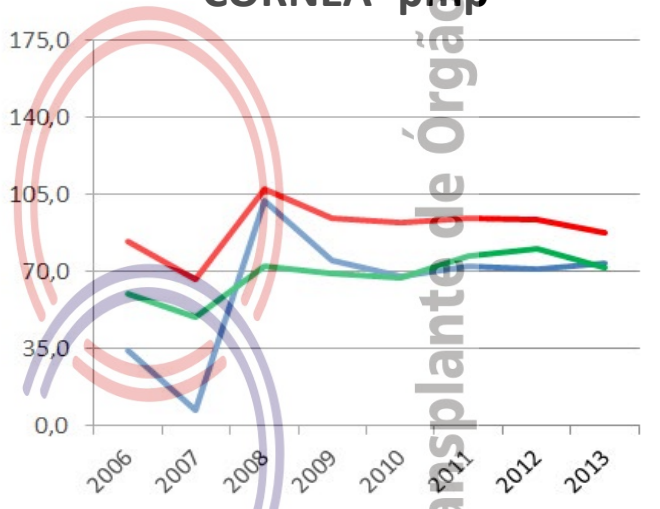

\begin{tabular}{|c|c|c|c|c|c|c|c|c|}
\hline $\begin{array}{l}\text { Número de equipes que realizaram } \\
\text { transplantes durante o ano }\end{array}$ & 2006 & 2007 & 2008 & 2009 & 2010 & 2011 & 2012 & 2013 \\
\hline CÓRNEA & Indisponível & Indisponível & Indisponível & sponivel & ponível & Indisponível-Ind & sponível & Indisponível \\
\hline RIM & 17 & 18 & 20 & 18 & 17 & 16 & 16 & 16 \\
\hline FÍGADO & 4 & 2 & 3 & 2 & 1 & $3=$ & 5 & 4 \\
\hline PÂNCREAS & 3 & 3 & 2 & 2 & 2 & $2=$ & 2 & 3 \\
\hline CORAÇÃO & & & 2 & & & $2 \frac{1}{6}$ & 2 & 2 \\
\hline PULMÃO & 1 & 1 & 1 & 1 & & 1 ํำ & 1 & 1 \\
\hline Número absoluto de transplantes & 2006 & 2007 & 2008 & 2009 & 2010 & 2011 & 2012 & 2013 \\
\hline CÓRNEA & 616 & 138 & 1.973 & 1.446 & 1.334 & 1.414 (0) & 1.391 & 1.441 \\
\hline RIM - total & 347 & 379 & 435 & 452 & 461 & $506=$ & 562 & 534 \\
\hline doador vivo & 174 & 194 & 175 & 200 & 195 & 191 & 179 & 185 \\
\hline doador falecido & 173 & 185 & 260 & 252 & 266 & 315 น & 383 & 349 \\
\hline FÍGADO & 67 & 64 & 84 & 58 & 78 & 81 & 110 & 75 \\
\hline PÂNCREAS & 41 & 14 & 6 & 17 & 13 & 16 & 30 & 18 \\
\hline CORAÇÃO & 17 & 18 & 26 & 19 & 24 & 12 & 30 & 27 \\
\hline PULMÃO & 2 & 2 & 2 & 2 & 3 & 1 & 1 & 2 \\
\hline Número de transplantes pmp & 2006 & 2007 & 2008 & 2009 & 2010 & 2011 & 2012 & 2013 \\
\hline CÓRNEA & 34,4 & 7,2 & 102,4 & 75,0 & 68,1 & 72,2 & 71,0 & 73,5 \\
\hline RIM - total & 19,4 & 19,7 & 22,6 & 23,5 & 23,5 & 25,8 & 28,7 & 27,2 \\
\hline doador vivo & 9,7 & 10,1 & 9,1 & 10,4 & 10,0 & 9,7 & 9,1 & 9,4 \\
\hline doador falecido & 9,7 & 9,6 & 13,5 & 13,1 & 13,6 & 16,1 & 19,5 & 17,8 \\
\hline FÍGADO & 3,7 & 3,3 & 4,4 & 3,0 & 4,0 & 4,1 & 5,6 & 3,8 \\
\hline PÂNCREAS & 2,3 & 0,7 & 0,3 & 0,9 & 0,7 & 0,8 & 1,5 & 0,9 \\
\hline CORAÇÃO & 1,0 & 0,9 & 1,3 & 1,0 & 1,2 & 0,6 & 1,5 & 1,4 \\
\hline PULMÃO & 0,1 & 0,1 & 0,1 & 0,1 & 0,2 & 0,1 & 0,1 & 0,1 \\
\hline
\end{tabular}




\section{PARÁ}

População atual

$7.581 .051(4,0 \%)$

Belém

1.393 .399

Extensão territorial $\left(\mathrm{Km}^{2}\right)$ 1.247.689,52

\begin{tabular}{lccccc}
\hline $\begin{array}{l}\text { Necessidade anual estimada } \\
\text { e no de transplantes }\end{array}$ & Córnea & Rim & Fígado & Coração \\
\hline Necessidade estimada & 682 & 455 & 190 & 45 \\
Transplantes realizados & 221 & 53 & 1 & 0 \\
\hline
\end{tabular}

\begin{tabular}{lrrrrrrrr}
\hline Número de Óbitos por ano & 2006 & 2007 & 2008 & 2009 & 2010 & 2011 & 2012 & 2013 \\
\hline Todas as causas & 27.015 & 27.626 & 29.633 & 30.512 & 31.600 & 32.638 & Indisponível & Indisponível \\
Causas Externas & 4.277 & 4.385 & 5.232 & 5.200 & 6.125 & 5.744 & Indisponível & Indisponível \\
Causas Neurológicas & 343 & 342 & 353 & 374 & 363 & 390 & Indisponível & Indisponível \\
População (censo IBGE) & 6.192 .307 & 7.065 .573 & 7.065 .573 & 7.065 .573 & 7.581 .051 & $\begin{array}{l}7.581 .051 \\
\text { Fonte: http://cnes.datasus.gov.br 17/12/2013 }\end{array}$
\end{tabular}

HOSPITAIS

№ Total

Capital do estado

Interior

№ de leitos

$\%$ Brasil $\quad \vdots$ CNCDO: Dra. Ana Cristina Simões Beltrão

$\begin{array}{cl}233(3,7) & \text { Fone/Fax: (91) 4006-4284 } \\ 40 & \vdots \text { E-Mail: cncdo.transplantes@gmail.com } \\ 193 & \vdots\end{array}$

(

193

$15.783(3,3)$

№ de leitos UTI

$854(2,3)$

Hospitais com mais de 80 leitos $\quad 55$

Hospital de ensino

Escolas médicas

№ serviços de neurocirurgia

Número de CIHDOTTS

Número de OPOs

55 $2 \quad \vdots$ em processo de implantação de quatro OPOs - duas em Belém, uma em Santarém e a despeito do grande número de mortes por causa externa. A CNCDO está em fase de conclusão e aprovação do Plano Estadual de Transplantes com a finalidade de sustentar melhorias e novas estratégias para o incremento de Política Estadual. Está $4(2,1) \quad$ outra em Redenção. Realiza transplantes de córneas e rins, e já dispõe de equipe de $8(1,9) \quad$ transplante hepático credenciada desde set/2013, aguardando solução de questões na $91 \quad$ pactuação entre o município e o estado.

0

\section{DOAÇÃO DE ÓRGÃOS}

\section{Potenciais doadores notificados - pmp}

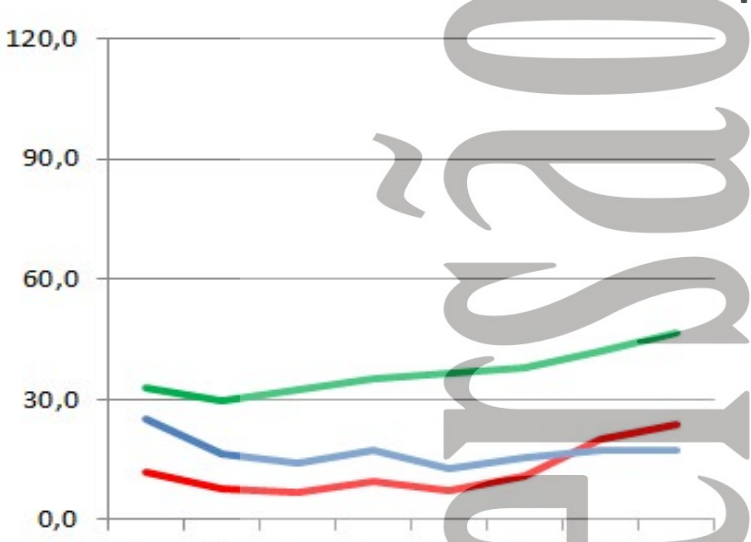

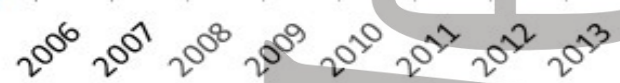

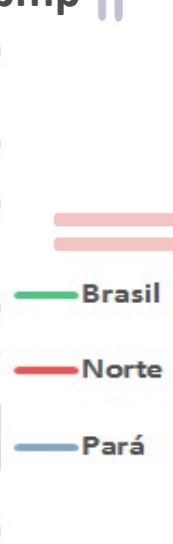

D2

\begin{tabular}{|c|c|c|c|c|c|c|c|c|}
\hline & 2006 & 2007 & 2008 & 2009 & 2010 & 2011 & 2012 & 2013 \\
\hline Número de doadores efetivos & 19 & 8 & 9 & 12 & 9 & 26 & 22 & 19 \\
\hline Número de doadores efetivos (pmp) & 3,1 & 1,1 & 1,3 & 1,7 & 1,2 & 3,4 & 2,9 & 2,5 \\
\hline $\begin{array}{l}\text { Número de notificações } \\
\text { (potenciais doadores) }\end{array}$ & 155 & 115 & 102 & 124 & 97 & 117 & 133 & 133 \\
\hline Número de notificações (pmp) & 25,0 & 16,3 & 14,4 & 17,5 & 12,8 & 15,4 & 17,5 & 17,5 \\
\hline Recusa familiar & 52 & 41 & 38 & 26 & 43 & 51 & 47 & 36 \\
\hline Percentual de recusa das entrevistas & Indisponível & Indisponível & Indisponível & Indisponível & Indisponível & Indisponível & 35 & 31 \\
\hline Parada Cardíaca & Indisponível & Indisponível & 23 & 17 & 20 & 15 & 30 & 25 \\
\hline Contraindicação médica & 78 & 39 & 25 & 49 & 16 & 20 & 27 & 41 \\
\hline Outros & 6 & 27 & 7 & 20 & 9 & 5 & 7 & 12 \\
\hline
\end{tabular}

\section{Doadores efetivos - pmp}
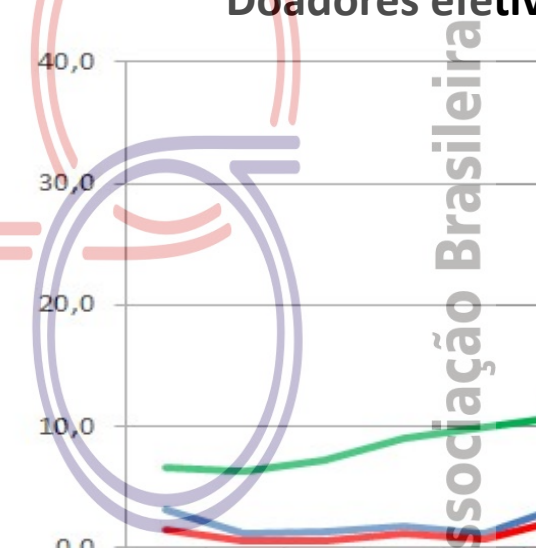

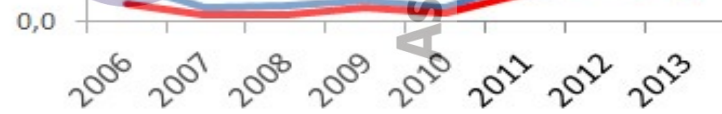




\section{PARÁ}

\section{TRANSPLANTE DE ÓRGÃOS}

\section{RIM com doador falecido - pmp}

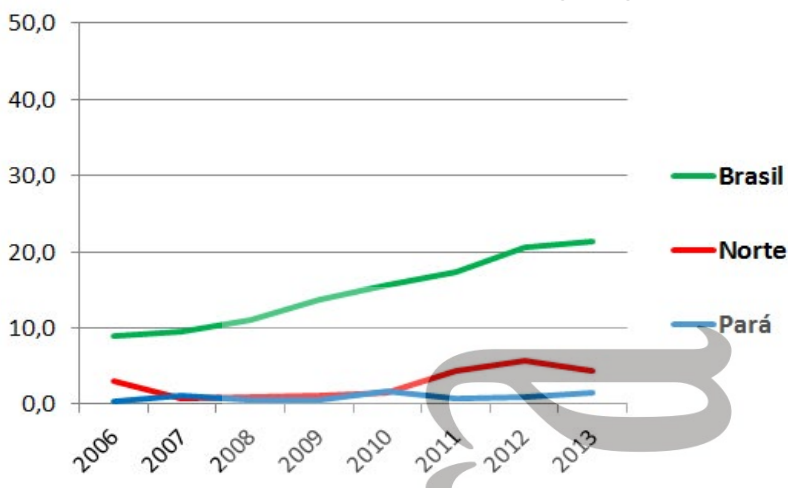

FÍGADO - pmp

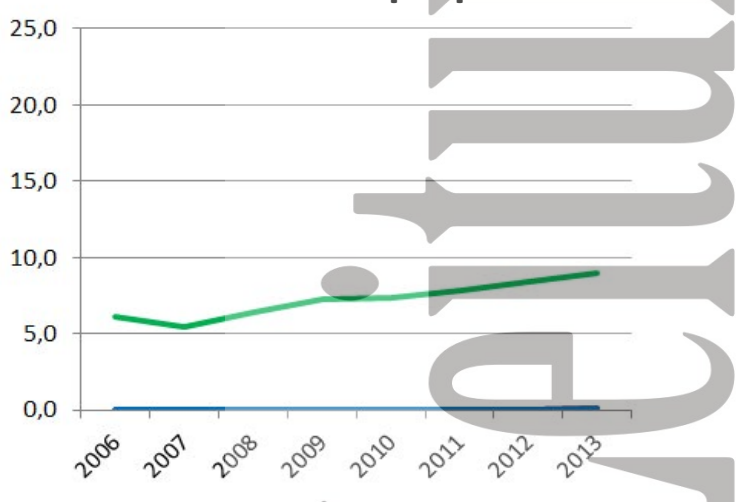

RIM com doador vivo - pmp

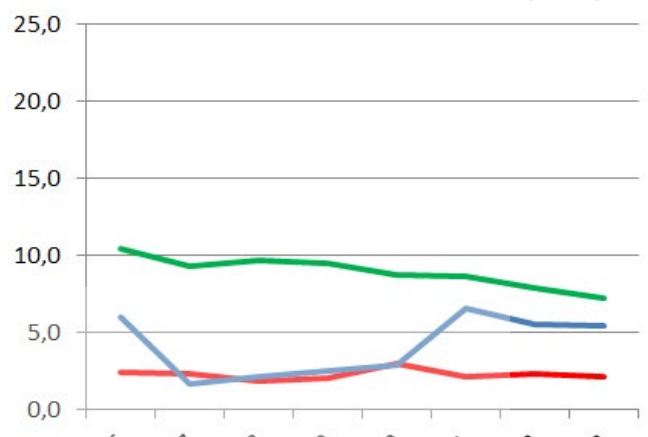

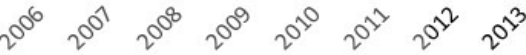
CÓRNEA- pmp

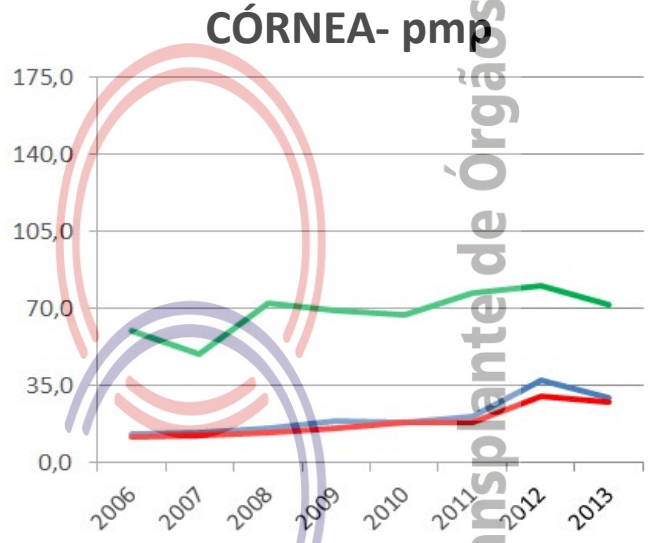

Número de equipes que realizaram $2006 \quad 2007$ transplantes durante o ano CÓRNEA

RIM

FÍGADO

PÂNCREAS (não realiza)

CORAÇÃO

PULMÃO (não realiza)

\begin{tabular}{l} 
Número absoluto de tran \\
\hline CÓRNEA \\
RIM - total \\
doador vivo \\
doador falecido \\
FÍGADO \\
PÂNCREAS (não realiza) \\
CORAÇÃO \\
PULMÃO (não realiza)
\end{tabular}

\begin{tabular}{|c|c|c|c|c|c|c|c|c|}
\hline Número de transplantes pmp & 2006 & 2007 & 2008 & 2009 & 2010 & 2011 & 2012 & 2013 \\
\hline CÓRNEA & 12,6 & 13,6 & 15,6 & 19,1 & 18,5 & 21,1 & 37,5 & 27,8 \\
\hline RIM - total & 6,3 & 2,8 & 2,7 & 3,1 & 4,6 & 7,3 & 6,5 & 7,0 \\
\hline doador vivo & 0,3 & 1,1 & 0,6 & 0,6 & 1,7 & 0,7 & 0,9 & 1,6 \\
\hline doador falecido & 6,0 & 1,7 & 2,1 & 2,5 & 2,9 & 6,6 & 5,5 & 5,4 \\
\hline FÍGADO & 0,0 & 0,0 & 0,0 & 0,0 & 0,0 & 0,0 & 0,0 & 0,1 \\
\hline \multicolumn{9}{|l|}{ PÂNCREAS (não realiza) } \\
\hline CORAÇÃO & 0,0 & 0,1 & 0,0 & 0,0 & 0,0 & 0,0 & 0,0 & 0,0 \\
\hline
\end{tabular}




\section{PARAÍBA}

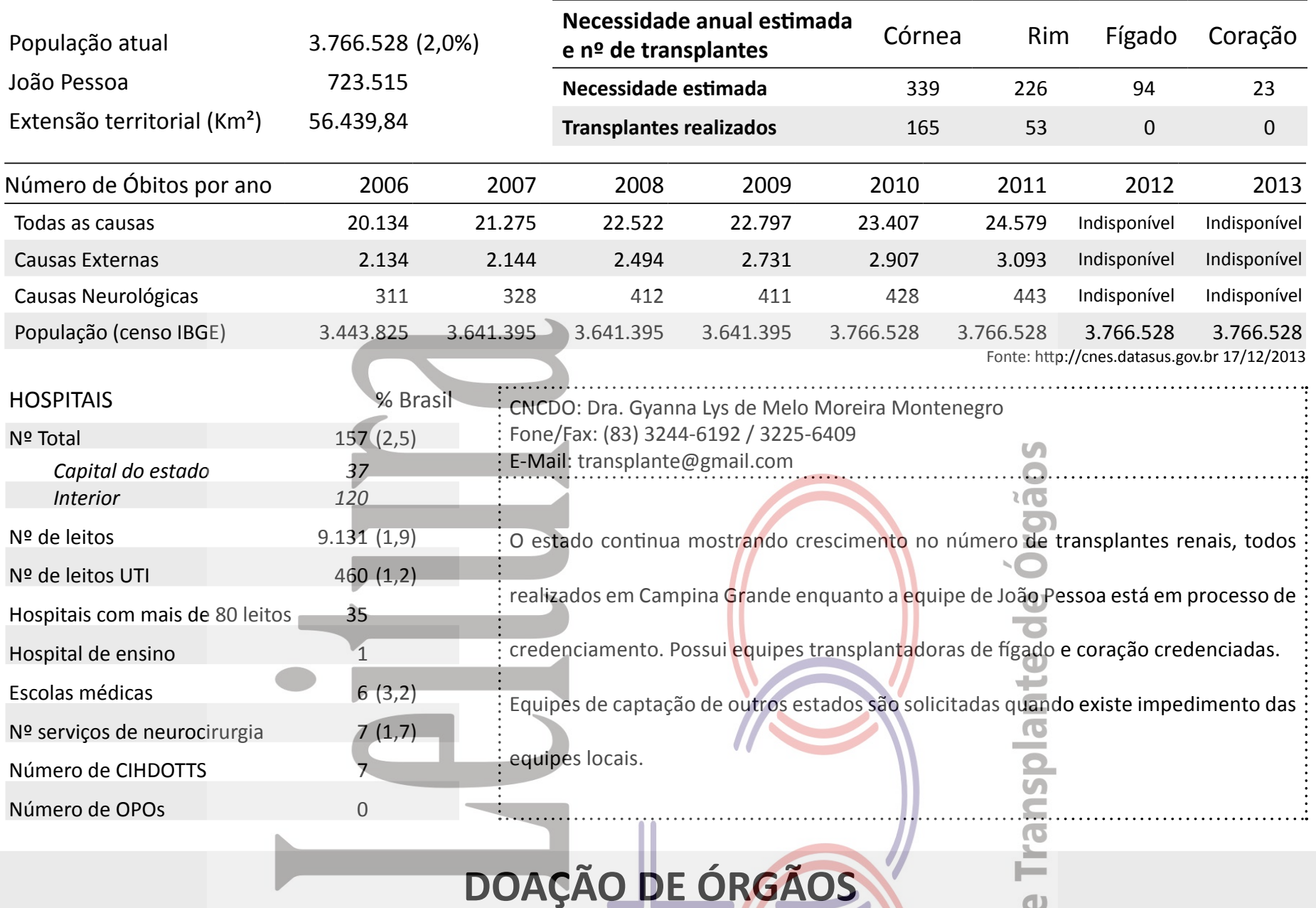

\section{Potenciais doadores notificados - pmp}

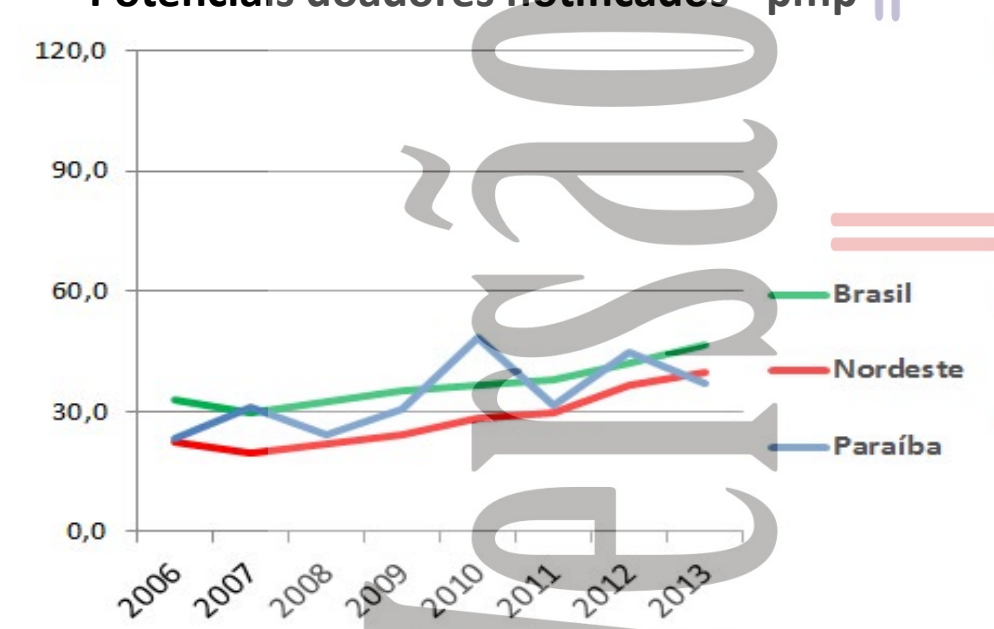

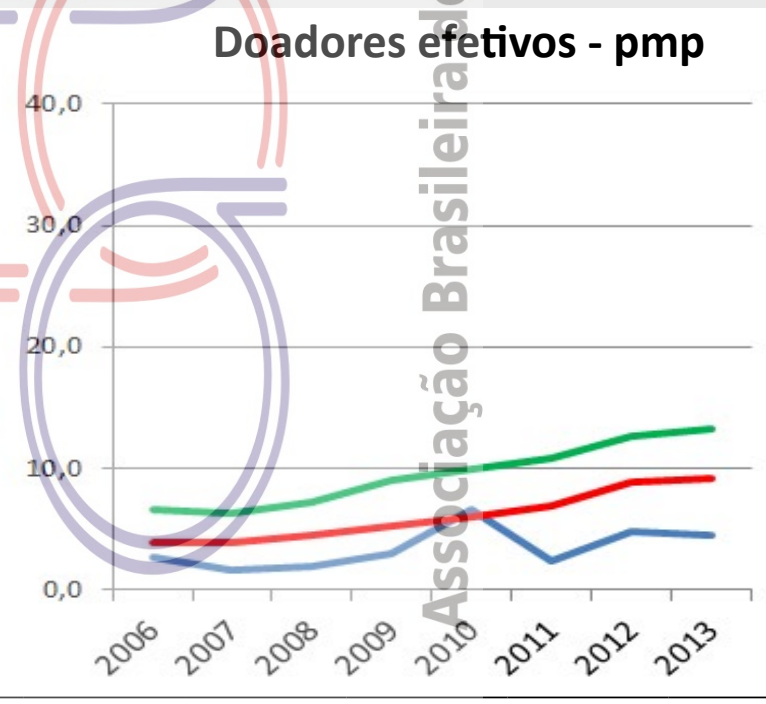

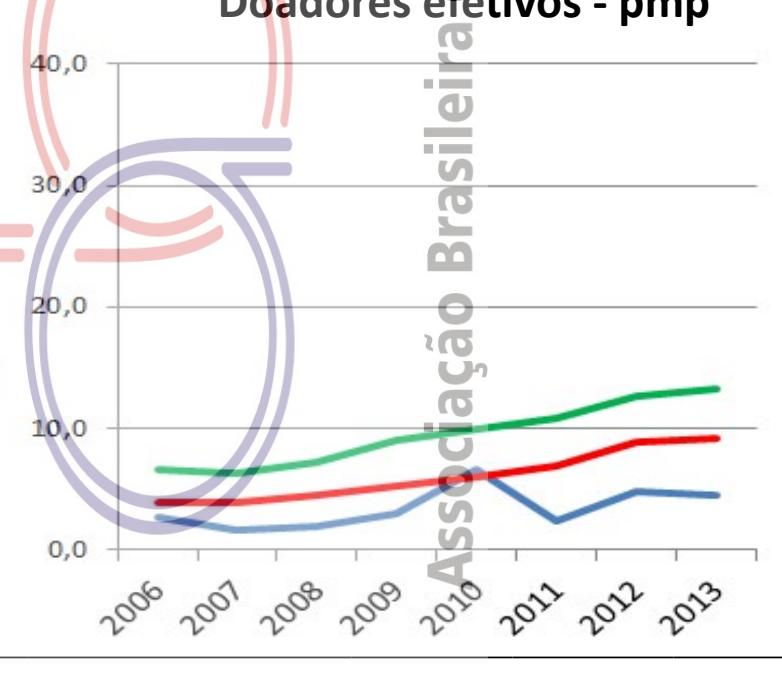

\begin{tabular}{lrrrrrrrr}
\hline & 2006 & 2007 & 2008 & 2009 & 2010 & 2011 & 2012 & 2013 \\
\hline Número de doadores efetivos & 9 & 6 & 7 & 11 & 25 & 9 & 18 & 17 \\
Número de doadores efetivos (pmp) & 2,6 & 1,6 & 1,9 & 3,0 & 6,6 & 2,4 & 4,8 & 4,5 \\
$\begin{array}{l}\text { Número de notificações } \\
\text { (potenciais doadores) }\end{array}$ & 80 & 114 & 88 & 112 & 183 & 119 & 169 & 139 \\
$\begin{array}{l}\text { Número de notificações (pmp) } \\
\text { Recusa familiar }\end{array}$ & 23,2 & 31,3 & 24,2 & 30,8 & 48,6 & 31,6 & 44,9 & 36,9 \\
Percentual de recusa das entrevistas & Indisponível & Indisponível & Indisponível & Indisponível & Indisponível & Indisponível & 64 & 31 \\
Parada Cardíaca & Indisponível & Indisponível & 32 & 40 & 32 & 16 & 4 & 44 \\
Contraindicação médica & 48 & 79 & 14 & 25 & 40 & 31 & 32 & 13 \\
Outros & 8 & 6 & 10 & 10 & 34 & 38 & 71 & 74
\end{tabular}




\section{PARAÍBA}

\section{TRANSPLANTE DE ÓRGÃOS}

\section{RIM com doador falecido - pmp}
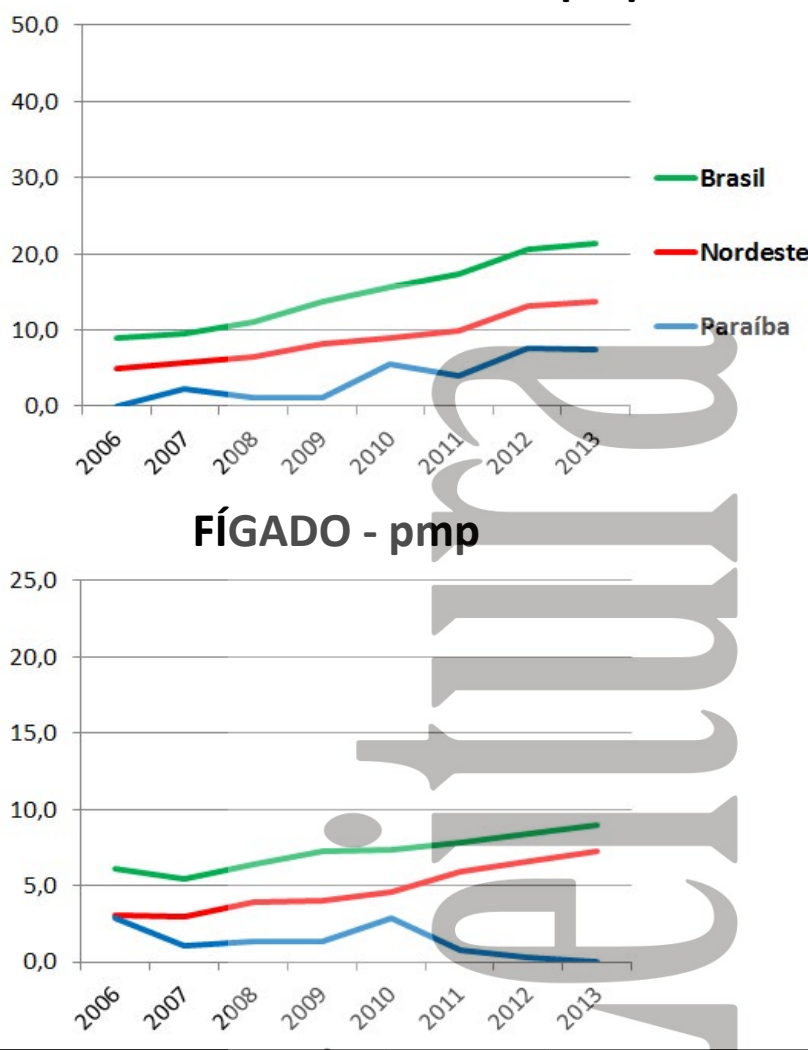

RIM com doador vivo - pmp

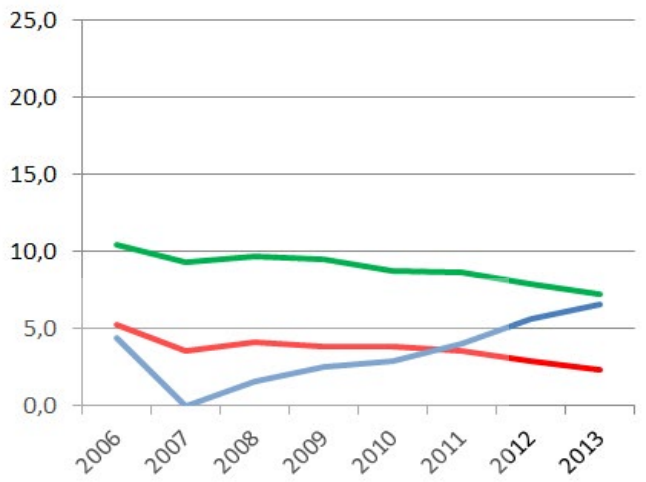

CÓRNEA- pmp

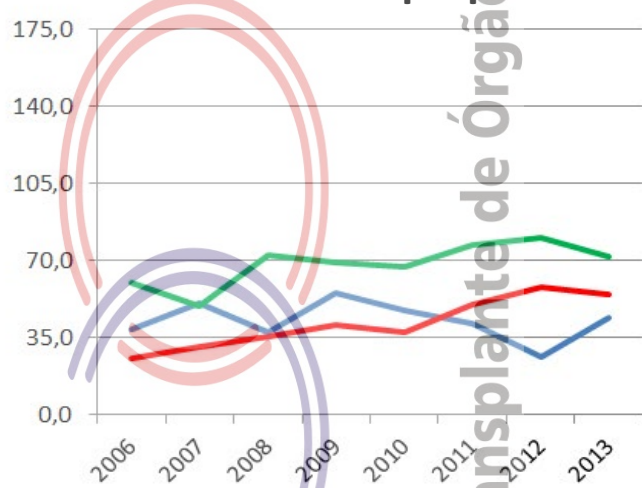

Número de equipes que realizaram $2006 \quad 2007$ transplantes durante $o$ ano CÓRNEA

RIM

FÍGADO

PÂNCREAS (não realiza)

CORAÇÃO

PULMÃO (não realiza)

\begin{tabular}{l} 
Número absoluto de tran \\
\hline CÓRNEA \\
RIM - total \\
doador vivo \\
doador falecido \\
FÍGADO \\
PÂNCREAS (não realiza) \\
CORAÇÃO \\
PULMÃO (não realiza)
\end{tabular}

\begin{tabular}{|c|c|c|c|c|c|c|c|c|}
\hline Número de transplantes pmp & 2006 & 2007 & 2008 & 2009 & 2010 & 2011 & 2012 & 2013 \\
\hline CÓRNEA & 38,9 & 50,8 & 37,1 & 55,5 & 47,3 & 41,2 & 26,3 & 43,8 \\
\hline RIM - total & 4,4 & 2,2 & 2,7 & 3,6 & 8,5 & 8,0 & 13,3 & 14,1 \\
\hline doador vivo & 4,4 & 0,0 & 1,6 & 2,5 & 2,9 & 4,0 & 5,6 & 6,6 \\
\hline doador falecido & 0,0 & 2,2 & 1,1 & 1,1 & 5,6 & 4,0 & 7,7 & 7,4 \\
\hline FÍGADO & 2,9 & 1,1 & 1,4 & 1,4 & 2,9 & 0,8 & 0,3 & 0,0 \\
\hline \multicolumn{9}{|l|}{ PÂNCREAS (não realiza) } \\
\hline CORAÇÃO & 0,3 & 0,0 & 0,0 & 0,3 & 0,0 & 0,0 & 0,0 & 0,0 \\
\hline
\end{tabular}


População atual

$10.444 .526(5,5 \%)$

Curitiba

1.751 .907

Extensão territorial $\left(\mathrm{Km}^{2}\right)$

$199.314,85$

\begin{tabular}{|rrrrrr}
\hline $\begin{array}{l}\text { Necessidade anual estimada } \\
\text { e no de transplantes }\end{array}$ & Córnea & Rim & Fígado & Coração \\
\hline \multicolumn{2}{l}{$\begin{array}{r}\text { Necessidade estimada } \\
\text { Transplantes realizados }\end{array}$} & 940 & 627 & 261 & 63 \\
\hline 2008 & 2009 & 2010 & 2011 & 2012 & 2013 \\
\hline 63.781 & 64.960 & 66.969 & 68.598 & Indisponível & Indisponível \\
9.074 & 9.286 & 9.535 & 9.376 & Indisponível & Indisponível \\
1.356 & 1.464 & 1.641 & 1.766 & Indisponível & Indisponível \\
10.284 .503 & 10.284 .503 & 10.444 .526 & 10.444 .526 & 10.444 .526 & 10.444 .526 \\
& & & Fonte: http://cnes.datasus.gov.br 17/12/2013
\end{tabular}

HOSPITAIS

№ Total

Capital do estado

Interior

№ de leitos

№ de leitos UTI

60.610

2007

8.463

61.597

1.168

8.832

$9.563 .458-10.284$

1.265

$\%$ Brasil

$477(7,6)$

63

414

$30.103(6,3)$

$2.334(6,2)$

Hospitais com mais de 80 leitos 116

Hospital de ensino

Escolas médicas

№ serviços de neurocirurgia

Número de CIHDOTTS

Número de OPOs

12

$11(5,8)$

$40(9,7)$

60

3
CNCDO: Arlene Terezinha Cagol Garcia Badoch

Fone/Fax: (41) 3304-1900/ 1909

E-Mail: sesatran@sesa.pr.gov.br

()

Dispõe de programa de transplantes bem estruturado há décadas, com número crescente de doadores efetivos e de transplantes, nos últimos cinco anos. Tem 60 Comissões Intra-Hospitalares de Doação de Órgãos e Tecidos (CIHDOTT) estruturadas, o Estado do Paraná conta com três OPO's públicas, localizadas em Maringá, Londrina e Cascavel, abrangendo uma população em torno de 5.500.000 habitantes. As limitações estão na resistência de profissionais na notificação de potenciais doadores e alta recusa familiar. Apresenta programa de humanização e-acolhimento de familiares de doadores.

A Central possui duas médicas intensivistas para apoio a todas as UTI's do Estado, dirimindo dúvidas relacionadas ao Protocolo de Morte Encefálica e procedendo a
orientações referentes à Manutenção Hemodinâmica de prováveis doadores.

\section{DOAÇÃO DE ÓRGÃOS}

Potenciais doadores notificados - pmp

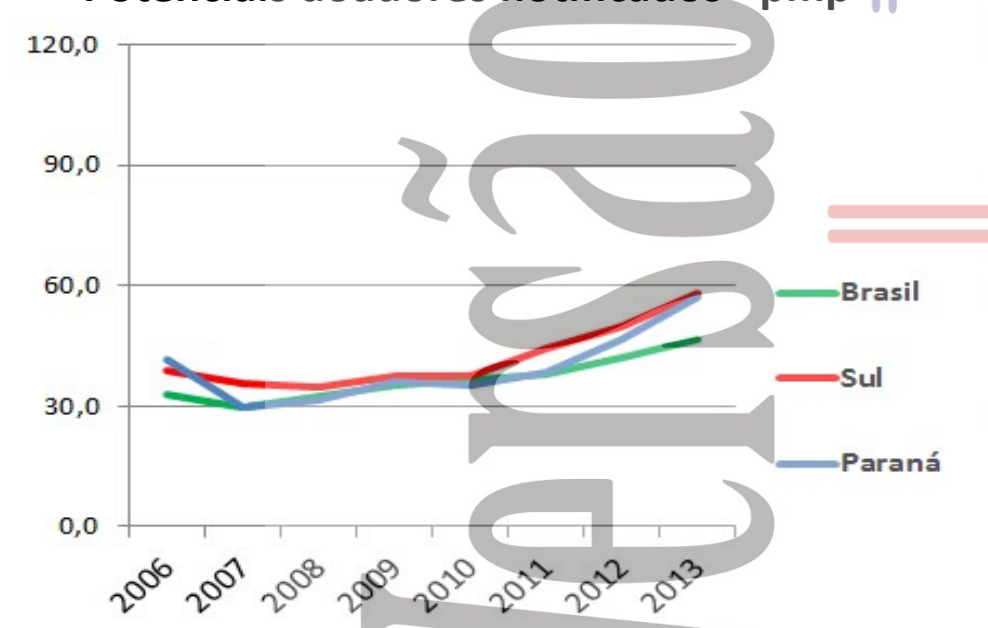

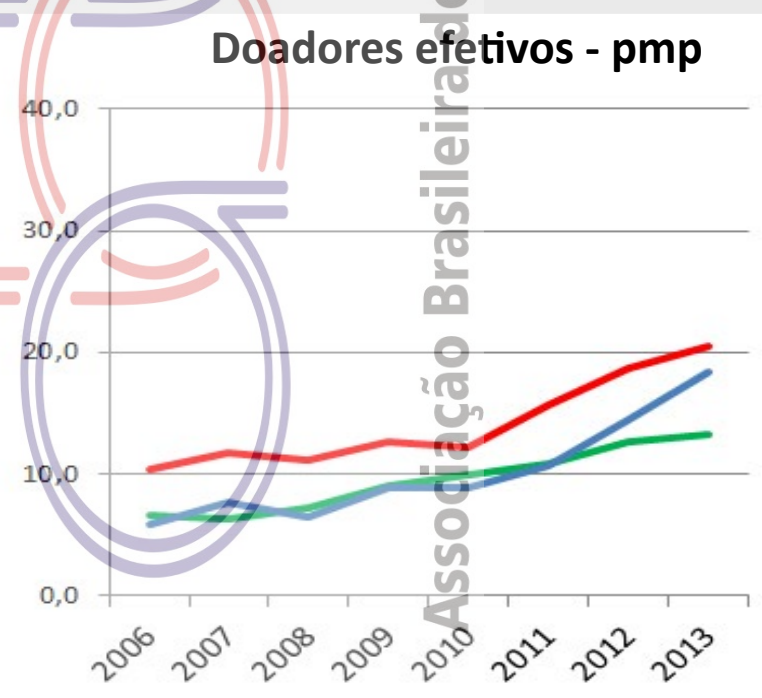

\begin{tabular}{lrrrrrrrr} 
& 2006 & 2007 & 2008 & 2009 & 2010 & 2011 & 2012 & 2013 \\
\hline Número de doadores efetivos & 55 & 78 & 66 & 91 & 93 & 112 & 151 & 191 \\
Número de doadores efetivos (pmp) & 5,8 & 7,6 & 6,4 & 8,8 & 8,9 & 10,7 & 14,5 & 18,3 \\
$\begin{array}{l}\text { Número de notificações } \\
\text { (potenciais doadores) }\end{array}$ & 398 & 307 & 326 & 372 & 370 & 401 & 488 & 597 \\
Número de notificações (pmp) & 41,6 & 29,9 & 31,7 & 36,2 & 35,4 & 38,4 & 46,7 & 57,2 \\
Recusa familiar & 67 & 81 & 105 & 103 & 90 & 122 & 159 & 156
\end{tabular}

Percentual de recusa das entrevistas

Parada Cardíaca

Indisponível Indisponível Indisponível Indisponível Indisponível Indisponível

48

42

\begin{tabular}{llrr} 
& Indisponível & Indisponível \\
\hline & Contraindicação médica & 206 & 135 \\
\cline { 2 - 3 } & Outros & 70 & 13
\end{tabular}

\begin{tabular}{llrr} 
& Parada Cardíaca & Indisponível & Indisponível \\
\hline$\sum_{0}^{m}$ & Contraindicação médica & 206 & 135 \\
\cline { 1 - 2 } & Outros & 70 & 13
\end{tabular}

93

11

50

59

66

93

167

137

52

51

157

54

0

56

61

0 


\section{PARANÁ}

\section{TRANSPLANTE DE ÓRGÃOS}

\section{RIM com doador falecido - pmp}
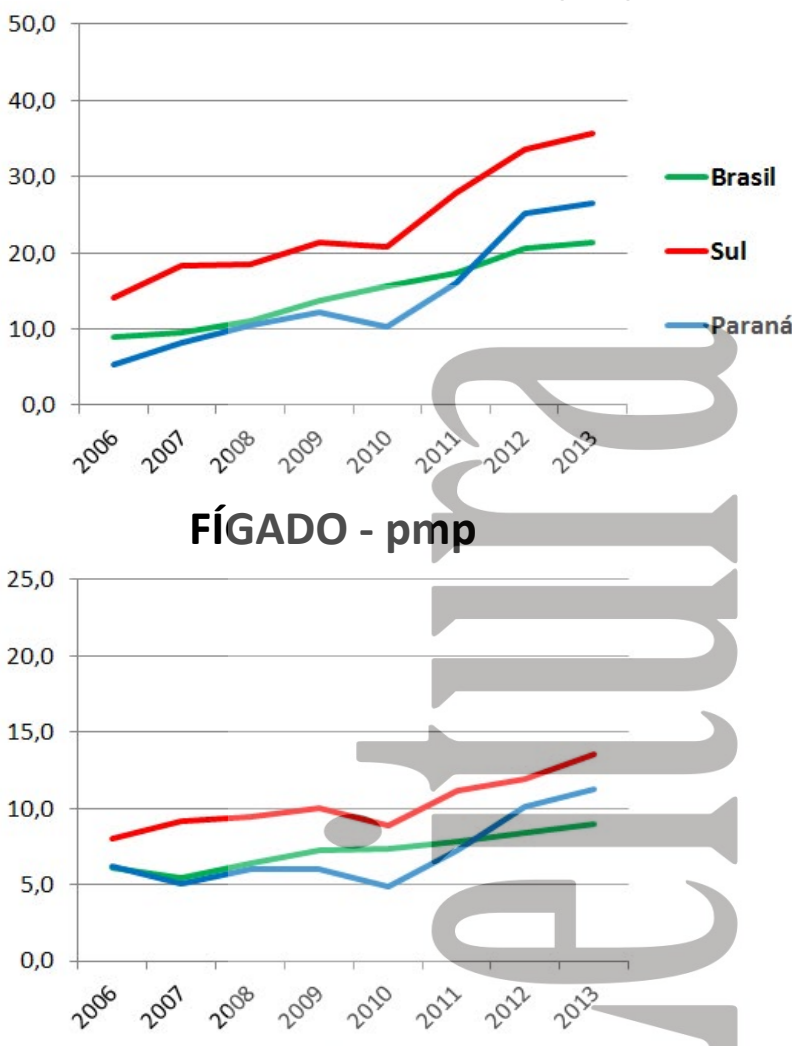

RIM com doador vivo - pmp

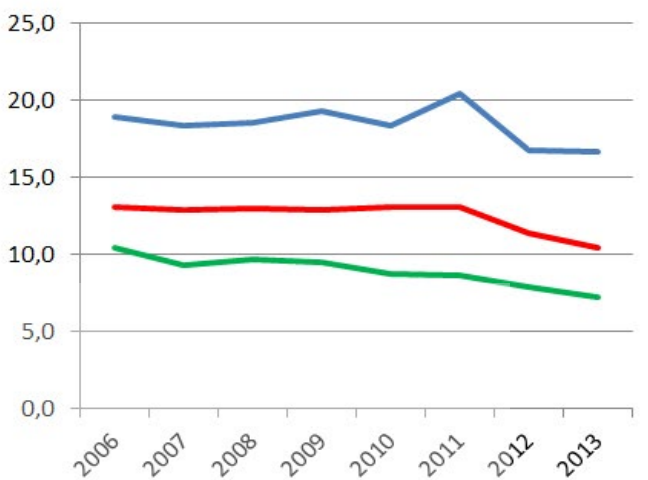

CÓRNEA- pmp

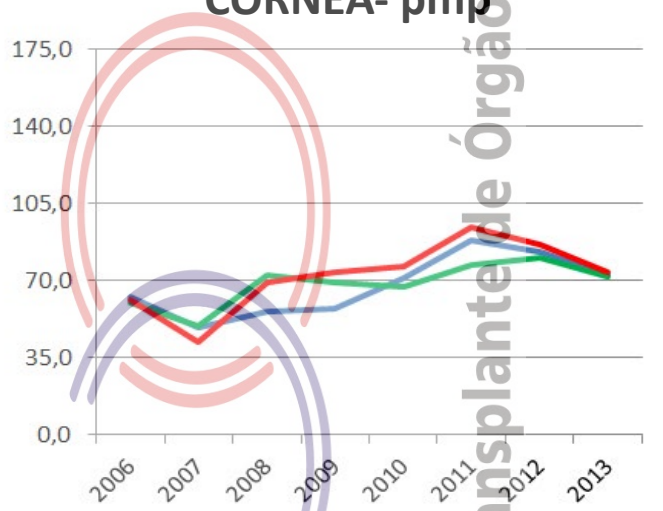

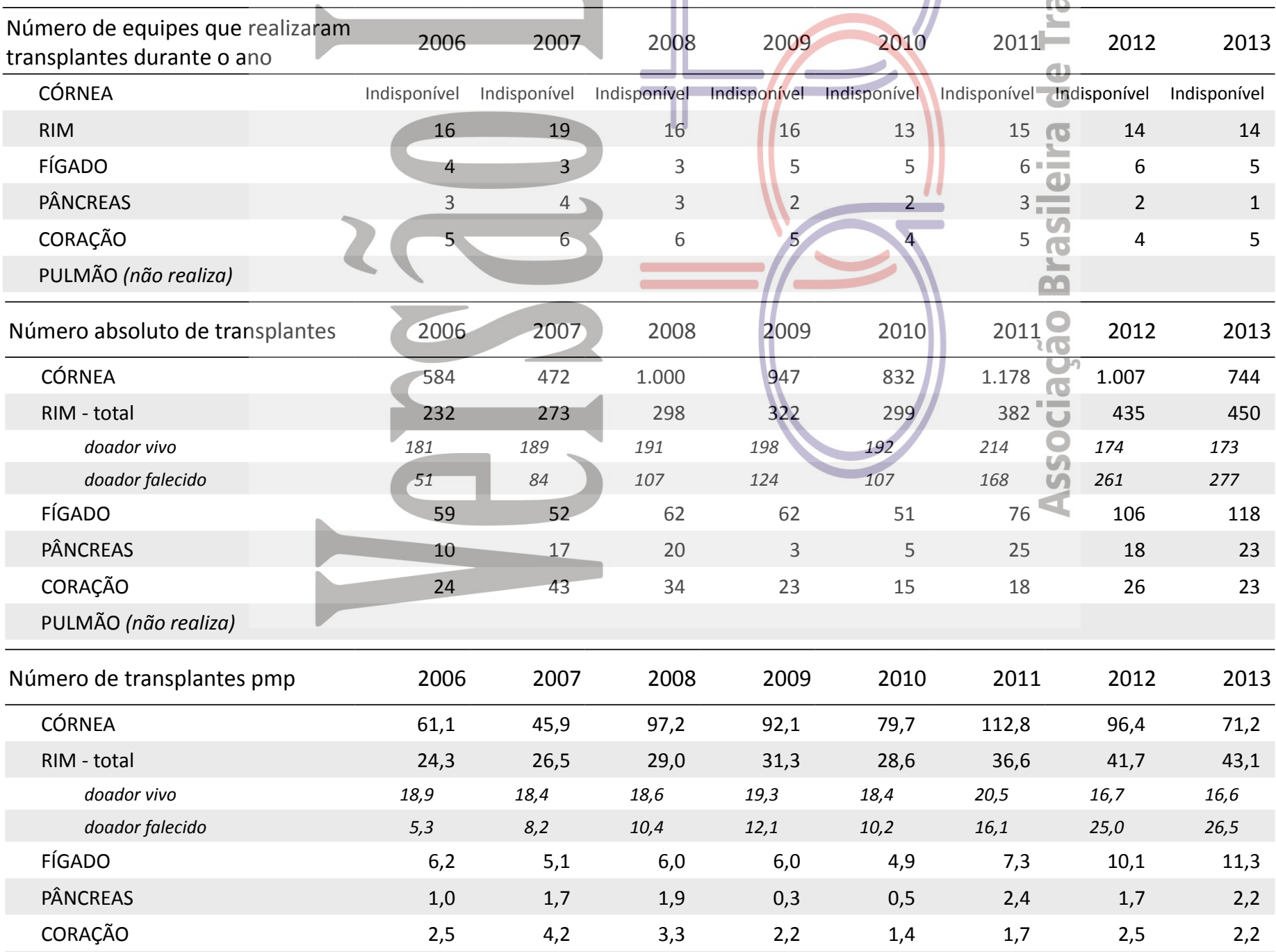

PULMÃo (não realiza) 


\section{PERNAMBUCO}

População atual

$8.796 .448(4,6 \%)$

Recife

1.537 .704

Extensão territorial $\left(\mathrm{Km}^{2}\right)$

$98.311,62$

\begin{tabular}{|rrrrrrr}
\hline $\begin{array}{l}\text { Necessidade anual estimada } \\
\text { e no de transplantes }\end{array}$ & Córnea & Rim & Fígado & Coração \\
\hline Necessidade estimada & 792 & 528 & 220 & 53 \\
\hline \multicolumn{2}{l}{ Transplantes realizados } & 865 & 281 & 127 & 27 \\
\hline 2008 & 2009 & 2010 & 2011 & 2012 & 2013 \\
\hline 54.124 & 54.678 & 54.570 & 57.219 & Indisponível & Indisponível \\
8.157 & 7.968 & 7.646 & 7.771 & Indisponível & Indisponível \\
726 & 705 & 811 & 904 & Indisponível & Indisponível \\
8.485 .386 & 8.485 .386 & 8.796 .448 & 8.796 .448 & $\begin{array}{c}8.796 .448 \\
8.796 .448\end{array}$ & 8.796 .45013 \\
\hline
\end{tabular}

\section{HOSPITAIS}

№ Total

\section{Capital do estado Interior}

№ de leitos

№ de leitos UTI

Hospitais com mais de 80 leitos

Hospital de ensino

Escolas médicas

№ serviços de neurocirurgia

Número de CIHDOTTS

Número de OPOs

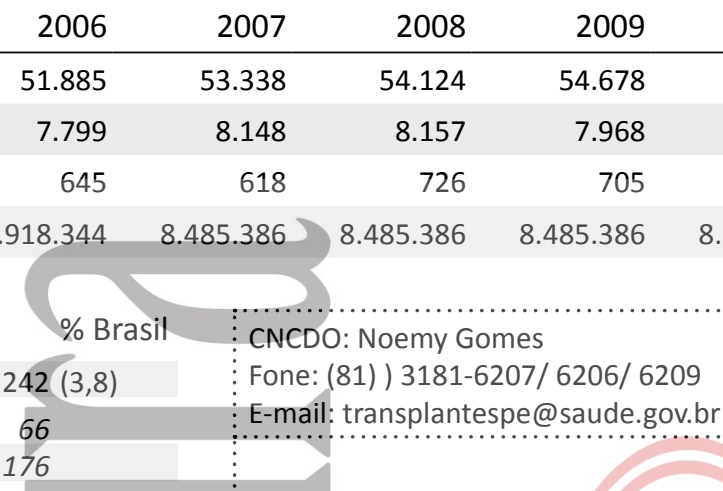

$20.861(4,4) \quad \vdots$ Programa bem estruturado, com apoio do governo estadual através do empenho $1.554(4,1) \quad \vdots$ pessoal do secretário de saúde. Tem número crescente de notificações de morte 84 encefálica e de doadores efetivos, mas ainda tem na negativa familiar o principal motivo $6 \quad \vdots$ de não doação, com uma taxa de $54 \%$. Dispõe de programa de educação permanente $5(2,6) \quad$ para treinamento das equipes hospitalares e de acompanhamento do desempenho das

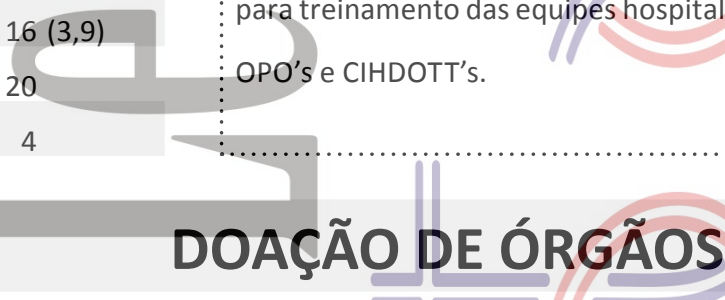

\section{Potenciais doadores notificados - pmp}

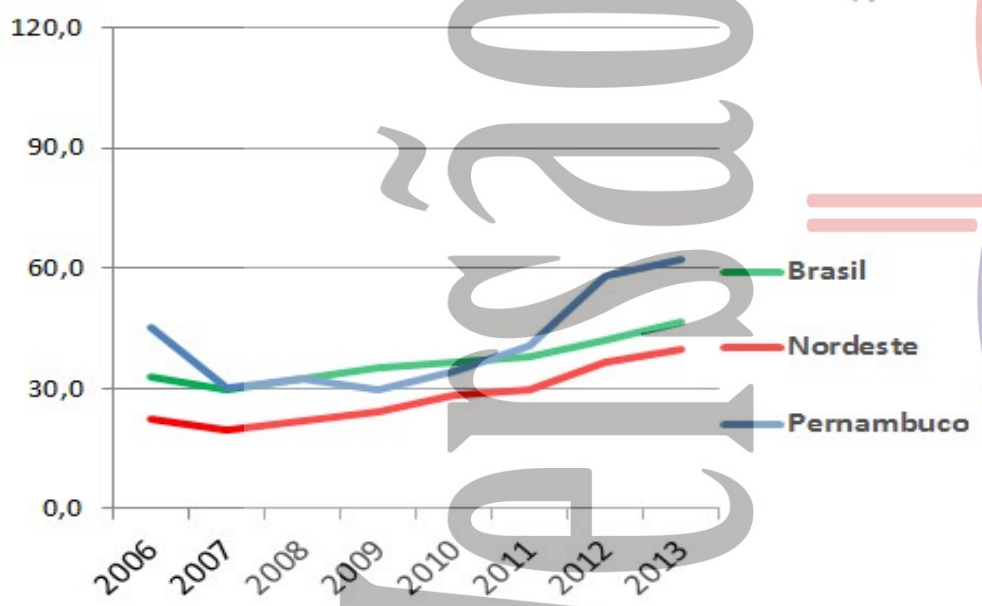

Doadores efetivos - pmp

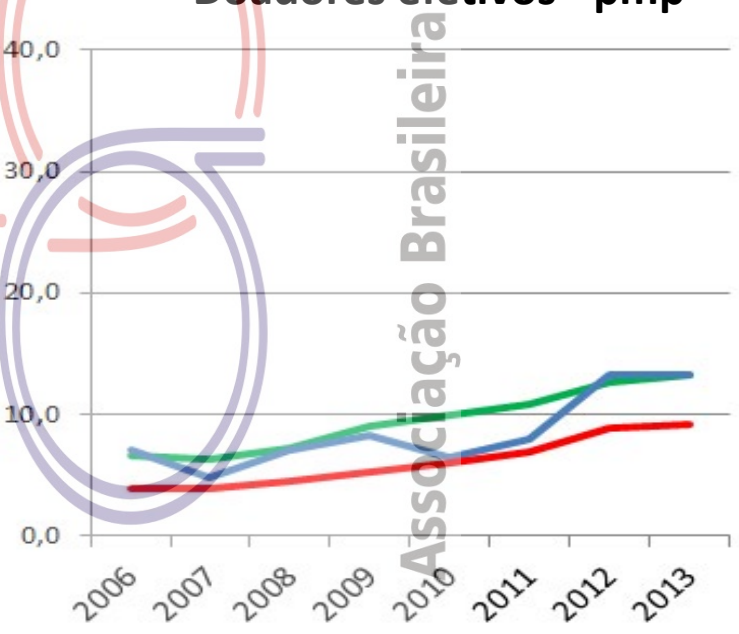

\begin{tabular}{|lrrrrrrrr}
\hline & 2006 & 2007 & 2008 & 2009 & 2010 & 2011 & 2012 & 2013 \\
\hline Número de doadores efetivos & 56 & 41 & 59 & 70 & 57 & 70 & 116 & 117 \\
\hline Número de doadores efetivos (pmp) & 7,1 & 4,8 & 7,0 & 8,2 & 6,5 & 8,0 & 13,2 & 13,3 \\
$\begin{array}{l}\text { Número de notificações } \\
\text { (potenciais doadores) }\end{array}$ & 360 & 258 & 274 & 251 & 302 & 359 & 512 & 546 \\
\hline Número de notificações (pmp) & 45,5 & 30,4 & 32,3 & 29,6 & 34,3 & 40,8 & 58,2 & 62,1 \\
\hline Recusa familiar & 88 & 60 & 59 & 59 & 69 & 86 & 141 & 175 \\
\hline Percentual de recusa das entrevistas & Indisponível & Indisponível & Indisponível & Indisponível & Indisponível & Indisponível & 53 & 54 \\
\hline Parada Cardíaca & Indisponível & Indisponível & 17 & 19 & 30 & 29 & 16 & 22 \\
\hline Contraindicação médica & 167 & 67 & 52 & 39 & 63 & 61 & 120 & 119 \\
\hline Outros & 49 & 90 & 87 & 64 & 83 & 113 & 119 & 113
\end{tabular}




\section{PERNAMBUCO}

\section{TRANSPLANTE DE ÓRGÃOS}

\section{RIM com doador falecido - pmp}
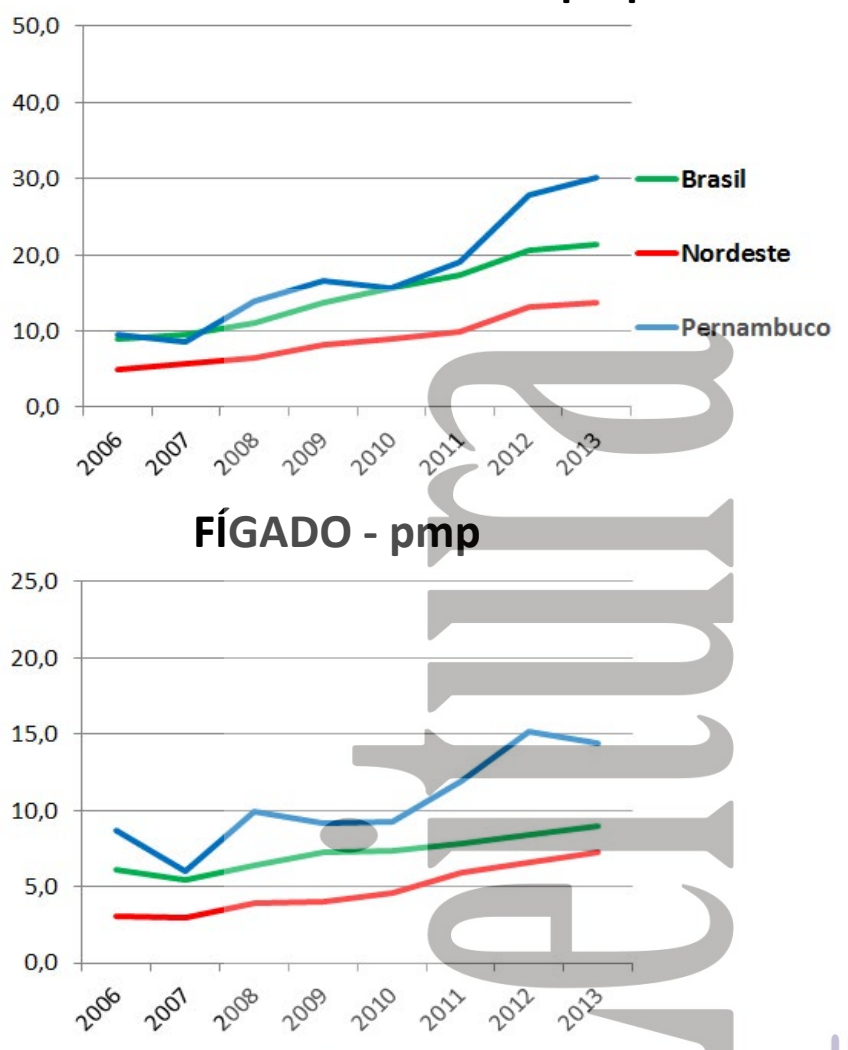

RIM com doador vivo - pmp
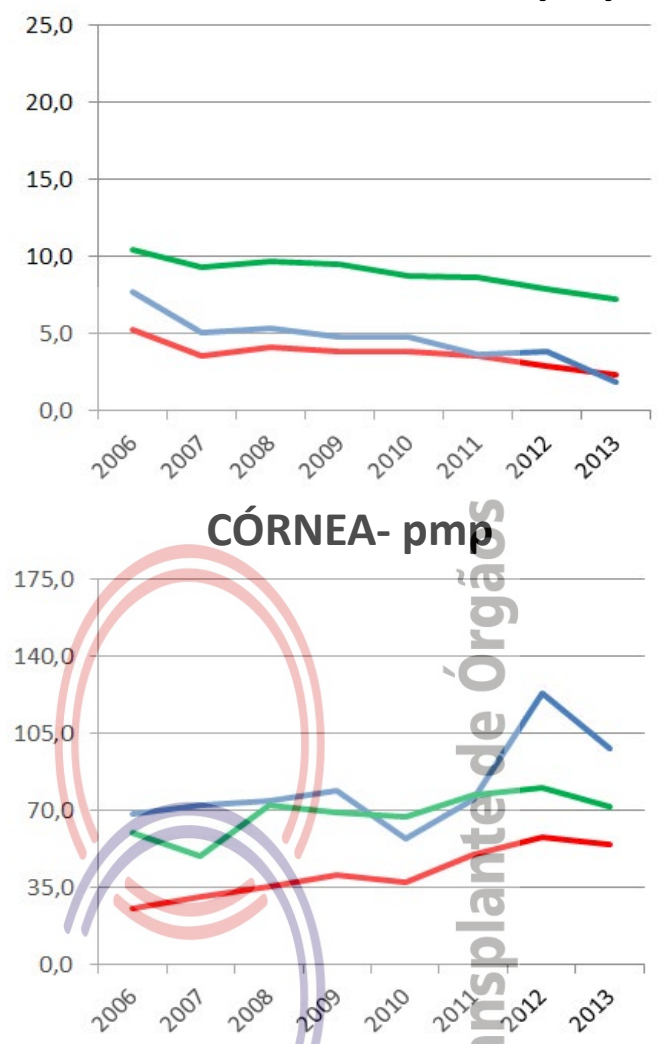

\begin{tabular}{lllllllll}
\hline $\begin{array}{l}\text { Número de equipes que realizaram } \\
\text { transplantes durante o ano }\end{array}$ & 2006 & 2007 & 2008 & 2009 & 2010 & 2011 & 2012 & 2013 \\
\hline
\end{tabular} transplantes durante ónNeA Indisponível Indisponível Indisponível Indisponível Indisponível Indisponível Indisponível Indisponível

RIM

FÍGADO

PÂNCREAS

CORAÇÃO

PULMÃO (não realiza)

\begin{tabular}{ccc}
\hline Número absoluto de transplantes & 2006 & 2007 \\
\hline CÓRNEA & 540 & 614 \\
RIM - total & 137 & 116 \\
doador vivo & 61 & 43 \\
doador falecido & 76 & 73 \\
\hline
\end{tabular}

FÍGADO

PÂNCREAS

CORAÇÃO

PULMÃO (não realiza)

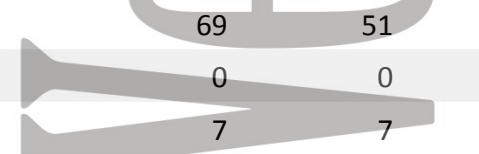

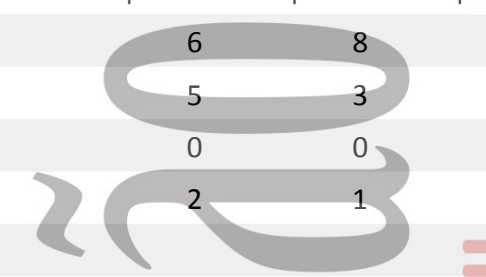

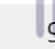

\section{3}

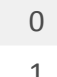

1

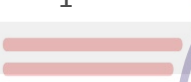

2008

633

164

164

45

119

\begin{tabular}{cc|cccc}
\hline 2009 & 2010 & 2011 & 2012 & 2013 \\
\hline 671 & 506 & 661 & 1.084 & 865 \\
182 & 180 & 200 & 278 & 281 \\
41 & 42 & 32 & & 33 & 16 \\
141 & 138 & 168 & แ & 245 & 265
\end{tabular}

84

78

82

$105<$

6 r 4

3 (1) 3

$0 \quad 1$

1

4

3

\begin{tabular}{ccccccccc}
\hline Número de transplantes pmp & 2006 & 2007 & 2008 & 2009 & 2010 & 2011 & 2012 & 2013 \\
\hline CÓRNEA & 68,2 & 72,4 & 74,6 & 79,1 & 57,5 & 75,1 & 123,2 & 98,3 \\
RIM - total & 17,3 & 13,7 & 19,3 & 21,4 & 20,5 & 22,7 & 31,6 & 31,9 \\
$\quad$ doador vivo & 7,7 & 5,1 & 5,3 & 4,8 & 4,8 & 3,6 & 3,8 & 1,8 \\
$\quad$ doador falecido & 9,6 & 8,6 & 14,0 & 16,6 & 15,7 & 19,1 & 27,9 & 30,1
\end{tabular}

FÍGADO

$8,7 \quad 6,0$

PÂNCREAS

$0,0 \quad 0,0$

CORAÇÃO

0,9

0,8

9,9

9,2

9,3

11,9

15,2

PULMÃO (não realiza)

0,0

0,8

0,0

0,9




\section{PIAUÍ}

$\begin{array}{lc}\text { População atual } & 3.118 .360(1,6 \%) \\ \text { Teresina } & 814.230\end{array}$

Extensão territorial $\left(\mathrm{Km}^{2}\right) \quad 251.529,19$

\begin{tabular}{|rrrrrrr}
\hline $\begin{array}{l}\text { Necessidade anual estimada } \\
\text { e no de transplantes }\end{array}$ & Córnea & Rim & Fígado & Coração \\
\hline $\begin{array}{r}\text { Necessidade estimada } \\
\text { Transplantes realizados }\end{array}$ & 281 & 187 & 78 & 19 \\
\hline 2008 & 2009 & 2010 & 2011 & 2012 & 2013 \\
\hline 15.489 & 15.573 & 15.614 & 17.052 & Indisponível & Indisponível \\
1.789 & 1.860 & 1.975 & 2.083 & Indisponível & Indisponível \\
296 & 267 & 258 & 274 & Indisponível & Indisponível \\
3.032 .421 & 3.032 .421 & 3.118 .360 & $\begin{array}{r}3.118 .360 \\
\text { Fonte: http://cnes.datasus.gov.br } 17 / 12 / 2013\end{array}$ \\
\hline
\end{tabular}

\section{HOSPITAIS}

№ Total

\section{Capital do estado} Interior

№ de leitos

№ de leitos UTI

$\begin{array}{rr}2006 & 2007 \\ 14.484 & 14.884 \\ 1.717 & 1.654 \\ 252 & 240\end{array}$

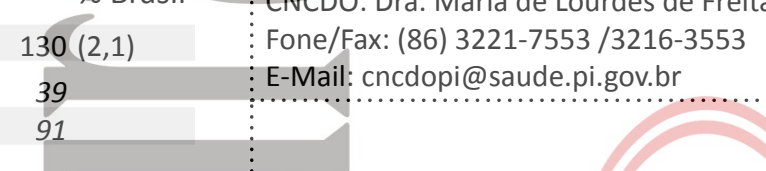

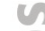<smiles>[GeH3]</smiles>

$6.707(1,4) \quad$ O Estado registrou, em 2013 a maior taxa de efetivação de potenciais doadores, em $286(0,8)$ relação os anos anteriores, porém continua com grandes dificuldades na manutenção Hospital de ensino Escolas médicas № serviços de neurocirurgia Número de CIHDOTTS Número de OPOs

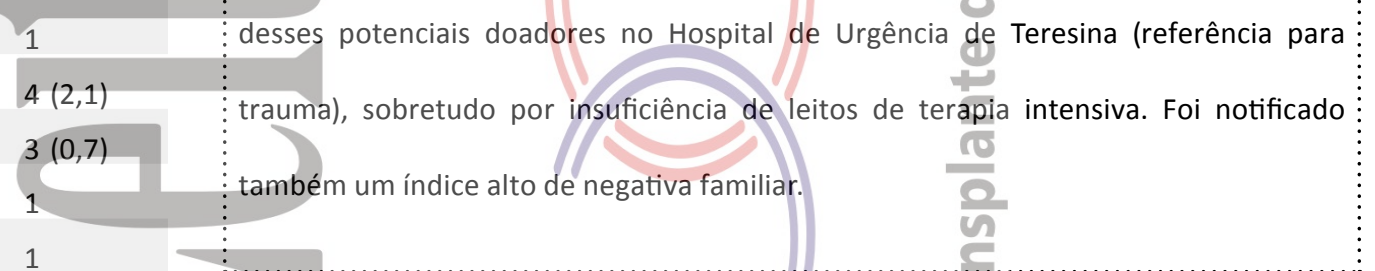

\section{DOAÇÃO DE ÓRGÃOS}

\section{Potenciais doadores notificados - pmp}

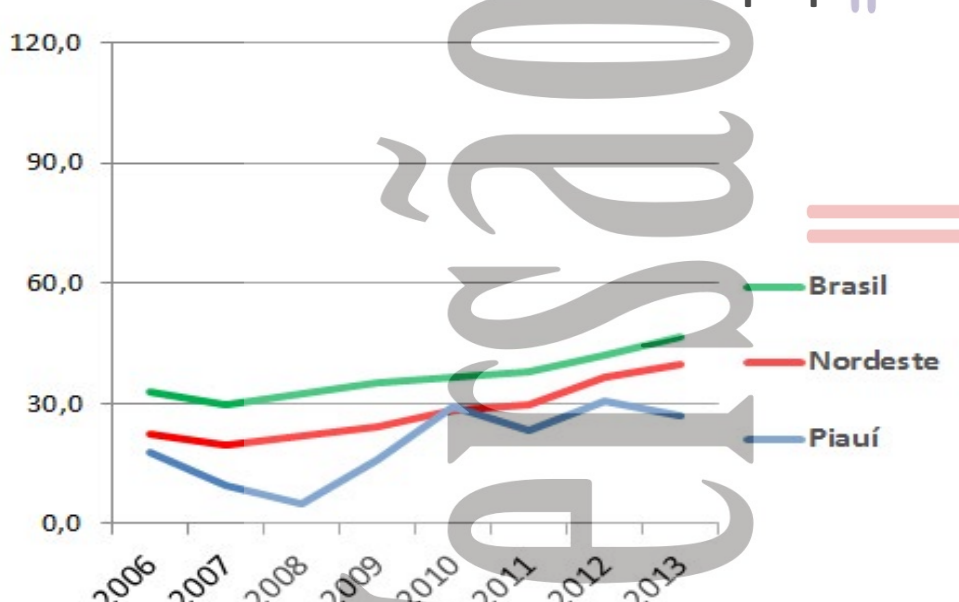

Doadores efetivos - pmp

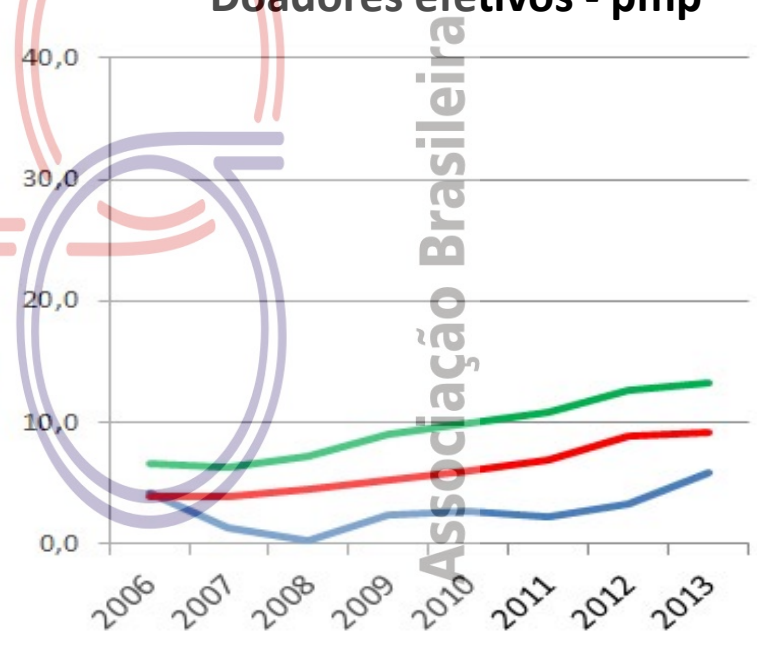

\begin{tabular}{|c|c|c|c|c|c|c|c|c|}
\hline & 2006 & 2007 & 2008 & 2009 & 2010 & 2011 & 2012 & 2013 \\
\hline Número de doadores efetivos & 12 & 4 & 1 & 7 & 8 & 7 & 10 & 18 \\
\hline Número de doadores efetivos (pmp) & 4,2 & 1,3 & 0,3 & 2,3 & 2,6 & 2,2 & 3,2 & 5,8 \\
\hline $\begin{array}{l}\text { Número de notificações } \\
\text { (potenciais doadores) }\end{array}$ & 51 & 29 & 15 & 48 & 91 & 73 & 96 & 84 \\
\hline Número de notificações (pmp) & 17,9 & 9,6 & 4,9 & 15,8 & 29,2 & 23,4 & 30,8 & 26,9 \\
\hline Recusa familiar & 23 & 18 & 8 & 15 & 41 & 13 & 20 & 37 \\
\hline Percentual de recusa das entrevistas & Indisponível & Indisponível & Indisponível & Indisponível & Indisponível & Indisponível & 57 & 62 \\
\hline Parada Cardíaca & Indisponível & Indisponível & 0 & 4 & 11 & 17 & 37 & 3 \\
\hline Contraindicação médica & 16 & 7 & 6 & 4 & 26 & 25 & 8 & 9 \\
\hline Outros & 0 & 0 & 0 & 18 & 5 & 11 & 21 & 17 \\
\hline
\end{tabular}




\section{PIAUÍ}

\section{TRANSPLANTE DE ÓRGÃOS}

\section{RIM com doador falecido - pmp}

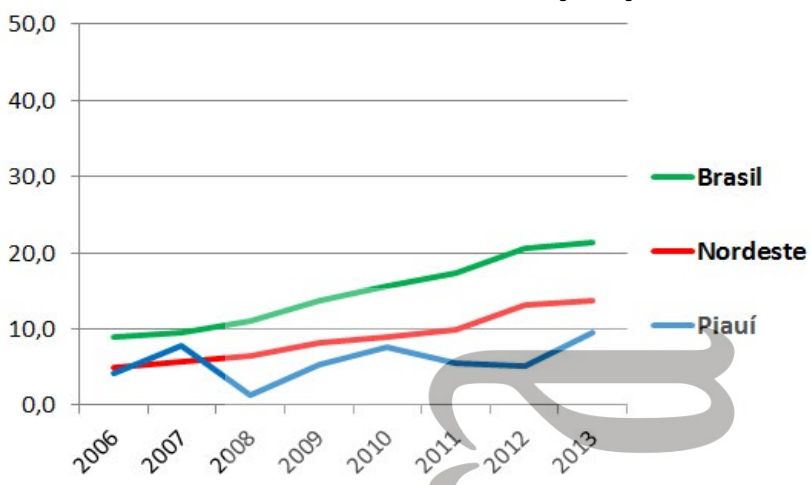

FíGADO - pmp (não realiza)

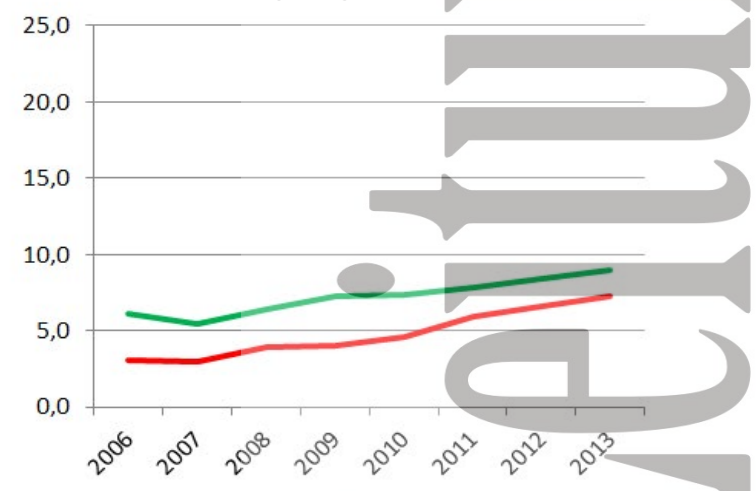

RIM com doador vivo - pmp

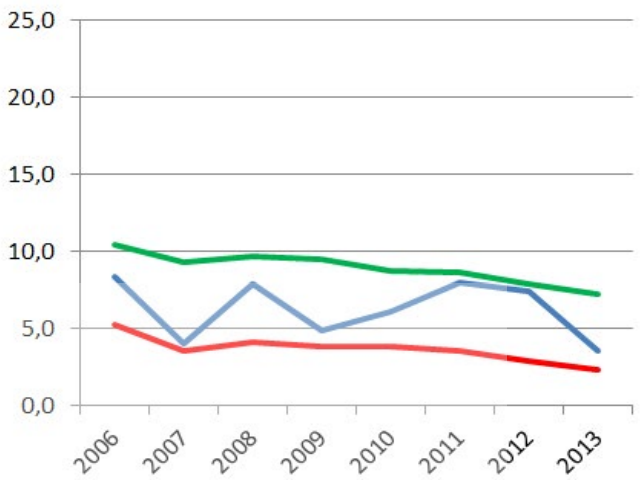

CÓRNEA- pmp

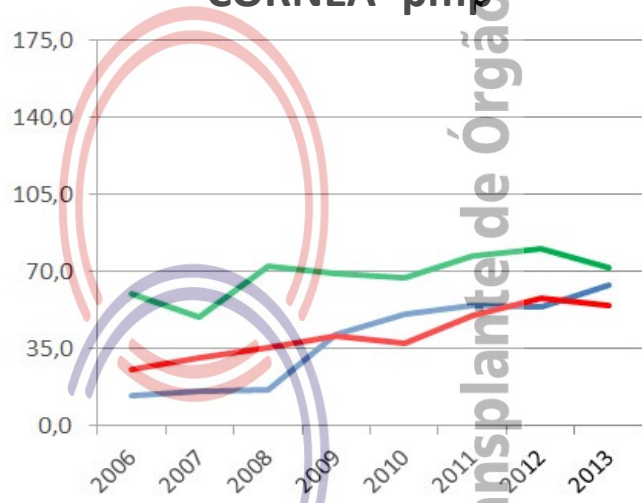

Número de equipes que realizaram $2006 \quad 2007$ transplantes durante o ano CÓRNEA

RIM

FÍGADO (não realiza)

PÂNCREAS (não realiza)

CORAÇÃO

PULMÃO (não realiza)

\begin{tabular}{l}
\hline Número absoluto de trans \\
\hline CÓRNEA \\
RIM - total \\
doador vivo \\
doador falecido \\
FÍGADO (não realiza) \\
PÂNCREAS (não realiza) \\
CORAÇÃO \\
PULMÃO (não realiza)
\end{tabular}

\begin{tabular}{ccccccccc}
\hline Número de transplantes pmp & 2006 & 2007 & 2008 & 2009 & 2010 & 2011 & 2012 & 2013 \\
\hline CÓRNEA & 13,7 & 15,5 & 16,2 & 41,6 & 50,3 & 54,5 & 53,6 & 63,8 \\
RIM - total & 12,7 & 11,9 & 9,2 & 10,2 & 13,8 & 13,5 & 12,5 & 13,1 \\
$\quad$ doador vivo & 8,4 & 4,0 & 7,9 & 4,9 & 6,1 & 8,0 & 7,4 & 3,5 \\
doador falecido & 4,2 & 7,9 & 1,3 & 5,3 & 7,7 & 5,5 & 5,1 & 9,6
\end{tabular}

FÍGADO (não realiza)

PÂNCREAS (não realiza)

CORAÇÃO

0,0

0,3

0,0

0,0

0,0

0,0

0,0

0,0 


\section{RIO DE JANEIRO}

População atual

$15.989 .929(8,4 \%)$

Rio de Janeiro

6.320 .446

Extensão territorial $\left(\mathrm{Km}^{2}\right)$

$43.696,05$

\begin{tabular}{|crrrrrr}
\hline $\begin{array}{l}\text { Necessidade anual estimada } \\
\text { e no de transplantes }\end{array}$ & Córnea & Rim & Fígado & Coração \\
\hline \multicolumn{2}{l}{$\begin{array}{l}\text { Necessidade estimada } \\
\text { Transplantes realizados }\end{array}$} & 1.439 & 959 & 400 & 96 \\
\hline 2008 & 2009 & 2010 & 2011 & 2012 & 2013 \\
\hline 122.534 & 123.890 & 127.536 & 127.095 & Indisponível & Indisponível \\
14.420 & 14.184 & 13.794 & 13.765 & Indisponível & Indisponível \\
2.438 & 2.564 & 2.865 & 2.855 & Indisponivel & Indisponível \\
\hline
\end{tabular}

\begin{tabular}{lrrrrrrrrr}
\hline Número de Óbitos por ano & 2006 & 2007 & 2008 & 2009 & 2010 & 2011 & 2012 & 2013 \\
\hline Todas as causas & 118.423 & 120.217 & 122.534 & 123.890 & 127.536 & 127.095 & Indisponível & Indisponível \\
Causas Externas & 14.938 & 15.189 & 14.420 & 14.184 & 13.794 & 13.765 & Indisponível & Indisponível \\
Causas Neurológicas & 1.938 & 2.160 & 2.438 & 2.564 & 2.865 & 2.855 & Indisponível & Indisponível \\
População (censo IBGE) & 14.391 .282 & 15.420 .375 & 15.420 .375 & 15.420 .375 & 15.989 .929 & 15.989 .929 & 15.989 .929 & 15.989 .929
\end{tabular}

HOSPITAIS

№ Total

Capital do estado

Interior

$\%$ Brasil

$544(8,6)$

254

290

№ de leitos

№ de leitos UTI

Hospitais com mais de 80 leitos

Hospital de ensino

Escolas médicas

№ serviços de neurocirurgia

Número de CIHDOTTS

Número de OPOs

\section{$51.546(10,8)$}

$5.843(15,5)$
CNCDO: Rodrigo Alves Sarlo

Fone: (21) 2333-7535 / 7543

E-Mail: transplantes@saude.rj.gov.br

()

Houve aumento expressivo na identificação de potenciais doadores (26\%), superando a média da região sudeste. Aumento de $2 \%$ no número de doador efetivo, porém apresentou alta taxa de negativa familiar (50\%). OPO, com sede no Hospital Estadual IECAC. O projeto conta com um total de cinco OPOs.

11 - Foram formadas oito CIHDOTTs no último ano, com profissionais em caráter exclusivo, dentre médicos, enfermeiros, assistentes sociais e psicólogos.

$15(7,9) \quad$ - Lançamos em Setembro, mais um Banco de Olhos no estado e houve aumento no $41(10,0) \quad \vdots$ número de transplantes entre 2012-2013 - 15\%, o que ainda não é suficiente para zerar $41 \quad \vdots$ a fila, mas já demonstra avanço nesse sentido.

$\begin{array}{lll}\text { Sormado um grupo de } & \\ \text { Sociais e psicólogos. }\end{array}$

\section{DOAÇÃO DE ÓRGÃOS}

\section{Potenciais doadores notificados - pmp}

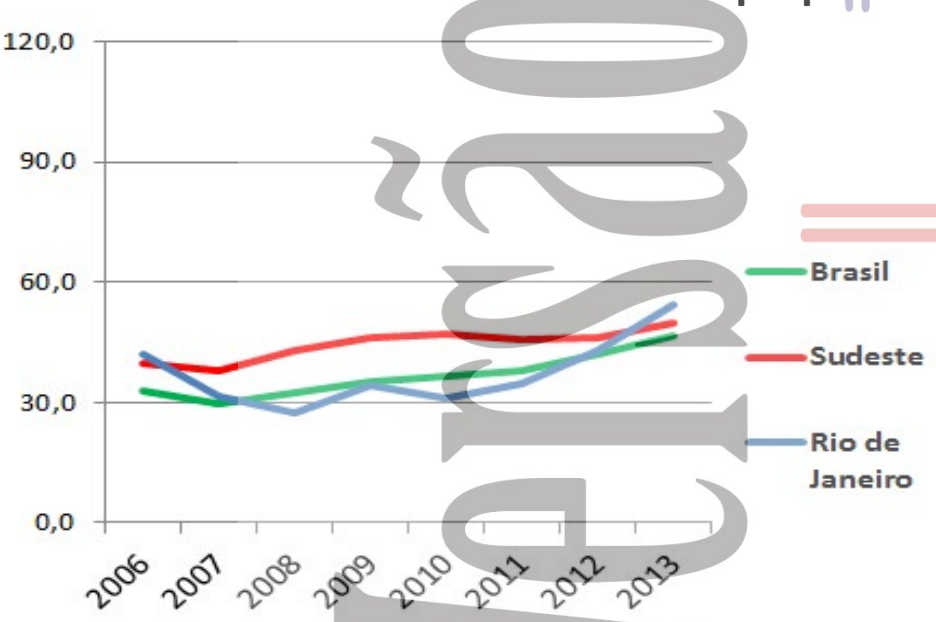

\section{Doadores efetivos - pmp}

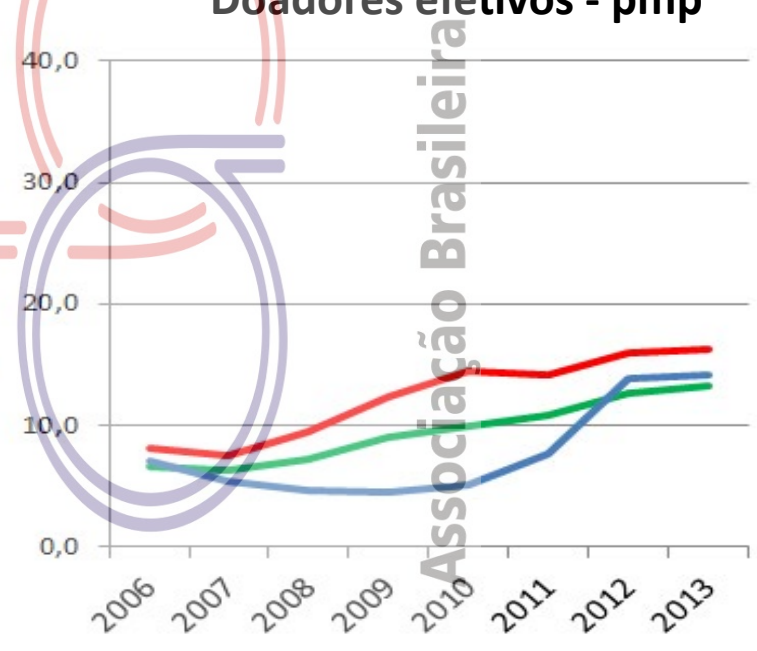

\begin{tabular}{lrrrrrrrr}
\hline & 2006 & 2007 & 2008 & 2009 & 2010 & 2011 & 2012 & 2013 \\
\hline Número de doadores efetivos & 101 & 82 & 71 & 69 & 80 & 121 & 221 & 225 \\
Número de doadores efetivos (pmp) & 7,0 & 5,3 & 4,6 & 4,5 & 5,0 & 7,6 & 13,8 & 14,1 \\
$\begin{array}{l}\text { Número de notificações } \\
\text { (potenciais doadores) }\end{array}$ & 603 & 488 & 421 & 526 & 498 & 556 & 688 & 869 \\
Número de notificações (pmp) & 41,9 & 31,6 & 27,3 & 34,1 & 31,1 & 34,8 & 43,0 & 54,3 \\
Recusa familiar & 204 & 148 & 114 & 131 & 126 & 153 & 179 & 229 \\
Percentual de recusa das entrevistas & Indisponível & Indisponível & Indisponível & Indisponível & Indisponível & Indisponível & 45 & 50 \\
Parada Cardíaca & Indisponível & Indisponível & 94 & 133 & 140 & 174 & 185 & 227 \\
Contraindicação médica & 241 & 187 & 105 & 149 & 112 & 72 & 59 & 135 \\
Outros & 57 & 71 & 37 & 44 & 40 & 36 & 44 & 53
\end{tabular}




\section{RIO DE JANEIRO}

\section{TRANSPLANTE DE ÓRGÃOS}

\section{RIM com doador falecido - pmp}
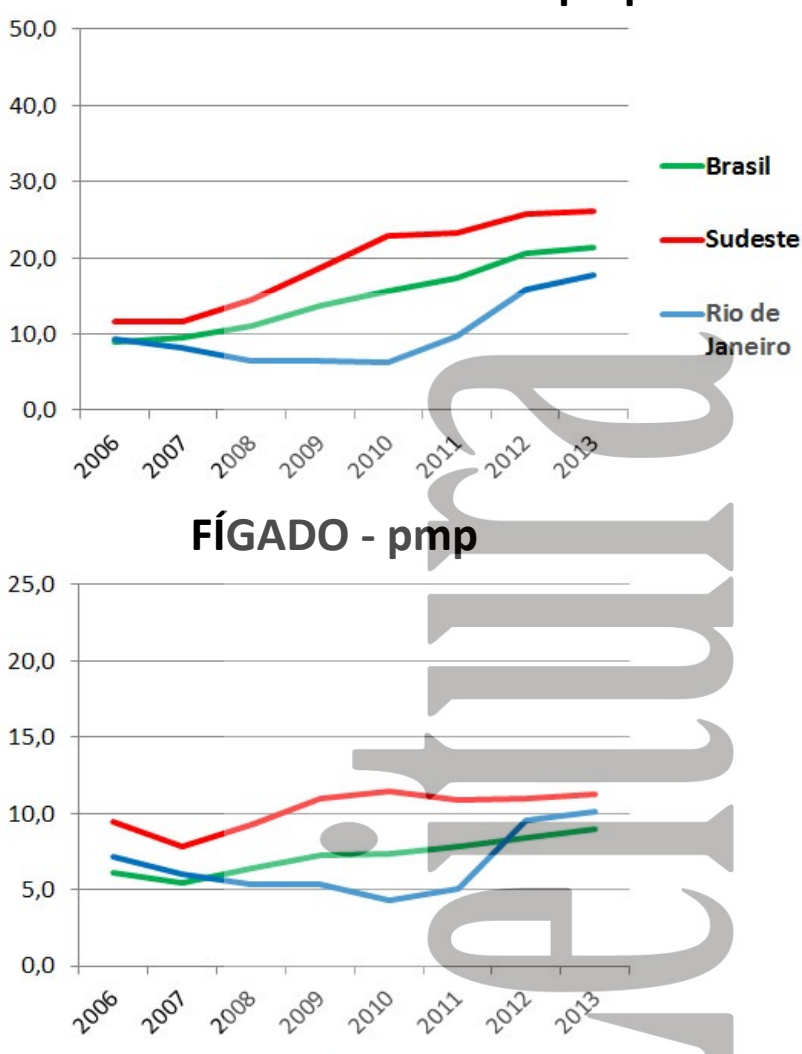

RIM com doador vivo - pmp

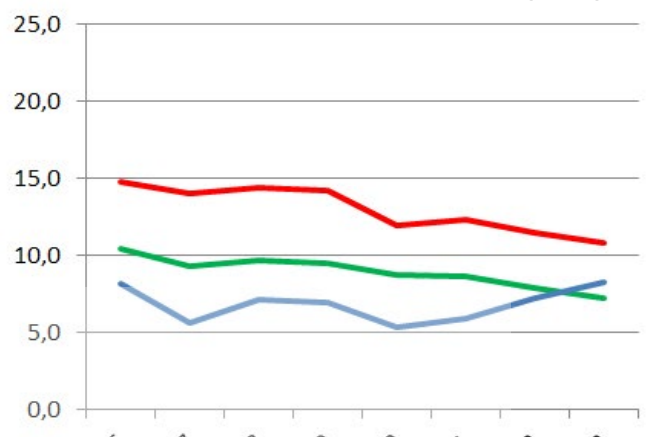

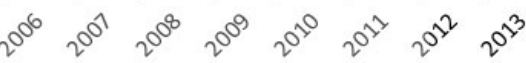
CÓRNEA- pmp

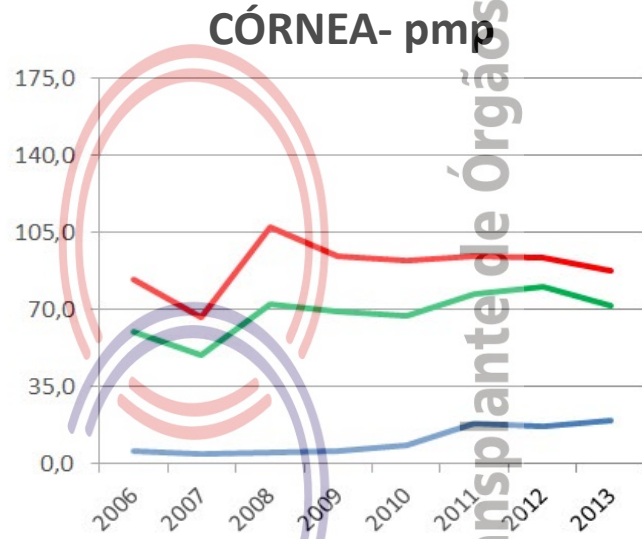

Número de equipes que realizaram $\quad 2006 \quad 2007$ transplantes durante o ano CÓRNEA

RIM

FÍGADO

PÂNCREAS

CORAÇÃO

PULMÃO

2006

2011

2012

2013

onível Indisponível Indisponível Indisponível Indisponível Indisponíve

\begin{tabular}{|c|c|c|c|c|c|c|c|c|}
\hline Júmero absoluto de transplantes & 2006 & 2007 & 2008 & 2009 & 2010 & 20110 & 2012 & 2013 \\
\hline CÓRNEA & 83 & 66 & 78 & 88 & 138 & 294 & 269 & 310 \\
\hline RIM - total & 253 & 211 & 211 & 205 & 186 & 251 & 367 & 416 \\
\hline doador vivo & 118 & 86 & 110 & 106 & 85 & 94 & 115 & 132 \\
\hline doador falecido & 135 & 125 & 101 & 99 & 101 & 157 U & 252 & 284 \\
\hline FÍGADO & 103 & 92 & 83 & 84 & 68 & $82<$ & 153 & 162 \\
\hline PÂNCREAS & 0 & 1 & 0 & 0 & 0 & 0 & 0 & 0 \\
\hline CORAÇÃO & 2 & 4 & 5 & 8 & 6 & 5 & 11 & 10 \\
\hline PULMÃO & 4 & 2 & 0 & 0 & 0 & 0 & 0 & 0 \\
\hline Júmero de transplantes $\mathrm{pmp}$ & 2006 & 2007 & 2008 & 2009 & 2010 & 2011 & 2012 & 2013 \\
\hline CÓRNEA & 5,8 & 4,3 & 5,1 & 5,7 & 8,6 & 18,4 & 16,8 & 19,4 \\
\hline RIM - total & 17,6 & 13,7 & 13,7 & 13,3 & 11,6 & 15,7 & 23,0 & 26,0 \\
\hline doador vivo & 8,2 & 5,6 & 7,1 & 6,9 & 5,3 & 5,9 & 7,2 & 8,3 \\
\hline doador falecido & 9,4 & 8,1 & 6,5 & 6,4 & 6,3 & 9,8 & 15,8 & 17,8 \\
\hline FÍGADO & 7,2 & 6,0 & 5,4 & 5,4 & 4,3 & 5,1 & 9,6 & 10,1 \\
\hline PÂNCREAS & 0,0 & 0,1 & 0,0 & 0,0 & 0,0 & 0,0 & 0,0 & 0,0 \\
\hline CORAÇÃO & 0,1 & 0,3 & 0,3 & 0,5 & 0,4 & 0,3 & 0,7 & 0,6 \\
\hline PULMÃO & 0,3 & 0,1 & 0,0 & 0,0 & 0,0 & 0,0 & 0,0 & 0,0 \\
\hline
\end{tabular}




\section{RIO GRANDE DO NORTE}

População atual

3.168.027 (1,7\%)

Natal

803.739

Extensão territorial $\left(\mathrm{Km}^{2}\right)$

$52.796,79$

\begin{tabular}{lccccc}
\hline $\begin{array}{l}\text { Necessidade anual estimada } \\
\text { e no de transplantes }\end{array}$ & Córnea & Rim & Fígado & Coração \\
\hline Necessidade estimada & 285 & 190 & 79 & 19 \\
Transplantes realizados & 171 & 50 & 3 & 0
\end{tabular}

\begin{tabular}{lrrrrrrrrr}
\hline Número de Óbitos por ano & 2006 & 2007 & 2008 & 2009 & 2010 & 2011 & 2012 & 2013 \\
\hline Todas as causas & 13.659 & 14.541 & 15.576 & 16.215 & 16.090 & 17.802 & Indisponível & Indisponível \\
Causas Externas & 1.730 & 1.934 & 2.084 & 2.286 & 2.162 & 2.414 & Indisponível & Indisponível \\
Causas Neurológicas & 238 & 276 & 319 & 315 & 345 & 389 & Indisponível & Indisponível \\
População (censo IBGE) & 2.776 .782 & 3.013 .740 & 3.013 .740 & 3.013 .740 & 3.168 .027 & $\begin{array}{c}3.168 .027 \\
\text { Fonte: http://cnes.datasus.gov.br 17/12/2013 }\end{array}$
\end{tabular}

HOSPITAIS

№ Total

Capital do estado Interior

$\%$ Brasil $\quad$ CNCDO: Artenise Revoredo

$93(1,5) \quad \vdots$ Fone: (84) 3232-7620 / 8839-8452

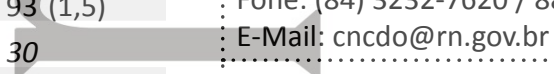

№ de leitos

63 Apresentou aumento expressivo do número de notificàções (de 47,7 para 55,9 PMP), $6.010(1,3) \quad \vdots$ em relação ao ano de 2012, não acompanhado de elevação no número de doadores № de leitos UTI $464(1,2) \quad \vdots$ efetivos, o que se deveu a um acréscimo no percentual de recusa familiar, que atingiu Hospitais com mais de 80 leitos 27 Hospital de ensino Escolas médicas № serviços de neurocirurgia Número de CIHDOTTS Número de OPOs $61 \%$ do total das entrevistas realizadas. A análise preliminar das causas de não aceitação tende a demonstrar que, principalmente, a qualidade da assistência ao paciente $3(1,6) \quad$ falecido interfere na decisão familiar. Aumentou o número de equipes de transplante $5(1,2) \quad \vdots$ renal e voltou a realizar transplante de fígado no estado, após cinco anos. É um estado 8 que tem conseguido manter um patamar de doações acima da média nacional e da $0 \quad$ Região Nordeste.

\section{DOAÇÃO DE ÓRGÃOS}

\section{Potenciais doadores notificados - pmp}

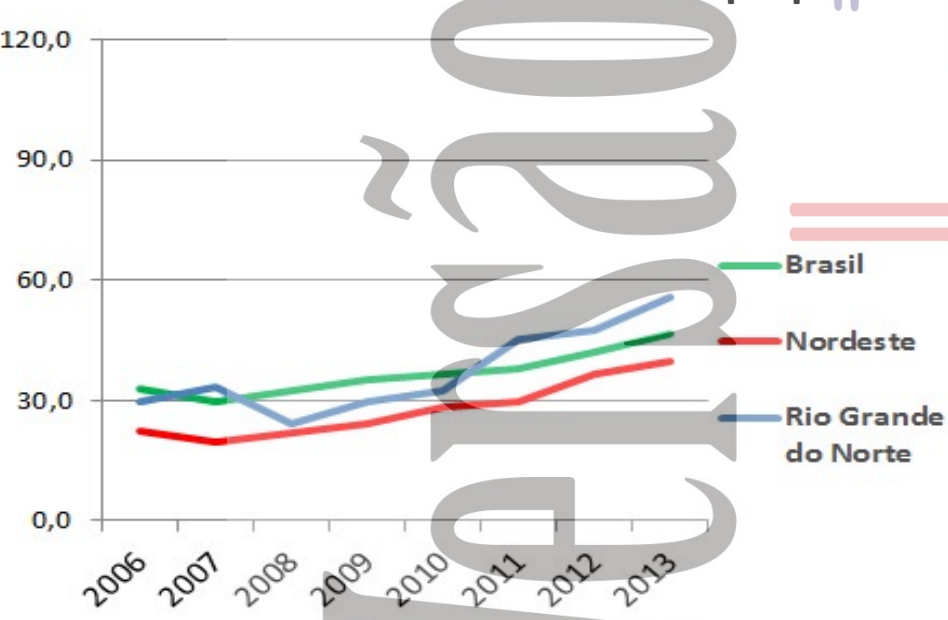

\section{Doadores efetivos - pmp}

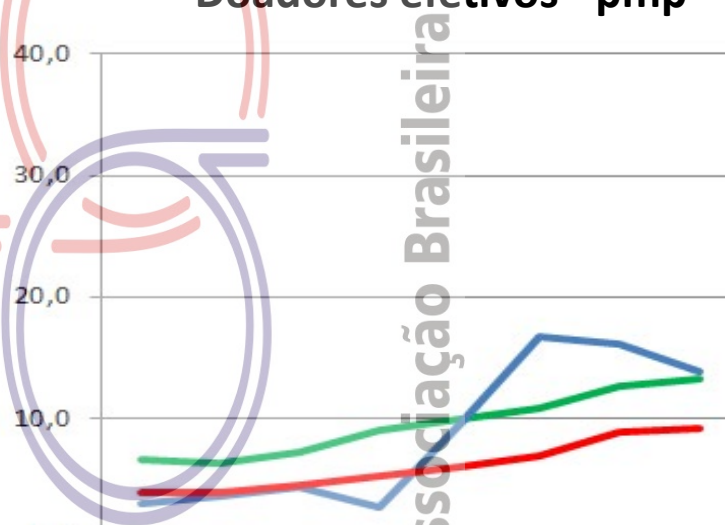

0,0

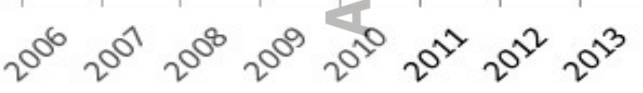

\begin{tabular}{lrrrrrrrr} 
& 2006 & 2007 & 2008 & 2009 & 2010 & 2011 & 2012 & 2013 \\
\hline Número de doadores efetivos & 8 & 11 & 13 & 8 & 30 & 53 & 51 & 44 \\
\hline Número de doadores efetivos (pmp) & 2,9 & 3,6 & 4,3 & 2,7 & 9,5 & 16,7 & 16,1 & 13,9 \\
$\begin{array}{l}\text { Número de notificações } \\
\text { (potenciais doadores) }\end{array}$ & 82 & 100 & 73 & 90 & 103 & 143 & 151 & 177 \\
Número de notificações (pmp) & 29,5 & 33,2 & 24,2 & 29,9 & 32,5 & 45,1 & 47,7 & 55,9 \\
Recusa familiar & 25 & 24 & 18 & 21 & 36 & 53 & 65 & 73 \\
Percentual de recusa das entrevistas & Indisponível & Indisponível & Indisponível & Indisponível & Indisponível & Indisponível & 54 & 61 \\
Parada Cardíaca & Indisponível & Indisponível & 16 & 8 & 19 & 20 & 11 & 5 \\
Contraindicação médica & 31 & 45 & 21 & 42 & 13 & 7 & 8 & 18 \\
Outros & 18 & 20 & 5 & 11 & 5 & 10 & 16 & 37
\end{tabular}




\section{RIO GRANDE DO NORTE}

\section{TRANSPLANTE DE ÓRGÃOS}
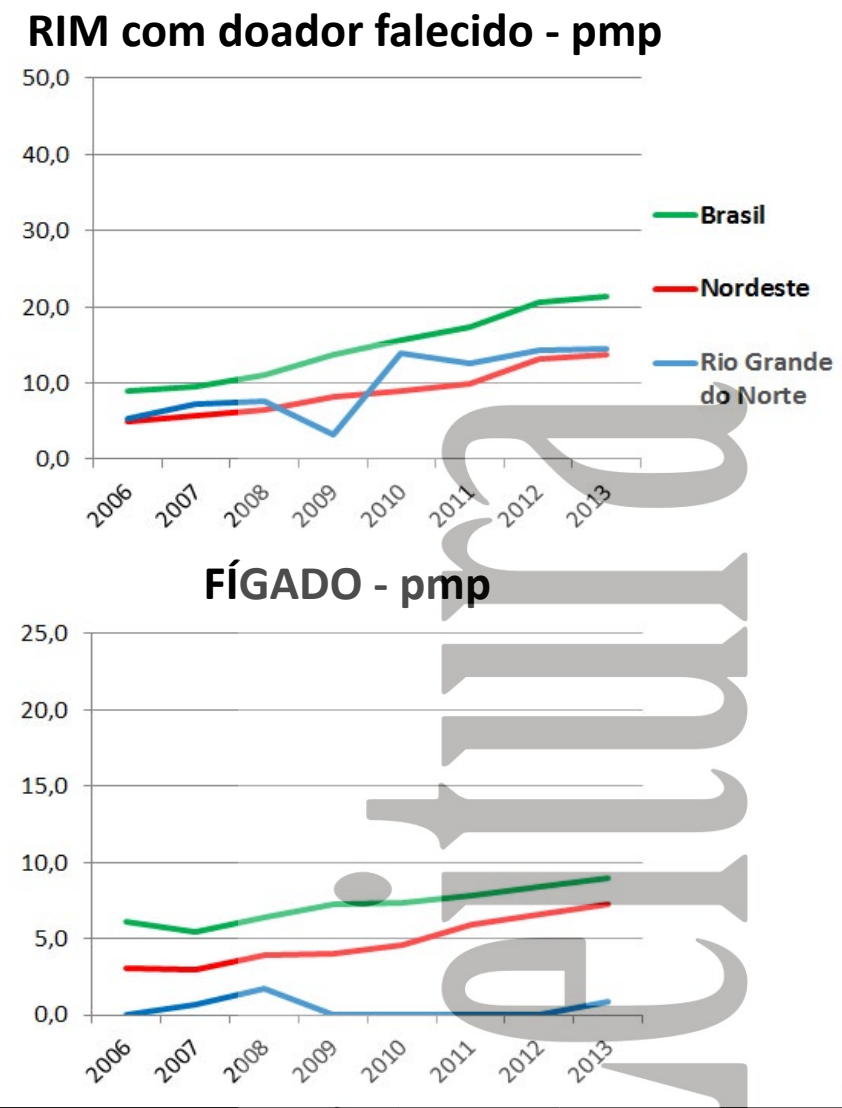

\begin{tabular}{|c|c|c|c|c|c|c|c|c|}
\hline $\begin{array}{l}\text { Número de equipes que realizaram } \\
\text { transplantes durante o ano }\end{array}$ & 2006 & 2007 & 2008 & 2009 & 2010 & 2011 & 2012 & 2013 \\
\hline CÓRNEA & Indisponível & Indisponível & Indisponível Indispo & oonível & isponível & Indisponível Indi & sponível & Indisponível \\
\hline RIM & 3 & 2 & 3 & 2 & 2 & $1 \%$ & 1 & 1 \\
\hline FÍGADO & 0 & 1 & 1 & 0 & 0 & $0=$ & 0 & 1 \\
\hline \multicolumn{9}{|l|}{ PÂNCREAS (não realiza) } \\
\hline CORAÇÃO & & & 1 & & & $0 \stackrel{n}{0}$ & 0 & 0 \\
\hline PULMÃO (não realiza) & & & 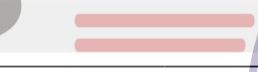 & & & ค & & \\
\hline Número absoluto de transplantes & 2006 & 2007 & 2008 & 2009 & 2010 & 20110 & 2012 & 2013 \\
\hline CÓRNEA & 78 & 135 & 89 & 171 & 224 & 286 & 205 & 171 \\
\hline RIM - total & 39 & 30 & 34 & 15 & 52 & $51^{-U}$ & 54 & 50 \\
\hline doador vivo & 24 & 8 & 11 & 5 & 8 & 110 & 9 & 4 \\
\hline doador falecido & 15 & 22 & 23 & 10 & & $40 \backsim$ & 45 & 46 \\
\hline FÍGADO & 0 & 2 & 5 & 0 & 0 & $0<$ & 0 & 3 \\
\hline \multicolumn{9}{|l|}{ PÂNCREAS (não realiza) } \\
\hline CORAÇÃO & 0 & 2 & 1 & 1 & 3 & 0 & 0 & 0 \\
\hline \multicolumn{9}{|l|}{ PULMÃO (não realiza) } \\
\hline Número de transplantes pmp & 2006 & 2007 & 2008 & 2009 & 2010 & 2011 & 2012 & 2013 \\
\hline CÓRNEA & 28,1 & 44,8 & 29,5 & 56,7 & 70,7 & 90,3 & 64,7 & 54,0 \\
\hline RIM - total & 14,0 & 10,0 & 11,3 & 5,0 & 16,4 & 16,1 & 17,0 & 15,8 \\
\hline doador vivo & 8,6 & 2,7 & 3,6 & 1,7 & 2,5 & 3,5 & 2,8 & 1,3 \\
\hline doador falecido & 5,4 & 7,3 & 7,6 & 3,3 & 13,9 & 12,6 & 14,2 & 14,5 \\
\hline FÍGADO & 0,0 & 0,7 & 1,7 & 0,0 & 0,0 & 0,0 & 0,0 & 0,9 \\
\hline \multicolumn{9}{|l|}{ PÂNCREAS (não realiza) } \\
\hline CORAÇÃO & 0,0 & 0,7 & 0,3 & 0,3 & 0,9 & 0,0 & 0,0 & 0,0 \\
\hline PULMÃO (não realiza) & & & & & & & & \\
\hline
\end{tabular}
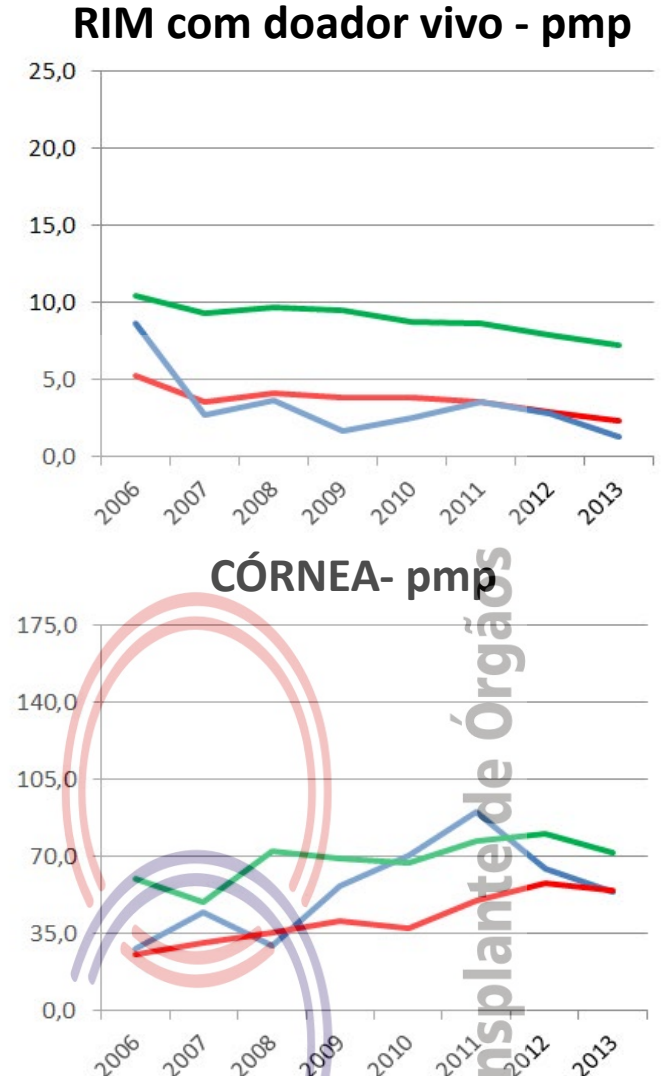
RIO GRANDE DO SUL

População atual

$10.693 .929(5,6 \%)$

Porto Alegre

1.409 .351

Extensão territorial $\left(\mathrm{Km}^{2}\right)$

\begin{tabular}{|crrrrr}
\hline $\begin{array}{l}\text { Necessidade anual estimada } \\
\text { e no de transplantes }\end{array}$ & Córnea & Rim & Fígado & Coração \\
\hline \multicolumn{2}{l}{$\begin{array}{l}\text { Necessidade estimada } \\
\text { Transplantes realizados }\end{array}$} & 962 & 642 & 267 & 64 \\
\hline 2008 & 2009 & 2010 & 2011 & 2012 & 2013 \\
\hline 73.996 & 76.788 & 77.985 & 80.148 & Indisponível & Indisponível \\
7.397 & 7.358 & 7.257 & 7.167 & Indisponível & Indisponível \\
1.921 & 2.028 & 2.221 & 2.407 & Indisponível & Indisponível \\
\hline
\end{tabular}

\begin{tabular}{lrrrrrrrr}
\hline Número de Óbitos por ano & 2006 & 2007 & 2008 & 2009 & 2010 & 2011 & 2012 & 2013 \\
\hline Todas as causas & 72.357 & 75.305 & 73.996 & 76.788 & 77.985 & 80.148 & Indisponível & Indisponível \\
Causas Externas & 6.976 & 7.278 & 7.397 & 7.358 & 7.257 & 7.167 & Indisponível & Indisponível \\
Causas Neurológicas & 1.625 & 1.930 & 1.921 & 2.028 & 2.221 & 2.407 & Indisponível & Indisponível \\
População (censo IBGE) & 10.187 .798 & 10.582 .840 & 10.582 .840 & 10.582 .840 & 10.693 .929 & 10.693 .929 & 10.693 .929 & 10.693 .929
\end{tabular}

HOSPITAIS

№ Total

Capital do estado

Interior

№ de leitos

№ de leitos UTI

$\%$ Brasil $\quad \vdots$ CNCDO: Dra. Rosana Reis Nothen

\begin{tabular}{|c|c|}
\hline$>$ & - \\
\hline $336(5,3)$ & Fone/Fax: (51) 3353-3030 \\
\hline & E-Mail: centraldetransplantes@saude.rs.gov.br \\
\hline
\end{tabular}

Fonte: http://cnes.datasus.gov.br 17/12/2013

Hospitais com mais de 80 leitos $\quad 119$

Hospital de ensino

Escolas médicas

№ serviços de neurocirurgia

Número de CIHDOTTS

308

E-Mail: centraldetransplantes@saude.rs.gov.br

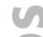

$33.210(7,0)$

$2.228(5,9)$ aumentando de maneira expressiva o número de notificações desde 2010 , sendo que apenas no ano passado aumentaram em $17 \%$, chegando a 54,6 pmp, quando o esperado seriam $70 \mathrm{pmp}$. Permanece com um dos methores índices de efetivação dentro do cenário nacional, embora tenha experimentado ligeira queda (4 pontos percentuais) em relação a 2012, devido ao aumento de contraindicações médicas. O 15 aproveitamento multiorgânico cresceu $25 \%$ em relação a 2012. As taxas de negativa $13(6,8) \quad$ familiar constituem-se hoje no maior desafio, tendo aumentado $5 \%$ em relação ao ano anterior, sendo também muito expressiva a dificuldade na manutenção do doador, expressa nas taxas de PCR, antes do fechamento do protocolo de morte encefálica. O estado dispõe de 41 CIHDOTTs em funcionamento, sob a supervisão de seis OPOs de

Número de OPOs

\section{$\begin{array}{cl}27(6,6) & \begin{array}{l}\text { anterior, sendo tamberm } \\ 41\end{array} \\ 7 & \text { expressa nas taxas de PCR, antes do fe } \\ \text { abrangência macrorregional e uma OP }\end{array}$}

\section{Potenciais doadores notificados - pmp}
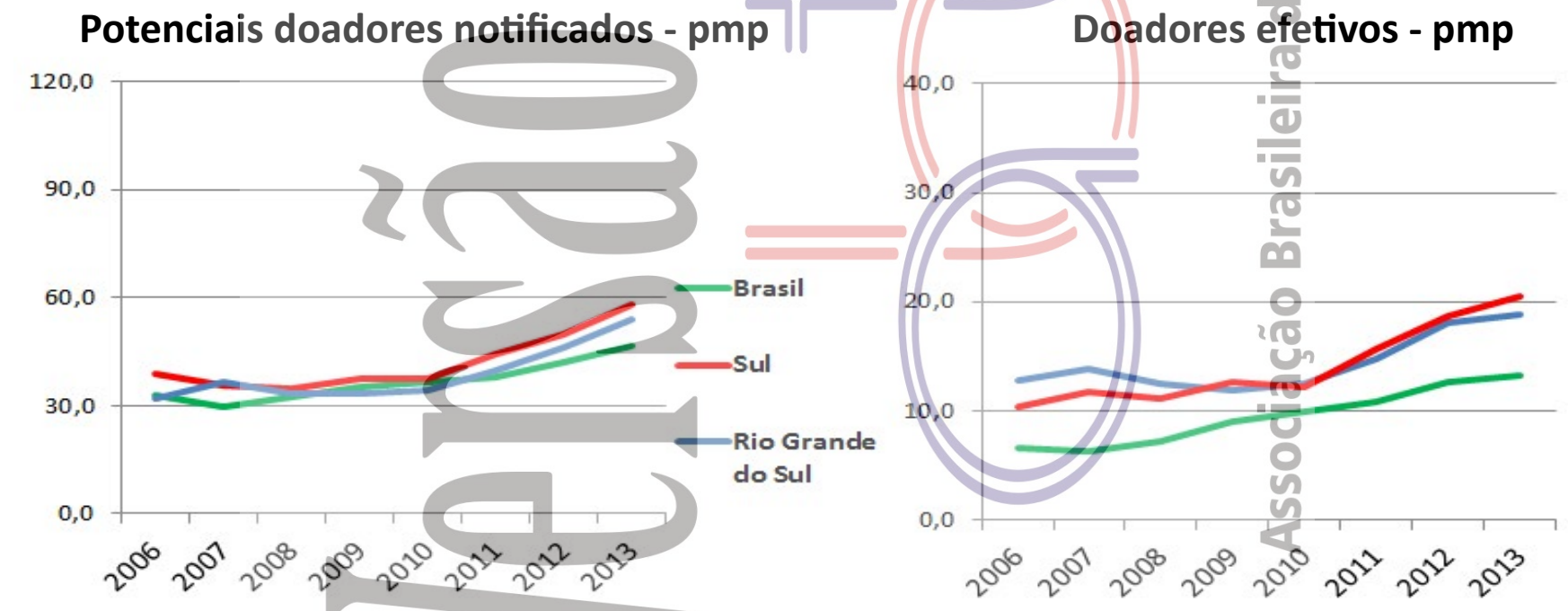

\begin{tabular}{lrrrrrrrr}
\hline & 2006 & 2007 & 2008 & 2009 & 2010 & 2011 & 2012 & 2013 \\
\hline Número de doadores efetivos & 130 & 147 & 132 & 126 & 133 & 158 & 194 & 201 \\
\hline Número de doadores efetivos (pmp) & 12,8 & 13,9 & 12,5 & 11,9 & 12,4 & 14,8 & 18,1 & 18,8 \\
$\begin{array}{l}\text { Número de notificações } \\
\text { (potenciais doadores) }\end{array}$ & 327 & 389 & 354 & 356 & 368 & 427 & 495 & 579 \\
Número de notificações (pmp) & 32,1 & 36,8 & 33,5 & 33,6 & 34,4 & 39,9 & 46,3 & 54,1 \\
Recusa familiar & 104 & 130 & 96 & 99 & 99 & 133 & 167 & 184 \\
Percentual de recusa das entrevistas & Indisponível & Indisponível & Indisponível & Indisponível & Indisponível & Indisponível & 41 & 45 \\
Parada Cardíaca & Indisponível & Indisponível & 88 & 88 & 88 & 94 & 81 & 113 \\
\hline Contraindicação médica & 89 & 112 & 38 & 43 & 46 & 36 & 47 & 65 \\
Outros & 4 & 0 & 0 & 0 & 2 & 6 & 6 & 16
\end{tabular}




\section{RIO GRANDE DO SUL}

\section{TRANSPLANTE DE ÓRGÃOS}

\section{RIM com doador falecido - pmp}
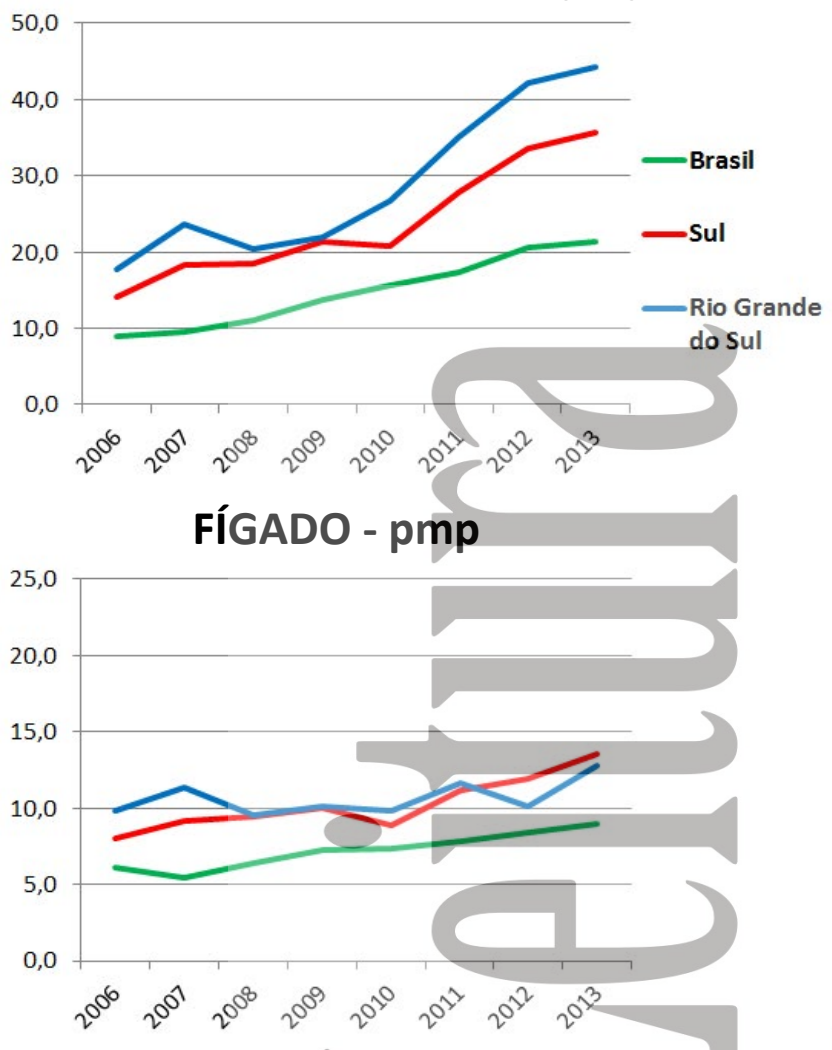

RIM com doador vivo - pmp

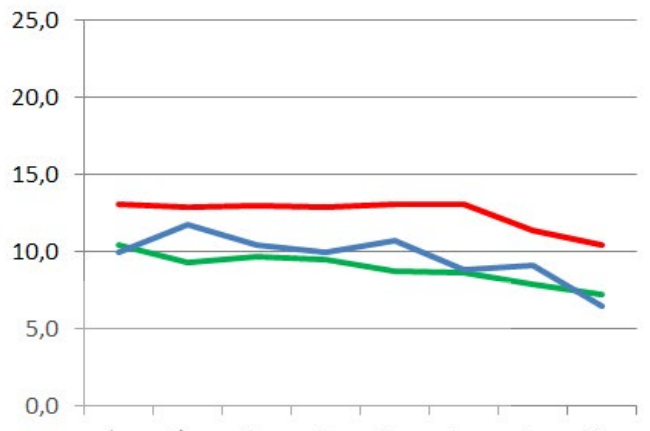

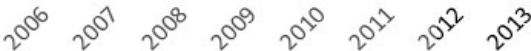
CÓRNEA- pmp

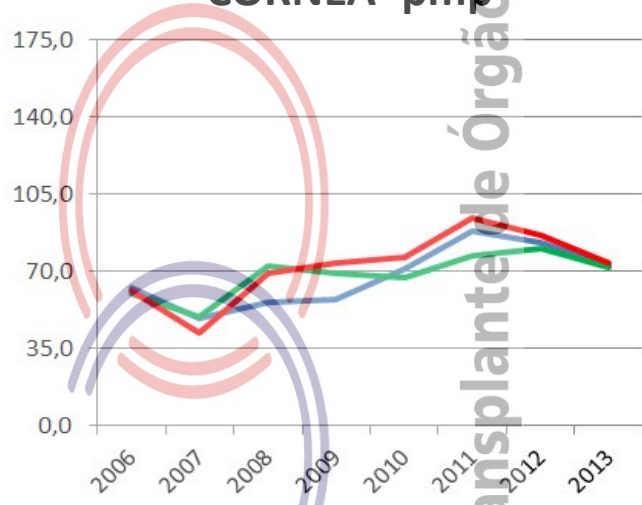

Número de equipes que realizaram $2008 \quad 2009 \quad 2010 \quad 2011-2012$ transplantes durante $o$ ano CÓRNEA

RIM

FÍGADO

PÂNCREAS

CORAÇÃO

PULMÃO

Indisponível Indisponível Indisponivel Indisponível Indisponível Indisponível Indisponível Indisponível

\begin{tabular}{|c|c|c|c|c|c|c|c|c|}
\hline Vúmero absoluto de transplantes & 2006 & 2007 & 2008 & 2009 & 2010 & 2011 (1) & 2012 & 2013 \\
\hline CÓRNEA & 636 & 518 & 595 & 607 & 757 & 941 ? & 886 & 776 \\
\hline RIM - total & 283 & 376 & 325 & 339 & 400 & $468=$ & 548 & 544 \\
\hline doador vivo & 102 & 125 & 110 & 106 & 114 & 94 & 97 & 70 \\
\hline doador falecido & 181 & 251 & 215 & 233 & 286 & 374 ص & 451 & 474 \\
\hline FÍGADO & 100 & 121 & 102 & 107 & 105 & 125 & 108 & 137 \\
\hline PÂNCREAS & 23 & 21 & 18 & 7 & 4 & 1 & 0 & 0 \\
\hline CORAÇÃO & 12 & 8 & 14 & 9 & 5 & 11 & 11 & 12 \\
\hline PULMÃO & 24 & 26 & 27 & 41 & 28 & 27 & 33 & 31 \\
\hline Vúmero de transplantes pmp & 2006 & 2007 & 2008 & 2009 & 2010 & 2011 & 2012 & 2013 \\
\hline CÓRNEA & 62,4 & 48,9 & 56,2 & 57,4 & 70,8 & 88,0 & 82,9 & 72,6 \\
\hline RIM - total & 27,8 & 35,5 & 30,7 & 32,0 & 37,4 & 43,8 & 51,2 & 50,9 \\
\hline doador vivo & 10,0 & 11,8 & 10,4 & 10,0 & 10,7 & 8,8 & 9,1 & 6,5 \\
\hline doador falecido & 17,8 & 23,7 & 20,3 & 22,0 & 26,7 & 35,0 & 42,2 & 44,3 \\
\hline FÍGADO & 9,8 & 11,4 & 9,6 & 10,1 & 9,8 & 11,7 & 10,1 & 12,8 \\
\hline PÂNCREAS & 2,3 & 2,0 & 1,7 & 0,7 & 0,4 & 0,1 & 0,0 & 0,0 \\
\hline CORAÇÃO & 1,2 & 0,8 & 1,3 & 0,9 & 0,5 & 1,0 & 1,0 & 1,1 \\
\hline PULMÃO & 2,4 & 2,5 & 2,6 & 3,9 & 2,6 & 2,5 & 3,1 & 2,9 \\
\hline
\end{tabular}




\section{RONDÔNIA}

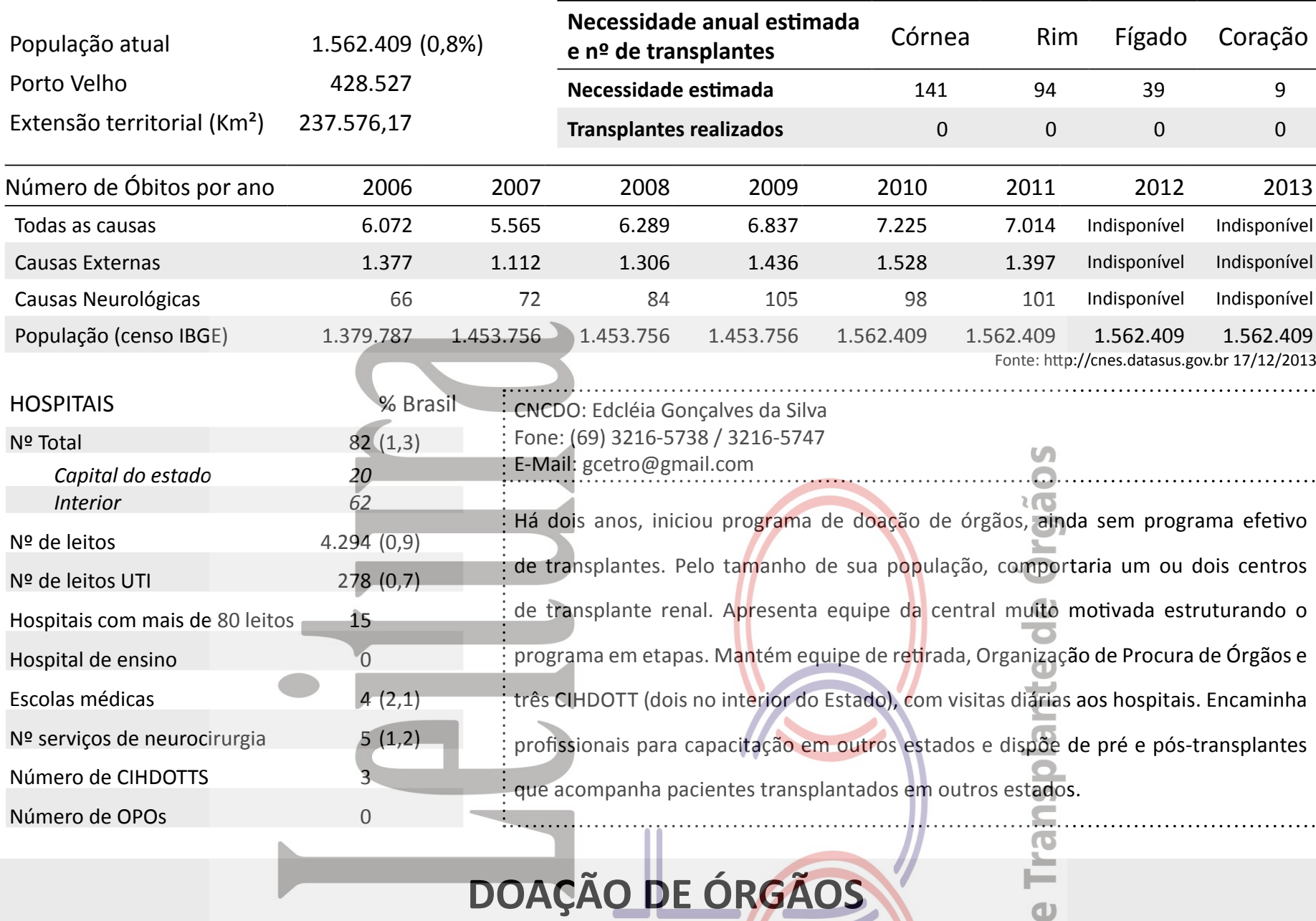

\section{Potenciais doadores notificados - pmp (não realiza) Doadores efetivos - pmp}

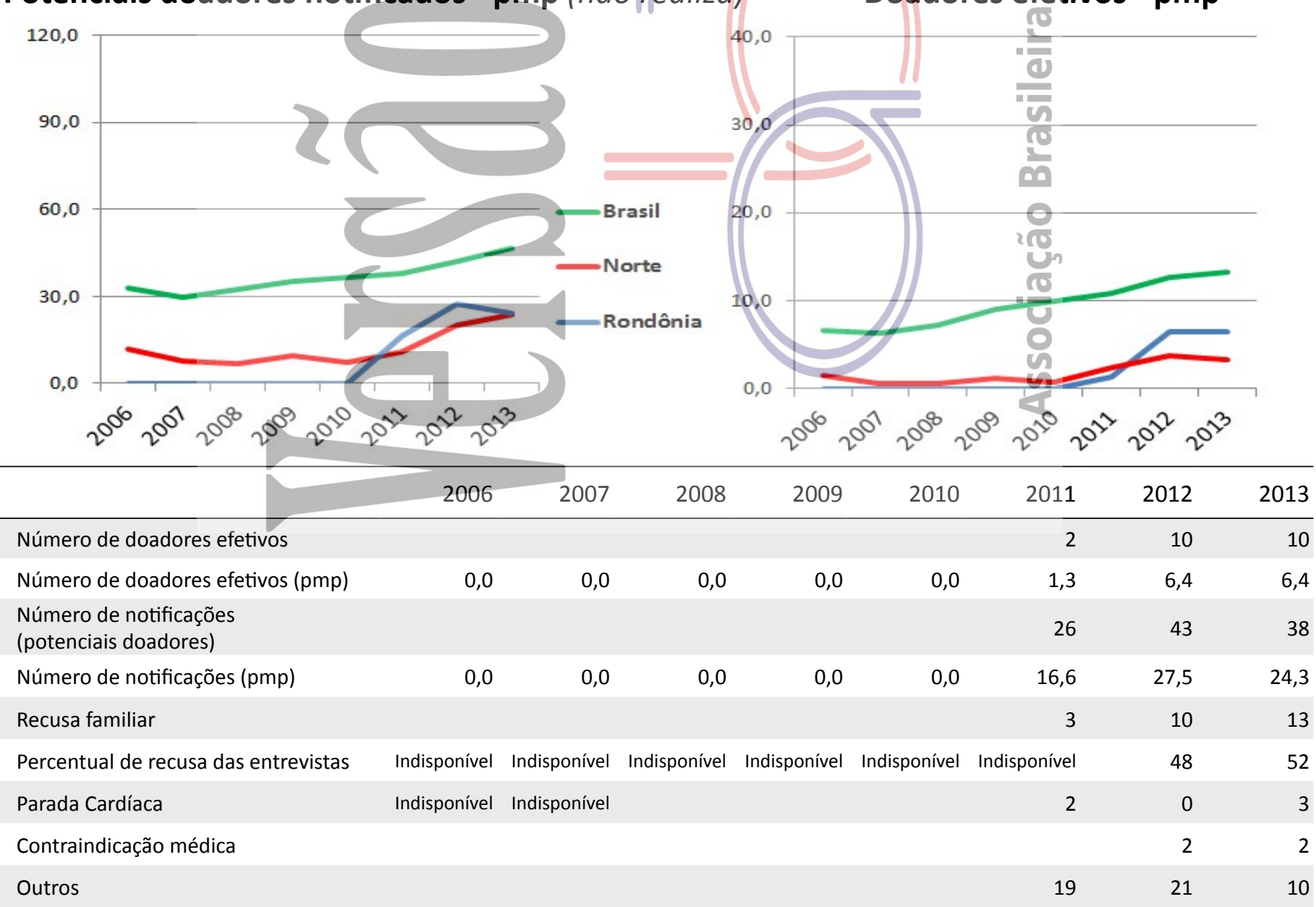




\section{RONDÔNIA}

\section{TRANSPLANTE DE ÓRGÃOS}

\section{RIM com doador falecido - pmp (não realiza)}

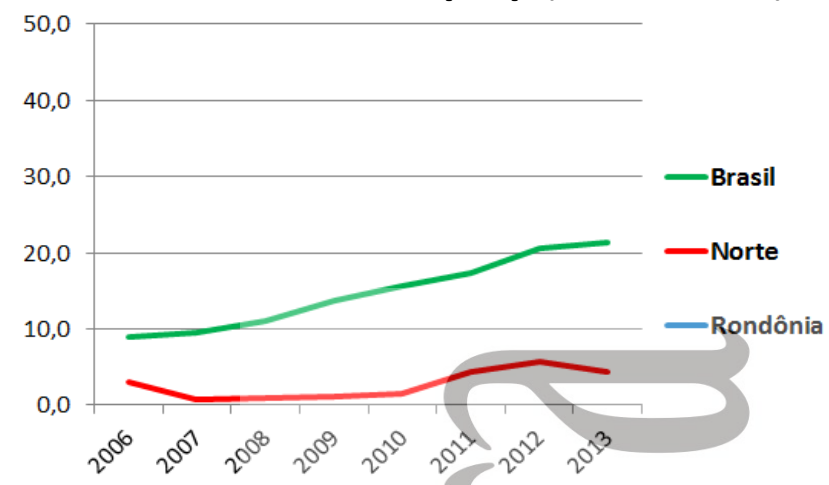

FÍGADO - pmp (não realiza)

RIM com doador vivo - pmp (não realiza)
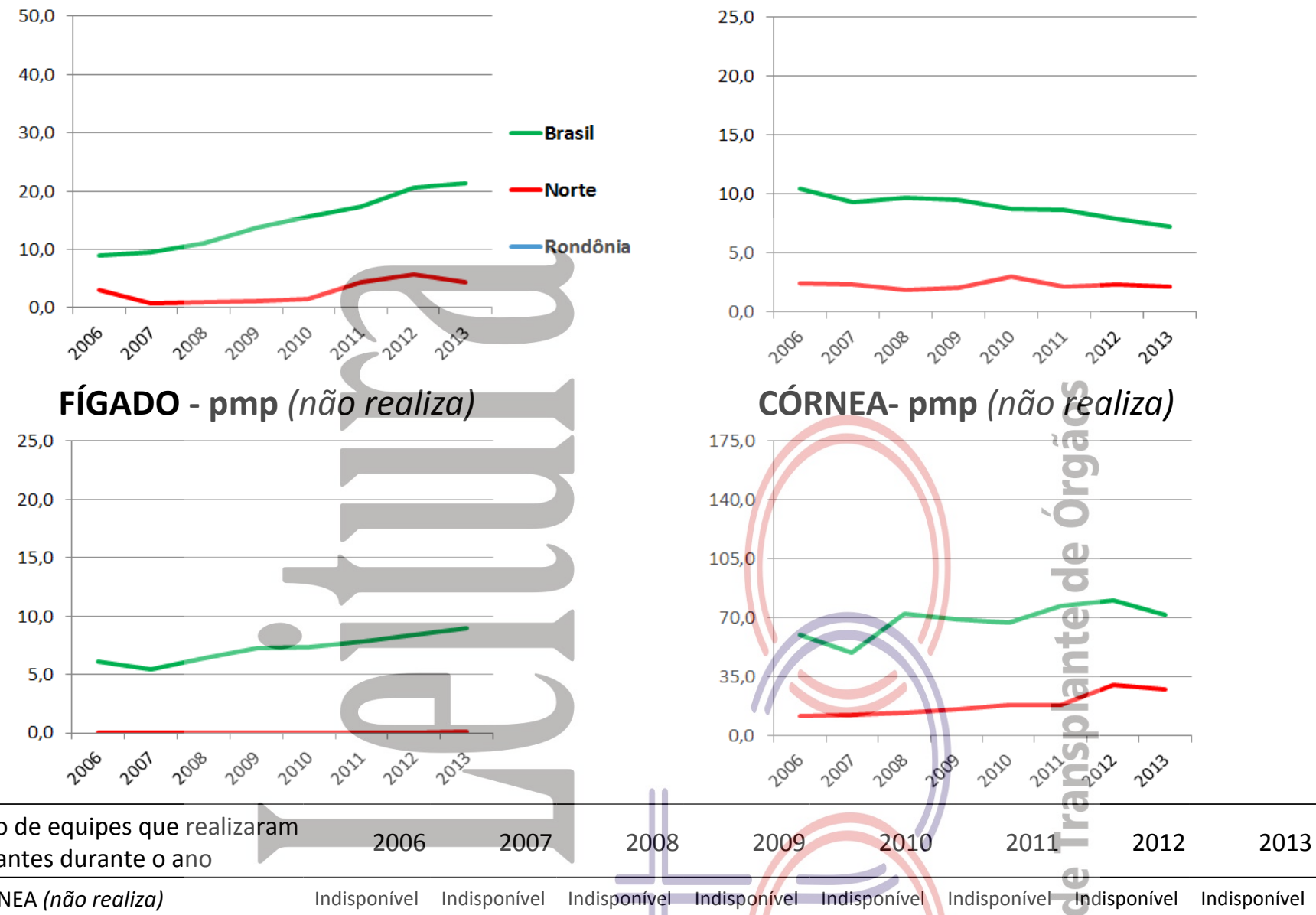

Número de equipes que realizaram $2006 \quad 2007$ transplantes durante o ano CÓRNEA (não realiza) RIM (não realiza) FÍGADO (não realiza) PÂNCREAS (não realiza) CORAÇÃO (não realiza) PULMÃO (não realiza)

\begin{tabular}{l}
\hline Número absoluto de transp \\
\hline CÓRNEA (não realiza) \\
RIM (não realiza) \\
doador vivo \\
doador falecido \\
FÍGADO (não realiza) \\
PÂNCREAS (não realiza) \\
CORAÇÃO (não realiza) \\
PULMÃO (não realiza)
\end{tabular}

Número de transplantes pmp

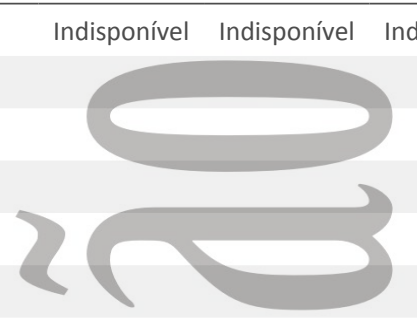

splantes

$2006 \quad 2007$

2008
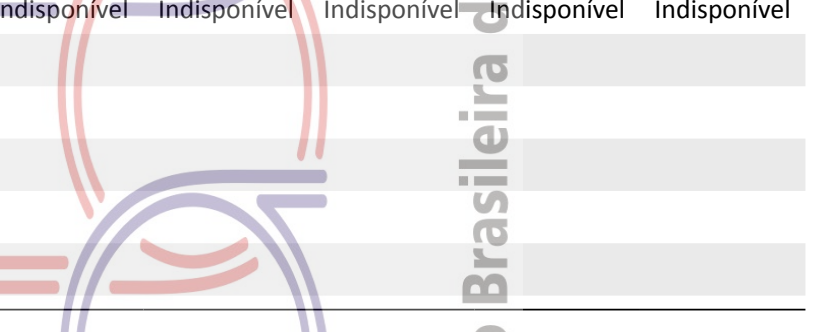

\footnotetext{
CÓRNEA (não realiza)

RIM (não realiza)

doador vivo

doador falecido

FÍGADO (não realiza)

PÂNCREAS (não realiza)

CORAÇÃO (não realiza)

PULMÃo (não realiza)
} 


\section{RORAIMA}

População atual

$450.479(0,2 \%)$

Boa Vista

284.313

Extensão territorial $\left(\mathrm{Km}^{2}\right)$

$224.298,98$

\begin{tabular}{lccccc}
$\begin{array}{l}\text { Necessidade anual estimada } \\
\text { e no de transplantes }\end{array}$ & Córnea & Rim & Fígado & Coração \\
\hline Necessidade estimada & 41 & 27 & 11 & 3 \\
Transplantes realizados & 0 & 0 & 0 & 0
\end{tabular}

\begin{tabular}{lrrrrrrrr}
\hline Número de Óbitos por ano & 2006 & 2007 & 2008 & 2009 & 2010 & 2011 & 2012 & 2013 \\
\hline Todas as causas & 1.509 & 1.494 & 1.481 & 1.536 & 1.640 & 1.599 & Indisponível & Indisponível \\
Causas Externas & 335 & 385 & 337 & 351 & 372 & 350 & Indisponível & Indisponível \\
Causas Neurológicas & 15 & 18 & 23 & 14 & 29 & 22 & Indisponível & Indisponível \\
População (censo IBGE) & 324.397 & 395.725 & 395.725 & 395.725 & 450.479 & $\begin{array}{c}450.479 \\
\text { Fonte: http://cnes.datasus.gov.br 17/12/2013 }\end{array}$
\end{tabular}

\section{HOSPITAIS}

№ Total

Capital do estado Interior

№ de leitos

№ de leitos UTI

Hospitais com mais de 80 leitos Hospital de ensino

Escolas médicas

№ serviços de neurocirurgia

Número de CIHDOTTS

Número de OPOs
\% Brasil $\quad \vdots$ CNCDO: Dr. Douglas Henrique Teixeira

\begin{tabular}{c|c}
7 & $\vdots$ \\
6 & $\vdots$ \\
$798(0,2)$ & $\vdots$ \\
\hline & $\vdots$
\end{tabular}

$33(0,1)$

$13(0,2) \quad \vdots$ Fone: 95-2121-0560/2121-0620

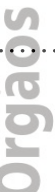

As atividades visando a doação de órgãos e transplantes iniciaram-se em 2013, com a 0

0

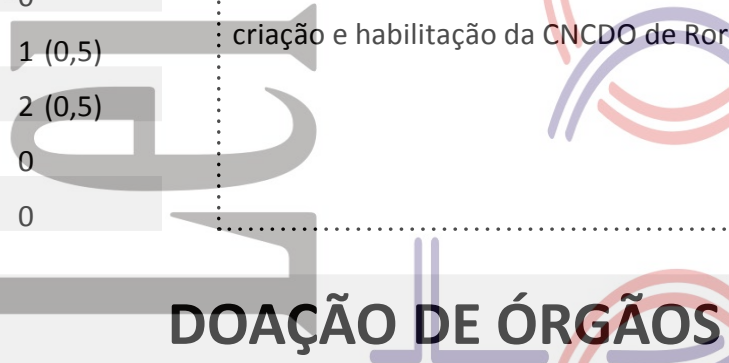

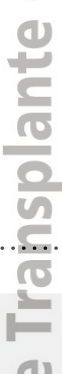

\section{Potenciais doadores notificados - pmp (não realiza) Doadores efetivos- pmp (não realiza)}

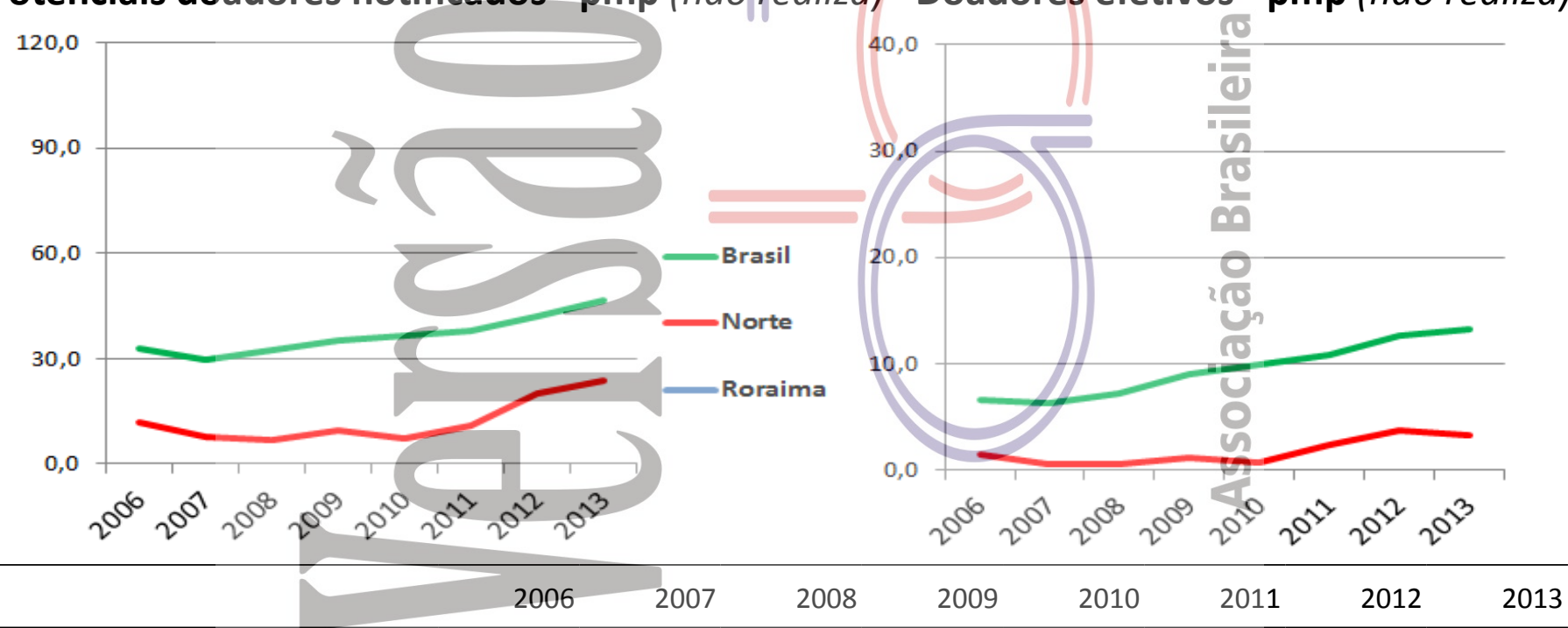

Número de doadores efetivos

Número de doadores efetivos (pmp)

Número de notificações

(potenciais doadores)

Número de notificações (pmp)

Recusa familiar

Percentual de recusa das entrevistas

Parada Cardíaca

Indisponível Indisponível Indisponível Indisponível Indisponível Indisponível

Indisponível

Contraindicação médica

Outros 


\section{RORAIMA}

\section{TRANSPLANTE DE ÓRGÃOS}

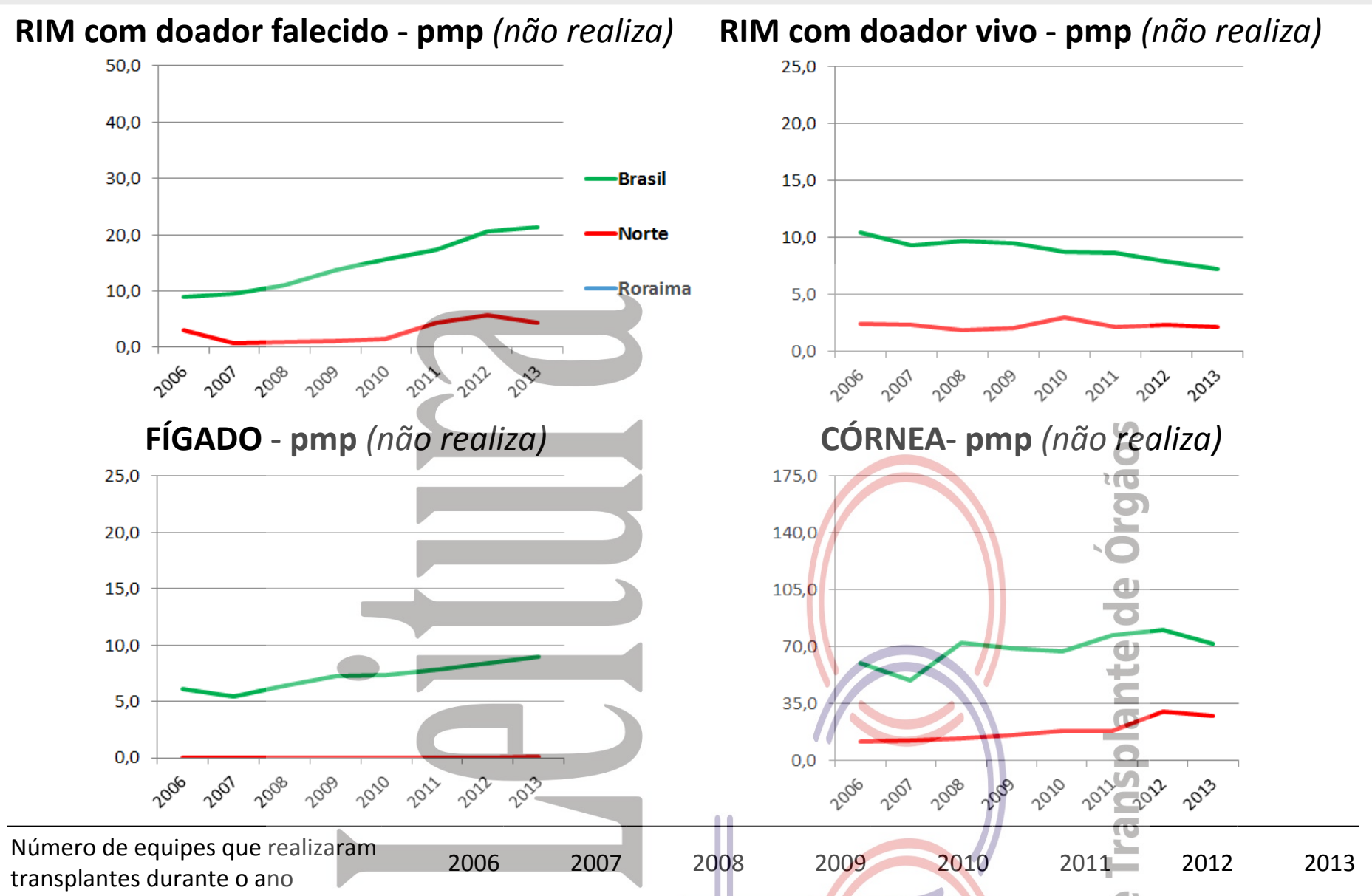

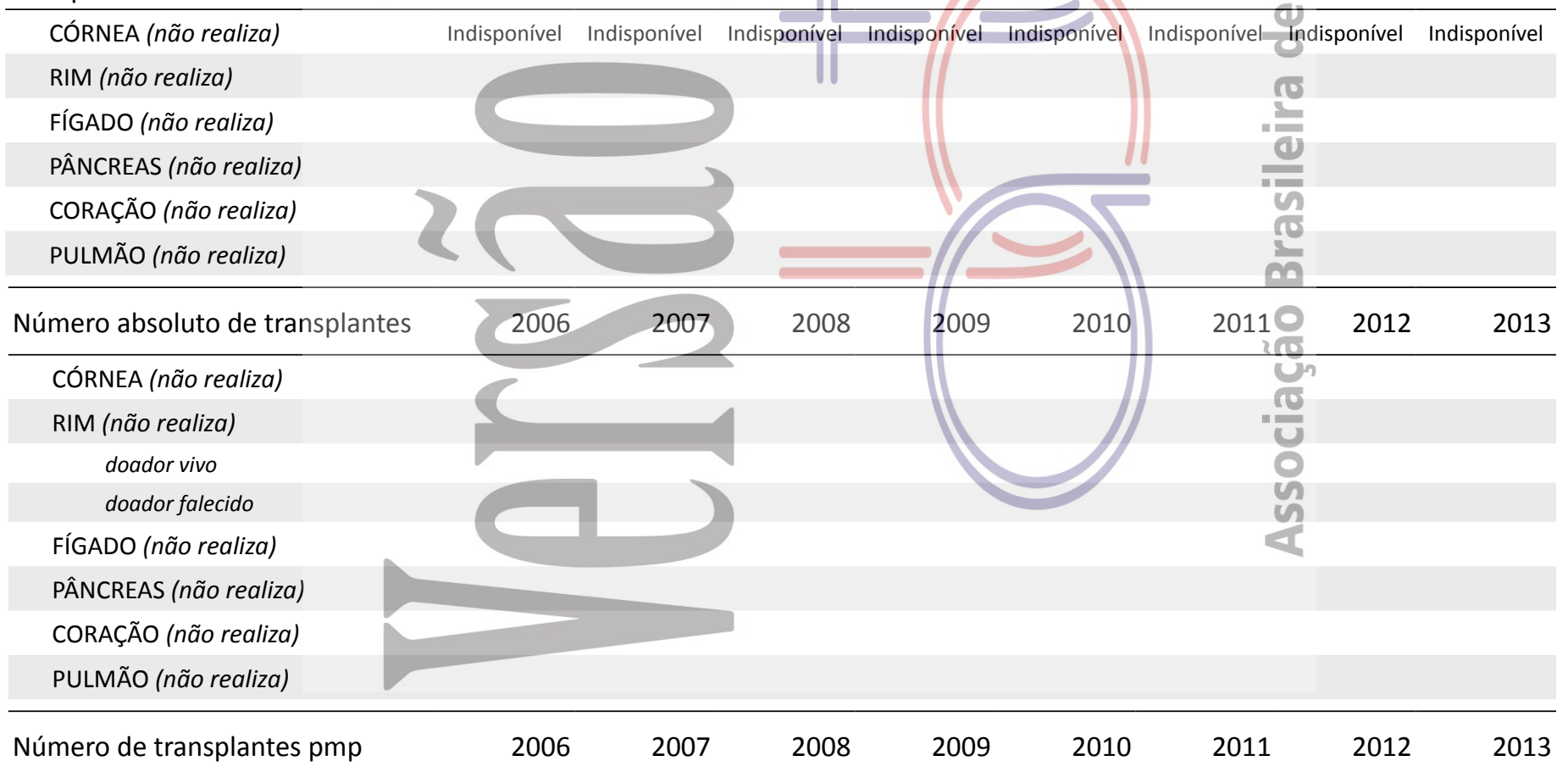

CÓRNEA (não realiza)

RIM (não realiza)

doador vivo

doador falecido

FÍGADO (não realiza)

PÂNCREAS (não realiza)

CORAÇÃO (não realiza)

PULMÃO (não realiza) 


\section{SANTA CATARINA}

População atual

$6.248 .436(3,3 \%)$

Florianópolis

421.240

Extensão territorial $\left(\mathrm{Km}^{2}\right)$

$95.346,18$

\begin{tabular}{lccccc}
\hline $\begin{array}{l}\text { Necessidade anual estimada } \\
\text { e no de transplantes }\end{array}$ & Córnea & Rim & Fígado & Coração \\
\hline Necessidade estimada & 562 & 375 & 156 & 37 \\
\hline Transplantes realizados & 504 & 270 & 117 & 4 \\
\hline
\end{tabular}

\begin{tabular}{|c|c|c|c|c|c|c|c|c|}
\hline Número de Óbitos por ano & 2006 & 2007 & 2008 & 2009 & 2010 & 2011 & 2012 & 2013 \\
\hline Todas as causas & 30.421 & 32.102 & 31.869 & 33.825 & 34.474 & 35.912 & Indisponível & Indisponível \\
\hline Causas Externas & 3.852 & 3.952 & 4.132 & 4.039 & 4.115 & 4.245 & Indisponível & Indisponível \\
\hline Causas Neurológicas & 655 & 657 & 684 & 778 & 819 & 896 & Indisponível & Indisponível \\
\hline População (censo IBGE) & 5.356 .360 & 5.866 .252 & 5.866 .252 & 5.866 .252 & 6.248 .436 & 6.248 .436 & 6.248 .436 & 6.248 .436 \\
\hline
\end{tabular}

HOSPITAIS

№ Total

Capital do estado

Interior

$\%$ Brasil $\quad \vdots$ CNCDO: Dr. Joel de Andrade

$224(3,6) \quad$ Fone: (48) 3212-1612 / 3212-1613

$22 \vdots$ E-Mail: getra@saude.sc.gov.br

202

$16.438(3,5)$

№ de leitos

$938(2,5)$

№ de leitos UTI

67

Estado que lidera o número de doadores efetivos pmp no Brasil. Tem 28 CIHDOTTs

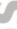

no Brasil. Tem 28 CIHDOTTs ativas, além de programas líderes em transplante renal e hepático. Tem baixa

Hospitais com mais de 80 leitos subnotificação de potenciais doadores, com recusa familiar próxima de $40 \%$. Hospitais Hospital de ensino

Escolas médicas

№ serviços de neurocirurgia

Número de CIHDOTTS

Número de OPOs

7

$9(4,7)$

$22(5,4)$

28 privados conseguem o

ressarcimento das despesas

com o processo de doação de órgão através da emissão de AlH. Possui equipe específica para retirada de órgãos, com cirurgiões dedicados a esse processo. Grande suporte do governo estadual.

0

DOAÇ̃̃OD DE ORGGOSOS

Potenciais doadores notificados - pmp

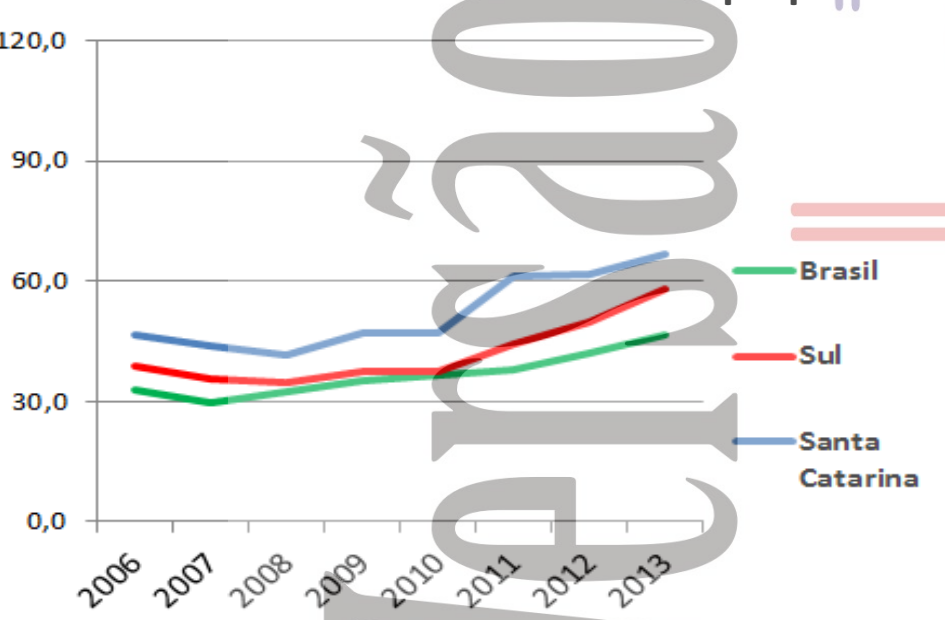

Doadores efetivos - pmp

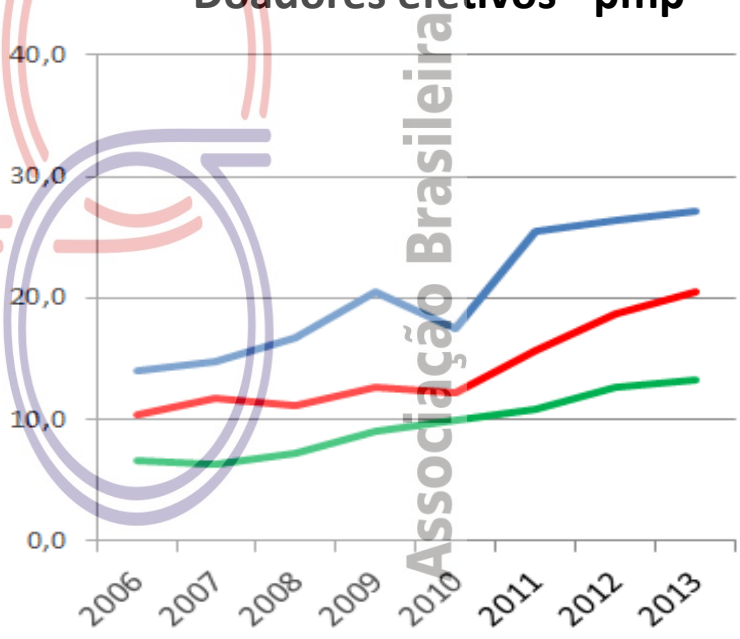

\begin{tabular}{lrrrrrrrr}
\hline & 2006 & 2007 & 2008 & 2009 & 2010 & 2011 & 2012 & 2013 \\
\hline Número de doadores efetivos & 75 & 87 & 98 & 120 & 109 & 159 & 165 & 170 \\
Número de doadores efetivos (pmp) & 14,0 & 14,8 & 16,7 & 20,5 & 17,4 & 25,4 & 26,4 & 27,2 \\
$\begin{array}{l}\text { Número de notificações } \\
\text { (potenciais doadores) }\end{array}$ & 249 & 257 & 244 & 277 & 295 & 384 & 386 & 416 \\
Número de notificações (pmp) & 46,5 & 43,8 & 41,6 & 47,2 & 47,2 & 61,5 & 61,8 & 66,6 \\
Recusa familiar & 95 & 104 & 70 & 94 & 91 & 94 & 111 & 115 \\
Percentual de recusa das entrevistas & Indisponível & Indisponível & Indisponível & Indisponível & Indisponível & Indisponível & 40 & 39 \\
Parada Cardíaca & Indisponível & Indisponível & 52 & 45 & 20 & 53 & 69 & 41 \\
Contraindicação médica & 36 & 37 & 13 & 8 & 71 & 74 & 32 & 40 \\
Outros & 43 & 29 & 11 & 10 & 4 & 4 & 9 & 50
\end{tabular}




\section{SANTA CATARINA}

\section{TRANSPLANTE DE ÓRGÃOS}

\section{RIM com doador falecido - pmp}
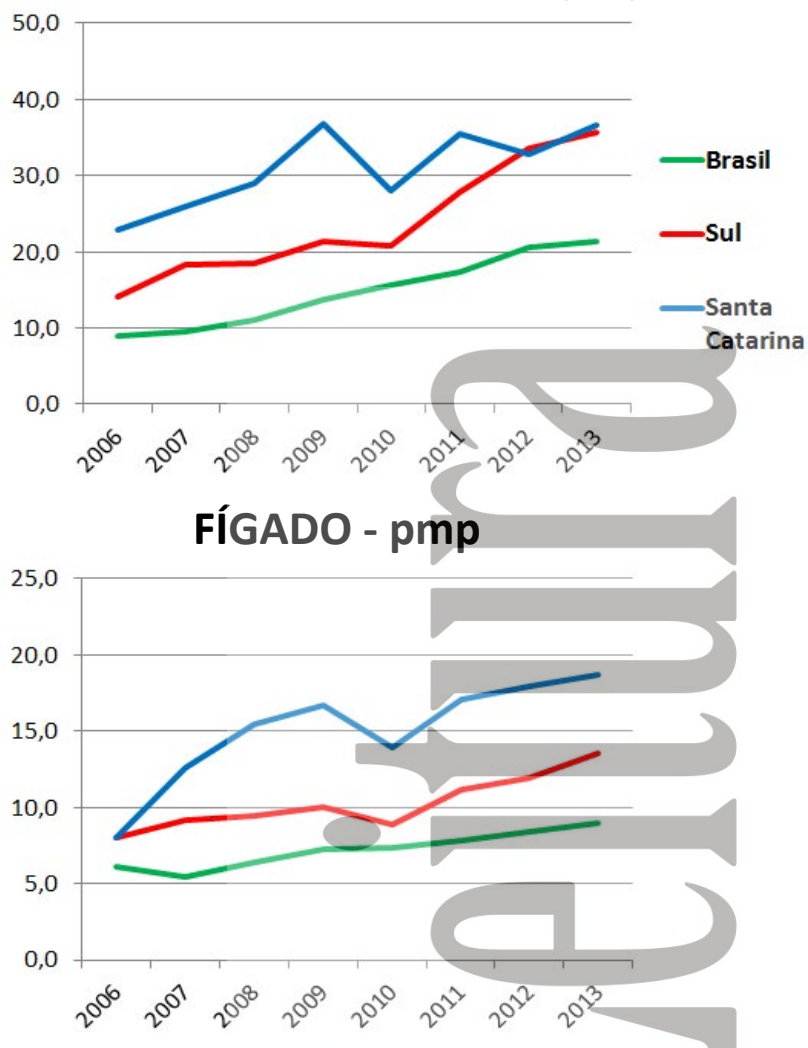

RIM com doador vivo - pmp

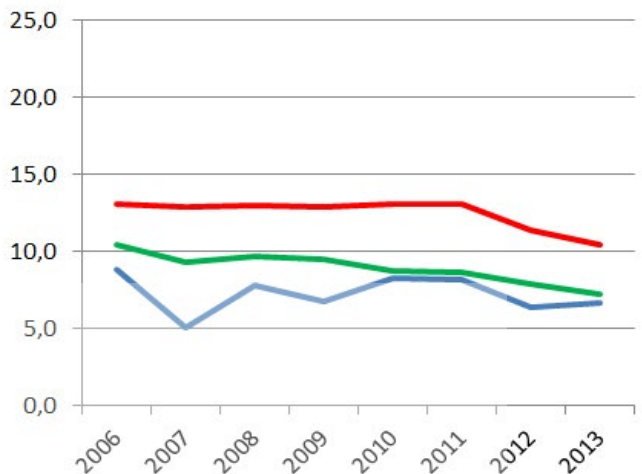

CÓRNEA- pmp

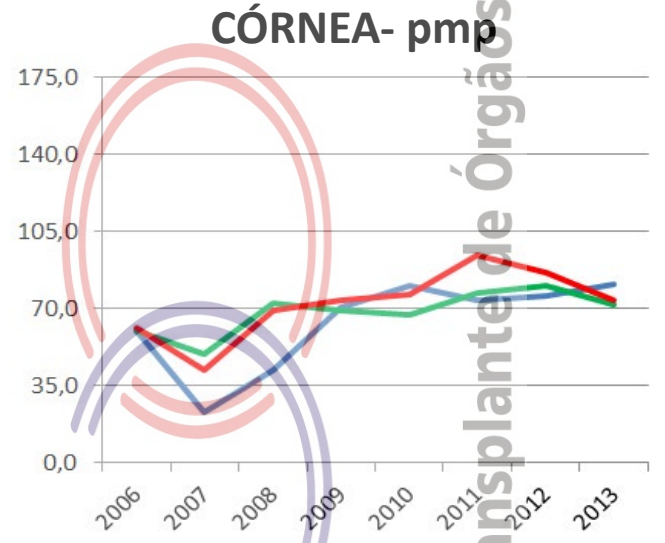

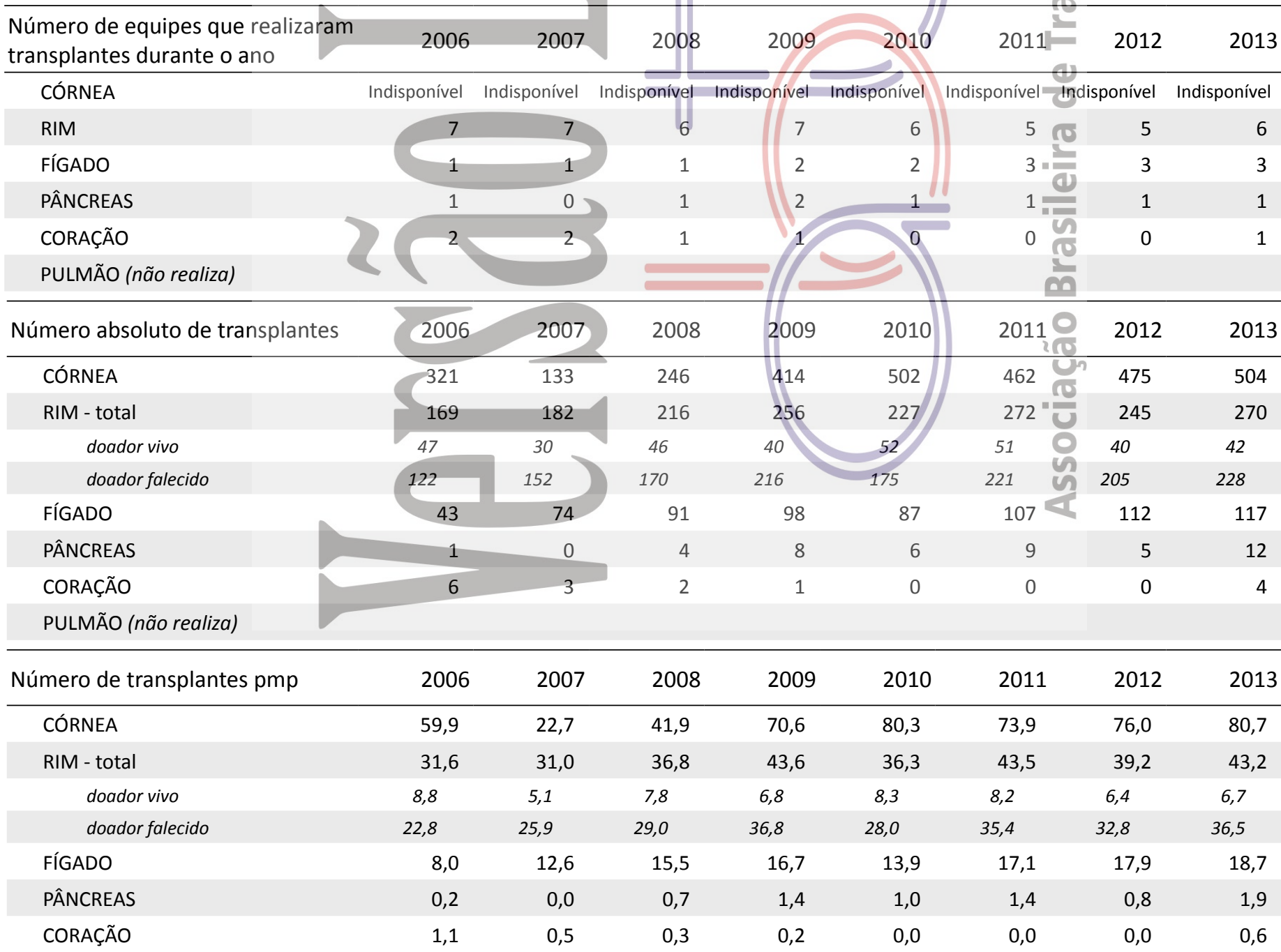

PULMÃO (não realiza) 


\section{SÃO PAULO}

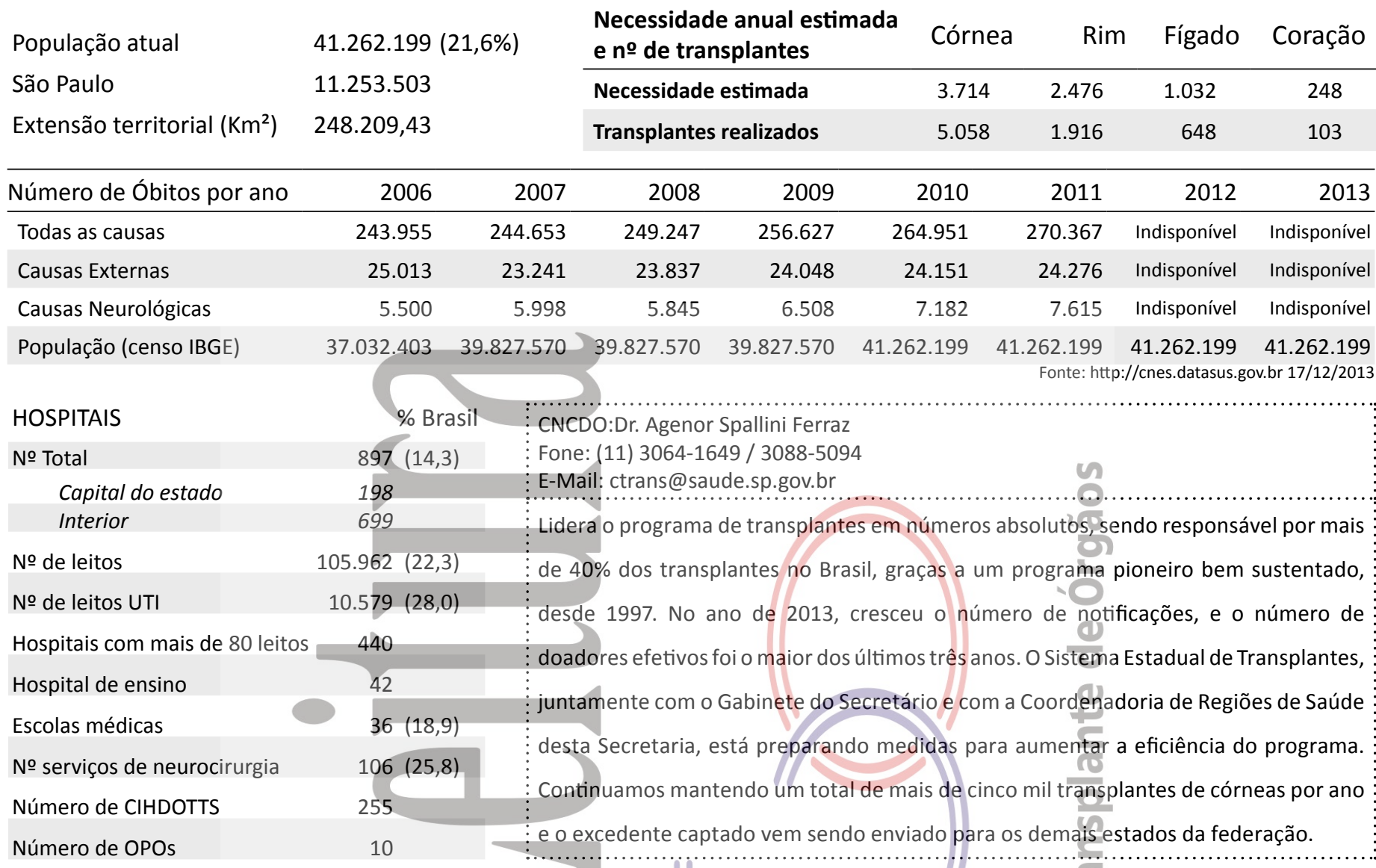

\section{DOAÇÃO DE ÓRGÃOS}

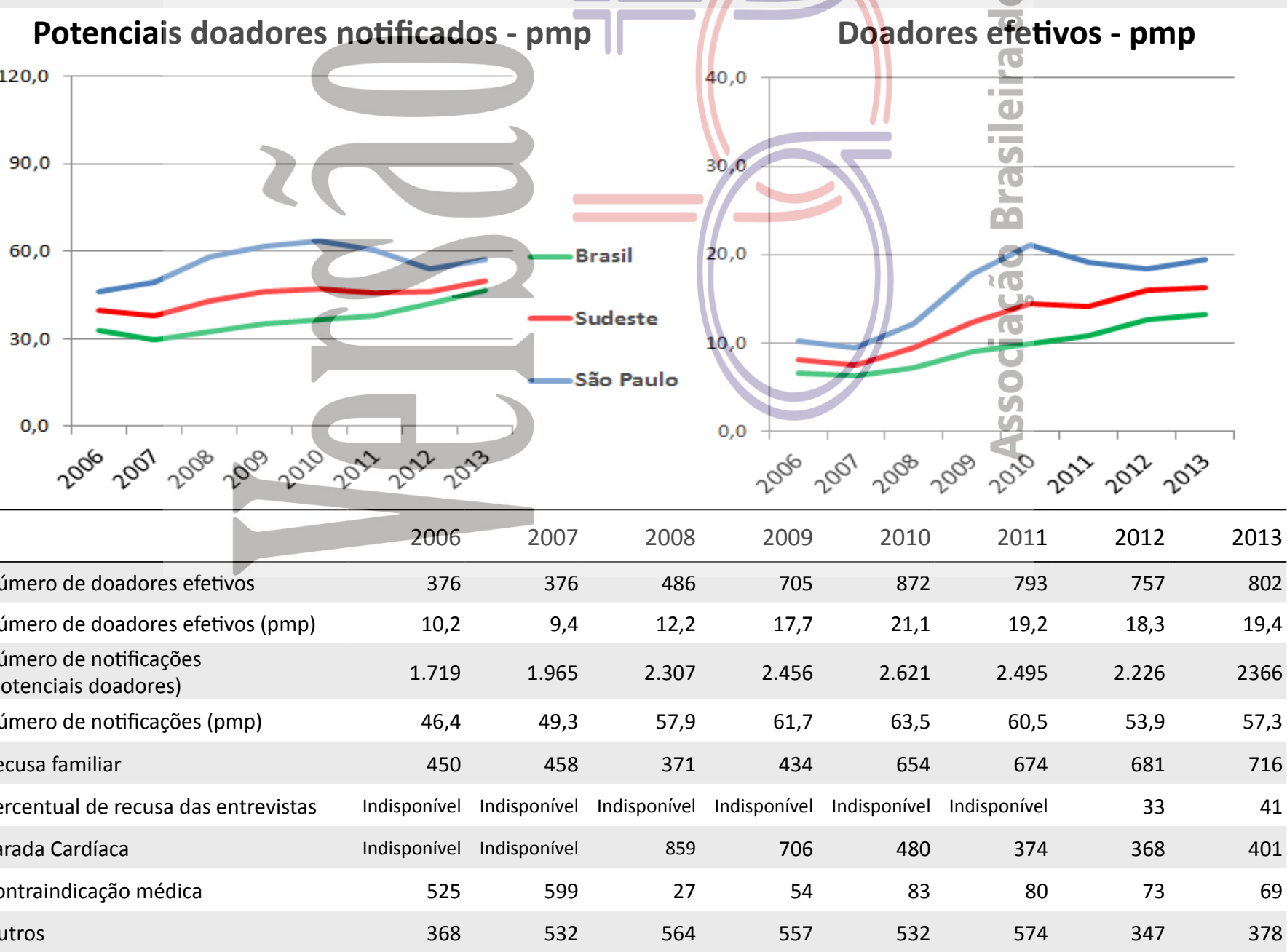




\section{SÃO PAULO}

\section{TRANSPLANTE DE ÓRGÃOS}

\section{RIM com doador falecido - pmp}
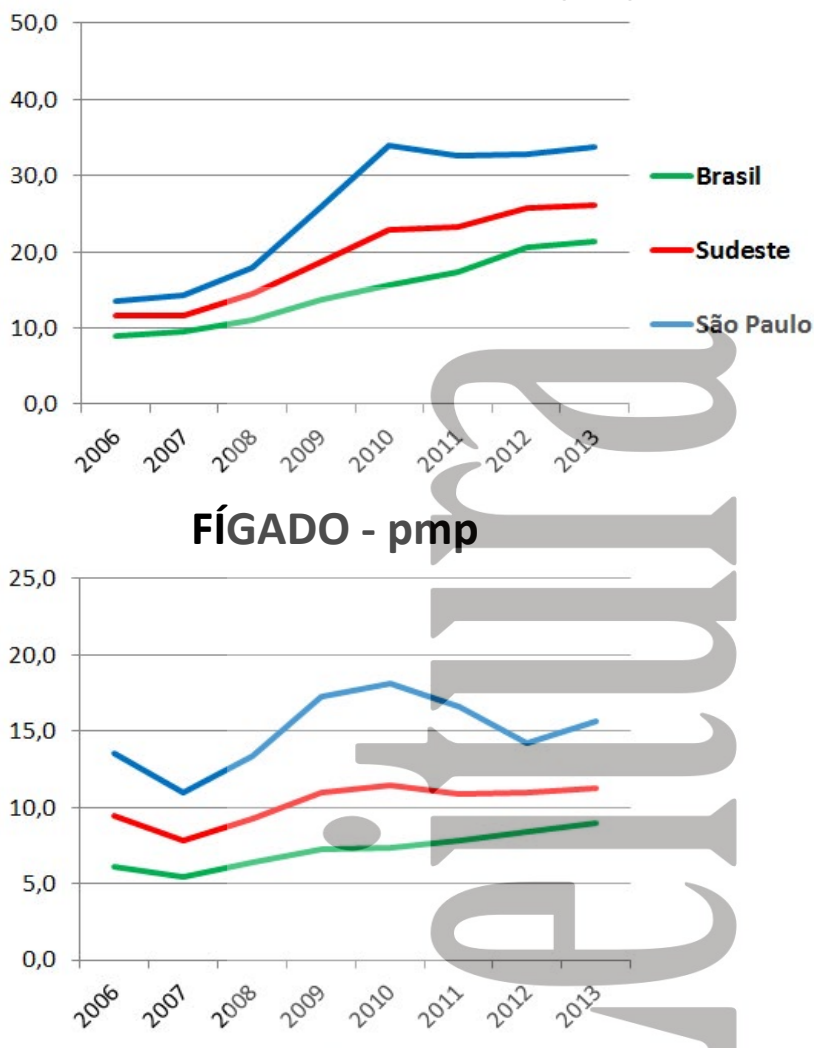

RIM com doador vivo - pmp

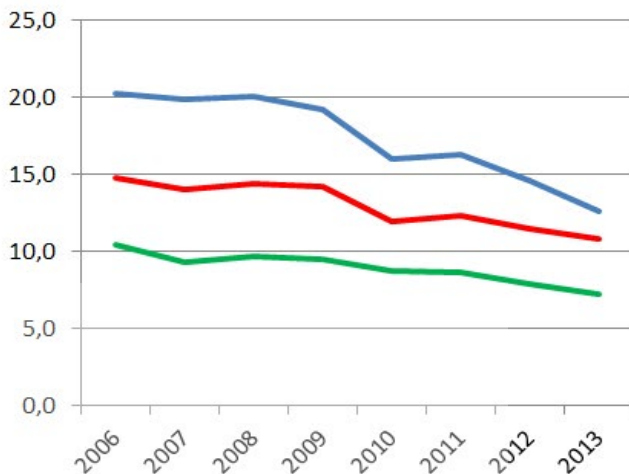

CÓRNEA-pmp

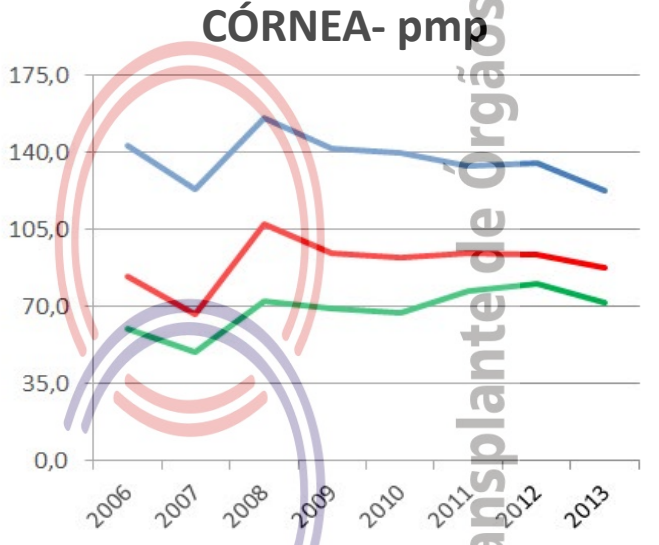

Número de equipes que realizaram $\quad 2006 \quad 2007$ transplantes durante o ano CÓRNEA

RIM

FÍGADO

PÂNCREAS

CORAÇÃO

PULMÃO

Número absoluto de transplantes

CÓRNEA

RIM - total

doador vivo

doador falecido

FÍGADO

PÂNCREAS

CORAÇÃO

PULMÃO

(1)

Indisponível Indisponível

2008

$2009 \quad 2010$

2011

2012

2013

(1) 2012

ivel 


\section{SERGIPE}

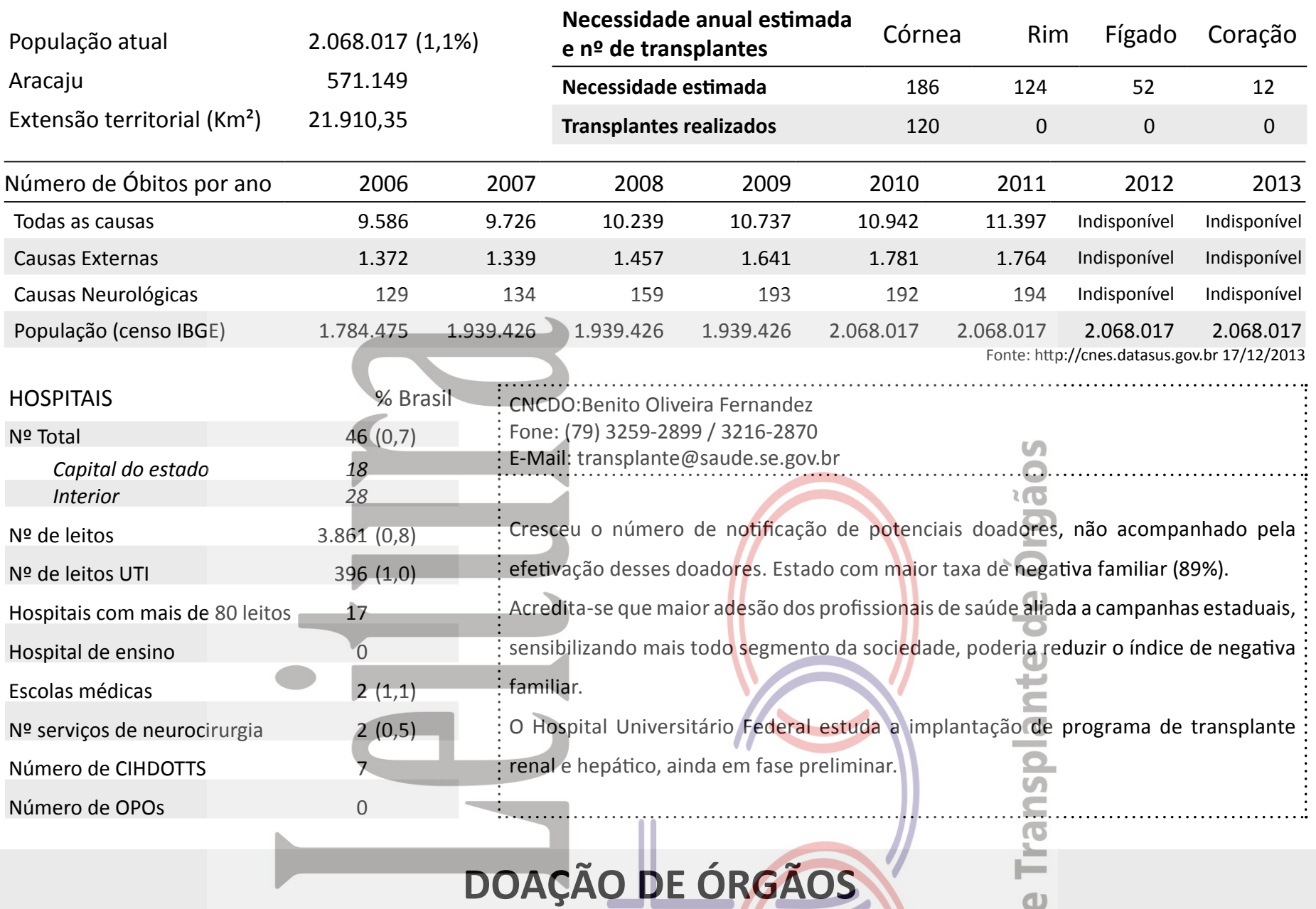

\section{Potenciais doadores notificados - pmp}

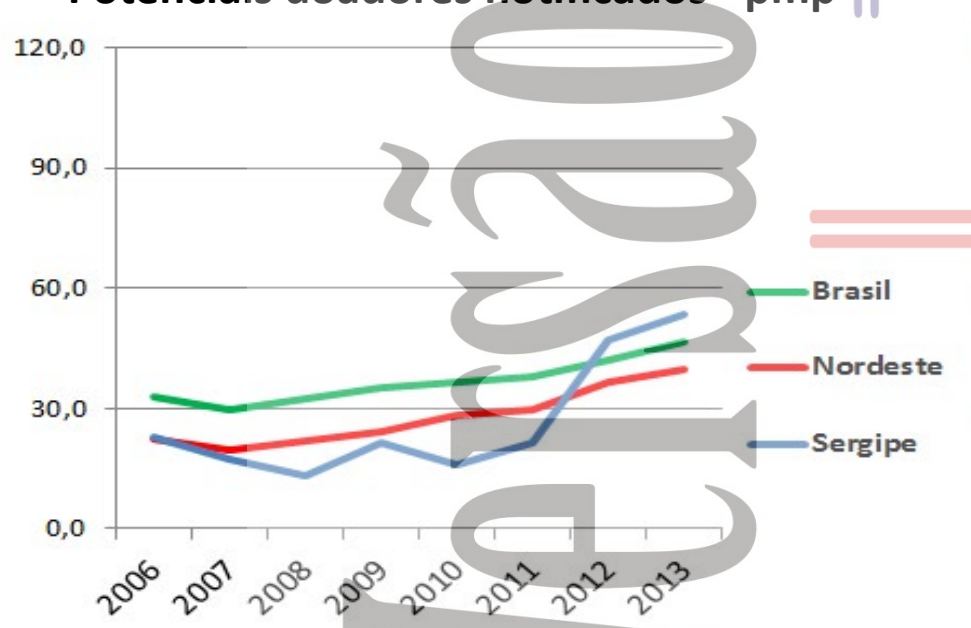

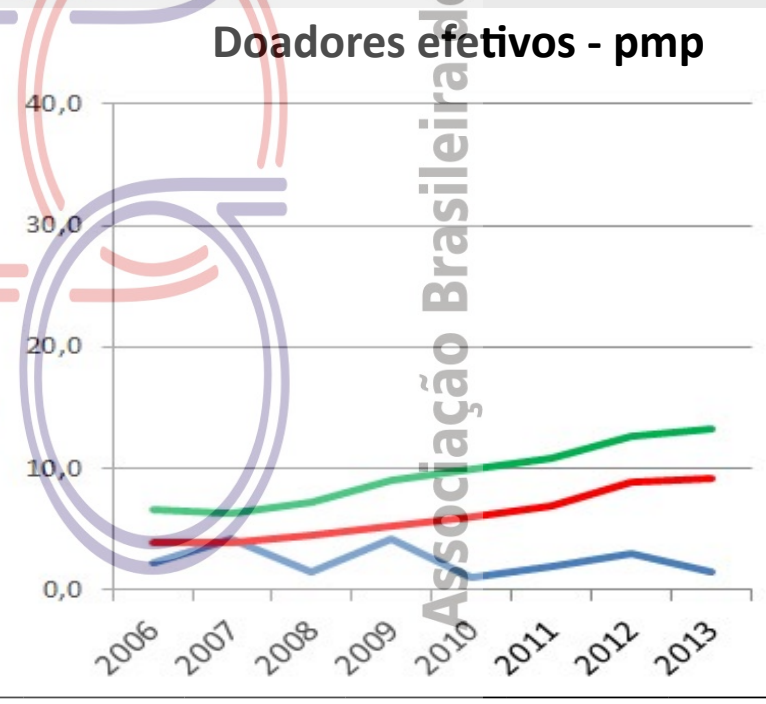

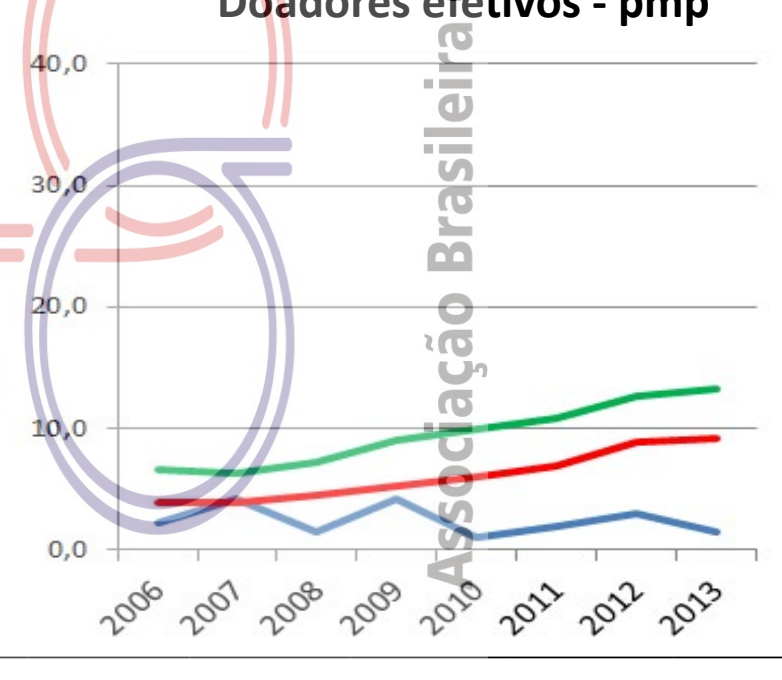

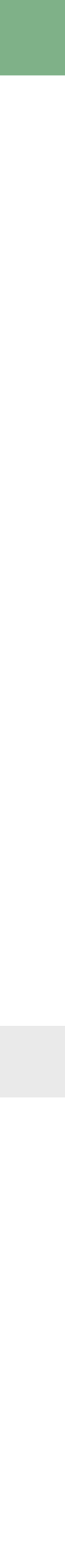

\begin{tabular}{|c|c|c|c|c|c|c|c|c|}
\hline & 2006 & 2007 & 2008 & 2009 & 2010 & 2011 & 2012 & 2013 \\
\hline Número de doadores efetivos & 4 & 8 & 3 & 8 & 2 & 4 & 6 & 3 \\
\hline Número de doadores efetivos (pmp) & 2,2 & 4,1 & 1,5 & 4,1 & 1,0 & 1,9 & 2,9 & 1,5 \\
\hline $\begin{array}{l}\text { Número de notificações } \\
\text { (potenciais doadores) }\end{array}$ & 41 & 34 & 26 & 42 & 33 & 44 & 97 & 111 \\
\hline Número de notificações (pmp) & 23,0 & 17,5 & 13,4 & 21,7 & 16,0 & 21,3 & 46,9 & 53,7 \\
\hline Recusa familiar & 19 & 16 & 5 & 5 & 10 & 15 & 43 & 49 \\
\hline Percentual de recusa das entrevistas & Indisponível & Indisponível & Indisponível & Indisponível & Indisponível & Indisponível & 77 & 89 \\
\hline Parada Cardíaca & Indisponível & Indisponível & 7 & 12 & 12 & 9 & 4 & 1 \\
\hline Contraindicação médica & 18 & 10 & 3 & 17 & 7 & 7 & 14 & 30 \\
\hline Outros & 0 & 0 & 8 & & 2 & 9 & 30 & 28 \\
\hline
\end{tabular}




\section{SERGIPE}

\section{TRANSPLANTE DE ÓRGÃOS}

\section{RIM com doador falecido - pmp}

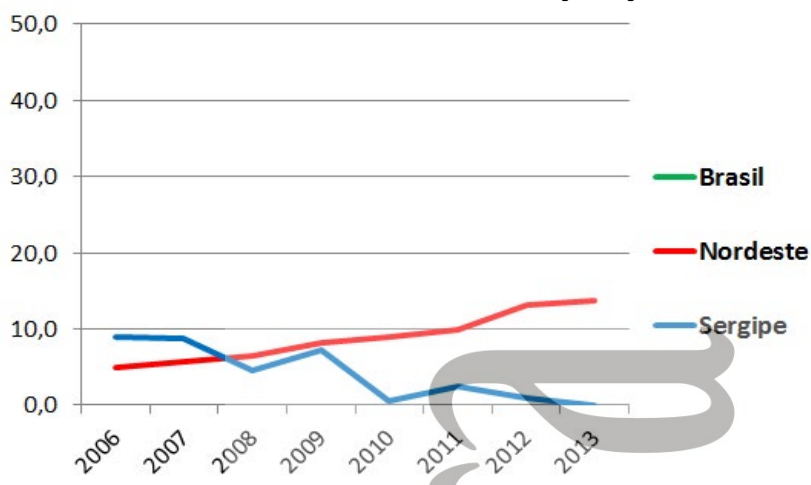

FÍGADO - pmp (não realiza)

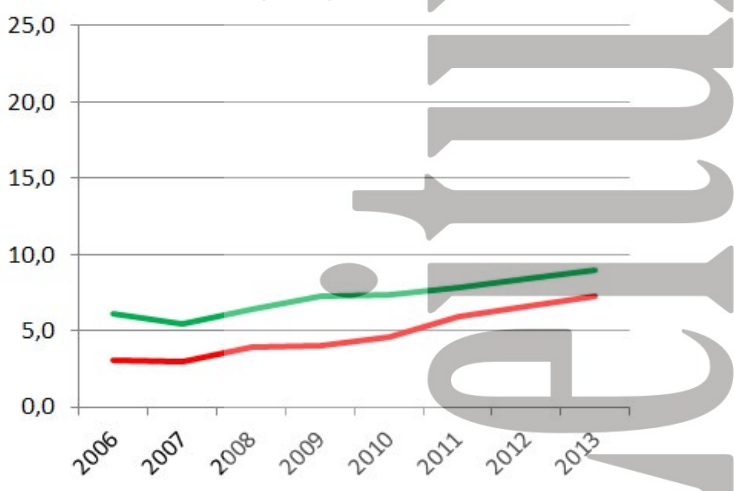

RIM com doador vivo - pmp

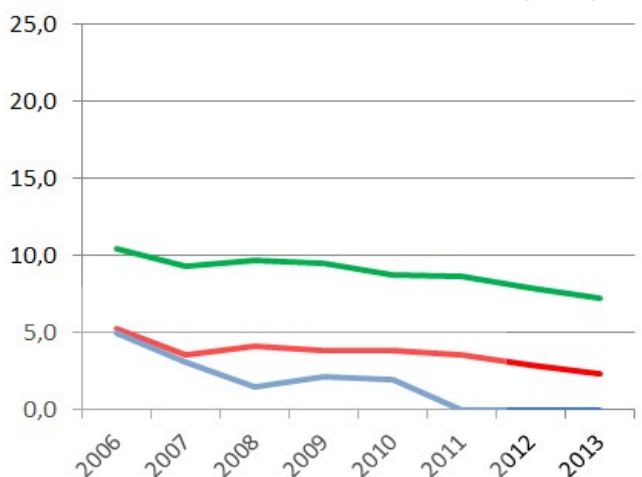

CÓRNEA- pmp

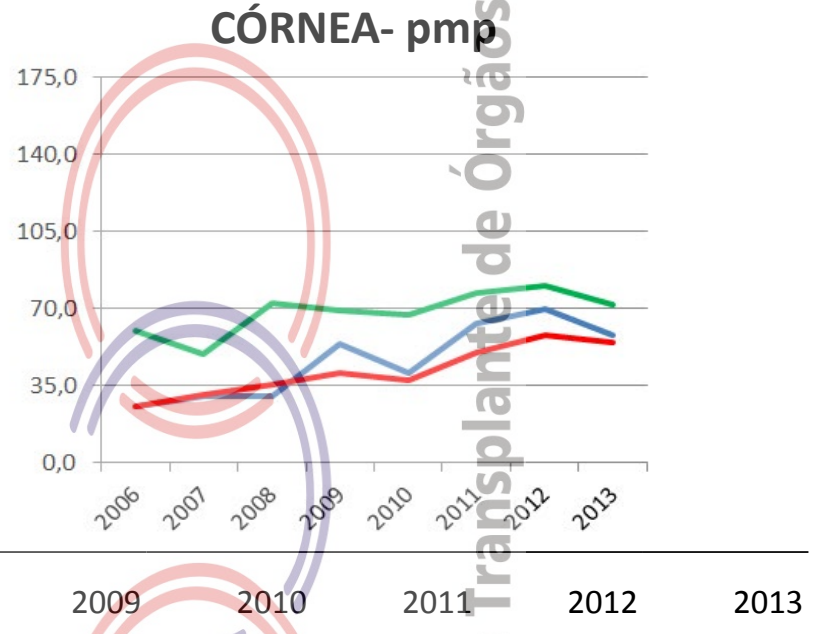

Número de equipes que realizaram $2006 \quad 2007$ transplantes durante o ano CÓRNEA

RIM

FÍGADO (não realiza)

PÂNCREAS (não realiza)

CORAÇÃO (não realiza)

PULMÃO (não realiza)

\begin{tabular}{l}
\hline Número absoluto de trans \\
\hline CÓRNEA \\
RIM - total \\
doador vivo \\
doador falecido \\
FÍGADO (não realiza) \\
PÂNCREAS (não realiza) \\
CORAÇÃO (não realiza) \\
PULMÃO (não realiza)
\end{tabular}

\begin{tabular}{|c|c|c|c|c|c|c|c|c|}
\hline \multirow{2}{*}{$\begin{array}{l}\text { CÓRNEA } \\
\text { RIM }\end{array}$} & \multirow{2}{*}{$\begin{array}{r}\text { Indisponível } \\
4\end{array}$} & \multirow{2}{*}{$\begin{array}{r}\text { Indisponível } \\
2\end{array}$} & \multicolumn{3}{|c|}{ Indisponível Indisponível Indisponível } & \multicolumn{2}{|c|}{ Indisponível Indisponível } & \multirow{2}{*}{$\begin{array}{r}\text { Indisponível } \\
0\end{array}$} \\
\hline & & & 2 & 2 & 2 & 2 & 1 & \\
\hline FÍGADO (não realiza) & & & & & & $-ㄴ$ & & \\
\hline PÂNCREAS (não realiza) & & & & & & 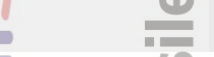 & & \\
\hline CORAÇÃO (não realiza) & & & & & & $\frac{1}{10}$ & & \\
\hline PULMÃO (não realiza) & & & 2 & & & $\frac{1}{20}$ & & \\
\hline Número absoluto de transplantes & 2006 & 2007 & 2008 & 2009 & 2010 & 20110 & 2012 & 2013 \\
\hline CÓRNEA & 46 & 58 & 59 & 104 & 84 & 130 ? & 144 & 120 \\
\hline RIM - total & 25 & 23 & 12 & 18 & & $5=$ & 2 & 0 \\
\hline doador vivo & 9 & 6 & 3 & 4 & 4 & 0 & 0 & 0 \\
\hline doador falecido & 16 & 17 & 9 & 14 & 1 & 5 น & 2 & 0 \\
\hline FÍGADO (não realiza) & & & & & & $<$ & & \\
\hline \multicolumn{9}{|l|}{ PÂNCREAS (não realiza) } \\
\hline \multicolumn{9}{|l|}{ CORAÇÃO (não realiza) } \\
\hline \multicolumn{9}{|l|}{ PULMÃO (não realiza) } \\
\hline Número de transplantes pmp & 2006 & 2007 & 2008 & 2009 & 2010 & 2011 & 2012 & 2013 \\
\hline CÓRNEA & 25,8 & 29,9 & 30,4 & 53,6 & 40,6 & 62,9 & 69,6 & 58,0 \\
\hline RIM - total & 14,0 & 11,9 & 6,2 & 9,3 & 2,4 & 2,4 & 1,0 & 0,0 \\
\hline doador vivo & 5,0 & 3,1 & 1,5 & 2,1 & 1,9 & 0,0 & 0,0 & 0,0 \\
\hline doador falecido & 9,0 & 8,8 & 4,6 & 7,2 & 0,5 & 2,4 & 1,0 & 0,0 \\
\hline
\end{tabular}

FÍGADO (não realiza)

PÂNCREAS (não realiza)

CORAÇÃO (não realiza)

PULMÃo (não realiza) 


\section{TOCANTINS}

$\begin{array}{lc}\text { População atual } & 1.383 .445(0,7 \%) \\ \text { Palmas } & 228.332\end{array}$

Extensão territorial $\left(\mathrm{Km}^{2}\right) \quad 277.620,91$

\begin{tabular}{lccccc}
\hline $\begin{array}{l}\text { Necessidade anual estimada } \\
\text { e no de transplantes }\end{array}$ & Córnea & Rim & Fígado & Coração \\
\hline Necessidade estimada & 125 & 83 & 35 & 8 \\
Transplantes realizados & 0 & 0 & 0 & 0 \\
\hline
\end{tabular}

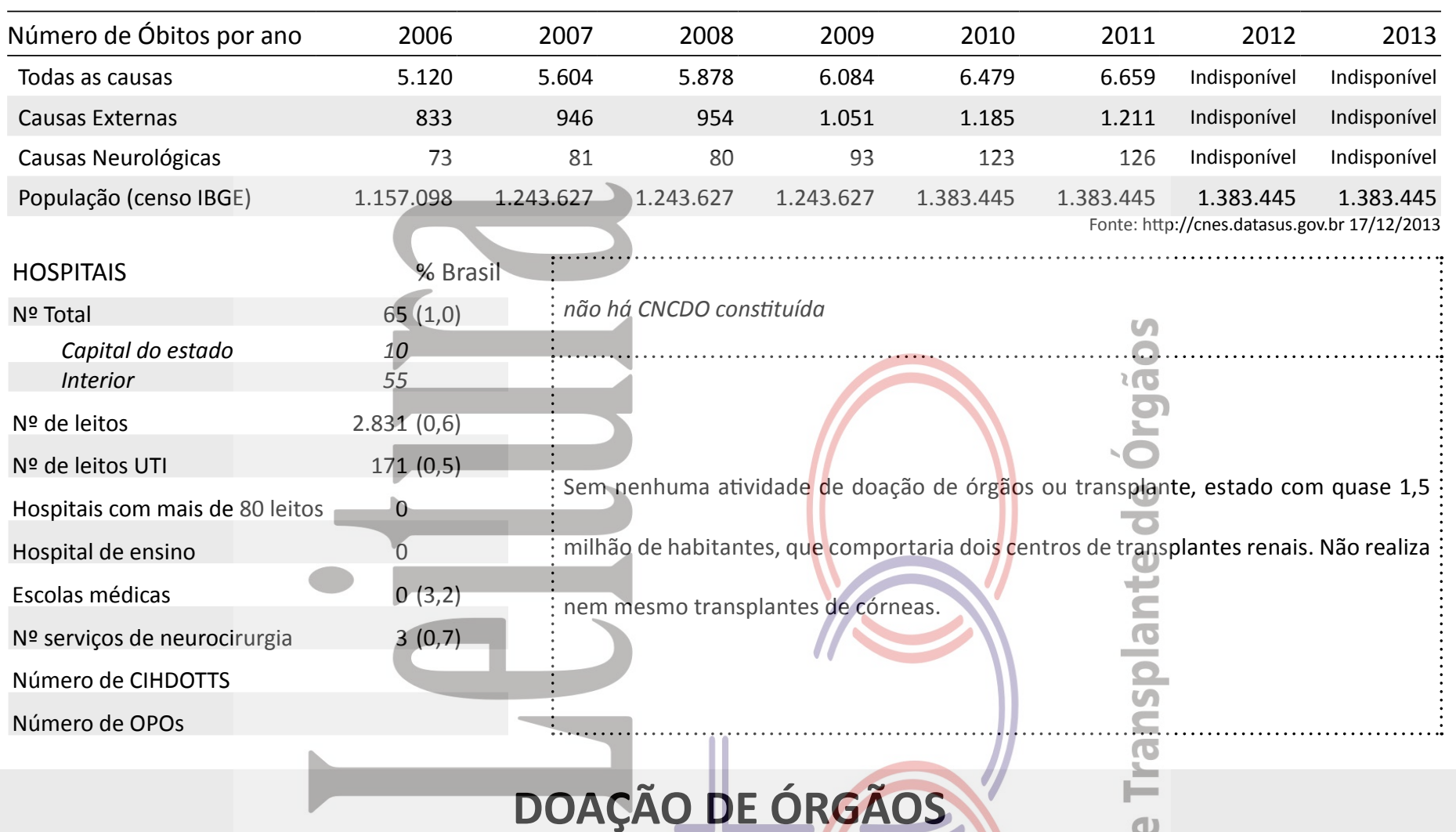

\section{Potenciais doadores notificados - pmp}

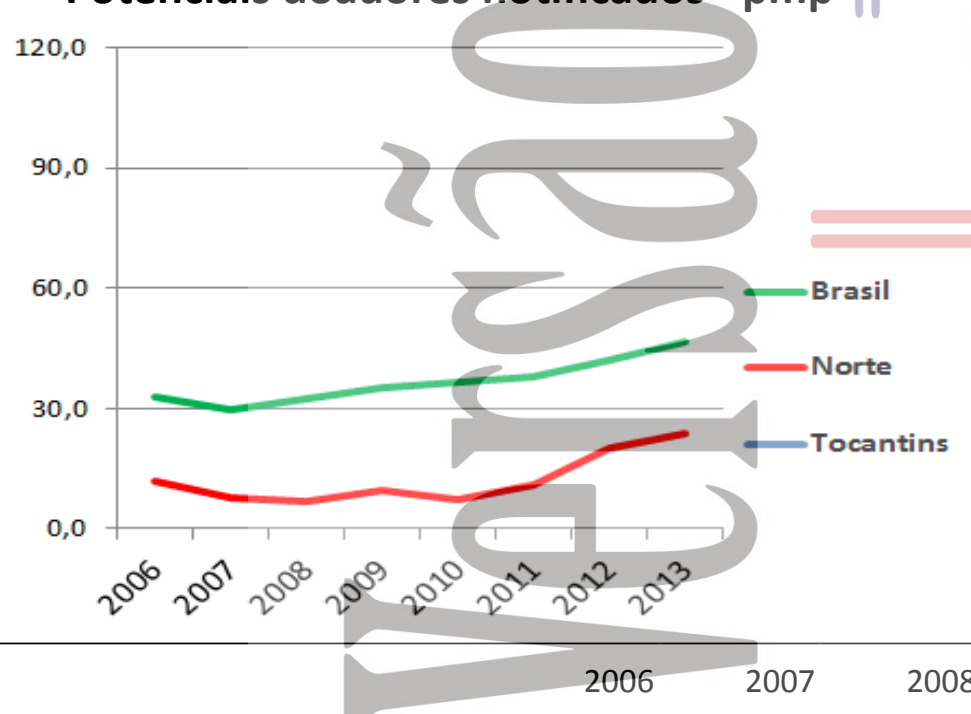

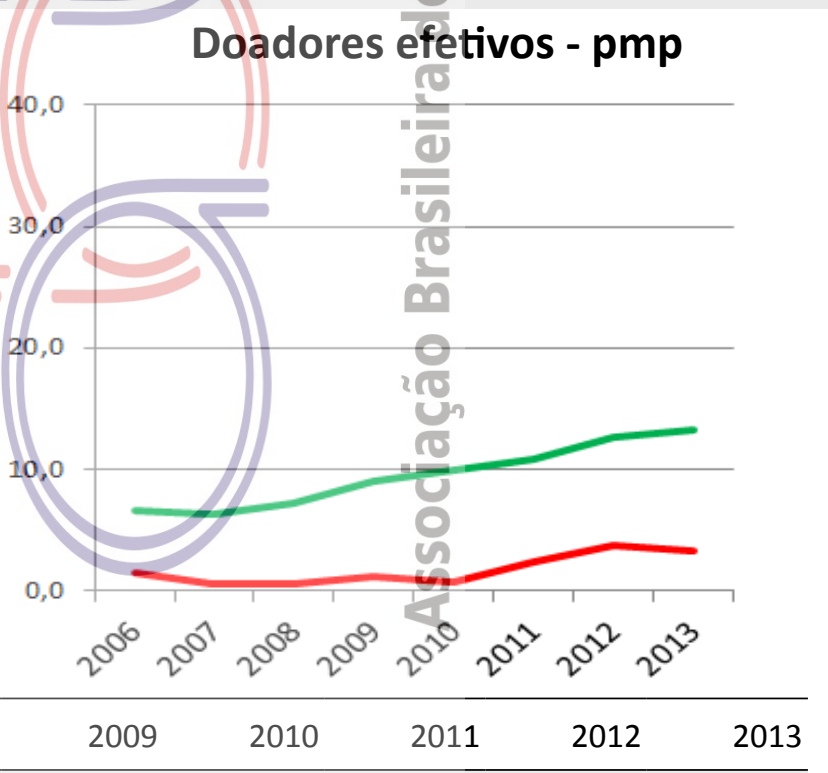

Número de doadores efetivos

Número de doadores efetivos (pmp)

Número de notificações

(potenciais doadores)

Número de notificações (pmp)

Recusa familiar

Percentual de recusa das entrevistas

Parada Cardíaca

Indisponível Indisponível Indisponível Indisponível Indisponível Indisponível Indisponível

Contraindicação médica

Outros 


\section{TOCANTINS}

\section{TRANSPLANTE DE ÓRGÃOS}

\section{RIM com doador falecido - pmp}

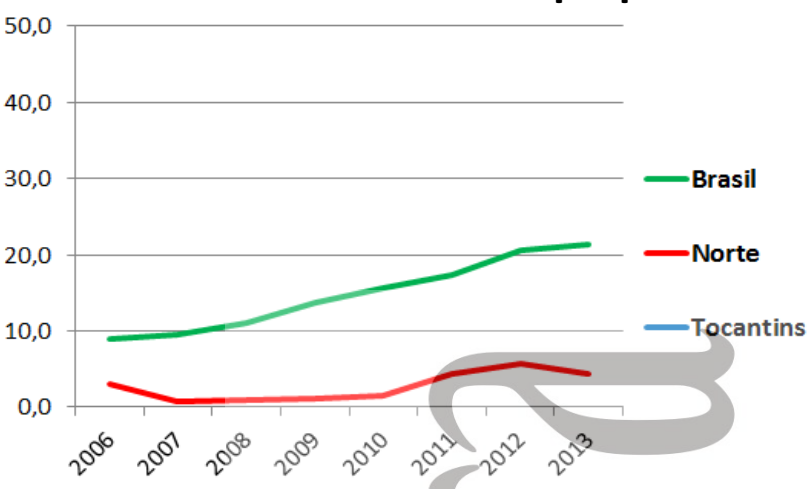

FÍGADO - pmp

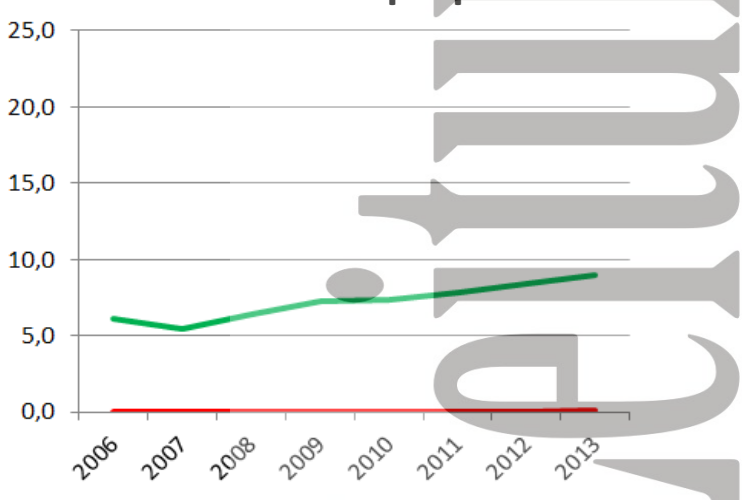

Número de equipes que realizaram transplantes durante o ano CÓRNEA (não realiza) RIM (não realiza) FÍGADO (não realiza) PÂNCREAS (não realiza) CORAÇÃO (não realiza) PULMÃo (não realiza)

\begin{tabular}{l}
\hline Número absoluto de trans \\
\hline CÓRNEA (não realiza) \\
RIM (não realiza) \\
doador vivo \\
doador falecido \\
FÍGADO (não realiza) \\
PÂNCREAS (não realiza) \\
CORAÇÃO (não realiza) \\
PULMÃO (não realiza)
\end{tabular}

Número de transplantes pmp

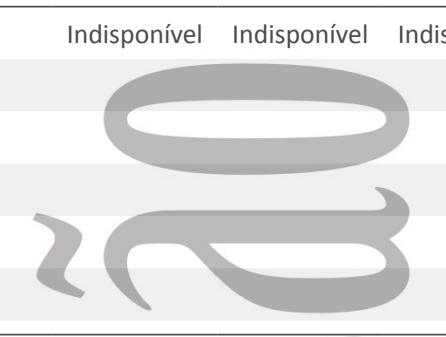

\section{s}

(2005) 2007

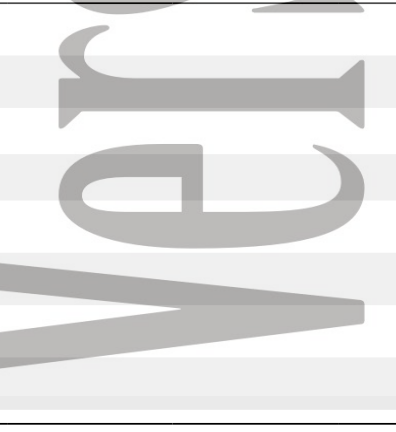

2007
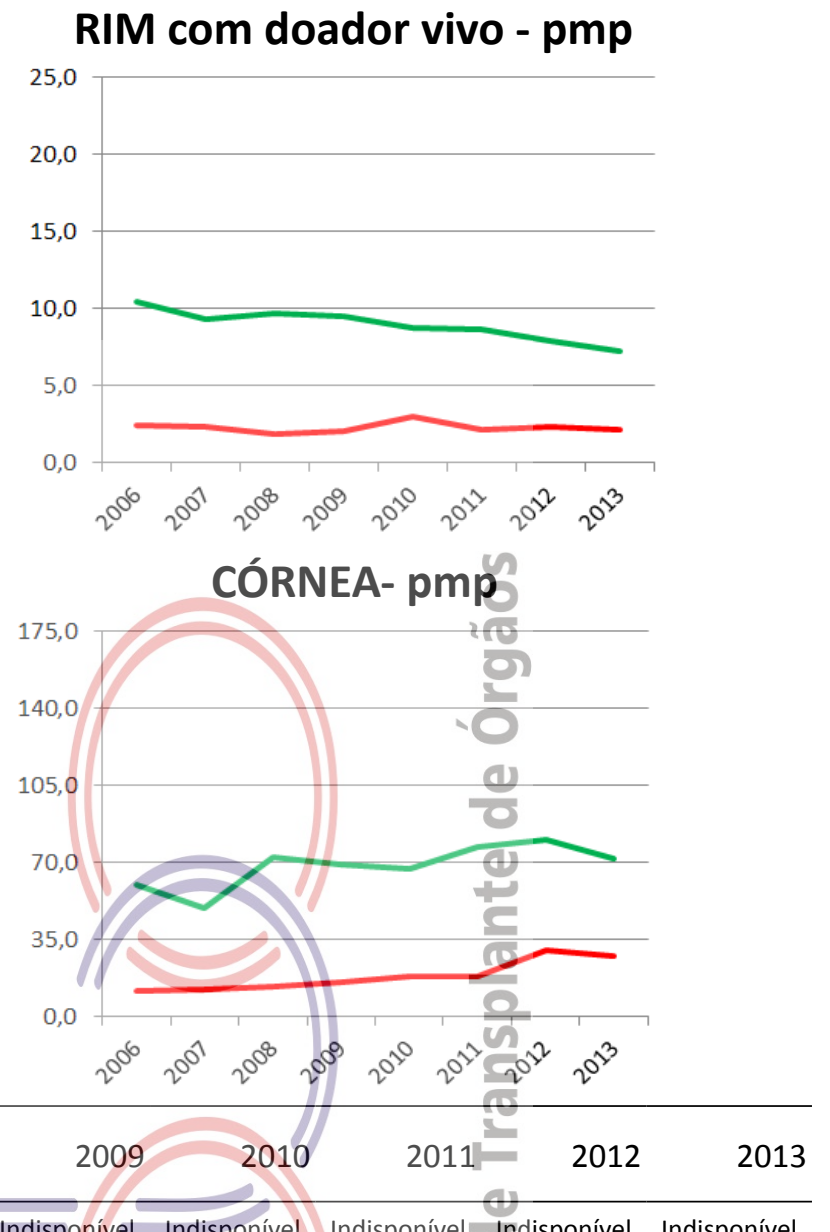

2008

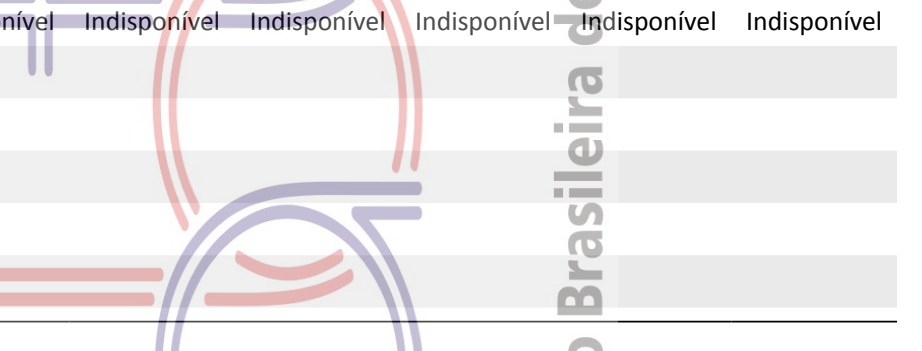

